\title{
Vietnamese Academics' Research Capacity in Tertiary Contexts
}

\section{HUYNH THANH TIEN}

A thesis submitted to Victoria University of Wellington in fulfilment of the requirements for the degree of Doctor of Philosophy in Education 


\begin{abstract}
Research carried out by academics at higher education institutions (HEIs) has substantially contributed to nations' development, particularly in a time of globalisation and internationalisation of higher education (HE). A range of studies on academics' research have been undertaken in western contexts. Those studies can be classified into studies of academics' research perceptions and studies of factors affecting academics' research productivity. However, there has been a very limited number of studies on academics' research capacity and HEIs' research capacities in Vietnam. Meanwhile, the Vietnamese Government has attempted to develop its HE system to contribute to the success of its national development. Over the past ten years, the Vietnamese Government has issued a series of research related policies and has had a greater investment into the development of its HE system. However, the research capacity of Vietnamese HEIs has been lower than that of its neighbouring countries in the region. Therefore, this study was conducted with the hope that it might provide an in-depth understanding of the research capacities of Vietnamese HEIs and their academics and how they can be better fostered in the Vietnamese HE system.
\end{abstract}

The study was conducted in three public HEls at different levels in southern Vietnam: provincial, regional, and national. The study employed an interpretive case study approach with a lens of historical and sociocultural theory. Three key tools used for data collecting were surveys, individual semi-structured interviews, and document analysis. The research participants were purposefully selected from the three institutions. For data analysis, the study utilised a combined framework adapted from the predictive model department research productivity of Bland, Center, Finstad, Risbey, and Staples (2005), the model of factors affecting academics' research productivity of Chen, Gupta, and Hoshower (2006), and Moore's (2015) socialecological model: Looking beyond the individual. The study's findings indicated that the research capacities of Vietnamese HEls and their academics were influenced by various factors at different levels. At societal level, they include socioeconomic, sociocultural, and political factors. At community level, they comprise resources, research orientation, research networks, professional development practices. At institutional level, they consist of establishment history, geographical location, and organisation. Additionally, the study identified that institutional contexts affected the academics' research motivation and research engagement at this level. Finally, this study suggested some recommendations for both academic leaders and academics from the three HEIs and Vietnamese HE policy makers to consider so that they may find ways to enhance the research capacities of the Vietnamese HEIs and their academics' research engagement. 


\section{ACKNOWLEDGMENT}

The writing of this PhD thesis was certainly challenging, but worth undertaking. In addition to the writing, it taught me to press on determinedly, to be persistent, and to encourage myself. The experience and knowledge that I have gained from this thesis would not have been possible without the love, support, guidance and participation of many people in my PhD journey in the wonderful and peaceful country of New Zealand.

Wholeheartedly, I would like to express my deep and sincere gratitude to my research supervisors. I am heartily thankful to my primary supervisor, Associate Professor Joanna Higgins, providing generous support, guidance, and critical comments from the initial to the final stage of my thesis. I would also like to show my appreciation to Dr. Kate Thornton for her guidance, support, and valuable comments. I wish to thank Professor Robert Strathdee for his supervision in the initial stage of my doctoral study. And I would like to express my thanks to Dr. Deborah Laurs from Student Learning Support at Victoria University of Wellington for her patience and time to read and provide constructive comments for my thesis.

I owe my sincere gratitude to all the lecturers who contributed their energy and time to participate in my study. Thank you very much for sharing your knowledge, views, and experience that shaped this thesis.

I am deeply appreciative of An Giang University's staff support, and its Board of Rectors giving me conditions to follow my doctoral journey. Especially, I would like to thank Vietnam International Education Development and Victoria University of Wellington for granting me a scholarship. Without this, I could not have achieved the success of my PhD journey.

I would like to thank all my colleagues in the Manor 31B Campbell Street, Mabel Hamon, Silia Finau, Kaye Stannard, Zawadi Juma, Upendo Biswalo, and Milka Otieno for sharing your experiences in study as well as taste of life as international students in Wellington.

I am indebted to my parents and relatives who always support me from my homeland and want my little family to go home soon.

I would like to thank my wife Hue Tran and my little Angel son Tien An who accompanied me during my challenging study in a beautiful country, New Zealand.

Lastly, I offer my regards and blessings to all of those who supported me in any respect during the completion of this project. 
Tomy father, Fuynk Thank Bach, a former high school teacher,

for your endless love, aspirations,

and trust in my achievements 


\section{TABLE OF CONTENT}

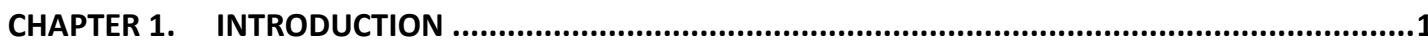

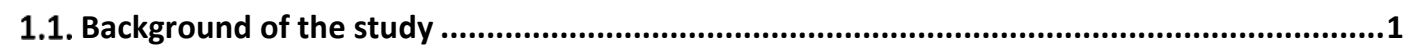

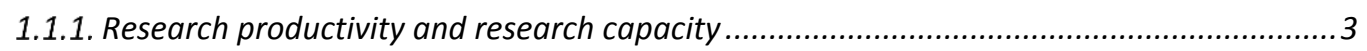

1.1.2. Vietnam in a context of the ASEAN community ......................................................... 4

1.1.3. Government policies supporting research at HEIs in ASEAN nations ............................... 5

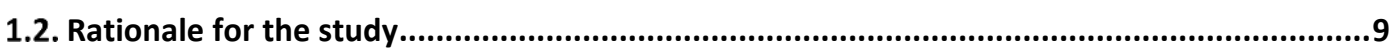

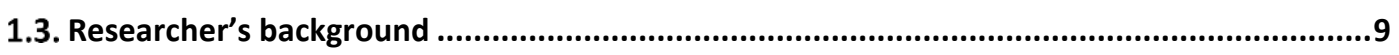

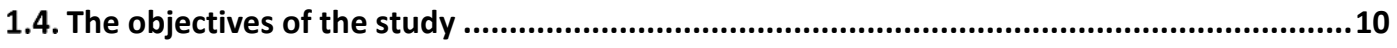

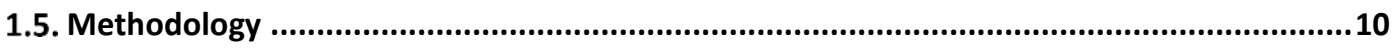

1.6. The study outline .......................................................................................................................11

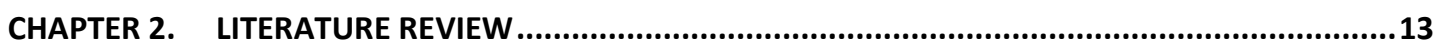

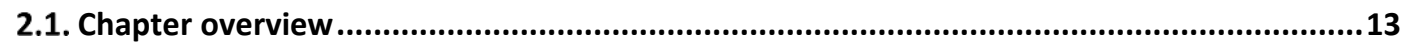

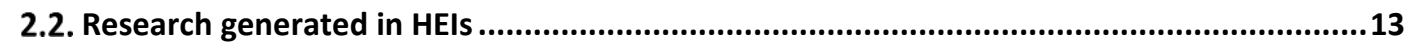

2.3. Research-led teaching and research-informed teaching ..................................................15

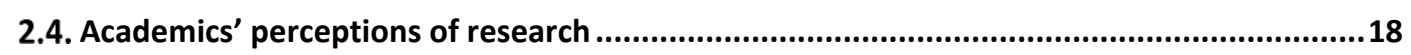

2.5. Factors affecting academics' research productivity .........................................................22

2.5.1. Academic disciplines............................................................................................ 22

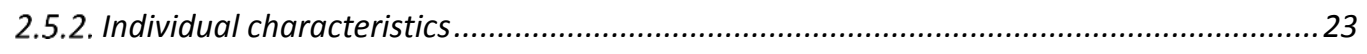

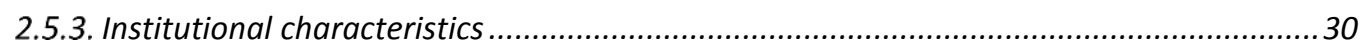

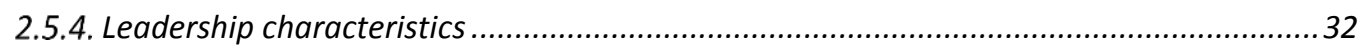

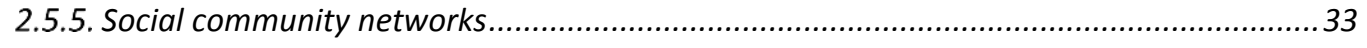

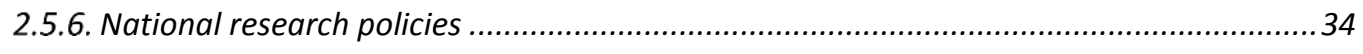

2.6. Studies of academics' research engagement in Vietnam's HE context..................................36

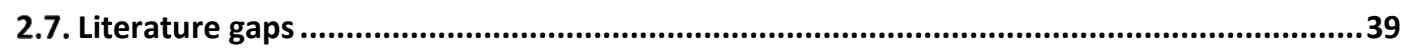

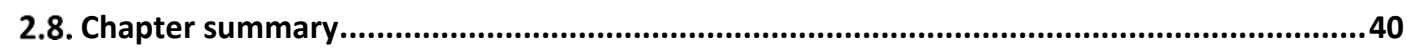

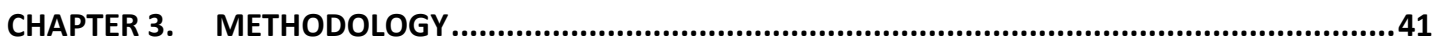

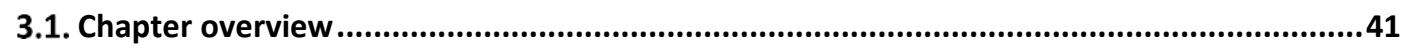

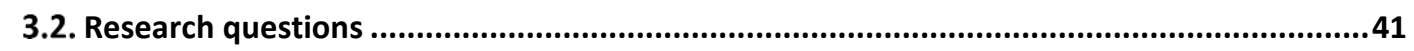

3.3. Interpretive qualitative case study approach ...................................................................41

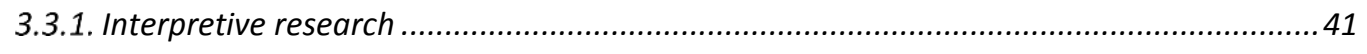

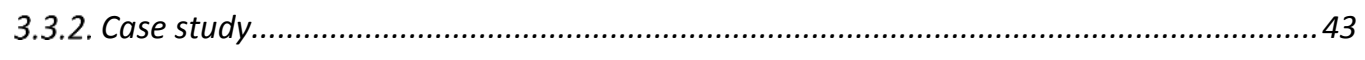

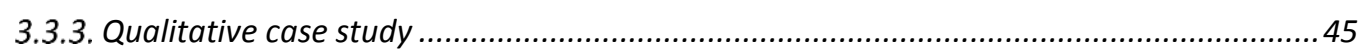




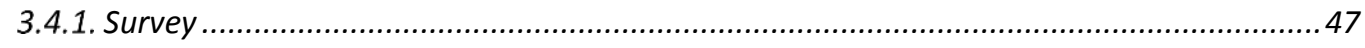

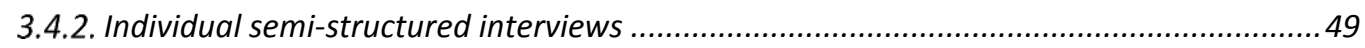

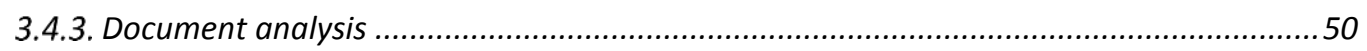

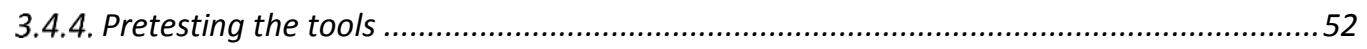

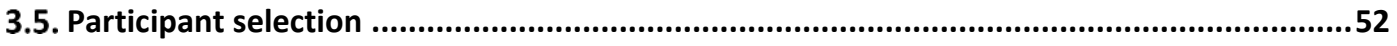

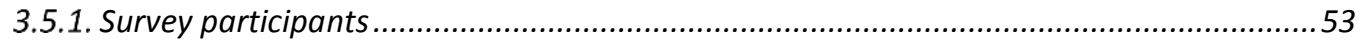

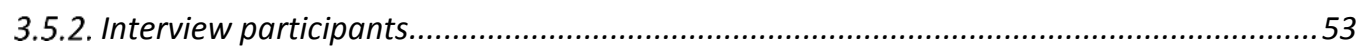

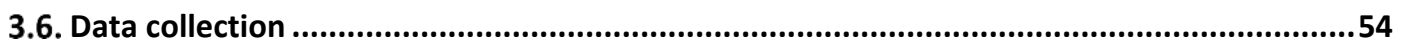

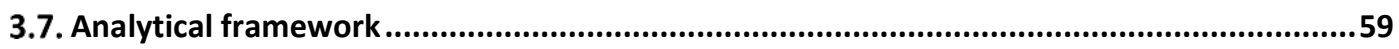

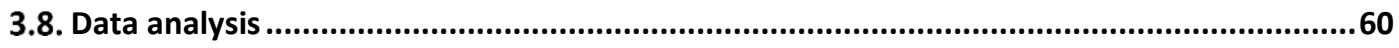

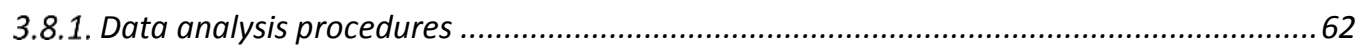

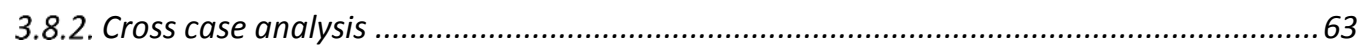

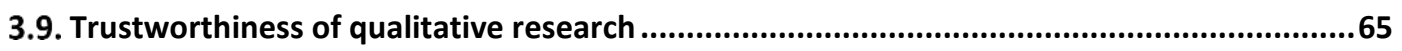

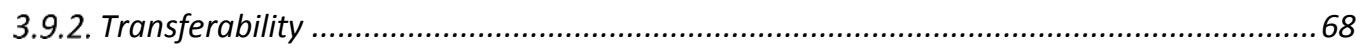

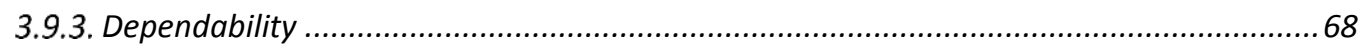

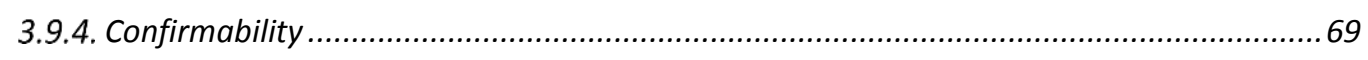

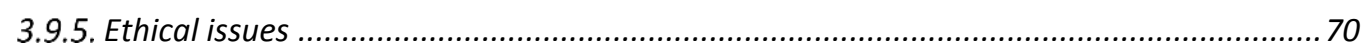

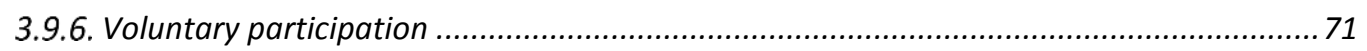

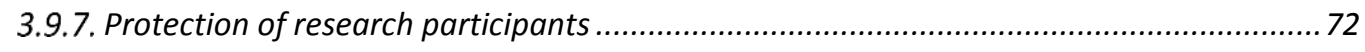

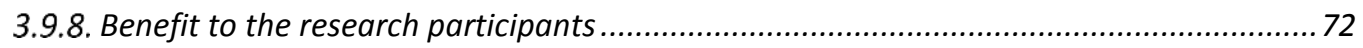

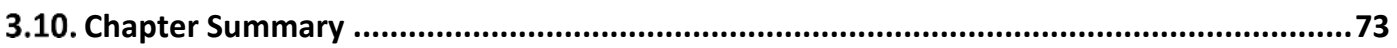

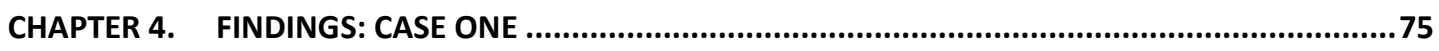

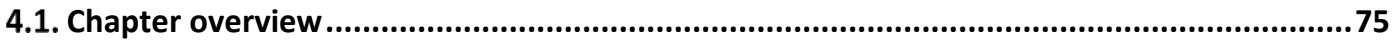

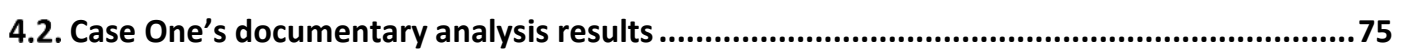

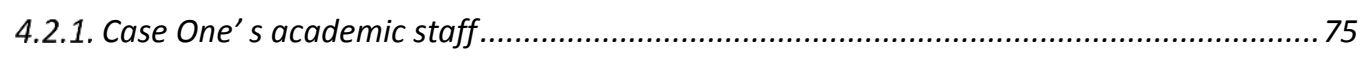

4.2.2. Case One's scientific research operations and orientation .......................................... 76

4.2.3. Case One's staff development strategy ................................................................... 80

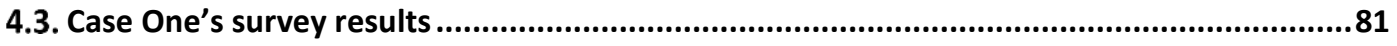

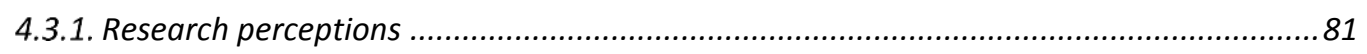

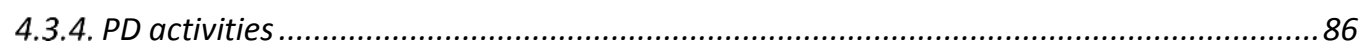

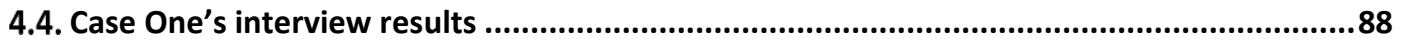

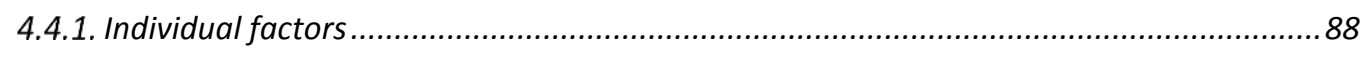

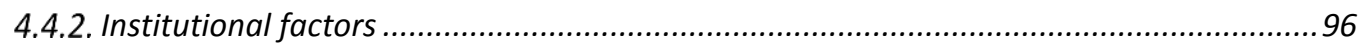

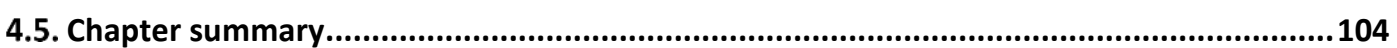




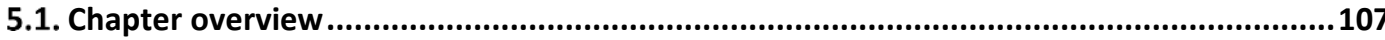

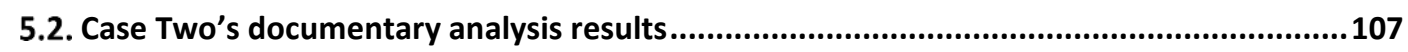

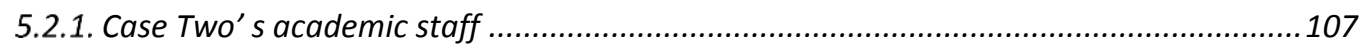

5.2.2. Case Two's evaluation of research activities in 2006-2010...................................... 108

5.2.3. Case Two's plan of S\&T activities in 2011-2015 ..................................................... 110

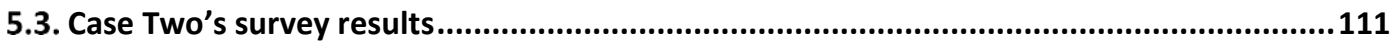

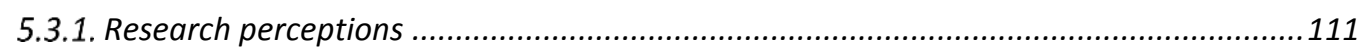

5.3.2. Positive factors impacting academics' research engagement .................................... 115

5.3.3. Negative factors impacting academics' research engagement .................................. 117

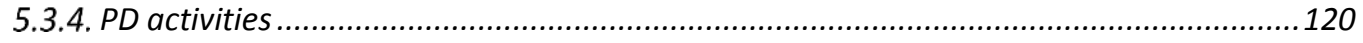

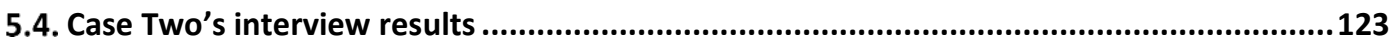

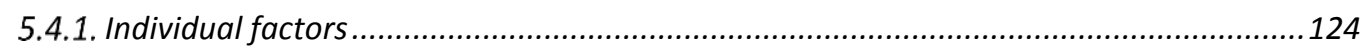

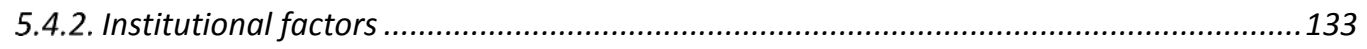

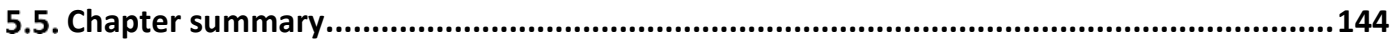

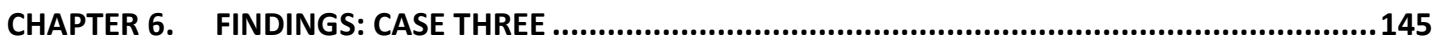

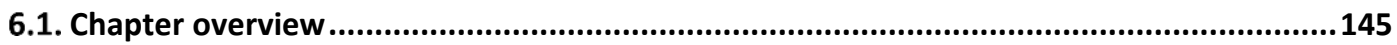

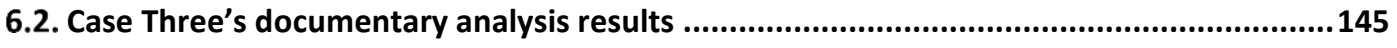

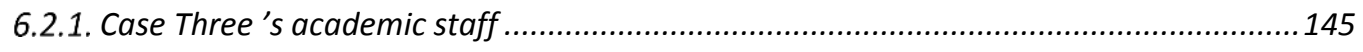

6.2.2. Case Three 's research strategies and orientation ................................................. 146

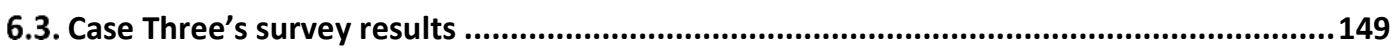

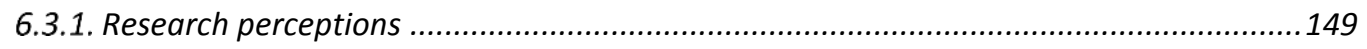

6.3.2. Positive factors impacting academics' research engagement .....................................151

6.3.3. Negative factors impacting academics' research engagement ................................... 154

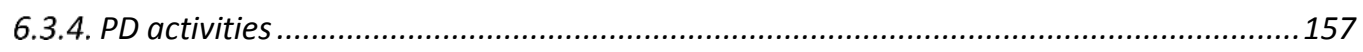

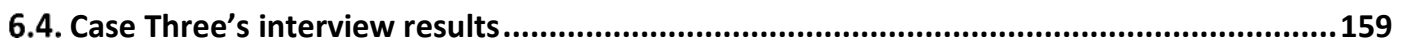

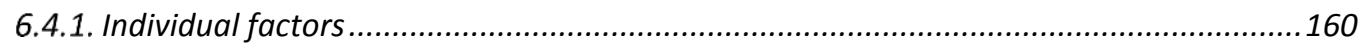

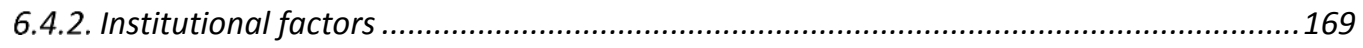

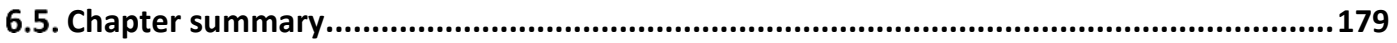

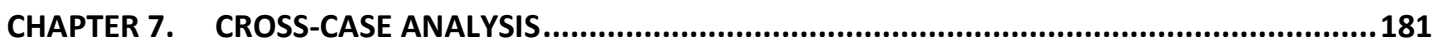

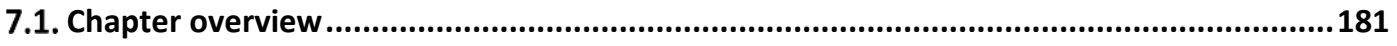

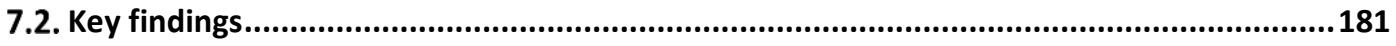

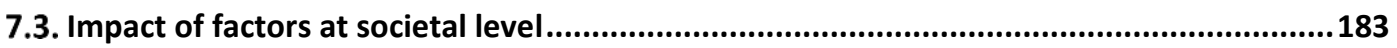

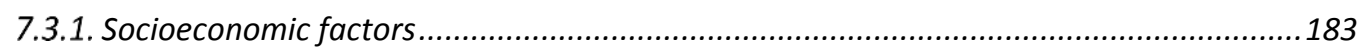

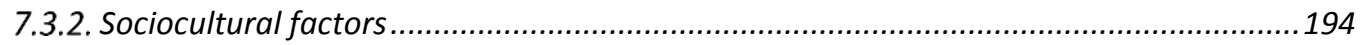




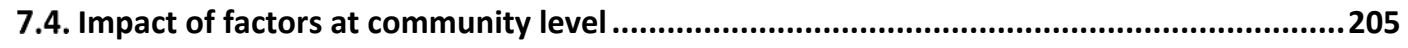

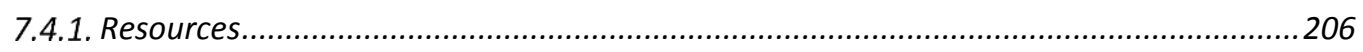

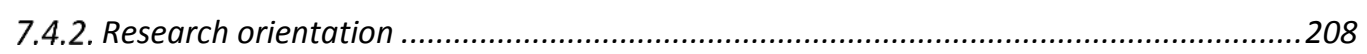

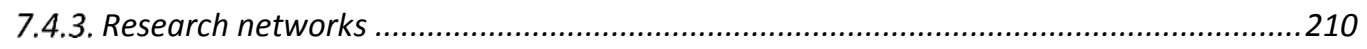

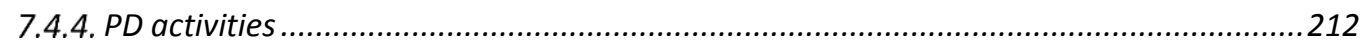

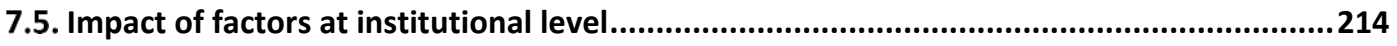

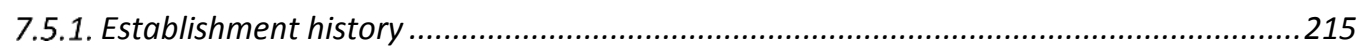

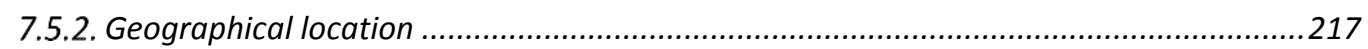

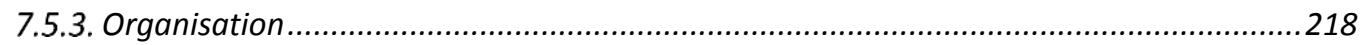

7.6. Effects of institutional contexts on academics' motivation and engagement in research .232

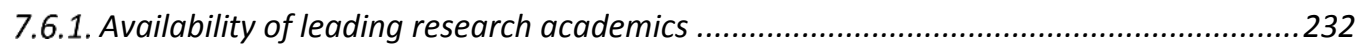

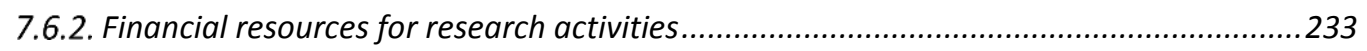

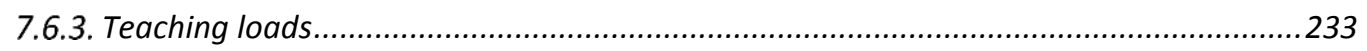

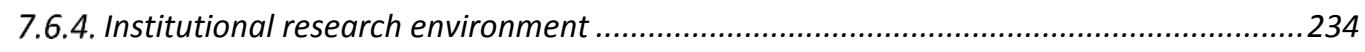

7.6.5. Institutional research policies and practices .....................................................2 236

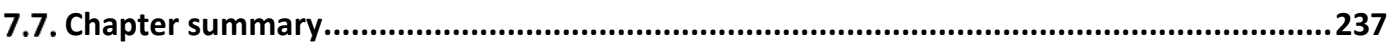

CHAPTER 8. RECOMMENDATIONS AND CONCLUSIONS..................................................2239

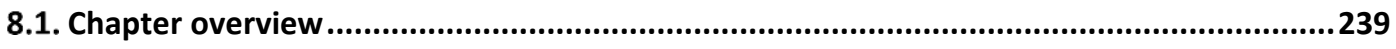

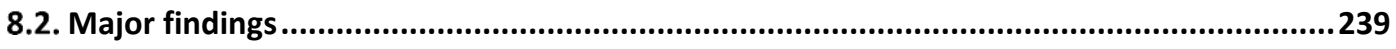

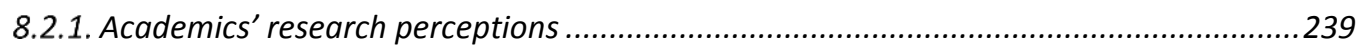

8.2.2. Factors impacting the research capacities of Vietnamese HEls and their academics' research

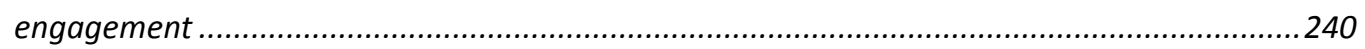

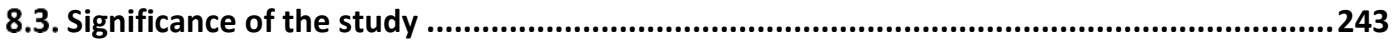

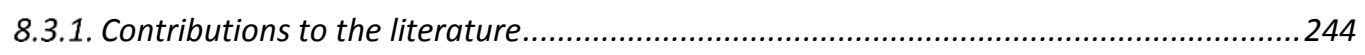

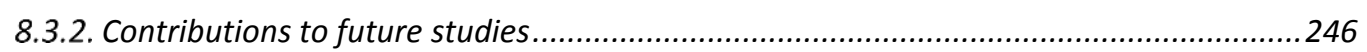

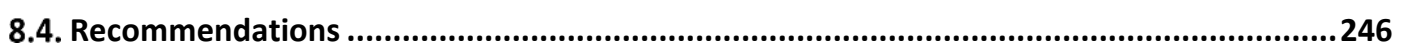

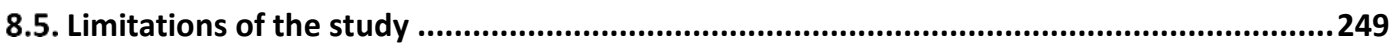

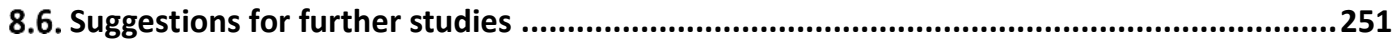

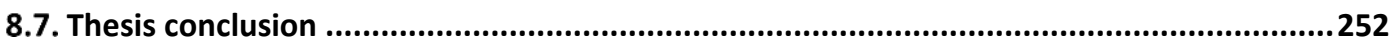

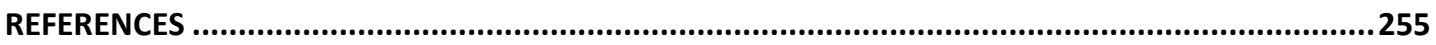

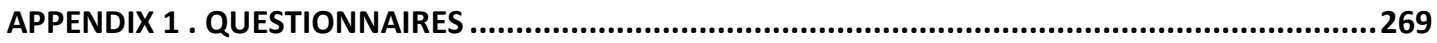

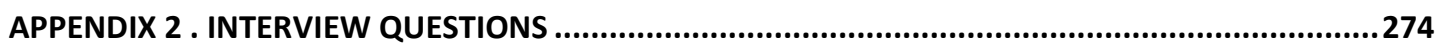

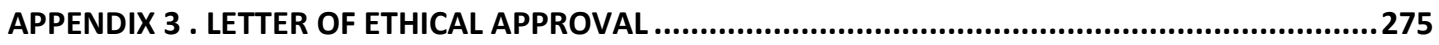


APPENDIX 4 . LETTER TO THE RECTOR

APPENDIX 5 . CONSENT FORM FOR RECTOR

APPENDIX 6 . LETTER TO THE DIRECTOR/HEAD

APPENDIX 7 . CASE ONE'S ORGANISATIONAL STRUCTURE..

APPENDIX 8 . RESEARCH INFORMATION SHEET.

APPENDIX 9 . CONSENT TO PARTICIPATE IN RESEARCH: QUESTIONNAIRE. .284

APPENDIX 10 . CONSENT TO PARTICIPATE IN RESEARCH: AUDIO-RECORDED INTERVIEW .285

APPENDIX 11 . CASE TWO'S ORGANISATIONAL STRUCTURE CHART .286 APPENDIX 12 . CASE THREE'S ORGANISATIONAL STRUCTURE. 287 


\section{LIST OF FIGURES}

Figure 2-1. Curriculum design and the research-teaching nexus (Healey, 2005, p 70). ..... 17

Figure 2-2. A framework of factors affecting academics' research productivity adapted from Chen et al. (2006, p. 181).

Figure 2-3. Model of the individual, environmental, and leadership factors affecting the faculty's research productivity adapted from Bland et al. (2005, p. 227).... 33

Figure 2-4. Social-ecological model: Looking beyond the individual adapted from Moore (2015, p.1).

Figure 3-1. The analytical framework for exploring factors affecting Vietnamese academics' research capacity [adapted from the models suggested by Bland et al. (2005), Chen et al. (2006), and Moore' (2015). 60

Figure 3-2. Data analysis process adapted from Creswell (2013, p. 185) 61

Figure 3-3. Multiple case study design adapted from Yin (2003, p. 50) 64

Figure 4-1. Case One's interview participants .88

Figure 5-1. Case Two's interview participants 124

Figure 6-1. Case Three's interview participants 160

Figure 7-1. The impact of societal, community, and institutional factors on the research capacities of the three HEls studied and their academics' research engagement 182

Figure 7-2. Socioeconomic factors affecting the research capacities of the three HEls ... 184

Figure 7-3. Political factors affecting the research capacities of the three HEls. 200

Figure 7-4. The management structure of the Vietnamese public HEls 204

Figure 7-5. Institutional factors affecting the research capacities of the three HEls 214

Figure 7-6. Institutional organisation affecting the research capacities of the three HEIS 219 


\section{LIST OF TABLES}

Table 1-1. Research publications by ASEAN countries .................................................. 8

Table 2-1. Vietnam's scientific publications during 2003 and 2004 ................................... 37

Table 3-1. The numbers and qualifications of the participants in the three cases ............. 52

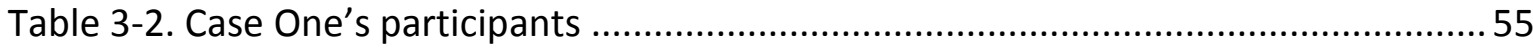

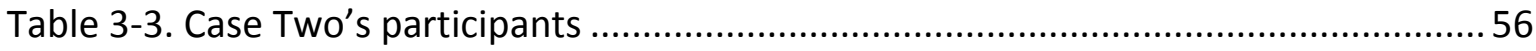

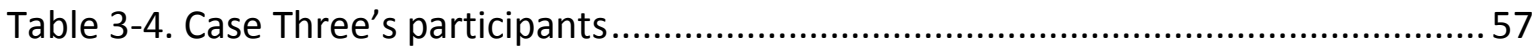

Table 3-5. Timeline of data collection in three institutions ............................................ 58

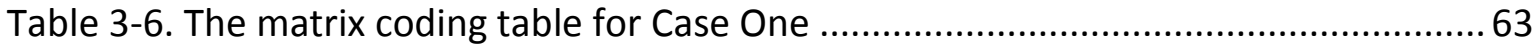

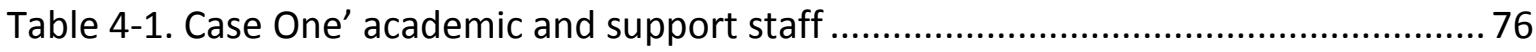

Table 4-2. Case One's provincial level research projects in 2006-2011 ........................... 77

Table 4-3. Case One's publications in the period 2009-2011 ....................................... 78

Table 4-4. Case One's expected sources of research funding ........................................ 79

Table 4-5. Case One's plan for staff development in the period 2012-2030 .....................80

Table 4-6. Case One's results of academics' research perceptions.................................. 82

Table 4-7. Positive factors affecting academics' research engagement in Case One ......... 83

Table 4-8. Factors hindering academics' research engagement in Case One ..................... 85

Table 4-9. Academics' level of satisfaction with PD activities organised by the university 86

Table 4-10. Academics' level of satisfaction with PD activities organised by the faculty ... 87

Table 4-11. Case One's comparison of research payment in 2007-2014 …....................... 97

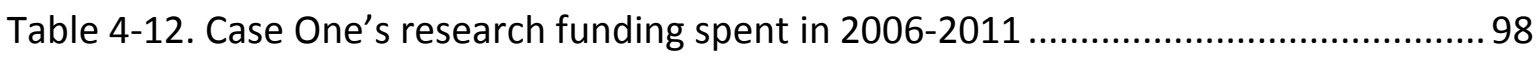

Table 4-13. Vietnamese HE academics' workload framework ...................................... 101

Table 5-1. Case Two's publications in the period 2006-2010....................................... 108

Table 5-2. Case Two's results of academics' research perceptions ................................. 112

Table 5-3. Case Two's convertible table of teaching and research time........................... 114 
Table 5-4. Positive factors impacting academics' research engagement in Case Two .....115

Table 5-5. Factors negatively affecting academics' research engagement in Case Two .. 118

Table 5-6. Academics' level of satisfaction with activities organised by the university.... 121

Table 5-7. Academics' level of satisfaction with activities organised by the faculty ........ 121

Table 5-8. Case Two's funding resources and research outcomes in 2006-2010 ............136

Table 5-9. Framework for standard teaching hours for Vietnamese academics .............. 139

Table 6-1. Case Three 's research outcome in the period 2006-2010.............................. 147

Table 6-2. Case Three's results of academics' research perceptions ................................ 150

Table 6-3. Positive factors impacting the academics' research engagement in Case

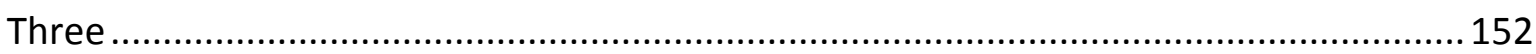

Table 6-4. Factors negatively affecting the academics' research engagement in Case

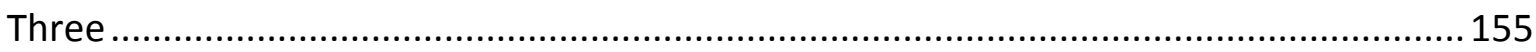

Table 6-5. Academics' level of satisfaction with PD activities organised by the

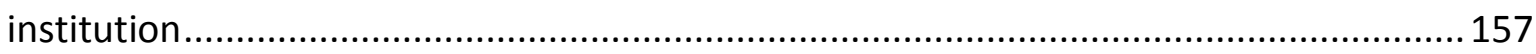

Table 6-6. Academics' level of satisfaction with PD activities organised by the faculty ... 157

Table 6-7. Case Three's survey participants' degrees and titles .................................... 161

Table 7-1. Research funding in the three cases in 2006-2010 .....................................206

Table 7-2. A brief introduction of the three HEls studied ...............................................209

Table 7-3. The number of doctoral and MA academics in the three HEls in $2014 \ldots \ldots \ldots . . .220$

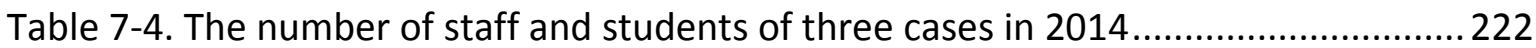




\section{ABBREVIATIONS AND ACRONYMS}

AEC

ASEAN

AUN

GDP

HE

HEls

HERA

MA

MOET

NFL

PD

PhD

RD

S\&T

SS\&H

TRIG

VNU

WB
ASEAN Economic Community

Association of Southeast Asian Nations

ASEAN University Network

Gross Domestic Product

Higher Education

Higher Education Institutions

Higher Education Reform Agenda

Master of Arts

Ministry of Education and Training

National Foreign Language

Professional Development

Doctor of Philosophy

Research Development

Science and Technology

Social sciences and humanities

Teaching and Research Innovation Grants

Vietnam National University

World Bank 


\section{CHAPTER 1. INTRODUCTION}

\subsection{Background of the study}

In the time of globalisation of higher education (HE), university academics' responsibility for research becomes important for an emerging economy like Vietnam because scientific research results may significantly contribute to the country's socioeconomic development and prosperity. Marsh and Hattie (2002) state that academics' roles in modern higher education institutions (HEIs) include teaching (transmission of knowledge), research (advancement of knowledge), administration, and community service (application of knowledge in the community). Among these roles, nations expect their university academics to perform clearly their research role. The National Science Board (2004) reported that many countries recognised the important role of academic research in the national development. Kearney (2009) states that university research plays a significant role in knowledge and innovation transfer at national, regional and international levels. Similarly, Johnson (2012) confirms that research is not only critical to the economic and social development of society, but it is also critical to a university's mission.

To foster the development and integration of its HE system, the Vietnamese Government has implemented the Resolution 14/2005 - namely Resolution of Vietnam Higher Education Reform Agenda (HERA) for nearly a decade. The general goal of the HERA was to gain a HE system that is internationally recognised, highly competitive, and appropriate to the socialist-oriented market mechanism (Nghi, 2010). Strengthening Vietnamese university research capacity to reach regional and international-standard HEls by the year 2020 is a major part of the overall objective of the HERA (Harman \& Ngoc, 2010). The reform also focuses on increasing science and technology (S\&T) activities within universities, developing key HEls into major scientific centres for the entire country, and in terms of revenue, increasing income from S\&T activities accounting for a minimum of 15\% of total HE income by 2010 and 25\% by 2020 (Harman \& Ngoc, 2010). In 2012, the Ministry of Science and Technology (MOST) proposed the strategy for S\&T development during the period 2011-2020: 
Development of S\&T together with education and training are the top national policies and key motivations for the country's fast and sustainable development. S\&T must play a decisive role to make development breakthrough in productive force, innovate growth models, enhance the competitiveness of the economy and speed up the country's industrialisation and modernisation (Vietnam Ministry of Science and Technology, 2012, p. 1)

This strategy is actually seen as a lever for the development of research and S\&T in all business sectors in Vietnam. The strategy also suggests a greater connection of HEls and industry in research and S\&T development for an overall objective to develop Vietnam during the period 2011-2020. In fact, since 2006, to achieve the HERA's goal, the Government has implemented various measures: increasing the number of qualified university academics; increasing the state budget for university research; issuing legal documents and policies for directing the development of S\&T activities at university; and expanding international training and research collaborations in HE. To increase the number of qualified academics, the Government implemented key projects such as the National Foreign Languages (NFL) Project, the Project for training Vietnamese scientific and technical staff abroad using the State budget (namely Project 322), and the Project for training Vietnamese college and university lecturers to achieve PhD degrees by 2020 (namely Project 911). Through these projects, the Government has sent a significant number of university academics to study in developed and Englishspeaking countries. It was expected that Vietnam would reach $20,000 \mathrm{PhD}$ holders to be trained abroad by the year 2020. The NFL Project was aimed to develop Vietnamese citizens' foreign language competence, particularly English language competence, in order to help the country and its citizens to have effective international integration (Vietnam Government, 2008). Although a multiple of national research policies and measures for the implementation of these policies have been approved, the research capacity of the Vietnamese HEls is limited. Very few studies associated with the research productivity as well as research capacity of Vietnamese HEls and their academics have been conducted. 


\subsubsection{Research productivity and research capacity}

Two terms commonly used in the literature are research productivity and research capacity. Research productivity can be defined as 'the totality of research performed by academics in universities and related contexts within a given time period' (Print \& Hattie, 1997, p. 454). According to Hardre, Beesley, Miller, and Pace (2011), research productivity is research publications such as refereed journal articles, academic books, book chapters, and conference proceedings presentations and publications. Academic research in Vietnamese HEIs is limited. It has recently been paid a greater attention by the Government. Lam (2005) and Harman and Ngoc (2010) suggest that the Vietnamese academics' research experience and competence are considered to be limited, so there are very few Vietnamese academics' research publications published in Englishlanguage scientific journals. Research productivity of Vietnamese HEls is considered to be lower than those of universities in developed countries and wealthy ASEAN countries such as Singapore, Malaysia, and Thailand.

Another term used to describe research activity is research capacity. Swedish International Development Cooperation Agency (SIDA) states that research capacity has several dimensions such as regional and international capacity, national capacity, institutional capacity, and individual capacity (Danish International Development Agency (DANIDA), 2014). This study adopted SIDA's definition of research capacity at institutional and individual dimensions. Institutional capacity is reflected in the ability to mobilise and allocate resources, access research, recruit and train researchers and supply laboratories, libraries, internet services, and other important infrastructure. Individual research capacity is reflected in the ability to identify, conduct and present research. For those above reasons, it was appropriate for my study to focus on investigating the research capacity rather than research productivity of Vietnamese HEls and their academics' research engagement. 


\subsubsection{Vietnam in a context of the ASEAN community}

The Association of Southeast Asian Nations, or ASEAN, was established on 8 August 1967 in Bangkok, Thailand, with the signing of the ASEAN Declaration (Bangkok Declaration) by the five original member states, namely Indonesia, Malaysia, Philippines, Singapore and Thailand. Brunei Darussalam then joined on 7 January 1984, Vietnam on 28 July 1995, Lao PDR and Myanmar on 23 July 1997, and Cambodia on 30 April 1999, making up what is today the ten Member States of ASEAN (Association of Southeast Asean Nations, 2014). At the $9^{\text {th }}$ ASEAN Summit in 2003, the ASEAN leaders resolved that an ASEAN Community should be established. At the $12^{\text {th }}$ ASEAN Summit in January 2007, the leaders affirmed their strong commitment to accelerate the establishment of an ASEAN Community by 2015 and signed the Cebu Declaration on the Acceleration of the Establishment of an ASEAN Community by 2015. The ASEAN Community comprises three pillars, namely the ASEAN Political-Security Community (APSC), ASEAN Economic Community (AEC) and ASEAN Socio-Cultural Community (ASCC). The three pillars are closely intertwined and mutually reinforcing to ensure durable peace, stability, and shared prosperity in the region. Each pillar has its own Blueprint, and, together with the Initiative for ASEAN Integration (IAI) Strategic Framework and IAI Work Plan Phase II (2009-2015), they form the Roadmap for an ASEAN Community 2009-2015 (Association of Southeast Asean Nations, 2014).

The AEC Blueprint documents that in facilitating the free flow of services (by 2015), ASEAN is working towards harmonisation and standardisation, with a view to facilitate their movement within the region (Association of Southeast Asian Nations, 2008). Actions for this free flow of services include:

- Enhance cooperation among ASEAN University Network (AUN) members to increase mobility for both students and staff within the region;

- Develop core competences and qualifications for job/occupational and trainers skills;

- Strengthen the research capabilities of each ASEAN Member Country in terms of skills, job placements, and developing labour market information networks among ASEAN Member Countries.

(Association of Southeast Asian Nations, 2008, p. 16) 
For the past two decades, a number of ASEAN nations have embarked on major reforms to develop modern $\mathrm{HE}$ systems that can support economic and social development and facilitate enhanced international trade and communications to respond to regional and global integration (Harman, Hayden, \& Nghi, 2010). The key themes of the HE reforms in these nations are similar. They include marketisation, privatisation, changes in governance, enhanced student access, modern curricula, and strong emphasis on S\&T. Like other countries in the region, Vietnam has restructured its HE system to provide new curricula and teaching methods and an enhanced role for university research with stronger links to business and industry. Additionally, Vietnam has made efforts to develop its lecturing staff and HE managers and to increase research and implementation activities in order to improve training quality (Nghi, 2010). Some Vietnamese HEls have been proactive in preparation for integrating the ASEAN'S HE systems and facing the ASEAN Economic Community in the future. There have been so far three Vietnamese HEls that have become AUN member universities (out of a total of 18 member universities). They are Vietnam National University, Hanoi (VNU-Hanoi), Vietnam National University, Ho Chi Minh City (VUN-HCM), and Can Tho University (Association of Southeast Asean Nations University Network, 2015).

\subsubsection{Government policies supporting research at HEls in ASEAN nations}

While policy instruments were often used to support the development of research and S\&T activities at universities by western governments (Dill \& Vught, 2010), Meek and Suwanwela (2006) stated that developing countries in Asia have rarely used policy instruments (legal policy, financial policy, and information policy) to improve the effectiveness of research and S\&T activities at HEls. Meek and Suwanwela pointed out two reasons why policy instruments were rarely used by Asian nations. First, their universities' mission mainly focused on teaching and basic issues (equity, access, and efficiency). Second, most Asian academic cultures were not focused on doing research. However, some ASEAN nations such as Indonesia, Malaysia, the Philippines and Thailand have developed different strategies to strengthen their research and S\&T activities at the HE level. For instance, to promote the academic research performance, 
the Indonesian government, in the mid 1990s, implemented measures, including the establishment of a research culture by the use of competitive research grant schemes and by disseminating research findings. The government created a programme, the University Research for Graduation Education, to improve its research and training activities. This programme included improving graduate courses, enhancing competitive funding for graduate education and university research, building up selection processes for grants and fellowships, incorporating university research and graduate training, and attracting highly qualified candidates for graduate education. These initiatives have significantly helped to improve institutional research capacity building (Koswara \& Tadjudin, 2006).

Malaysia has been reshaping its HE policies since before the 1970s. Malaysia's HE system has developed in terms of quantity between 1970 and 1990 . The quality of training and research at HEls has developed since 1990. Privatisation and corporatisation policies and the establishment of the HE quality assurance agencies were introduced in the period of 1990-2000 (Singh, Schapper, \& Mayson, 2010). The establishment of research universities (RUs) policy was implemented. Four research universities, including the Universiti Malaya, Universiti Sains Malaysia, Universiti Kebangsaan Malaysia, and Universiti Putra Malaysia were established in 2006 (Malaysia Ministry of Higher Education, 2007). The Research Trustees Committee was constituted to manage all internal or external funding granted or allocated for research in order to "liberate the RU from the rigid financial procedures of Treasury" (Malaysia Ministry of Education, 2004, p. 9). The development of a performance and competitive culture is also embedded in the policy of RUs. For example, incentives and grants were suggested to reward the RUs that provide high quality research training environments and support excellent and diverse research activities (Malaysia Ministry of Education, 2004).

Similarly, since 1998 the Philippines has developed national research policies. One of the policies was to design a 10-year National Higher Education Research (NHER) Agenda for 1998 to 2007. This agenda delineated policies, priorities and procedures for the encouragement and support of research in HEls. It defined HE research goals, elements of the HE research framework and priority research areas. The framework 
provided general policy statements for the development of a research culture and environment, policy directions for research management and administration, technical assistance programmes for research and research funding, and intervention strategies to increase the quality and quantity of research outputs of HEls (Salazar-Clemena, 2006).

In Thailand, research was recognised in the country's first national Economic Development Plan in 1959. The National Research Council was then established in 1961. Three independent agencies for enhancing research were established in 1993: the Thailand Research Fund, National S\&T Development Agency, and the Institute of Health Services Research. In 2003, a new Comprehensive Research Support Scheme was introduced to promote large visionary research and development ventures according to national priorities. However, only about $17 \%$ of the total budget for research goes to universities.

In an attempt to keep up with the S\&T level of the top ASEAN nations and develop HE research, the Vietnamese Government gradually increased the State's financial investment in scientific research development activities. Specifically, it is reported by Nguyen and Pham (2011) that investment in S\&T development in 2006 was USD 428 million ( $0.17 \%$ of GDP). In 2012 the figure increased to USD 650 million ( $0.27 \%$ of GDP). In parallel, the Government issued legal documents related to national research policies and strategies to direct organisations and individuals to join in research and S\&T development activities properly. The policies included the Law of Technology Transfer 2006, Law of High Tech 2008, Law of Intellectual Property (revised in 2009), and Law of Science and Technology (revised 2013) (Ly, 2013). Associated with university research, it was stated in the HERA that the Government required Vietnamese HEls to increase the funding for scientific research and related services to $25 \%$ of total HE revenue by 2020 (Wilkson \& Chirot, 2010). Furthermore, the Government made efforts to cooperate with foreign partnerships to strengthen its HEls' training collaborations and research capacity. For instance, the Government obtained the loan of USD 400 million from the World Bank (WB) and Asian Development Bank to build four world-class model research universities by 2020. Part of Vietnam's New Model University Project, two international standard universities were opened: the Vietnam-Germany University 
(VGU) in Ho Chi Minh City in 2008, and the Hanoi University of Science and Technology (USTH) in 2010. Another two are expected to be set up in Da Nang City and Can Tho City after 2015 (Mai, 2013).

Table 1-1. Research publications by ASEAN countries

\begin{tabular}{|lccc|}
\hline \multicolumn{1}{|c}{ Country } & $\mathbf{1 9 9 1 - 2 0 0 0}$ & $\mathbf{2 0 0 1 - 2 0 1 0}$ & Rate of increase \\
\hline Brunei & 201 & 345 & 1.65 \\
\hline Cambodia & 97 & 880 & 9.07 \\
\hline Indonesia & 2638 & 5784 & 2.19 \\
\hline Laos & 41 & 375 & 9.15 \\
\hline Malaysia & 5366 & 21203 & 3.95 \\
\hline Myanmar & 189 & 546 & 2.89 \\
\hline Philippines & 2630 & 4956 & 1.88 \\
\hline Singapore & 18220 & 56101 & 3.07 \\
\hline Thailand & 6673 & 28148 & 4.22 \\
\hline Vietnam & 2398 & 8220 & 3.43 \\
\hline Total & 38453 & 126558 & 3.29 \\
\hline
\end{tabular}

(Khanh, Ly, \& Tuan, 2012b)

Although the Vietnamese government has made efforts to develop research capacity for its HEls, the performance of their scientific research has been considered still limited in comparison with other ASEAN countries such as Singapore, Malaysia, and Thailand. As seen from Table 1-1, the number of scientific research publications of Malaysia, Thailand, and Singapore in the period of 2001 and 2010 was nearly 3.0, 3.5, 7.0 times higher respectively than those of Vietnam. The increase rate of scientific publications between the period of 1991-2000 and 2001-2010 of Malaysia (3.95) and Thailand (4.22) was also higher than that of Vietnam (3.43). It is important to explore factors affecting academics' research engagement and HEls' research capacity in Vietnam because the Government has been keen to know how effective present research policies related to universities' scientific research activities are.

In conclusion, many studies report that the strength of $\mathrm{HE}$, research and knowledge plays a crucial role toward a nation's sustainable socioeconomic development. In recent times, ASEAN countries have paid greater attention to their S\&T 
development strategies. While they have implemented various measures to enhance academic research performance, the success of academic research in each country is different.

\subsection{Rationale for the study}

As previously mentioned, the Vietnamese government has carried out a series of measures to develop its university research capacity. Three key projects such as Project 322, Project 911, and NFL Projects have been implemented to achieve the HERA's goals. A significant number of Vietnamese academics (approximately 1,000 ) at HEls have obtained scholarships from these three projects to study PhD courses in developed countries since 2005. It is possible to say that the key projects and other related policies somehow have created a more dynamic environment for academics' research engagement.

However, Vietnamese university research performance and productivity have still been limited in comparison with other neighbouring countries like Singapore, Malaysia, and Thailand. Therefore, it is useful to conduct a comprehensive study on Vietnamese academics' research perceptions and factors affecting their research engagement. This study findings will assist Vietnamese HE policy makers in developing strategies and policies for enhancing university research capacity in the challenging and competitive time of Vietnam's HE context.

\subsection{Researcher's background}

As a university academic in a highly competitive period among Vietnamese HEls, I understand that university academics have multiple roles in their academic life such as teaching, research, administration, and community service. Additionally, I have an insight into difficulties that my colleagues and I have had in participating in research activities within our institution. I expect that I may have similar difficulties that academics in other institutions experience in their scientific research activities and gain insights from them. I also hope that that my thesis will contribute recommendations for the development of Vietnamese HEls' research capacity. For these reasons, I intend to 
investigate Vietnamese academics' research perceptions and factors affecting their research engagement in order that I can improve my research capacity. This study can also be seen as a resource for Vietnamese academics who want to improve their research capacity as well as for leaders of Vietnamese HEls who are ambitious to enhance their institutions' research capacity.

\subsection{The objectives of the study}

The study was conducted with two objectives. It may first help to understand the realities of a practical environment for research activities at Vietnamese universities, particularly the research engagement of the participants across the three institutions in the study. Second, the study findings may suggest some considerations for Vietnamese HE policy makers and the leaders of HEls to provide appropriate initiatives, strategies, and policies related to research, S\&T development in order to narrow the gap of Vietnam's university research capacity with other nations' strong university research capacities in the region and in the world.

Two research questions were posed to address the objectives of this study:

1). How do Vietnamese university academics perceive research in the tertiary context?

2). What factors support or hinder Vietnamese university academics from undertaking research?

\subsection{Methodology}

The interpretive multiple qualitative case study approach was used as the research method to address the two research questions. Specifically, the study was conducted in three HEls (provincial, regional, and national) in southern Vietnam. The participants across the three institutions were from faculties and research institutes located in their institutions. They specialised in various disciplines, including education, agriculture, economics, computer science, and social sciences. There were two groups of participants across the three cases: 95 survey participants and 25 interview participants. 
The study employed three data collection instruments: document analysis, survey, and recorded semi-structured interviews. The study adopted an interpretive multiplecase study with a qualitative approach suggested by Klein and Myers (1999) and Diaz Adrade (2009). This methodological approach helped me to gain insights into the supporters and difficulties that Vietnamese academics in general and the Vietnamese academics across the three institutions have experienced in their research engagement.

\subsection{The study outline}

This study is composed of eight chapters. Following this chapter is Chapter 2 - Literature Review. This chapter reviews relevant studies related to the importance of research carried out by academics at HEls. It also reviews studies of academics' research perceptions and factors that affect their research productivity, and research engagement. Finally, studies of academics' research engagement in the Vietnamese HE context are included.

Chapter 3 outlines the research methodology conducted in this study. It starts with the restatement of the two research questions and provides the rationale for the employment of the interpretive multiple case qualitative approach. Additionally, this chapter describes selected participants and institutions, and provides the grounds for the three selected data collection instruments (document analysis, surveys, and semistructured recorded interviews). Finally, the process of data analysis, strategies to enhance the trustworthiness of qualitative research, and ethical issues in conducting the qualitative research are included.

The next three chapters are chapters of findings. Chapter 4 - Findings: Case One - presents the findings collected in Case One. Chapter 5-Findings: Case Two-presents the findings collected in Case Two. Chapter 6-Findings: Case Three - presents the data collected in Case Three. The organisation of these three findings chapters is outlined as follows. The first section is the chapter overview. The second section presents the findings collected from the document analysis. The third section describes the survey 
results, which is followed by the interview results - the fourth section. They finally end with the chapter summary.

Chapter 7 is Cross-case analysis. This chapter starts with a brief review of the findings of previous studies related to academics' research productivity and their research engagement. It then provides a description of the general and specific factors that impact the research activity in the three institutions. The study's discussions are also included in this chapter. This study ends with Chapter 8 - Conclusions and recommendations, which presents the significance, contribution of the study, and suggestions for further research. 


\section{CHAPTER 2. LITERATURE REVIEW}

\subsection{Chapter overview}

This chapter is organised into sections as follows. The chapter begins with the review of studies of research generated in HEls. Literature on academics' research perceptions is reviewed in the second section. This is followed with the third section, the distinction between research-led teaching and research-informed teaching. The fourth section describes factors affecting academics' research productivity as well as their research engagement. Then, a summary of studies related to academics' research engagement in the Vietnamese tertiary context is presented, which is followed by discussions of literature gaps of studies related to research perceptions and research productivity of academics. Finally, this chapter ends with the chapter summary.

\subsection{Research generated in HEls}

It has been suggested that research at HEls plays an important role in a nation's socioeconomic development. According to Etzkowitz, Webster, and Gebhardt (2000), and Abbott and Doucouliagos (2004), research is considered to be the most important source of knowledge generation, and it helps with promoting a nation's prosperity and its citizens' well-being as well as positioning its status in the knowledge-based era. Additionally, Abbott and Doucouliagos hold that research not only helps solve practical problems and brings about material improvements via high-tech products, but also provides insights and new ideas that enrich human understanding of various social, economic and cultural phenomena.

Ben-David (1984) considered that scientific research should have been added to the main mission of HEls - that is, teaching or training - in the $19^{\text {th }}$ century. Atkinson and Blanpied (2008) state that it was only in the $19^{\text {th }}$ century that German universities began to require their academics to engage in the production as well as the dissemination of knowledge. With the rise of technology-based industry in the 1870s, Germany considered scientific research academics to be a valuable asset to the country's industrial concerns. Similarly, the first American universities were established 
on the German research university models and American university academics were expected to engage in research in the aftermath of the Civil War (Atkinson \& Blanpied, 2008). This shows that university research has been considered to be important to society for the past two centuries. Recent scholars have affirmed the role of HE in nations' socioeconomic development. For instance, Etzkowitz et al. (2000) state that research at HEls has contributed to nations' economic prosperity and it is regarded as a driving force for the nation's economic development (Mowery, 2005). In terms of application, Jenkins, Healey, and Zetter (2007) state that HE research, its application and technology transfer to businesses where social needs are important. Similarly, Varghese (2008) considers that HE research contributes to increasing the body of theoretical knowledge and also applies to practical problems by providing research training and undertaking research in education. In a broader view, Kearney (2009) suggests that the function of $\mathrm{HE}$ research is to develop a prior source of knowledge and innovation at national, regional and international levels. Recent studies of HE research and innovation have a greater focus on practical application in society to create a strong knowledge-production link in a knowledge-based society to meet the society's needs. $\mathrm{HE}$ research and innovation have been regarded as a key part of innovation systems at all levels of analysis including national and regional, and through the ecosystem which links firms together with their collaborators (Coombs \& Georghiou, 2002). In a knowledge economy, European Commission (2007) indicates that it is important to create a reciprocal relationship between industry and research institutions. In this relationship, many companies treat public research as a strategic resource, and research institutions need to play a more active role in their relationship with industry in order to maximise the use of research results. This new role requires academic researchers to identity and manage knowledge resources with business potential, i.e. how best to take a new idea to market, ensure appropriate resources (funding, support services, etc.) to make it happen, and to obtain adequate buy-in by all stakeholders. It has been acknowledged by the European Commission that the involvement of business in the governance of research institutions can enable to orient research and education activities towards the needs of society. The European Commission considers that the interaction between industry and research institutions has helped to facilitate 
intersectoral mobility, namely through temporary staff exchanges as well as through the hiring of young graduates by industry.

There have been numerous studies on research, innovation, development, and management policies in $\mathrm{HE}$. As argued above, there is an agreement that research generated in HEls is important. However, very few studies of this strand have been undertaken in the ASEAN region, especially in Vietnam. Therefore, it is important for more studies related to this research area to be conducted in this region. Such studies may provide an overview of academic research conducted at HEIs, and how to better support HEls' research capacity.

\subsection{Research-led teaching and research-informed teaching}

To enhance research productivity, HEls have strived to connect teaching to research. Two terms commonly used in the literature to show the relationship between research and teaching are research-led teaching and research-informed teaching. Many studies have been conducted to explore this relationship between research and teaching. A few debates about the research and teaching link at HEls arise. For instance, Hattie and Marsh (1996, p. 529) argued that "the common belief that teaching and research were inextricably intertwined is an enduring myth". A study of academics' conceptions of 'teaching' and 'research' conducted by Prosser, Martin, Trigwell, Ramsden, and Lueckenhausen (2005) found that lecturers who see their research as tentative and as part of a wider debate in the discipline, and see their teaching as supporting student conceptual change, are more likely to bring their teaching and research together. By contrast, lecturers who distinguish their research from their teaching which focused on the transmission of information are less likely to experience strong connections between teaching and research. Seeing the important role of the connection between research and teaching in the development of HEIs, many universities in the UK, Australia, and New Zealand have been encouraging research-led teaching modes to teach students. However, research-led teaching can mean many things depending on disciplinary context and prevailing student backgrounds (Holbrook \& Devonshire, 2005). Brew (2003) groups research-led teaching into three broad categories: (i) teaching that 
draws on discipline-based research, (ii) teaching that develops student research skills, and (iii) teaching research that investigates the effectiveness of learning activities and student learning. Clarifying Brew's (2003) classification of research-led teaching, Holbrook and Devonshire (2005) proposed the first category to be research-informed teaching, while the second and the third listed categories be respectively labelled research-skills teaching, and research-inquiry teaching. Harman (2005) defines research-led teaching as teaching and research that occur in the lecturer's research area. Trowler and Wareham (2008) state that research-led teaching reflects and makes use of the teacher's disciplinary research to benefit student learning and outcomes.

Griffiths (2004) has created a framework demonstrating the different kind of links between research and teaching. According to Griffiths, teaching can be research-led, research-oriented, and research-based. He explains these terms as follows. Teaching can be research-led where students learn about research findings, the curriculum content is dominated by staff or current disciplinary research interests, and some or much of the teaching may emphasise information transmission. Teaching can be research-oriented where students learn about research processes, the curriculum emphasises as much the processes by which knowledge is produced as knowledge that has been achieved, and staff try to engender a research ethos through their teaching. Teaching can be research-based where students learn as researchers, the curriculum is largely designed around inquiry-based activities, and the division of roles between teacher and student is minimised. Griffith's framework of the research and teaching link was adopted by Healey (2005) and Jenkins et al. (2007), and has informed practice across the UK education sector. Healey (2005) has expressed these differences diagrammatically using two axes. 


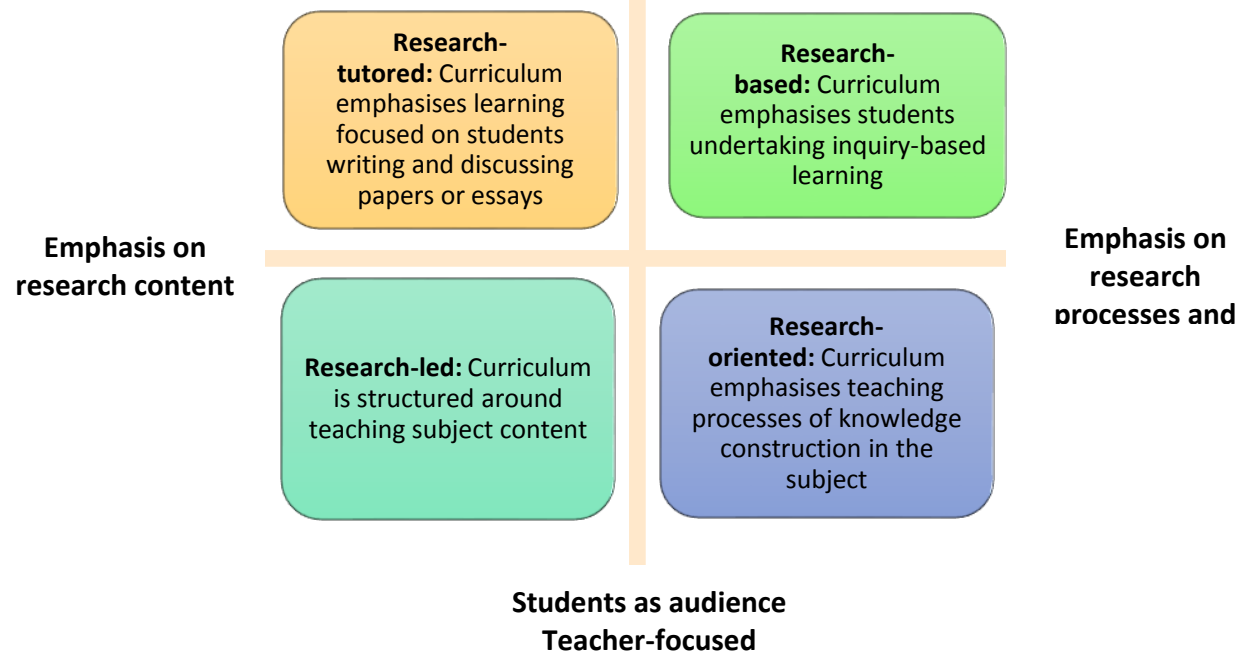

Figure 2-1. Curriculum design and the research-teaching nexus (Healey, 2005, p 70).

The vertical axis classifies approaches to the link between research and teaching according to the extent to which they are teacher-focused and students are treated as the audience or student-focused and treat students as participants. The horizontal axis classifies the approach as emphasising research content or research processes and problems.

Research-informed teaching is defined by Harman (2005) as research carried out on pedagogy and teaching methodology. Research-informed teaching is interpreted by Staffordshire University (2016) as follows:

Understanding how to link teaching and research and highlight innovative ways of demonstrating and promoting research informed teaching activity at its institutional context,

Developing student appreciation of research in the discipline and research skills in addition to other disciplinary and generic skills,

Using teaching and learning based processes which simulate research processes, Using assignments which involve elements of research processes; giving students first hand experience of research based consultancy; bringing data/findings from staff research into the curriculum. 
The use of research-led teaching approaches is very limited in Vietnamese HEls because quality training in many Vietnamese HEls in Vietnam is low, and many Vietnamese academic staff are not highly qualified (Harman \& Bich, 2010). Additionally, research activities have been paid little attention because most Vietnamese HEls are more teaching-oriented rather than research-oriented, and they have limited resources (Vietnam Ministry of Education and Training, 2005). Harman and Bich (2010) suggest reasons why there is a very limited use of the research-led teaching mode in Vietnamese HEls. They include the persistence of the Soviet model of separating research and teaching. In the Soviet model, researchers in national institutes were isolated from teaching activities and the real demands of national, social, and economic needs, and universities were traditionally more teaching oriented. Lam (2005) and Hayden and Lam (2007) comment that most Vietnamese academics have limited research capacities because they do not have sufficient research training. They have heavy teaching loads and little time for research. Researchers at HEls have not been paid enough attention. In conclusion, the research capacity of Vietnamese HEls is limited. Perhaps, one of the reasons that has weakened the Vietnamese HEls' research capacity is the infrequency of using research-led and research-informed teaching modes in training and research activities.

\subsection{Academics' perceptions of research}

The literature shows that one area of research relating to $\mathrm{HE}$ is the exploration of academics' research perceptions. Numerous studies have been conducted to understand university academics' research perceptions for over two decades. Such studies have provided a view about the academics' research perceptions and have also made recommendations for leaders of HEls that impact on their universities' research development. It would be challenging for the leaders of HEls to develop their institutional research capacity, especially in the present time of globalisation and international integration of $\mathrm{HE}$, if they have limited insights into their academics' research perceptions. Therefore, it is necessary to have good relationships and trust in academic research between the leaders and their academics at HEIs. Relationships and trust provide a foundation for academics to have positive research perceptions and 
research engagement (Timperley \& Parr, 2007). The major findings of academics' research perceptions in the literature are summarised as follows. Research can be perceived as knowledge discovery, knowledge development, solving problems, achieving career goals, recognition in the community, and contribution to mankind's needs (Borg \& Alshumaimeri, 2012; Bowden, Green, Barnacle, Cherry, \& Usher, 2005; Brew, 2001; Kiley \& Mullins, 2005).

There has been a range of studies related to research perceived as knowledge discovery. Brew (2001), for instance, in his investigation into Australian academics' research perceptions, interviewed 57 researchers from various disciplines in five Australian universities. Brew found that research was a journey of knowledge discovery, and such knowledge discovery might lead to transformation, which he called "journey conception" (p. 280). This study also found that research was perceived as a process of discovering, uncovering or creating underlying meanings "layer conception" (Brew, 2001, p. 280). Using a phenomenographic methodology to explore the significance and value of research from 18 Information Technology researchers in south east Queensland, Bruce, Pham, and Stoodley (2004) found that the significance and value of research were of great importance in contributing to academics' personal goals of knowledge discovery. Using a similar research method that Bruce et al. utilised to investigate research perceptions of 24 academics from various disciplines in the Royal Melbourne Institute of Technology (RMIT), Bowden et al. (2005) found that the participants conducted research in order to pursue their personal discovery of knowledge and satisfy their passions. Meanwhile, Meyer, Shanahan, and Laugksch (2005) revealed that research is the discovery of truth and of what has been hidden. It can be an insightful process of exploration and discovery to help gain a deeper insight and understanding of the topic. Moreover, research is perceived as creativeness and innovation. For example, Kiley and Mullins (2005) indicated that supervisors viewed research as the creation of new knowledge and innovative approaches to the discovery of that knowledge. Similarly, Stubb, Pyhalto, and Lonka (2012) found that doctoral students expressed research as a personal journey, and making a difference. 
Some studies indicate that research is perceived as knowledge development. For instance, Bowden et al. (2005) affirmed that research enables the researchers to develop their knowledge and even contribute to the development of their institutions. Having the same viewpoint, Åkerlind (2008) concluded that research assists in developing oneself personally - a type of personal understanding. Moreover, it was seen as an enabler of a broader chance to benefit a larger community. Furthermore, Borg and Alshumaimeri (2012) found over $80 \%$ of the research participants who were university teacher educators at a leading university in Saudi Arabia perceived that research was good for professional development (PD).

Research perceived as solving problems is discussed in many studies. For instance, Brew (2001) found that research was defined as a process of synthesising separate elements so that problems were solved, and questions were answered or opened up termed a "domino conception" (p.280). Referring to its application in real life, Bruce et al. (2004) stated that research was conducted to address real-world problems and to find solutions to such problems. Comparably, Bowden et al. (2005) showed that the significance of research was not only to solve problems but also to help with adding to human knowledge. In addition to contributing to values to human community life, research brings significant meanings to the researchers themselves. For instance, Kiley and Mullins (2005) argued that research provided the researcher a new way of seeing the world, oneself or a new problem. Likewise, Borg and Alshumaimeri (2012) stated that research was perceived as solving problems in professional work.

Research can be considered as a means to help academic researchers and scientists to achieve their career goals. Bruce et al. (2004) found that most participants pursued research to achieve their personal interests and career goals. Similarly, 28 academic researchers in an Australian research-intensive university in a study by Åkerlind (2008) and doctoral student participants in a study by Stubb et al. (2012) articulated that they conducted their research to fulfil their academic requirements or to gain qualifications and accomplishment. Meanwhile, Bai and Millwater (2011) and Bai, Millwater, and Hudson (2012), conducting research with the Chinese Teaching English as Foreign Language (TEFL) academics, found that the participants rated the 
value of research as helping these Chinese academics to get promotion in their jobs and to satisfy their institutional research requirements.

A few studies indicate that academics actively engage in conducting research in order to gain recognition and respect in their scholarly community. For example, Bowden et al. (2005) found that the academics were excited, and proud of their research performance when they introduced research results that received great attention from the scholar community. In addition, to be recognised and respected by colleagues, academic researchers expected their research products to meet clients' and business' needs because there has been an increasingly strong link between university and industry in HE. In this instance, research is perceived as a type of social market place where the exchange of products takes place - trading conception (Brew, 2001).

Academics have perceived their research achievement as a significant contribution to people's needs. This was indicated in the study of Bruce et al. (2004), stating that the significance and value of research were to generate positive research outcomes for the research community. Moreover, the participants in the study expressed that, by doing research, they may contribute to existing human knowledge and provide benefits to people. Comparably, Åkerlind (2008) found that the academics' understanding about research was considered as an impetus for change to benefit a larger community.

In general, studies conducted in western universities and two studies conducted in Chinese universities investigate academics' research perceptions in a single or crossdiscipline. The findings show that academics have various research perceptions which were classified into two categories: one, the researchers' intrinsic satisfaction (e.g., personal interests to discover new knowledge in the disciplinary areas, career goals, institutional requirements), and the other, the researcher's extrinsic satisfaction to meet the community's needs (e.g., solving human problems, contributing human knowledge). However, there is still a limited number of studies on academics' research perceptions in the Vietnamese tertiary educational context. 


\subsection{Factors affecting academics' research productivity}

Research has been conducted to investigate factors affecting academics' research productivity. In HEls, academic productivity is generally measured by their teaching such as courses taught and class size as well as by their research outputs (Boyer, 1990). In contrast, in research universities, academics' research productivity is often assessed as scholarly publications and presentations, sometimes including grants (Wong \& Tierney, 2001). Zainab (1999) considered research productivity as reporting and publishing research findings in national and international journals, conference presentations, patent registration, and measures of research impact factors. Similarly, according to Hedjazi and Behravan (2011), research productivity refers to innovative thoughts and ideas which, after theoretical and applied studies, lead to publication of articles in leading journals, patent registrations or documentation. Hedjazi and Behravan found that studies of universities' research productivity have increasingly gained attention since 1970. Because many governments, including the governments of developing nations, expect their countries to develop rapidly in the knowledge economy, the role of research in universities is considered more important than ever before.

The literature shows that factors which have substantial effects on the research productivity and their research engagement include academic disciplines (Jung, 2012), intrinsic and extrinsic personal factors [individual level] (Chen et al., 2006; Chen, Marry, Ashok, \& Leon, 2010), institutional and leadership characteristics [institutional level] (Bland et al., 2005), social and community factors (community level) and national policy factors [national level] (Moore, 2015). Therefore, this thesis investigates different factors affecting the Vietnamese HEls' research capacities and their academics' research engagement. Following sections describe the factors at different levels influencing academics' research productivity and their research engagement.

\subsubsection{Academic disciplines}

Academic disciplines were defined by Cohen and Lloyd (2014) as academic studies that focus on a self-imposed limited field of knowledge and are taught or researched at 
tertiary level. Becher and Trowler (2001) reported that, for HE researchers, the concept of an academic discipline is not a straightforward one but it is considered an important factor affecting academics' research productivity and their research engagement. Becher and Trowler considered that academic disciplines have differences in theories, research methods and basic paradigms. Jung (2012) stated that the academic discipline is one of the most important variables influencing the academic activity and research productivity of academics. For instance, Kevik (2003) found that the number of publications (articles in scientific journals, articles in books and reports, books, and reports) in national and foreign journals from 1980 to 2000 by Norwegian academics of technology, natural and medical sciences was higher than those of their colleagues in the SS\&H. In particular, books were most common in the SS\&H and accounted for 11 and $9 \%$ respectively of the total number of publications, compared to $3-5 \%$ in the other fields. Kevik concluded that the differences were likely due to differences in publication patterns, in co-authorship, and the manner that publications were reported. Stack (2004) used the 1995 Survey Doctoral Recipients (SDR) dataset to conduct a study of gender and children affecting academic researchers' research productivity. His findings indicate that the academics in sciences of biology, physics, and health/medicine published more articles than the academics in the social sciences. Engineering and mathematics academics had a level of research productivity that was similar to social sciences academics. It has been argued that disciplinary differences in research productivity might not be indicative of the level of intellectual output necessary for respective fields, but instead might reflect the number of resources available and the level of agreement on the study method and findings of research reports in the disciplines (Teodorescu, 2000; Wanner, Lewis, \& Gregorio, 1981).

\subsubsection{Individual characteristics}

The literature indicates that academics' research productivity is considerably affected by their individual characteristics. Numerous studies, including Chen et al. (2006), Fabel, Hein, and Hofmeister (2008) and Hardre et al. (2011), have divided individual characteristics affecting academics' research productivity into intrinsic and extrinsic factors. 


\section{Intrinsic factors}

Studies indicate that intrinsic factors found to impact academics' research productivity. They include demographic characteristics (age, gender, and family background), personal traits, and knowledge and experience. For instance, using the expectancy theory of Vroom (1964) to examine factors affecting business academics of 10 midwestern universities in the United States, Chen et al. (2006) found that there was a negative link between research performance and years in academia. They explained: firstly, the decrease in research publications in years was the possibility of the decline in ability and energy with age; secondly, senior academic members might have more service requirements, possibly revealing the influence of individual and institutional factors on academics' research practice. Analysing the relationship between age and research productivity at four Norwegian universities, Kyvik (1990) indicated that publishing activity reached a peak in the $45-49$ age group and declined by $30 \%$ among researchers at the age of 60 . Examining academics' productive time in their career age, Fabel et al. (2008) showed that journal article publications decreased with career age. The study indicated that senior academics were likely to publish more books in their late career. Related to gender, Stack (2004) considered that male scientists had a tendency to publish more than female scientists. Likewise, Ding, Murray, and Stuart (2006) indicated female life scientists' patents were about $40 \%$ of male scientists' patents. The study findings of Parker, Lortie, and Allesina (2010) noted that the vast majority of highly cited environmental science and ecology papers belonged to male scientists. Larivière, Vignola-Gagné, and Villeneuve (2011) revealed that women at universities in Quebec, on average, were generally less productive in terms of publications than men and concluded that the rate of research productivity in female academics was lower than that in male academics. However, Chen et al. (2006) found that there was no relationship between research productivity and gender.

Family background has been found to be a significant element of demographic individuals that impact on academics' research productivity. Cole and Zuckerman (1984) indicated that the American natural and social scientists who were married with children published more per year during the course of their career than the unmarried 
female researchers. They added that children's age might have different effects on parents' scientific productivity because academics with younger children had greater demands on their time and energy. Kyvik (1990) found that married people were more productive than unmarried people; women with children were more productive than those without children; women with more than two children were less productive than those with only one, and women who had children under 10 years old produced $47 \%$ fewer publications than their male colleagues in the same position or those with older children. The study explained that married women might have more energy and stamina than women without children; married women might get support from their husbands; family life increased their self-respect; and being married neutralised the effect of gender since married women cooperate more with their male colleagues than unmarried women.

Academics' personal traits have been considered as important intrinsic factors that impact their research productivity. Chen et al. (2006), and Chen et al. (2010) found that the factors related to academics' personal traits included intelligence, insight, creativity, curiosity, self-competence, self-motivation, recognition and being respected in the field, ambition, and the need to collaborate with others. For example, Hunter and Kuh (1987) found that to be productive knowledge producers, individuals need to "be creative, confident, sensitive, curious, open-minded, flexible in thinking, intellectually playful, willing to work long hours, over periods of time." (p. 444). Likewise, Wood (1990) claimed that ability, creativity, motivation, self-discipline and ambition were regarded as factors to vary academics' research productivity. Additionally, academics having a strong desire for achievement, recognition, capability, a need for curiosity, and following the research field are productive researchers (Chen et al., 2006; Chen et al., 2010; Hassan, Tymms, \& Isamil, 2008; Jeans \& Murphy, 2009). Sarunya (2008), using a qualitative multiple-case study involving leaders from 11 faculties in a Thailand university, claimed that self-motivation was the elemental factor to encourage academics to do research. Bland et al. (2005), Dundar and Darrell (1998), and Hardre et al. (2011)commented that university academics naturally have such personal traits, but those who have positive personal traits are more likely to become productive researchers in their career. 
Other intrinsic factors, which were found in a range of studies, include knowledge and experience. Blackburn, Bieber, Lawrence, and Trautvetter (1991), Hassan et al. (2008), Hunter and Kuh (1987), and Sarunya (2008) agreed that knowledge and experience greatly affected academic research performance. Sarunya (2008) found that skills and experiences - the two elements in a group of the essential factors known as the career development factors - motivated lecturers in selected universities to engage in research. Other elements in the group of essential factors included attitude, academic origin, tenure status, and level of qualification. Similarly, Jones et al. (2003), exploring general practitioners' research training needs and the barriers to involvement in research, found some participants admitted that they lacked specific research skills and considered the lack of these skills as a barrier to undertaking research. However, Chen et al. (2006) stated that the effect of knowledge and experience on academics' motivation to conduct research was not clear.

In conclusion, studies showed that academics' research productivity and their research engagement were affected by intrinsic factors. The intrinsic factors include demographic characteristics, personal traits, knowledge, and experience. Academics' positive personal traits and their knowledge and experience were seen as significant factors that make them become productive researchers.

\section{Extrinsic factors}

Extrinsic factors, including promotion, finance, tenure, teaching loads, and research networks, have been considered to have a substantial impact on academics' research productivity and research engagement. For instance, Chen et al. (2006) mentioned that tenure and promotion were potential motivators for research productivity. Similarly, Tien (2008) claimed that there was a close link between publication and promotion in many current instructional policies; more publications entailed promotion and an increase in income. Furthermore, examining 82 university educators' engagement with and in educational research, Borg and Alshumaimeri (2012) found that undertaking research helped the participants to get promotion. It is understandable that when a 
university lecturer gets promotion, he/she will be more respected and powerful in the organisation, and have opportunities for a higher income.

Additionally, finance is considered to be an important extrinsic motivator that leads academics to actively engage in research. For example, exploring to what degree the promotion system rewarded Taiwanese academics' research productivity, Tien (2007) conducted a study in nine universities. He confirmed that the reward of finance and promotion were factors in stimulating academics to research. Comparatively, Tareef (2009) stated that the poor economic conditions and the decrease of research funding discouraged the participants from doing research. Consequently, research productivity in Jordan's HEls was low. However, finance was not clearly found as a factor affecting the research outputs of the academics in Malaysia and Thailand (Hassan et al., 2008; Sarunya, 2008). It is perceived that economic conditions in Malaysia, Thailand, and Vietnam are quite similar. The academics in those countries understand that their countries' economic conditions are still difficult; therefore, they may actively engage in research not for money but for status and respect in society. On balance, it seems that finance is not seen as a very substantial factor that motivates the academics in Southeast Asian countries to conduct research.

Heavy teaching loads are regarded as a factor affecting university academics' research productivity. Academics' heavy teaching loads hinder them from engaging in research activities because they have limited time for their own research work. Chen et al. (2006) found that when academics had a greater allocation of research time by reducing their teaching workload, their research productivity would be higher. In the same way, Jones et al. (2003) and Sarunya (2008), ascertained that the most important factor impacting on lecturers' low performance in research is their heavy teaching workloads. Borg and Alshumaimeri (2012) found that university teacher educators working in a leading university in Saudi Arabia did not have to conduct research because they were busy with teaching and other academic work in their institutions. In Vietnam, university academics have also had heavy teaching loads. Students to teacher ratios increased from $6.6: 1$ in 1987 to $28: 1$ in 2009 . At private universities, the ratio of students to lecturer was considerably higher (Clark, 2010). The ratio of students to 
lecturer in Vietnam was higher than in any other country in Southeast Asia: in Vietnam (30:1), the Philippines (23:1), Malaysia (20:1), Indonesia (15:1) (Chapman, 2009). Obviously, with this high ratio, Vietnamese academics had a great number of teaching hours in a semester, so their time for research was very limited. Heavy teaching loads possibly have a great influence on Vietnamese academics' research engagement. Therefore, it is reasonable to recommend that teaching loads should be reduced for improving productive research institutions (Metlich-Medlich, 2009).

Tenure is found to be a substantial factor that motivates academics to engage in research, and it has been found to enhance their research productivity more than other factors such as promotion and finance. For instance, Butler and Cantrell (1989) found that tenured faculty were motivated by anticipated rewards, and assistant professors had a greater need for money than associate professors. Similarly, Chen et al. (2006) found that tenured faculty members were more motivated by intrinsic rewards. Generally, academics have more intrinsic factors to do research for improving knowledge than getting promotion or having tenure.

Research networks are seen as a decisive factor that contributes to an increase in scientific experts' and academics' research productivity. Pravdic and Oluić-Vuković (1986) analysed collaborative patterns in the field of chemistry at individual and group levels. They found that scientific output, as measured by publications, closely depended on the frequency of collaboration among authors. Melin (2000) surveyed 195 university professors in Sweden about their motives for collaboration and the benefits of collaboration. The study's survey findings (from open-ended questions) indicated that $41 \%$ of the participants' motivation to collaborate for co-authorship was to gain special competence, $20 \%$ for special data or equipment, $16 \%$ for social reasons, $14 \%$ for supervisor-student relations, and $9 \%$ for development and testing of new methods. The benefits of collaboration found are an increase in knowledge (38\%), higher scientific quality (30\%), future work connections (25\%), and generation of new ideas (25\%).

Bozeman and Elizabeth (2004) argued that when publishing, productivity was measured by counting a scientist's total number of publication, collaboration was a 
major factor in promoting and transmitting scientific and technical human capital. Lee and Bozeman (2005) considered that early career researchers may substantially benefit from the junior-senior collaborations, and learn professional knowledge from senior researchers. Huang (2014) outlined the following reasons for researchers to collaborate: "the need to address complex research issues; the need for learning and productivity in research; the need to reduce research cost; and the need for intellectual companionship" (p.92).

Chen et al. (2006) summarised various individual factors affecting academics' research productivity (see Figure 2-1). They include intrinsic motivators, extrinsic factors, and demographic and institutional factors. Chen et al. (2006) stated that academics have intrinsic factors to achieve peer recognition, gain respect from students, satisfy personal needs for creativity or curiosity, satisfy personal needs to collaborate with others, and satisfy personal needs to stay updating in the field. Their extrinsic motivators to engage in research include receiving tenure, being full professors or getting promotion, getting better salary raises, getting administrative assignment, getting chaired professorships, getting reduced teaching loads or finding better jobs at another university. The demographic and institutional factors include tenure status, number of years of academics, gender, academic rank, time spent on research, and discipline.

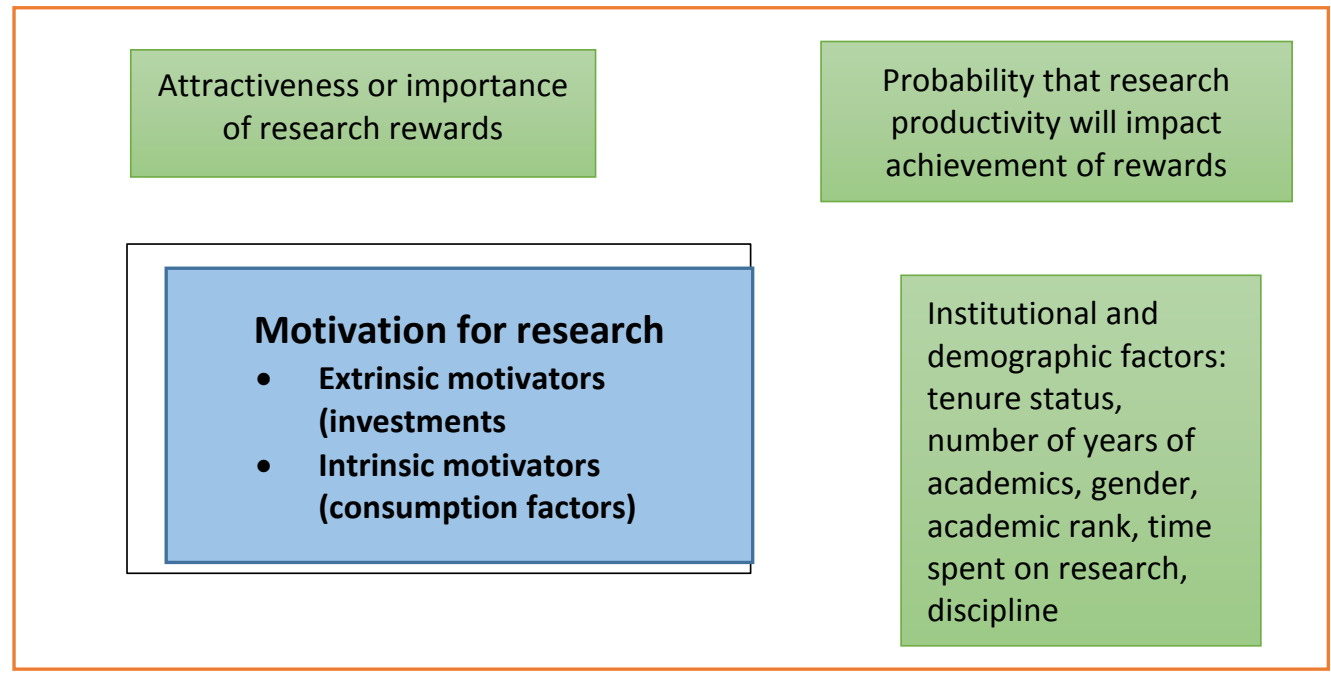

Figure 2-2. A framework of factors affecting academics' research productivity adapted from Chen et al. (2006, p. 181) 
In conclusion, the literature has shown that academics' research productivity and their research engagement have been substantially affected by their individual characterisics. They include intrinsic and extrinsic factors. Academics' personal traits and their knowledge and research experience were found to be prominent intrinsic factors, whereas finance, teaching loads, and research networks were seen as important extrinsic factors affecting their research productivity.

\subsubsection{Institutional characteristics}

Institutional characteristics are considered as significant factors affecting academics' research productivity. They include institutional faculty/department size, revenue amount, the availability of technology and facilities, and resources such as books, journals in the library, institutional culture, working conditions, workload policies, the availability of leave and travel, research funds, and the availability of leading research academics (Bland et al., 2005; Borg \& Alshumaimeri, 2012; Creswell, 1986; Dundar \& Darrell, 1998; Fox, 1983; Huang, 2014). For instance, Fox stated that research productivity was affected by structural aspects of researchers' working environment such as the capability of the training institution, the prestige of the institutional affiliation, and other features of institutional location. Dundar and Darrell considered that a programme and department with a larger number of academics was a better predictor of publications. Creswell (1986) stated that the culture of a department or institution was an important factor in determining individual academics' research performance. Creswell added that institutional characteristics contributing to academics' research productivity included the employment of a reward system in performance-based management (tenure, promotion, salary increments), the employment of a financial support system for academics' research engagement based on their attaining success in concrete indicators (the number of publications, book awards, research grants), and the use of quantifiable forms of recognition. These criteria not only influenced promotion decisions, but also reinforced future academic research and attracted more research funding (Braxton, Luckey, \& Helland, 2002; Fairweather, 1993). 
In support of Creswell's (1986) study, Dundar and Darrell (1998) indicated that a faculty with better finance and resources may have a higher research output, and heavy teaching loads in a department may lead to a reduced research performance. Moreover, they hold that a positive research culture such as professional relationships in the institution or department had a considerable impact on academics' research productivity. For instance, when there is collaboration between inexperienced or junior academic researchers and senior, experienced ones in a department or 'star' faculty mentioned by Dundar and Darrell (1998), the research productivity and academics' level of research engagement in that department tended to be better. They concluded that institutional factors included leadership, culture, structure, and policies affected academics' research productivity.

Similarly, in an investigation into factors affecting academics' research productivity in a public university in Thailand, Sarunya (2008) identified that participants felt obstructed in conducting research because of the lack of research facilities, resources, stationery, books, and departmental supports. Sarunya added that the policy of financial incentives was unclear in some departments, which discouraged the participants from engaging in research. She also found that in any department where there was a good culture of research, the lecturers in that department were more active in research engagement and that department's research productivity was higher, too. Investigating university teacher educators' research engagement in Saudi Arabia, Borg and Alshumaimeri (2012) also found that the participants had low research engagement because they did not receive good support related to research activities from their institutions. Huang (2014) assumed that when institutional factors of research policy, culture, and structure were improved, this enhanced the institution's research capacity. Using data from a University of Minnesota Medical School in 2000, Bland et al. (2005) listed 15 institutional factors (resources, rewards, sufficient work time, clear coordinating goals, size/experience/expertise, mentoring, culture, communication, research emphasis, recruitment and selection, positive group climate, communication with professional network, assertive-participative governance, brokered opportunity structure, and decentralised organisation) that all affected the institution's research performance. 


\subsubsection{Leadership characteristics}

Leadership characteristics of an institution have been found to have a significant impact on academics' research productivity. For instance, Barnett (1990) holds that the contribution of leadership to research performance is even stronger given the climate of output-driven systems, of precious financial resources, of heightened competition, and where the 'raison d'être' of universities is a topical contemporary philosophical and political issue. Barnett's study is supported by research of Bushaway (2003), and Ball (2007). Bushaway stated that research leadership in universities could improve research outcomes, staff enthusiasm and commitment to research. In the examination of the leadership role of university academics in hospitality management, Ball found that leadership was important for the advancement of research in universities. Therefore, Ball (2007) suggested that universities might enable the achievement of research outputs and objectives through the recognition of the need for, and promotion of research leadership. Exploring the relationship between leader behaviours and team performance outcomes, Burke et al. (2006) used the electronic databases of ScienceDirect, EBSCOhost, Academic Search Premier, Business Source Premier, PsycARTICLES, and PsycINFO to search for related studies published between 1900 and 2004 and found that team leadership behaviour influenced employee performance, team productivity, team learning, and proactive behaviour. Meanwhile, Bland et al. (2005) concluded that an institution's conductive research environment was a result of effective leadership which had four characteristics. The institution's leaders should be highly recognised and capable scholars. It should be a research-oriented institution; its leaders may use an assertive-participative leadership style, and its leaders fully fulfil their critical roles (manager, fund-raiser, keeping goals visible, ensuring presence of individual and institutional characteristics).

In conclusion, numerous studies indicate that academics' research productivity has been influenced by different factors. They include academic disciplines, individual characteristics, institutional characteristics, and leadership characteristics. Particularly, when academics have more positive individual characteristics, and more positive points of academic disciplines, institutional characteristics, and leadership characteristics, 
their research productivity is much better. Bland et al. (2005) summarise individual characteristics, institutional characteristics and leadership characteristics that affect academics' research engagement and their research productivity. The three groups of influential factors can be seen from Figure 2-2.

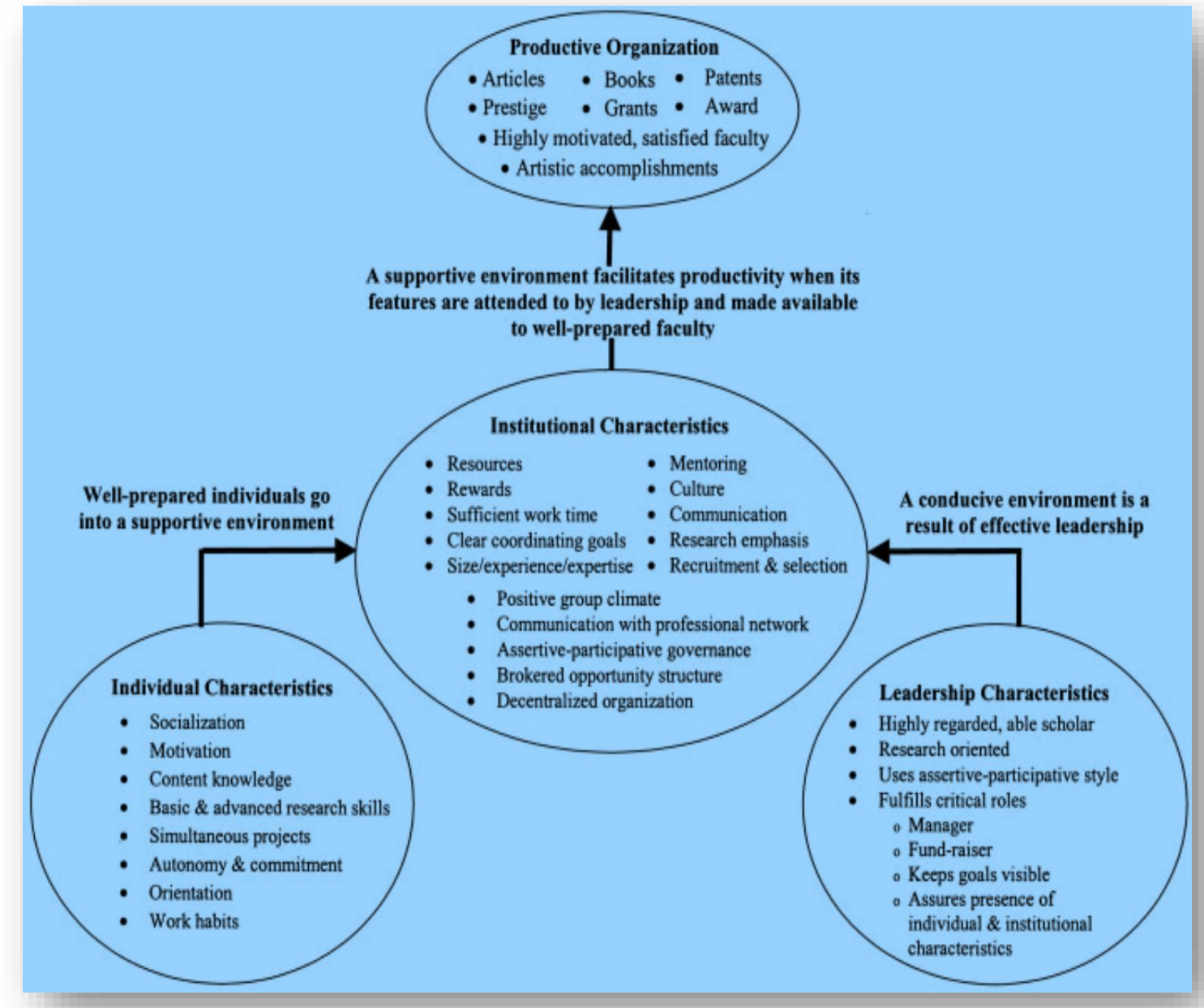

Figure 2-3. Model of the individual, environmental, and leadership factors affecting the faculty's research productivity adapted from Bland et al. (2005, p. 227)

\subsubsection{Social community networks}

Some studies in the literature show that social community networks have substantial impact on the research productivity and research engagement of academics. Cadima, Ojeda, and Monguet (2012) state that social community networks play an important role in learning environments as a key channel for knowledge sharing and as a source 
of social support. Research engagement is considered as a form of academics' professional learning development activity. Dawson (2008) suggested that we are all in the involvement in learning activities, group work and collaboration to promote learner-to-learner interactions that supports the co-construction of knowledge and the sharing of information and resources. From an environmental perspective, Santo, Engstrom, Reetz, Schweinle, and Reed (2009) state that academics who had limited networks with colleagues were less productive in research than those who had networks of colleagues in their disciplines. They considered that members might gain research advice and support in the networks that they engaged in. From a social perspective, Cho, Gay, Davidson, and Ingraffea (2007) suggest learning is a social and collective outcome achieved through seamless conversations, shared practices, and networks of social connections. Thus, academics may learn from looking for some knowledge through their informal networks of colleagues and friends. In conclusion, it seems that social community networks have influences on academics' research engagement and the research capacities of their HEls.

\subsubsection{National research policies}

Numerous studies have shown that national policies and strategies impact on individual members' behaviours and activities. These studies such as Senterfitt, Long, Shil, and Teutsch (2013), and Moore (2015) investigated social and economic factors affecting people's health. For instance, in exploring how social and economic factors affect people's health, a study by Senterfitt et al. (2013) shows that across life span, determinants of people's health are affected by different factors illustrated in a fivelevel circle. The first level is innate individual traits. The second level is individual behaviour. The third level is social, family, and community networks. The fourth level is living and working conditions, and the fifth level is broad social, economic, cultural, health, and environmental conditions, and policies at the goals, national, states, and local levels. Similarly, in a study of factors affecting people's health, Moore (2015) says "the world we live in influences on us" (p. 1) and suggests a socio-ecological model indicating that people's health is influenced by different levels of factors, including 
individual, interpersonal, organisational, community, and public policy factors (see Figure 2-4).

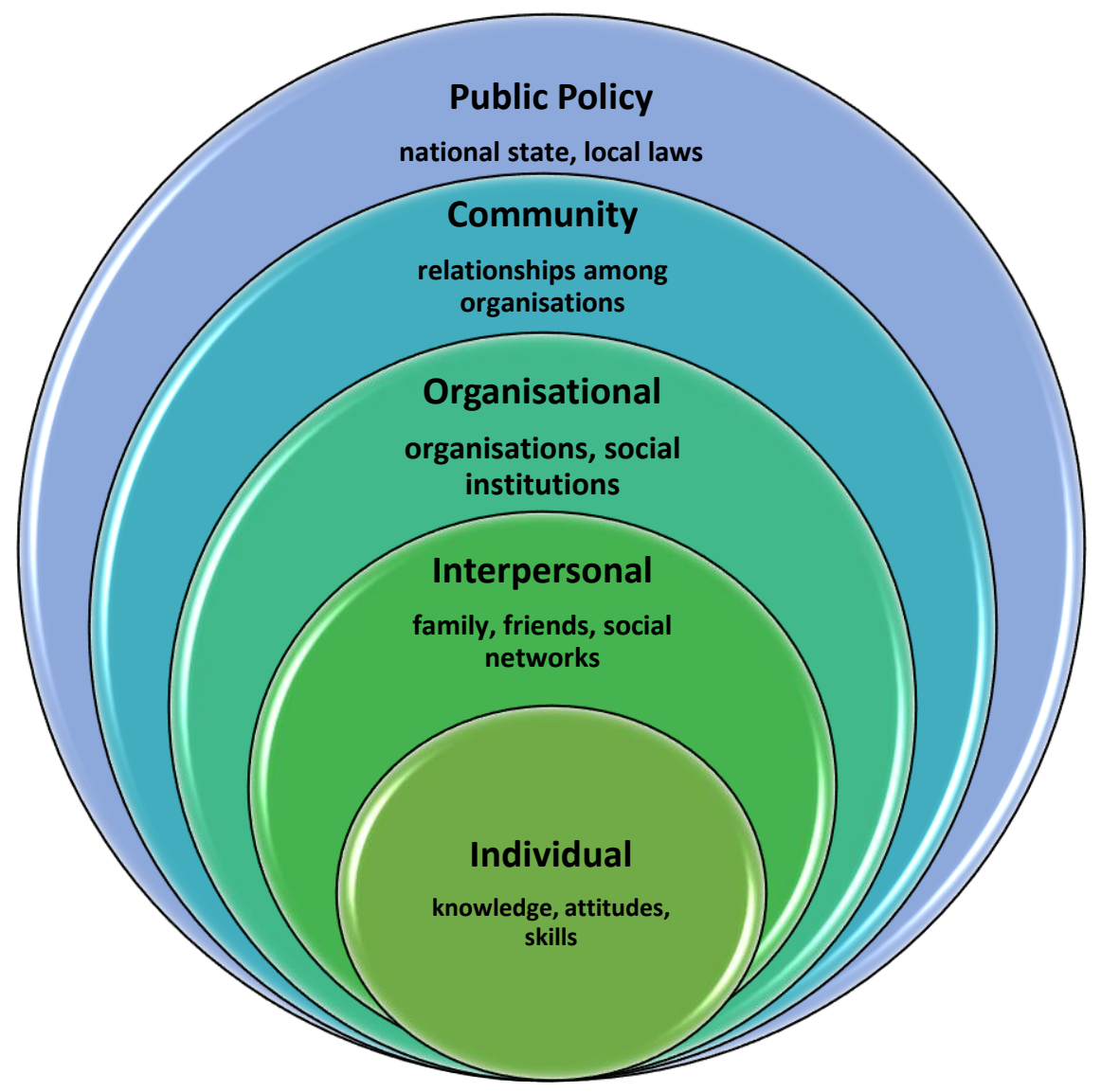

Figure 2-4. Social-ecological model: Looking beyond the individual adapted from Moore (2015, p.1)

It is apparent that individual academics' research engagement and HEls' research capacity in all nations are affected by their social research networks, organisational institutions, and policies for the goals of national, regional, and local levels. However, there seems to be a very limited number of studies on the research capacity of academics and HEls that use the socio-ecological model as an analytical model for factors affecting the research capacity of academics and HEls. For this reason, it is useful to have a combined models of Bland et al. (2005) Chen et al. (2006), Moore's (2015) as the analytical model in my study which is explained in Chapter 3 in consideration of factors impacting the Vietnamese HEls' research capacities and their academics' research engagement. 


\subsection{Studies of academics' research engagement in Vietnam's HE context}

In recent times, the Vietnamese government has investigated a range of measures and policies to enhance its HEls' research capacity. The research capacity of Vietnamese universities, however, is low in comparison to that of universities in ASEAN nations. Despite the fact that numerous studies related to academics' research productivity and their research engagement have been conducted in the United States, Australia, and in some countries in northern Europe and in South East Asia, there has been a limited number of studies of Vietnamese academics' research engagement undertaken in Vietnam. Some studies related to academics' research engagement that were conducted in Vietnam included studies by Hiep (2006), Pham (2006), Hien (2010), and Ly (2013).

Hiep (2006) investigated the research culture of English language academics at the tertiary level in Vietnam. He used semi-structured interviews and document reviews as his data collection instruments. The participants were seven English language education teachers from two institutions in Central Vietnam. The findings showed that the participants acknowledged the necessity of doing research, and key factors that discouraged those doing research were identified. The factors included the participants' dissatisfaction with current evaluation regulations, research conventions and formats of research reports. They had limited time and resources for research, and very few opportunities to disseminate their research results. The author suggested ways to develop Vietnamese English language education teachers' research engagement. First, more effort needed to be made at the local and international level. Second, Vietnamese academics needed to be encouraged to conduct real and quality research instead of superficial projects for extra income. Third, Vietnamese academics needed to be offered opportunities to present their research reports at institutional and national conferences, and their attendance to present their reports at conferences should be considered as a criterion for annual evaluation of their work performance. Finally, Vietnam's government needs to invest more money in research, and to offer financial support to researchers wanting to present their research at international conferences. 
According to Pham (2006), the Institute for Science Information data indicated there were 1,796 co-authored scientific articles (co-authorship between Vietnamese and foreign scholars), which accounted for $80 \%$, and 450 scientific articles (20\%) written by Vietnamese scholars in the period of 2000-2005. The number of articles with coauthorship between Vietnamese and foreign scholars that were published in international journals doubled in this five-year period while the number of articles published in foreign journals by Vietnamese authors was around 89 annually. However, the figure for articles published in foreign journals was still more limited than for those published in national journals. Table 2-1 indicates the number of scientific articles published on national journals during 2003 and 2004.

Table 2-1. Vietnam's scientific publications during 2003 and 2004

\begin{tabular}{|l|c|c|c|c|}
\hline \multicolumn{1}{|c|}{ Fields } & \multicolumn{2}{|c|}{ Year 2003} & \multicolumn{2}{c|}{ Year 2004 } \\
\hline & $\begin{array}{c}\text { Publication } \\
\text { Number }\end{array}$ & Percentage & $\begin{array}{c}\text { Publication } \\
\text { number }\end{array}$ & Percentage \\
\hline $\begin{array}{l}\text { Social sciences } \\
\text { and Humanities }\end{array}$ & 3,268 & 44.7 & 4,345 & 51.7 \\
\hline Natural sciences & 868 & 11.9 & 702 & 8.4 \\
\hline Technology & 1,495 & 20.4 & 1,312 & 15.6 \\
\hline Medical science & 785 & 10.7 & 1,111 & 13.2 \\
\hline $\begin{array}{l}\text { Agriculture- } \\
\text { Forestry-Fishery }\end{array}$ & 893 & 12.3 & 938 & 11.1 \\
\hline \multicolumn{1}{|c|}{ Total } & 7,309 & $100 \%$ & 8,408 & $100 \%$ \\
\hline
\end{tabular}

Vietnam Ministry of Science and Technology (2004)

The ratio of scientific articles produced by universities and that by research institutes in Vietnam in $2000-2004$ was $179 / 271$ (66\%). The ratio in the period 1995 2004 was lower, $257 / 458$ (56\%). However, most of these articles focused on the disciplines of mathematics and theoretical physics.

Pham (2006) concluded that there was an imbalance in Vietnam's scientific research, which focused more on theoretical research than practical and applied research. University research at the international level was more limited than that in research institutes. Pham added that fewer international level projects conducted in Vietnamese universities than in research institutes was not appropriate for universities and their academics because the universities' mission was to train high quality human resources for society. Pham suggested that it was necessary to strengthen research at 
key universities to build international level research groups within research universities which was seen as a vital factor in determining the survival of Vietnam's HE and S\&T sectors.

Hien (2010) conducted a comparative study of research performance of 11 East and Southeast Asian nations based on the total number of peer-refereed international publications (PRIP) per one million people (research intensity), the mean citation, and the contribution of domestic researchers in PRIP production. The results showed that Vietnam was one of the countries with low research intensity in the region in 2008. Other weaknesses included the heavy reliance on foreign authors, and the low indicators of PRIP in various fields. The author recommended that there should be a shift from a teaching-based approach to research-based approach in Vietnamese HEls. Moreover, he suggested that the nation concentrated its resources and determination to build multidisciplinary universities that have internationally recognised standards in teaching, research, and governance. By doing this, Vietnamese HEls with excellence in research and technology innovation may create a new image for Vietnam's science and HE system.

In a case study exploring the effectiveness of research and innovation management at policy and institutional levels in Vietnam, Ly (2013) concluded that there were some significant gaps in research management. They included a lack of awareness of international contexts and global research environment, deficiencies in policy development and analysis skills, weaknesses in monitoring the implementation of the policies, and a general lack of effective communication with all stakeholders. She suggested that there should be a need to create effective leadership and a professional management system for the development of research capacity in Vietnam (Ly, 2013).

In summary, this section reviews the studies of academics' research engagement that have been conducted in Vietnam so far. The above studies somehow indicate the realities of Vietnamese HEls. They explore the research culture of academics teaching English as a foreign language (EFL) in some Vietnamese HEls in a single disciplinary perspective, show the number of scientific articles published on national journals, 
comparing research performance of the ASEAN countries, and investigating the effectiveness of research and innovation management at policy and institutional levels in Vietnam. Particularly, at recent times, after the issue of the HERA in 2006 (reforming the Vietnamese HE system, among of which academics are required to develop and improve their research capacities), there seems to be some tension for HEls and their academics to implement this Government's policy (Vietnam Government, 2005). In reality, there is little known about the Vietnamese academics' perceptions of research as well as factors affecting the research capacity of HEls and their academics' research engagement. Therefore, it is necessary to have such a study conducted to contribute into a better understanding of the Vietnamese academics' research perceptions, their research engagement as well as their HEls' research capacities in a multiple and broader perspective.

\subsection{Literature gaps}

As previously mentioned, numerous studies of the research perceptions and research productivity of academics have been conducted. Studies of research perceptions such as studies by Åkerlind (2008), Brew (2001), and Prosser, Martin, Trigwell, Ramsden, and Middleton (2008) have mainly focused on exploring the conceptions of research of senior researchers, doctoral students, and their supervisors, and the links between the conceptions of research and the conceptions of teaching. Studies of research productivity such as studies by Bland et al. (2005), Borg and Alshumaimeri (2012), and Chen et al. (2006) were conducted to find out factors affecting academics' research productivity within academic disciplines and across countries. Brew, Boud, Namgung, Lucas, and Crawford (2015) reported that there has been a growth in emphasis on studies viewing the researcher role, researcher identification, research collaboration, and research management. These studies have been mainly conducted in developed countries like the United States, Australia, and some northern European countries. In the past ten years, there have been some studies related to academics' research productivity conducted in South East Asia such as a study by Sarunya (2008) in Thailand, and Hien (2010) in Vietnam. One study associated with research and innovation management was conducted in Cambodia, Malaysia, Thailand, and Vietnam by Olsson 
and Meek (2013). However, there is a very limited number of studies related to Vietnamese academics' research perceptions and factors affecting their research engagement.

\subsection{Chapter summary}

This chapter reviewed previous research related to factors affecting academics' research perceptions and research productivity, and Vietnamese academics' research engagement. The literature shows that academics' research productivity is affected by a range of factors. They include academic disciplines, individual characteristics (including both intrinsic and extrinsic factors), institutional characteristics, and leadership characteristics of academic management. However, most studies have been conducted in Europe, and some have been conducted in Asian countries like China, Malaysia, Taiwan, and Thailand. In the integrated globalisation era of HE, nations and universities have been focused on enhancing their research capacity. Recently, Vietnam and its HEls have also paid attention to developing their research capacity. In particular, the Government has issued a range of policies and directions that were aimed to support and direct HEls' research capacity. However, Vietnamese HEls' research capacity is still limited. There have been few studies on academics' research engagement in Vietnam. The studies have not fully explained Vietnamese academics' research perceptions and research engagement at HE contexts. Therefore, it is necessary to conduct a study of factors affecting Vietnamese academics' research engagement in order to response to the Government's concern and to suggest some solutions for promoting Vietnamese HEls' research. 


\section{CHAPTER 3. METHODOLOGY}

\subsection{Chapter overview}

This chapter outlines the research design of the study. The chapter includes four main sections. The first section provides a description and rationale for the interpretive multiple-case qualitative approach. Details of the data collection, including the survey and interview schedule, and the process of data analysis are presented in the second section. Trustworthiness, transferability, credibility, confirmability, and ethical considerations involved in the study are discussed in section three. A description of the background of the three institutional cases is then provided in section four, and this is followed by the chapter summary.

\subsection{Research questions}

To address the research problems, this study poses two research questions. They are:

1. How do Vietnamese university academics perceive research in tertiary contexts?

2. What factors support or hinder Vietnamese university academics from undertaking research?

\subsection{Interpretive qualitative case study approach}

In order to answer the two research questions, this study employed an interpretive qualitative case study approach to investigate Vietnamese university academics' research perceptions and factors affecting their research engagement. The grounds for selecting this approach for this study are discussed in detail in the following sections. To begin with, the nature of interpretive research is discussed.

\subsubsection{Interpretive research}

Interpretive research is a framework and practice within social science research that is invested in philosophical and methodological ways of understanding social reality (Bhattacharya, 2008). Taylor (1995) commented that the interpretive approach rests on the premise that in social life there is only interpretation. Everyday life revolves around 
people interpreting and making decisions about how to act based on their own experiences and their interpretation of the experience and behaviour of others. An interpretive approach, according to Schwandt (1994), provides a deep insight into "the complex world of lived experience from the point of view of those who live it"(p. 118). Cavana, Delahaye, and Sekaran (2001) assume that reality is socially constructed and the researcher becomes the vehicle by which the reality is revealed. Mingers (2001) suggests that the interpretive approach is consistent with the construction of the social world characterised by the interaction between the researcher and the participants. Additionally, the researcher's interpretations play a key role in this approach, bringing "such subjectivity to the fore, backed with quality arguments rather than statistical exactness" (Garcia \& Quek, 1997, p. 457). Discussing the distinction between qualitative research and an interpretive approach, Klein and Myers (1999) state that they are not, by all means, equivalent and interchangeable terms. Interpretive research assumes "that our knowledge of reality is gained only through social constructions such as language, consciousness, shared meanings, documents, tools, and other artifacts" (Klein \& Myers, 1999, p. 69), whereas qualitative research refers to a broader view. It generally refers to a study process that investigates a social human problem where the researcher conducts the study in a natural setting and builds a whole and complex representation by a rich description and explanation as well as a careful examination of informants' words and views (Creswell, 1998; Miles \& Huberman, 1994). As a consequence, "qualitative research may or may not be interpretive depending upon the philosophical assumptions of the researcher" (Klein \& Myers, 1999, p. 69).

To summarise, this study takes an interpretive qualitative approach to exploring Vietnamese academics' research perceptions and factors affecting their research engagement. The Vietnamese academics' research engagement may be affected by national, institutional research policies, and social changes at the time this research was conducted, and their research perceptions may be shaped by shared meanings in their working environment. The role of the researcher is to interpret the words and views of the informants as well as research documents and social changes happening in Vietnam at the time of research. 


\subsubsection{Case study}

To gain a deep insight into Vietnamese academics' research perceptions and factors affecting their research engagement, this study adopted a multiple case interpretive qualitative approach. As defined by Yin (2003) a case study is

an empirical inquiry that investigates a contemporary phenomenon within its reallife context, especially when the boundaries between phenomenon and context are not clearly evident. (p. 13)

Simons (2009) comments that a case study is an in-depth exploration from multiple perspectives of the complexity and uniqueness of a particular project, policy, institution, programme or system in a 'real life' context. Case studies can provide a deep understanding of phenomena, events, people, or organisation (Berg, 2001). Making the distinction between a case and issue study, Stake (1995) defines the case as an integrated system whereas issues or problems are foci for study, and issue questions provide a conceptual structure for organising the study of a case. For a single case study, Stake categorises it into an intrinsic and instrumental case study. When the researcher has an intrinsic interest in the case, it is called the intrinsic case study, and when the researcher uses the case study to understand something else, it is called the instrumental case study (Stake, 1995). In this study, the issues that need to be studied are to explore Vietnamese academics' research engagement in their own HEls in the Vietnamese HE reform context since 2005. In this context, the government required HEls to proactively develop their university research and S\&T development activities (Vietnam Government, 2005). The research issues in my study were investigated in three different institutions. Therefore, this research was considered as a collective instrumental-intrinsic case study (Stake, 1995) or a multiple case study (Baxter \& Jack, 2008). 


\section{Multiple case studies}

Multiple case studies are considered to be more robust than single case designs (Herriott \& Firestone, 1983). Multiple case studies are used to explore the differences within and between cases (Baxter \& Jack, 2008). Specifically, the investigator of this study aimed to explore the differences in academics' research perceptions, and the factors impacting their research engagement across three institutions. Moreover, Yin (2009) states a multiple case study consists of multiple holistic cases or multiple embedded cases, depending on the type of phenomenon being studied and the research questions. This study used a multiple institutional case design: multiple data sources including a survey, and semi-structured interviews, and document analysis. The survey was conducted to collect data about the participants' research perceptions and factors affecting their research and PD activities. Semi-structured interviews were designed to collect further data on the participants' research perceptions, factors influencing their research engagement, and institution's research policies and strategies. Institutional and national documents related to research activities were reviewed to triangulate the data collected from the two afore-mentioned tools. Comparisons of the study results were drawn in the multiple-case study so it is important that the cases are chosen carefully in order that similar or contrasting results across cases could be predicted by the researcher (Yin, 2009).

\section{Case selection}

The three institutions in the study represented three types of public HEls in the Vietnamese education system: provincial, regional, and national. They were located in southern Vietnam. Case One was a provincial institution, Case Two a regional institution, and Case Three an institution member of the Vietnam National University (VNU). The provincial and regional institutions were multi-disciplinary universities, whereas the national one was a mono-disciplinary university majoring in social sciences and humanities. The three institutions were selected because they represented the three different kinds of public universities in the Vietnamese HE system, and were strong in scientific research activities and technology transfer in the fields of education, agriculture, and social sciences and humanities. Moreover, these institutions were the 
TRIG Project's university members, so their research activities would be more active than other institutions in Vietnam. This helped the investigator to collect rich information to answer the research questions. Additionally, it is possible that different institutions may provide different policies and conditions for their academics' research engagement. Berg (2001) states that a case study is the systematic gathering of sufficient information about a particular organisation, which allows the investigator to explore further the life of that organisation. Therefore, each institution was chosen as a case to provide the researcher with deep insights into each institutional management culture and practice of research activities affecting the participants' research engagement.

In summary, this study employs a case study as its research approach due to its strengths, including depth, high conceptual credibility and transferability, understanding of context and process, understanding of what causes a phenomenon, and linking causes and outcomes (Flyvbjerg, 2011). This is a multiple case design because the researcher seeks to gain understandings of similar or contrasting results of the phenomenon of the Vietnamese university academics' research engagement across the three institutions.

\subsubsection{Qualitative case study}

As previously mentioned, this study aimed to explore Vietnamese university academics' research perceptions and factors influencing their research engagement. The practices of PD and research activities in academics' research engagement are regarded as their everyday professional practices. The phenomenon of university academics' research engagement is found to be affected by their institutional contexts and their nation's social development contexts (Bland et al., 2005; Braxton et al., 2002). For these reasons, it was appropriate to adopt a qualitative case study for this research. Qualitative research is defined by Creswell (1998) as:

An inquiry process of understanding based on distinct methodological traditions of inquiry that explore a social or human problem. The research builds complex, holistic pictures, analyses words; reports detailed views of informants, and conducted the study in a natural setting. (p. 15) 
It is appropriate for this study to employ qualitative research. As Merriam (1998, p. 1) states, "having an interest in knowing more about one's practice, and indeed in improving one's practice leads to asking researchable questions, some of which are best approached through a qualitative design." Merriam believes that focusing on discovery, insight, and understanding from the perspectives of those being studied offers the greatest promise of making a difference in people's lives. Qualitative researchers focus on interpretation of phenomena in their natural settings to make sense in terms of the meanings people bring to these settings. Qualitative research involves collecting information about personal experiences, interviewing, and related documents that describe routines and are meaningful to individuals' lives (Denzin \& Lincoln, 2005). As previously mentioned, the study focused on obtaining an in-depth understanding of academics' research perceptions, experiences, and meanings of these experiences to them in research engagement, and thus a multiple case study design is suitable for this study. Moreover, previous studies show that working in different disciplines, departments and institutions, academics might have different research perceptions and motivations (Metlich-Medlich, 2009). Therefore, using a qualitative approach allows the researcher to analyse academics' research engagement in realistic settings and influence of contextual factors on their research perception and practices.

\subsection{Data sources}

In line with previous studies related to academics' research productivity, surveys and interviews were used to collect data. For instance, in the study of faculty at work in public research universities, Blackburn and Lawrence (1995) used surveys and interviews as data sources. Providing reasons for the use of quantitative and qualitative approaches, they stated had both strengths and weaknesses. They chose questionnaires because they needed data from many people in order to test the framework. Questionnaires, however, could not penetrate to the level that skilful interviews could attain. For in-depth interviews, they assumed that the researcher could explore interviewees' deep feelings, subtle motivations, and attitudes. Such subtleties were unlikely to be discovered through the questionnaire. In studying the factors related to faculty publishing productivity, Hughes (1998, June) used a postal survey, but she 
received a low return rate ( $N=845$ from 3,383 respondents). She stated that the use of surveys had been criticised especially when the survey includes potentially sensitive questions, such as questions about attitudes towards colleagues and Department Chairs.

For those reasons, this study used a survey and semi-structured interviews for gathering data. However, the interview was seen as the main tool to gather in-depth data about the academics' research engagement. The survey was considered as a useful tool to select interview participants for the study. In addition to these tools, documents related to research activities at different levels were reviewed as a triangulation tool.

\subsubsection{Survey}

The survey in this study was utilised for collecting the data related to academic participants' research perceptions and the factors affecting their PD activities as well as their research engagement. However, using questionnaires for collecting data has both benefits and disadvantages.

Hannan and Anderson (2007) point out two benefits of using questionnaires. First of all, they provide a wealth of data through the simple counting of boxes or through the content analysis of written responses. Second, the participants may have sufficient time to think of answers before completing the survey. Due to the abstract nature of research perceptions and the sensitivity of providing data associated with the factors impacting on the academic participants' research engagement, it is necessary for them to have time to think about the answers. Thus, it enabled the researcher to have rich data for later analysis.

There were several other important reasons for using the survey in this study. First, as a researcher I could save time and energy because of the distance of the selected cases in this study from my geographical location. Second, many Vietnamese people tend not to openly discuss their disciplinary areas, organisations, and political issues with strangers (Foreign Affairs and International Trade Canada, 2014). Thus, it was useful to employ an anonymous survey to collect information relating to their disciplinary knowledge and organisations from the participants. Additionally, the utility 
of the survey was seen as a means of protecting the participants' confidentiality and anonymity. Therefore, the participants were more likely to offer reliable data for research.

Moreover, the survey in this study was utilised as part of an interpretive qualitative research approach. This means that there were two reasons for using a survey tool. The first reason was to select relevant participants for the follow-up interview, based on whether the survey participants ticked the box indicating 'YES' or 'NO'. The second reason was to clarify further information related to the informants' research perceptions and the factors affecting their research engagement. While the survey revealed the research perceptions of the participants, and factors affecting the development of their disciplinary knowledge and professional careers, the participants might not provide enough information in the survey. Consequently, it was important for the researcher to use the survey data as a means of sorting initial information to inform the interviews conducted as a part of this study.

Hannan and Anderson (2007) mention potential risks for researchers when using questionnaires: first, when the question contains ambiguity or bias or when the range of available questions or answers does not allow the respondent the opportunity to state what he or she wishes; second, the agenda is normally set by the researcher, so the respondent feels somewhat constrained to follow planned pathways; and finally, the information given in the questionnaire is often more concrete and fixed than it may be in the dynamic flow of social interaction. To deal with the above risks, in designing the survey, enough space was provided for the respondents to supplement their answers with comments. Related to time for answering the questionnaire, I offered a flexible period for the respondents to complete it. It was hoped that by creating such convenience for the respondents, I was likely to obtain useful data from the questionnaire tool for the following stages of research.

In this study, the questionnaire comprised two main parts: respondents' background information and survey content (Appendix 1). The first part asked about background information of the respondent including the institution name, the 
discipline/faculty, position, qualification degree, and academic ranks and titles. The second part included items that explored participants' research perceptions, the factors affecting either positively or negatively their research engagement as well as their research and PD activities. The survey took approximately 30 minutes to complete. The questionnaire was designed using a combination of the selected themes from the findings of previous studies. For instance, the thematic findings of Brew (2001), Bowden et al. (2005), and Åkerlind (2008) were adapted to explore the participants' research perceptions in this study. To identify factors motivating academics to research, I adapted Chen et al.'s (2010) survey and Borg's (2009) study findings. Factors de-motivating academics in research were drawn from the study results of Borg and Alshumaimeri (2012). Finally, I translated the survey into Vietnamese to enable the participants to have a full understanding of all the items in the survey. To ensure the correctness of the translation, both English and Vietnamese versions of the survey were verified by a translator working at An Giang Province's Foreign Affairs.

\subsubsection{Individual semi-structured interviews}

Merriam (1998) advocates for interviews as a common means of collecting qualitative data. They enable the investigator to understand the participants' feelings, thoughts, intentions, experiences, and the meanings they attach to what goes on in the world. Similarly, Kvale (1996) holds that qualitative research interviews are conversations to help the researcher to understand something from the participants' points of view and to uncover the meaning of their experiences. Individual semi-structured interviews were used as a major tool in the study to collect data because they helped me understand the participants' interpretations of research perceptions, motivational factors in research, research practices, organisational cultures, and research management policies and strategies. Through interviews, the investigator also gained insights into institutional/departmental practices that affected academics' research capacity and PD activities. Reasons for using an individual semi-structured interview were as follows. First, it is flexible, allowing new questions to be brought up during the interview as a result of what the interviewee says. Second, the interviewer generally has structured the interview questions by themes, and has an interview guide prepared, including an 
informal "group of topics and questions that the interviewer can ask in different ways for different participants" (Lindlof \& Taylor, 2011, p. 195). Moreover, the research participants were university academics with very busy work schedules. It was therefore quite hard to find a time for conducting an interview with them. Importantly, talking about academics' professional knowledge, their PD activities, and their institutions' research strategic development plans were seen as important and confidential issues to Vietnamese academics. Consequently, it seems to be quite uncomfortable for the participants to overtly express or discuss such vital issues. For this reason, the researcher of this study needed to spend enough time making friends with interview participants and understand the contexts of the institutions.

In this study, 16 questions were posed to guide the interview (Appendix 2). Questions 1-13 were used for academic managers and academic lecturers, and questions 14-16 were just for academic lecturers. The questions were grouped into themes: seeking research perceptions (question 1), individual roles towards research activities in the institution (questions 2-3), factors impacting research work (questions 4-7), individual understandings of institutional and national research policies and ways to implement such policies (questions 8-13), and individual research and PD practices (questions 14-16). Before being used in the study, the words of Vietnamese interview questions were appropriately edited by my father who was a retired teacher of Vietnamese literature and history, and these interview questions were translated into English and sent to my supervisors for checking. Then, I pretested the questions by interviewing one academic manager from Case One to ensure appropriateness of the study.

\subsubsection{Document analysis}

The third data collection tool was document analysis. Collected documents included governmental and institutional documents related to research development plans and polices. Governmental research development policies consisted of:

- The Government's Resolution 14 "Substantial and comprehensive renewal of Vietnam 's tertiary education in the 2006-2020 period" 
- The Central Executive Board's Resolution 20 "building Vietnamese labouring class in the period of accelerating the state's industrialisation and modernisation"

- The Prime Minister's Decision 418 "Strategy for science and technology development in 2011-2020"

- Vietnam's university charter in 2010

- Vietnam Law on HE in 2012

- Vietnam's Law on science and technology 2013

- Project 322 "Training scientific and technical staff overseas by the state's budget"

- Project 911 "Training Vietnamese academics at HEls to obtain PhD degrees abroad for the period 2010-2020"

- Project "Teaching and learning foreign languages in the national education system, period 2008-2020".

Relevant institutional documents included five-year research activities reports, research development strategies, and research reward policies of the three institutions in the study. Those governmental and institutional documents were analysed to understand the implementation of national research policies in each institution as well as the practices and strategies of research development in the three institutions.

As Corbin and Strauss (2008) have stated, document analysis is a systematic procedure for reviewing or evaluating documents (both printed and electronic materials). In qualitative research, document analysis is useful because when examined and interpreted, it can help investigators to gain understandings and develop empirical knowledge of the organisation in the study. Atkinson and Coffey (2004) referred to documents as "social facts", which are produced, shared, and used in socially organised ways (p. 47). Furthermore, Merriam (1998) pointed out that "documents of all types can help the researcher uncover meaning, develop understanding, and discover insights relevant to the research problem" (p. 118). In summary, relevant documents were reviewed to enable the investigator to gain understandings of institutional leadership styles and organisational cultures that may affect academics' drive in research engagement (Metlich-Medlich, 2009; Sharobeam \& Howard, 2002). 


\subsubsection{Pretesting the tools}

I pretested the questionnaire and individual semi-structured interview questions in Case One. First, after receiving the consent from five academics from the Faculty of Political Studies and one academic manager from the Faculty of Engineering \& Technology in Case One, I delivered the questionnaire and asked them to complete it in a week. The interview was then conducted with a faculty leader. These two tools were pretested to make sure there were rich, credible, and dependable data for analysing later, and to ensure their effectiveness, and adjusted if necessary for proper use at the real stage of collecting data.

The survey was pretested to ensure there was clarity around survey items and research focus. Such issues as wording, question order, and procedure were modified when necessary. One participant suggested that some items of the survey should be reworded to clarify the meaning. Then, they were rewritten to suit the Vietnamese formal written language style. The pretested interview was transcribed and translated into English. After that, the data of the pretested survey were preliminarily analysed. The English translation of the pretested interview transcript was used for later analysis.

\subsection{Participant selection}

There were two groups of participants in this study: survey participants (96) and interview participants (26). They were university lecturers and academic managers who were at minimum MA degree holders, and were experienced in research activities. Table 3-1 shows the number and qualifications of the participants in the three cases.

Table 3-1. The numbers and qualifications of the participants in the three cases

\begin{tabular}{|l|c|c|c|c|c|c|c|c|c|}
\hline & \multicolumn{2}{|c|}{ Case One } & \multicolumn{2}{c|}{ Case Two } & \multicolumn{2}{c|}{ Case Three } & \multicolumn{2}{c|}{$\begin{array}{c}\text { Total No. of } \\
\text { participants }\end{array}$} \\
\cline { 2 - 11 } & \multicolumn{2}{|c|}{ Qualifications } & \multicolumn{2}{c|}{ Qualifications } & \multicolumn{2}{c|}{ Qualifications } & \multicolumn{3}{c|}{ Qualifications } \\
\cline { 2 - 10 } & $M A$ & $P h D$ & $M A$ & $P h D$ & $M A$ & $P h D$ & $M A$ & $P h D$ & \\
\hline $\begin{array}{l}\text { Survey } \\
\text { participants }\end{array}$ & 37 & 0 & 3 & 12 & 36 & 7 & 76 & 19 & 95 \\
\hline $\begin{array}{l}\text { Interview } \\
\text { participants }\end{array}$ & 9 & 2 & 0 & 6 & 1 & 8 & 10 & 16 & 26 \\
\hline
\end{tabular}


A similar process of recruiting participants was used in the three cases. The participants selected were representative of different levels of active research involvement in their faculties (e.g. fully active, active, and less active in research involvement). In addition, the faculties selected were from across the research rankings of their institutions.

\subsubsection{Survey participants}

The questionnaire participants were recruited in two ways. Firstly, while waiting for the approval for conducting my research for each case, I accessed the websites of all faculties in each institution to get an overview of their research activities. I noticed potential participants (because their profiles and emails were posted on their faculties' websites) that met my section criteria, and then I emailed and sent the consent form to invite them to join in my research. Secondly, other survey participants were recruited after my first interview with the head of the research management office of each institution. In this interview, I could have a better understanding of the institution's research capacity and learn which faculties were strong and less strong in research activities. After this, I asked their permission to have a meeting with one of their junior staff to help me send my questionnaires to the selected faculties. I also had a letter to ask for permission to conduct my study at these faculties, including the Rector's approval for the research. By doing this, I thought that some questionnaire participants might receive two invitations (one by email, and the other by their faculty dean). I wrote an email, saying sorry for this coincidence. After collecting the number of questionnaires that was smaller than I expected, I attempted to invite other potential participants in these selected faculties.

\subsubsection{Interview participants}

Interview participants were recruited in two ways. The first group of the interview participants was selected from the completed surveys with the tick box saying 'YES' for joining in the follow-up interview section. The second group was recruited from suggestions by the head of the research management office at the end of their interview when they were asked to suggest people in their institution who were research active (both research managers and lecturers). After this, I had the list of potential interview 
participants. Then, I revised the two interview group lists and invited the participants who did not belong to the survey list to be interviewed. After I had a sufficient number of interview participants, I scheduled the appropriate interview time for each participant in each case.

\subsection{Data collection}

The data were sequentially collected from Case One, Case Two, and Case Three. The process of data collection is described in detail as follows.

\section{A. Data collection phase in Case One}

After this study was granted ethical approval (see Appendix 3), Case One's Vice Rector was approached and his institution was invited to participate in the project. The Vice Rector was provided with a letter describing necessary information about this research and asking for permission to conduct the research at the institution (Appendix 4). The Vice Rector was also asked for his written consent (Appendix 5). Some meetings with potential research participants were suggested by the Vice Rector. A letter asking for permission to conduct research in potential faculties/ departments was also sent to the leaders of these faculties/departments (Appendix 6). Data collection was carried out after a formal acceptance for conducting research in this institution was received from the Vice Rector and these leaders.

\section{- Institution and participants}

The institution was developed from its local province's Teacher Training College and became the first provincial multi-disciplinary university in southern Vietnam. It was founded in 2000 in accordance with the Prime Minister's decision. This institution had six faculties: Education, Agriculture and Natural Resources, Economics and Business Administration, Technology and Environment, Political Studies, and Culture and Arts, nine support service units, a school for pedagogical practice, and a central library (see Appendix 7). Its number of academics and support staff was 765. Among them, there were $24 \mathrm{PhD}$ holders and $337 \mathrm{MA}$ holders (including 52 managerial staff in offices and faculties because their backgrounds are also academics) (Case One, 2014d). This 
institution's research participants consisted of 37 survey participants and 10 interview participants. The interview participants included six academic managers, one of whom was a PhD holder, and four academic lecturers (one of them holding a PhD degree).

Table 3-2. Case One's participants

\begin{tabular}{|c|c|c|c|c|}
\hline \multicolumn{3}{|c|}{ Survey Participants } & \multicolumn{2}{|c|}{ Interview Participants } \\
\hline $\begin{array}{c}\text { Questionnaires } \\
\text { delivered }\end{array}$ & \multicolumn{2}{|c|}{40} & Academic Managers & Academic Lecturers \\
\hline \multirow{7}{*}{$\begin{array}{l}\text { Questionnaires } \\
\text { collected }\end{array}$} & \multicolumn{2}{|c|}{37} & MPro 1 & LPro 1 \\
\hline & Academic & Academic & MPro 2 & LPro 2 \\
\hline & \multirow{5}{*}{10} & \multirow{5}{*}{27} & MPro 3 & LPro 3 \\
\hline & & & MPro 4 & LPro 4 \\
\hline & & & MPro 5 & \\
\hline & & & MPro 6 & \\
\hline & & & MPro 7 (pilot) & \\
\hline
\end{tabular}

- Delivering the survey

In the second week of December 2012, an information sheet (Appendix 8), consent form (Appendix 9), and the questionnaire were sent via email to 40 potential participants in Case One. The participants printed them out, answered the surveys and returned them in the letterbox placed in the scientific research and international relations office. Thirtyseven completed surveys were collected two weeks later.

\section{- $\quad$ Conducting interviews}

Twelve questionnaire participants volunteered to participate in the interviews (7 academic managers and 5 academic lecturers). However, ten of them were selected as seen in Table 3-1 because two participants came from the same working unit.

Each interview lasted from 45 minutes to an hour. Before each interview, the interviewee was provided the consent form (Appendix 10) for the interview. The list of semi-structured interview questions was provided. The interviews were audio-recorded to ensure that all of the interviewees' responses were captured. After interviews, the 
audio-recordings and their transcripts were sent to the interviewees so that they could check or modify the information if necessary.

\section{- Document collection}

During the time taken to conduct research in Case One, all necessary documents for analysis were collected. Some documents were downloaded from its website, and other documents were provided by the interview participants.

\section{B. Data collection phase in Case Two}

\section{- Institution and participants}

This institution is the only regional multi-disciplinary university in southern Vietnam. It is a key Vietnamese national HEl. It delivers undergraduate and postgraduate training degrees. At the time of its establishment, there were four faculties: Sciences, Law and Social Sciences, Letters, and Education. Presently, it has 20 academic units and 18 support service units (Appendix 11). It has 937 academic lecturers and 981 support staff. There were 15 survey participants (11 of whom were academic managers) and six interview participants (all of them academic managers) in Case Two. Table 3-3 presents the research participants in Case Two.

Table 3-3. Case Two's participants

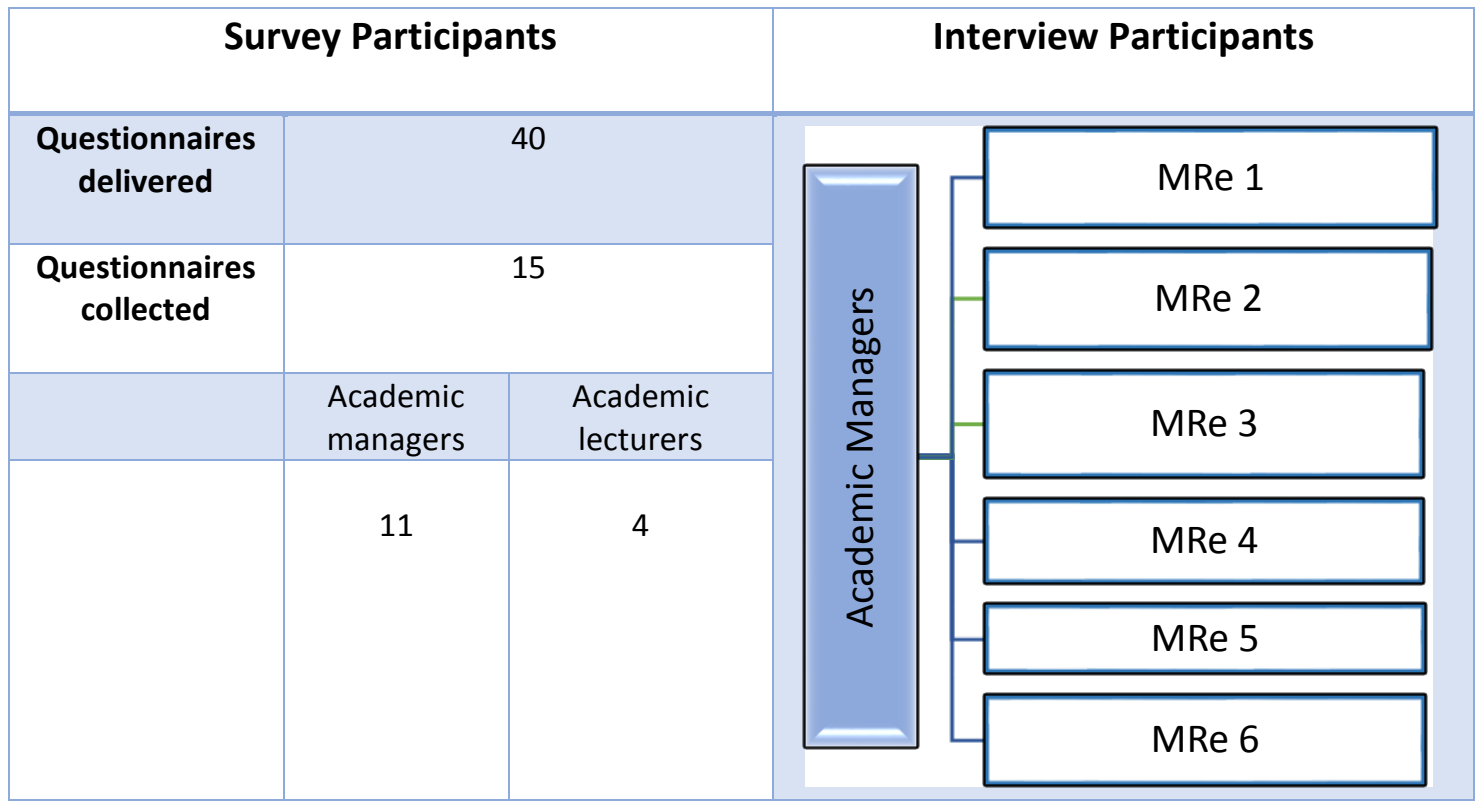




\section{Data Gathering}

After finishing collecting the data in case one, this study's researcher carried out necessary steps to conduct research Case Two. A letter asking for permission to conduct research at the institution was sent to the Rector of Case Two. After approval was given for the research conducted in this institution, the researcher was given conditions to approach the potential participants and collect data from them. Like Case One, the data collection process in this institution was sequentially performed.

\section{Data collection phase in Case Three}

- Institution and participants

Case Three was established in the 1960s, and was originally called the Faculty of Letters. It officially became an institution member of the VNU in 1996 that delivered a wide range of disciplines in Social Sciences and Humanities (SS\&H) (Appendix 12). This institution had 890 academic lecturers and staff. Nearly $100 \%$ of its academic lecturers were qualified with postgraduate degrees. It delivered 28 undergraduate degrees, 38 postgraduate degrees and more than 10 joint training programmes in collaboration with international partners. The participants in this national institution included 43 survey respondents and nine interview respondents (see Table 3-4).

Table 3-4. Case Three's participants

\begin{tabular}{|l|l|l|l|}
\hline \multicolumn{2}{|c|}{ Survey Participants } & Interview Participants \\
\hline $\begin{array}{c}\text { Questionnaires } \\
\text { delivered } \\
\text { Questionnaires } \\
\text { collected }\end{array}$ & $\begin{array}{c}\text { Academic } \\
\text { managers }\end{array}$ & $\begin{array}{c}\text { Academic } \\
\text { lecturers }\end{array}$ \\
\hline 17 & & Academic \\
Managers
\end{tabular}




\section{- $\quad$ Data Gathering}

The process of gathering data in Case Three was carried out. This process was sequentially performed as in the provincial and regional institutions.

The whole process of data collection in the three cases was undertaken within five months. During this period, the interviews from Case One and Case Two were transcribed in Vietnam. Simultaneously, necessary documents for review such as institutional research reports, research strategies and plans were collected. Case Three's interview data were transcribed in two weeks after my returning to Wellington, New Zealand in the first week of July 2013.

Table 3-5. Timeline of data collection in three institutions

\begin{tabular}{|c|c|c|c|}
\hline Tasks & & Time & Work done \\
\hline \multirow{3}{*}{$\begin{array}{l}\text { Pretested } \\
\text { tools }\end{array}$} & The survey & Week 1, Nov 2012 & Collected 5 questionnaires \\
\hline & The interview & Week 3, Nov 2012 & $\begin{array}{l}\text { Conducted one interview, } \\
\text { transcribed it and translated it into } \\
\text { English }\end{array}$ \\
\hline & $\begin{array}{l}\text { Preliminary } \\
\text { data analysis }\end{array}$ & Week 4, Nov 2012 & $\begin{array}{l}\text { Analysed the data from the } \\
\text { pretested tools }\end{array}$ \\
\hline \multirow[t]{3}{*}{$\begin{array}{c}\text { Data } \\
\text { collection }\end{array}$} & Case One & Dec 2012 to Jan 2013 & $\begin{array}{l}\text { - Delivered } 40 \text { questionnaires and } \\
\text { collected } 37 \text { completed } \\
\text { questionnaires. } \\
\text { - Conducted } 10 \text { interviews ( } 6 \\
\text { academic managers and } 4 \\
\text { academics). } \\
\text { - Collected documents. } \\
\text { - Transcribed interview data }\end{array}$ \\
\hline & Case Two & Feb-Apr 2013 & $\begin{array}{l}\text { - Delivered } 40 \text { questionnaires and } \\
\text { collected } 15 \text { completed ones. } \\
\text { - Conducted } 6 \text { interviews ( } 6 \\
\text { academic managers) } \\
\text { - Collected documents } \\
\text { - Transcribed interview data }\end{array}$ \\
\hline & Case Three & $\begin{array}{l}\text { Apr - Jun } 2013 \\
\text { Week } 2 \text { July } 2013\end{array}$ & $\begin{array}{l}\text { - Deliver } 45 \text { questionnaire and } \\
\text { collected } 43 \text { completed ones. } \\
\text { - Collected documents } \\
\text { - Conducted } 9 \text { interviews ( } 6 \\
\text { academic managers and } 3 \\
\text { academics) } \\
\text { - Transcribed interview data }\end{array}$ \\
\hline
\end{tabular}




\subsection{Analytical framework}

After finishing collecting the data from the three cases, the data analysis phase was carried out. This study used a combined framework of Bland et al.'s (2005), Chen el al.'s (2006), and Moore's (2015) (see Figure 3-1) as an analytical framework. As mentioned in the previous chapter, Bland et al. (2005) and Chen et al. (2006) stated that academics' research productivity has been influenced by academic individual, institutional characteristics, and academic disciplines. Additionally, Bland et al. (2005) added leadership characteristics to impact on academics' research engagement and institutions' research productivity. They suggested that in order to optimise academics' research productivity, all features in each component must be present and accessible. In a broader view, Moore (2015) stated that, in addition to the factors at individual, interpersonal, and organisational levels, individuals' outcomes have also been affected by factors of social community and national policies because "the world we live in influences us" (p. 1). From Moore's (2015) model (see Figure 2-4), we may conclude that university academics' research capacity is likely to be affected by the interwoven relationships between societal level (national research development strategies and policies), community level (universities, research institute networks, and virtual research networks), institutional/organisational level (structure, culture, working conditions, and leadership), and individual level (individual academics' characteristics and their disciplines). To conclude, academics' research capacity, as well as factors affecting their research engagement, may be impacted by four levels of factors: societal, community, institutional, and individual as seen from Figure 3-1. Therefore, I used the framework in Figure 3-1 to analyse the collected data for this study. 


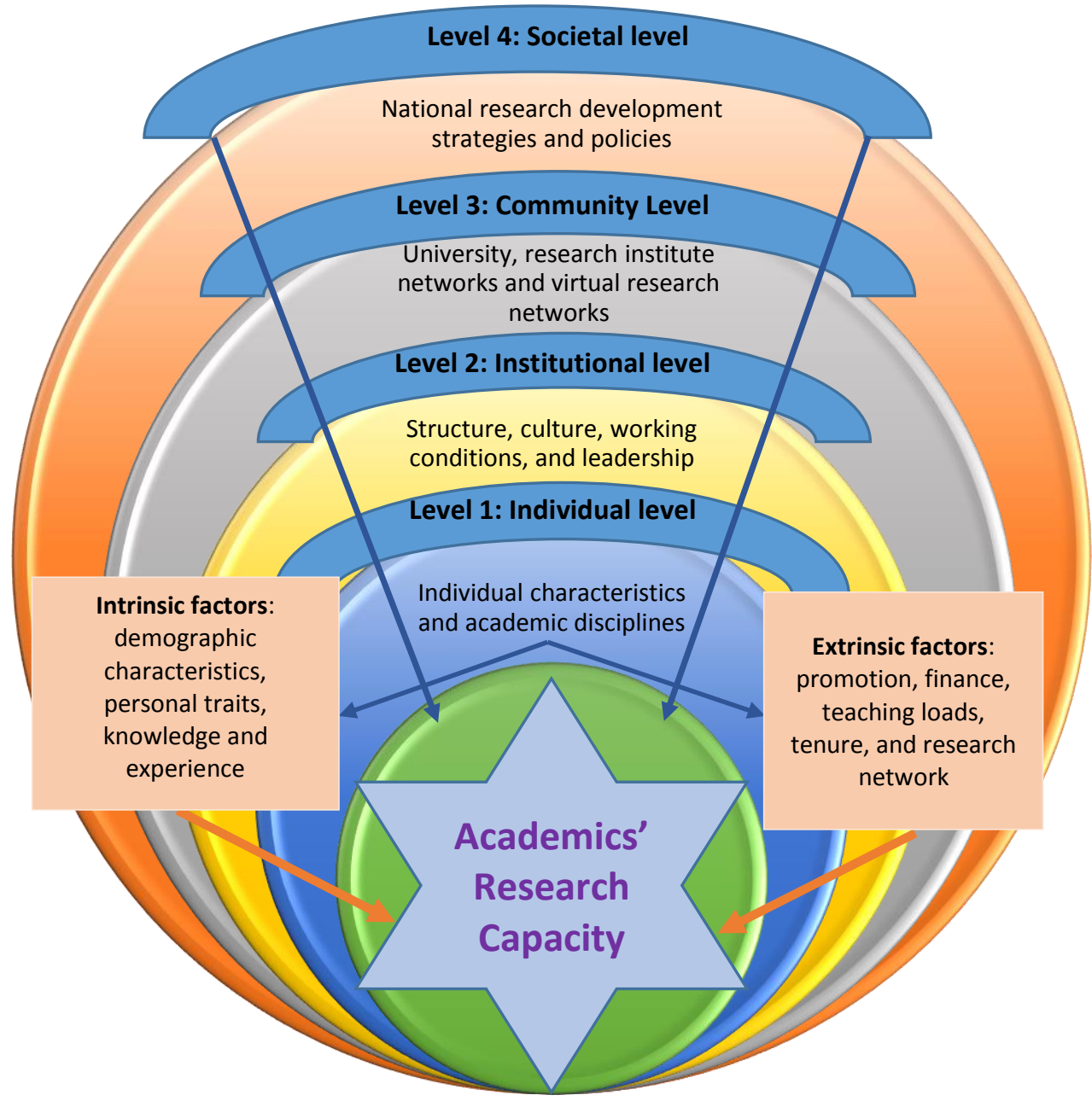

Figure 3-1. The analytical framework for exploring factors affecting Vietnamese academics' research capacity [adapted from the models suggested by Bland et al. (2005), Chen et al.

(2006), and Moore' (2015)

In summary, the analytical framework for exploring factors affecting the research capacities of Vietnamese HEls and their academics' research engagement in this study is built from Bland et al.'s (2005) model of factors affecting the faculty's research productivity, Chen et al.'s (2006) framework of factors affecting academics' research productivity, and Moore's (2015) social-ecological model. This analytical framework is used for analysing and discussing data in the following chapters.

\subsection{Data analysis}

Data analysis is a vital phase in qualitative research. Creswell $(2013$, p. 183) states that the process of qualitative data analysis "involves making sense out of text data". In this 
study, the data were collected from documents, surveys, and interview transcripts. Patton (2002) states that the qualitative researcher serves not only as the data collection instrument but also as the human tool for data analysis. These two tools remain intertwined because data analysis begins during data collection. Patton adds that the goal of qualitative data analysis is to uncover emerging themes, patterns, concepts, insights, and understandings, allowing the researcher to progressively focus on interviews, and decide how to test emerging conclusions.

Based on the process of data analysis suggested by Creswell (2013), this study used the following strategies for data analysis: organising and preparing data for analysis, reading through all data, coding the data by hand and categorising it into themes, discussing themes and interconnecting them in each individual case and cross-cases, and interpreting the meaning of data (Figure 3-2).

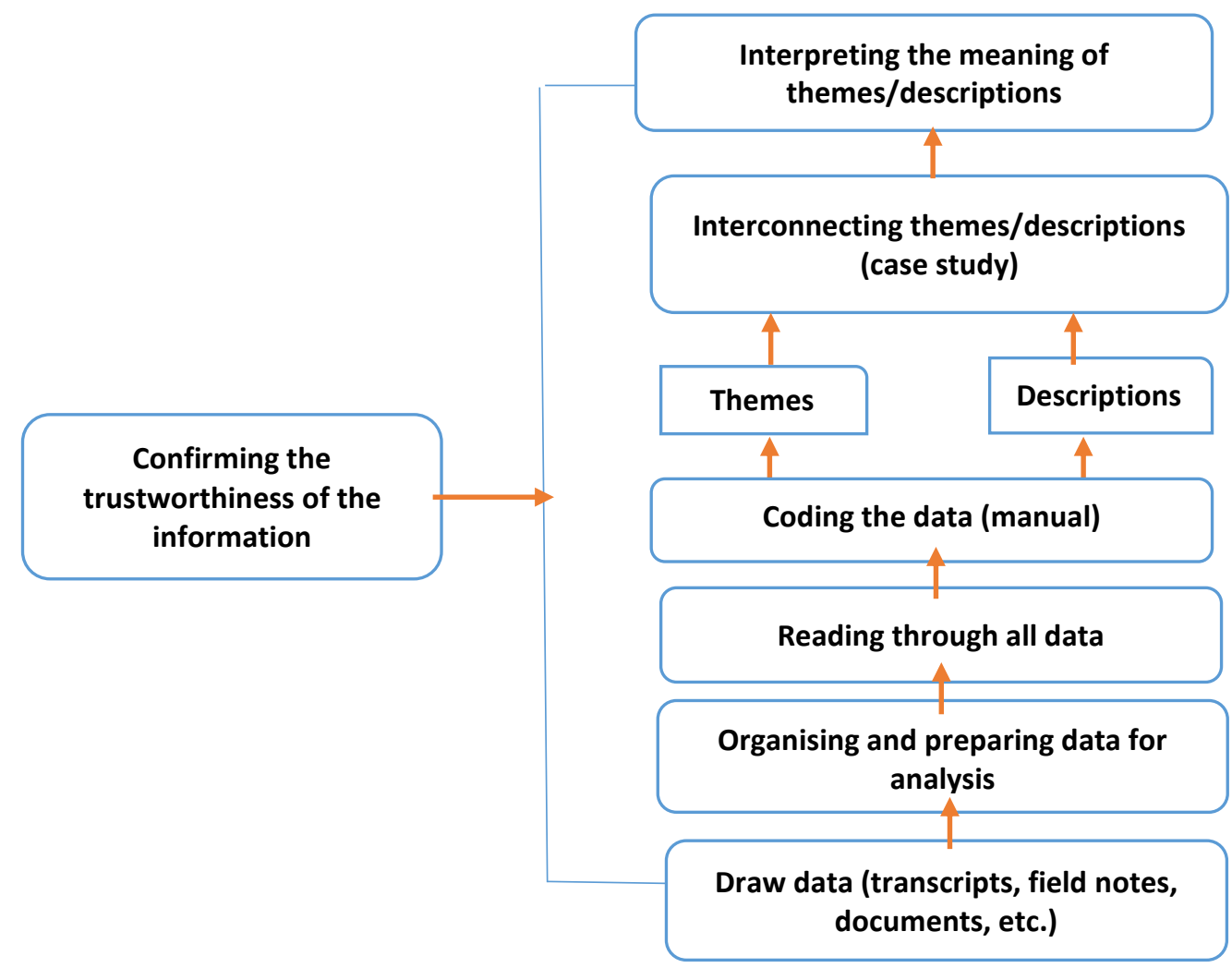

Figure 3-2. Data analysis process adapted from Creswell (2013, p. 185) 


\subsubsection{Data analysis procedures}

Before analysing the data, I established a database consisting of all the data collected in one university from the survey, interviews, and document review. From the survey data, I used tables for counting simple numeric data. For instance, the data from multiple choice questions in the questionnaire were tabulated to identify the range of participants' research perceptions as well as their evaluations of the factors impacting their PD practices and their research engagement. Next, the data from open-ended questions were grouped into closely related features or a new feature that depended on its meaning. By so doing, some simple measures were determined to identify the participants' research perceptions as well as the factors affecting their research engagement.

Procedures for analysing the data in a single case were carried out as follows. First, a coding scheme for analysing the major categories such as research perceptions, factors impacting research engagement and frequent research activities was established. This enabled the researcher to easily access the data for the analysis and interpretation stage. The categories in the initial coding scheme were drawn from the studies of Åkerlind (2008), Borg and Alshumaimeri (2012), Bowden et al. (2005), Brew (2001), and Chen et al. (2010) on academic research perceptions and factors affecting academics' research engagement and from my research questions.

\section{Process of data coding}

The qualitative data from interview transcripts were sequentially hand-coded. Based on the interview questions, initial themes were drawn from previous studies by reading the transcripts, and highlighting important phrases and sentences related to such themes. The audio recordings were listened to multiple times to make sense out of interviewees' particular intonations and pauses associated with themes.

To help access the database for each case easily, I made a qualitative codebook for each case study with its content organisation: interviewee codes marked for example MPro 1 (for academic manager 1 in Case One) or LPro 1 (academic lecturer 1 in Case 
One), theme codes, interview question codes, and phrase/sentence codes, extracted codes from documents. Next, theme codes were put into matrix tables to identify their inter-relations in terms of interviewee or question codes with quotes presented by phrases or sentences (see Table 3-6).

Table 3-6. The matrix coding table for Case One

\begin{tabular}{|c|c|c|c|c|c|c|c|}
\hline \multirow[t]{2}{*}{ Interviewees } & \multicolumn{7}{|c|}{ Themes } \\
\hline & Research & & Fact & rs impac & gres & ch (Q2-16) & \\
\hline \multirow[t]{7}{*}{ MPro1 } & & \multicolumn{2}{|c|}{ Individual factors } & \multirow[t]{2}{*}{ Quotes } & \multicolumn{2}{|c|}{ Institutional factors } & \multirow[t]{2}{*}{ Quotes } \\
\hline & & 1 & $\begin{array}{l}\text { Disciplinary } \\
\text { knowledge }\end{array}$ & & 1 & Policies & \\
\hline & & 2 & $\begin{array}{l}\text { Research } \\
\text { experience }\end{array}$ & & 2 & $\begin{array}{l}\text { Funding/ } \\
\text { structure }\end{array}$ & \\
\hline & & 3 & Motivation & & 3 & Resources & \\
\hline & & 4 & Confidence & & 4 & Teaching load & \\
\hline & & 5 & $\begin{array}{c}\text { EL } \\
\text { competence }\end{array}$ & & 5 & Leadership & \\
\hline & & 6 & $\begin{array}{l}\text { Research } \\
\text { network }\end{array}$ & & 6 & $\begin{array}{c}\text { Research } \\
\text { environment }\end{array}$ & \\
\hline
\end{tabular}

The coding of the first interviewee's transcript was sent to my supervisors for checking to validate the coding scheme. After that, the matrix coding table and the summary of emerging themes in the provincial case were sent to the supervisors for reviewing. Finally, all the data from three different sources (the survey, the interview, and the document review in Case One) were analysed. In interpreting this institution's data analysis, a neutral voice was adopted in comments contrasting ideas between academics and academic managers. Similarly, the process of coding and analysing the data collected in the regional and national institutions was sequentially conducted. All the steps of data coding and analysis were replicated for each institution, which is suggested for a multiple case study by Creswell (2013).

\subsubsection{Cross case analysis}

At this stage, the findings from the three institutional cases were compared and contrasted as the purpose of multiple-case studies is to seek similarities and differences 
within or between them (Baxter \& Jack, 2008). Figure 3-3 shows the process of multiple case study design for this study.

\section{Stage 1: Design and refine}

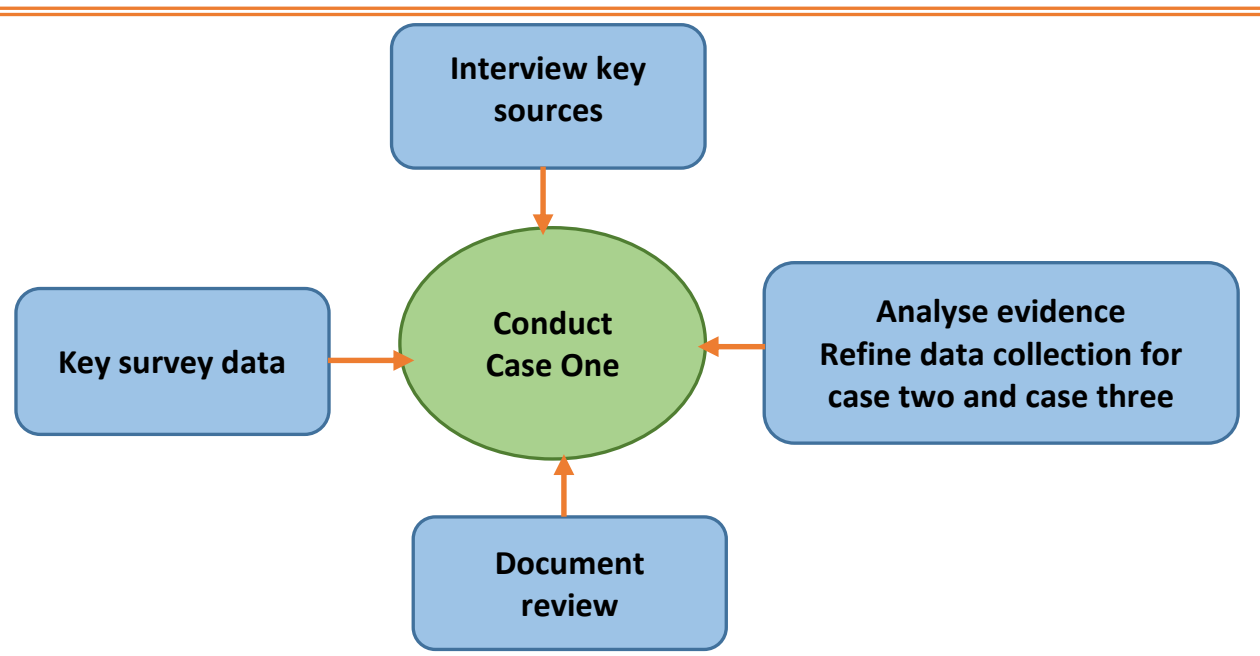

\section{Stage 2: Triangulate and Analyse}

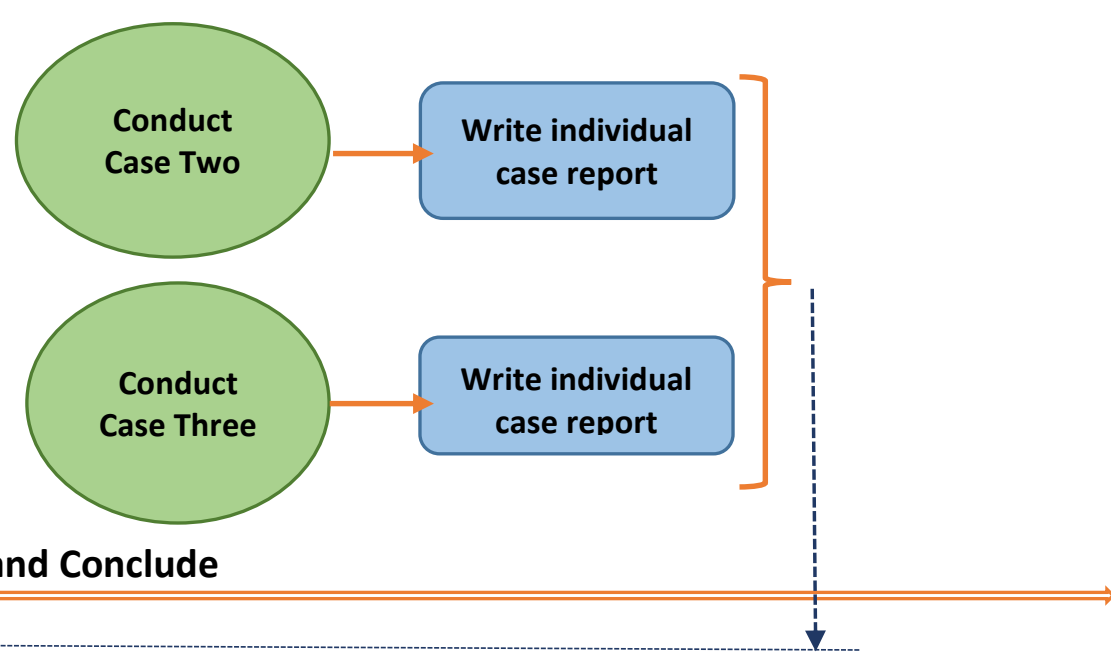

Stage 3: Analyse and Conclude

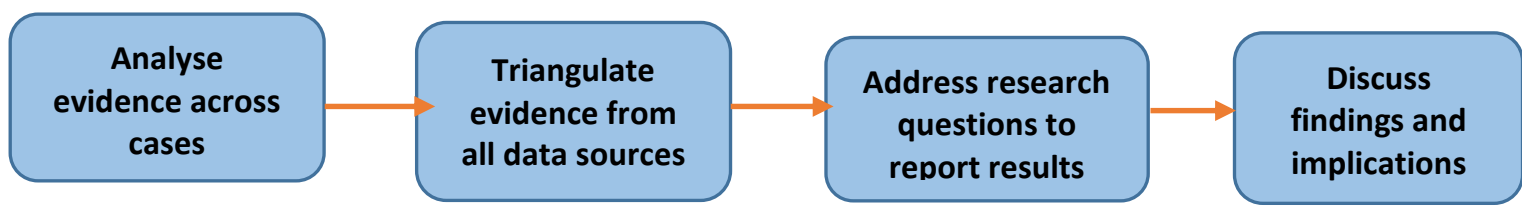

Figure 3-3. Multiple case study design adapted from Yin (2003, p. 50)

The data from all sources were coded directly in the Vietnamese language to retain the original meanings of the data. However, this study's researcher selected representative data for translation into English (for example, metaphors and usage of 
the Sino-Vietnamese language were used in senior academic participants) and used such translations as important quotes in the chapters of findings and discussion in this thesis. To ensure the accuracy of the translation, some quotes were sent back to the participants for verifications. Other quotes were translated by myself as the researcher, and then the translation was checked with two colleagues (Vietnamese PhD students at Victoria University of Wellington) who were fluent in both Vietnamese and English languages. This helped to ensure that the participants' responses and their meanings were appropriately conveyed in English.

The aim of the cross-case analysis of this study was to identify distinctive themes in each case. After analysing the data across three cases, emerging themes and factors affecting academics' research engagement in the study were identified. Then, the crosscase report was written as the discussion chapter.

\subsection{Trustworthiness of qualitative research}

The trustworthiness of qualitative research generally is often questioned by positivists, perhaps because concepts of validity and reliability cannot be addressed in the same way in naturalistic work (Shenton, 2004). Guba (1981) proposed four criteria that he believes should be considered by qualitative researchers in pursuit of trustworthiness. Guba's constructs correspond to the criteria employed by the positivist investigator: credibility (in preference to internal validity), transferability (in preference to external validity), dependability (in preference to reliability), and confirmability (in preference to objectivity). Although Lincoln (1995) wrote that the whole area of qualitative inquiry was "still emerging and being defined" (p. 275), Guba's constructs have been accepted by many contemporary qualitative researchers. Therefore, this study employed Guba's four criteria for enhancing the trustworthiness of qualitative research.

\subsubsection{Credibility}

Lincoln and Guba (1989) argued that ensuring credibility is one of the most important factors in establishing trustworthiness, and the authors elaborate six techniques to ensure credibility: (i) prolonged engagement, (ii) persistent observations, (iii) peer 
debriefing, (iv) negative case analysis, (v) progressive subjectivity, and (vi) member checks. Additionally, Guba (1981) included triangulation for assessing credibility and confirmability. In this study, to ensure its trustworthiness, five techniques suggested by Lincoln and Guba (1989) and one technique suggested by Guba (1981) were applied. These are now discussed.

\section{Prolonged engagement}

Prolonged engagement means the researcher spending enough time on the research site. In this study, as an academic in a Vietnamese university, in addition to understanding the common difficulties of Vietnamese academics, I spent enough time to learn the context of each institutional case to understand the reality of research activities in each university. I proactively invited the head of the scientific research office in each institution to participate in the interview section so that I could explore more information related to research activities in each institution. Further, after reviewing the completed survey in each institutional case, and carrying out interviews with academic managers and academics in each institution, I had an adequate understanding of specific advantages and disadvantages in each institution in the study. This helped me to decide the following steps in my necessary exploration of data for the study.

\section{Persistent observation}

To ensure persistent observation for this research, I collected sufficient national and institutional research-related strategy and policy documents to study. Additionally, I proactively conducted interviews with the participants who appeared to have a deep understanding about their institution's scientific research context through the completed questionnaires and major responsibilities for scientific research affairs in their institutions. This helped me have a relatively comprehensive overview of each single institutional case in the study. 
Peer debriefing

For peer debriefing, I discussed implicit information from the interviews with my supervisors and colleagues at institutional and international conferences. Importantly, in discussing with Vietnamese university academics in the country and abroad, I discussed contrasting ideas in official national documents related to research and S\&T activities as a basis for the study.

\section{Progressive subjectivity}

Progressive subjectivity means the researcher ensures the monitoring of bias in the study (Bitsch, 2005). To ensure this criterion, in addition to finding what was expected in the literature on factors affecting academics' research productivity and research engagement, I developed specific factors of changes in Vietnamese tertiary educational contexts that impacted on their research engagement. This process helped the discussion of the study's findings avoid biases that qualitative research may be induced to.

\section{Member checks}

In qualitative research, member checks means addressing research participants' input in the interpretations and reports. To ensure this technique, I sent the Vietnamese transcripts back to the interview participants to check whether the information provided through recorded interviews was accurately transcribed before the data were analysed.

\section{Triangulation}

The study used data triangulation, which means collecting the accounts from different participants in the interview section in each individual institution. The interview data were contrasted with the survey data and institutional and national related-research documents collected. By so doing, the trustworthiness of the data from different sources could be increased for the data analysis phase. 
In conclusion, to ensure the criterion of credibility in a qualitative research, the study applied six techniques suggested by Guba (1981), and Lincoln and Guba (1989). In addition to the important criterion, this study aimed to respond to other criteria of ensuring the trustworthiness in the quality of qualitative research such as transferability, dependability, and confirmability.

\subsubsection{Transferability}

Transferability parallels external validity and generalisability in quantitative research (Bitsch, 2005; Lincoln \& Guba, 1985). Transferability refers to the degree to which the results of qualitative research can be generalised or applied in other contexts or with other respondents. To increase transferability, Jenson (2008)suggests that qualitative researchers should focus on two key considerations: (i) how closely the participants are linked to the context being studied, and (ii) the contextual boundaries of the findings. According to Jenson, the researcher has a responsibility "to paint a full picture of the context and then allow the reader to determine if the work is transferable to their context" (p. 887). In this study, I used two techniques - thick description and purposive sampling - to increase transferability. The study addressed the first consideration by purposively selecting potential questionnaire and interview participants who were relevant academics of the research community in their institutions. For the second consideration, I provided a full context (the situation of academics' research engagement in the reform of the HE system in Vietnam taking place across the three institutions) to be studied, ensuring that the research questions were appropriately answered.

\subsubsection{Dependability}

Dependability, according to Lincoln and Guba (1985), relates to the findings being consistent and likely to be repeated. Similarly, Gasson (2004, p. 94) states that dependability deals with the core issue - "the way a study is conducted should be consistent across time, researchers, and analysis techniques". Bitsch (2005) related dependability to the stability of the findings over time in qualitative research. To increase the dependability in conducting qualitative research, the emerging research 
design is carefully tracked and an audit trail kept (a detailed chronology of research activities and processes) which influences the data collection and analysis, emerging themes or categories. The audit trail may then be examined by peer researchers, a student advisor or colleagues in the field.

The dependability of this study was enhanced with an audit trail, which was examined by supervisors, and my colleagues who were PhD students of education at VUW. For instance, at the stage of interview transcriptions and data analysis, I selected interesting phrases, sentences, and even metaphors in the Sino-Vietnamese language to be translated into English. Additionally, I discussed literal translations of those sentences with my supervisors to unveil the deep meanings that the economic, social, and cultural contexts influenced on the academics' research engagement. Then, we agreed on emerging themes before coming to the discussions and recommendations of the study.

In conclusion, to ensure the dependability, I followed the necessary steps of qualitative research processes. Its audit trail was carefully examined by my colleagues, and supervisors who had experience in conducting qualitative research.

\subsubsection{Confirmability}

The final criterion to enhance the trustworthiness in the qualitative research is confirmability, based on the acknowledgment that research is never objective. It addresses the core issue that "findings should represent, as far as is (humanly) possible, the situation being researched rather than the beliefs, pet theories, or biases of the researcher" (Gasson, 2004, p. 93). Jenson (2008) states that confirmability is a means through which to verify the two basic goals of qualitative research: (i) to understand a phenomenon from the perspective of the research participants and (ii) to understand the meanings people give to their experiences. Jenson suggests that confirmability is likely to be expressed through an audit trail where an independent reviewer is allowed to verify the research process and interpretations of the data as being consistent on both the literature and methodological levels. Selected participants could also be asked 
to review some of the coding and meaning-making process to determine whether the researcher's interpretations are consistent with their perceptions.

Applying Jenson's suggestions for the enhancement of confirmability in the qualitative research, supervisors and several Vietnamese PhD students of education played roles as independent reviewers to verify the research process and data interpretations. They were reliable reviewers in this study because they had rich experience in qualitative research.

To sum up, the acceptance for the quality in qualitative and interpretative research has been debated by many positivists (Lincoln, 1995; Shenton, 2004). For two decades, qualitative researchers have applied the criteria for enhancing the trustworthiness in the qualitative research suggested by Lincoln and Guba (1989). This study strictly followed techniques suggested by Bitsch (2005), Gasson (2004), Jenson (2008), Lincoln and Guba (1989), and Shenton (2004) to increase the quality and trustworthiness of qualitative research. Therefore, it is hoped that this study would be likely to adhere to quality criteria for qualitative research.

\subsubsection{Ethical issues}

Ethics in qualitative research, according to Marvasti (2004), relates to the nature of the researcher's responsibilities in the relationship with those they study. In other words, ethics in qualitative research is related to things that should or should not be done regarding the people being observed and written about. This study followed the basic principles for ethics in qualitative research suggested by Marvasti, including voluntary participation, protection of the research participants, confidentiality and anonymity, benefit to the research participants, and the informed consent model.

This study adhered to the formal ethical guidelines from Victoria University of Wellington (VUW). After the study was granted ethical approval from the Ethics Committee Faculty of Education, VUW on $26^{\text {th }}$ October 2012, I invited and sent the consent form to ask for voluntary participation in the pre-test survey from five participants in Case One. The survey consent form was designed with a 'tick box' for an 
agreement to join the following interview section. Based on this, I contacted them to set up the time and location that was most convenient to them. To interview academic managers (faculty and research centre heads), I invited them to voluntarily participate via email or phone. After that, the interview schedule was set up.

Finally, in this study, the identification of the gender of the interview participants was omitted for ethical considerations. Across the three cases, there were only two female participants from Case Three who were interviewed. The researcher considered that they were identifiable from the description of the participants as well as from their quotes, and consequently the identification of their institution. As a result, the effect of gender on individual academics' research engagement was not analysed in order to protect the participants' identities.

\subsubsection{Voluntary participation}

To ensure voluntary participation from the research participants, potential participants were sent an information sheet and consent form in both English and Vietnamese so that they fully understood the research procedures before they agreed to participate. This study's ethical approach to the research participants was implemented as follows.

Initially, the information sheet and the letter asking for permission to conduct research were sent to the Rector of each institution in the study. After receiving the approval, I approached the Director of each Research Affairs Office to obtain information about the institution's research practice. After this meeting, I met potential faculty and research centre heads to invite them to participate in the study as questionnaire or interview informants. The potential participants were sent the information sheet and consent form before they agreed to join the study. From their introductions, I contacted and invited other potential academics (via email and phone) to participate in the study. After obtaining their agreement to participate, I sent the information sheet, consent form, and questionnaire sheet to them to complete. After finishing collecting data in Case One, I carried out data collection in the two other institutions sequentially, and the procedure for recruiting the participants was similar in the first institution. However, due to the far distance of the selected institutions in the 
study, an email saying 'yes' was considered to be consent for questionnaire respondents. All interview respondents signed a consent form.

\subsubsection{Protection of research participants}

Research participants were ensured that they were safe when participating in this study. For example, the participants understood that they could withdraw from the research at any time. Additionally, I ensured confidentiality and anonymity for the participants and my PhD colleagues. For instance, for confidentiality, the identity of the participants was not disclosed to anyone, including their managers. For anonymity, their real names and their institution's name were not mentioned, instead I used numerous notes to help me remember. Similarly, the confidentiality forms for transcriptions signed by my colleagues were also ensured.

\subsubsection{Benefit to the research participants}

To ensure that there was mutual benefit in the research-subject relationship, this study brought some benefits to both the institutions and the research participants. I sent this study's summary report to the management staff and research participants in each institution. This could help them to reflect on the strengths and weaknesses in their operational research practices, which provide the opportunity for them to adjust their research practices and management appropriately to enhance their institutional research capacity. Similarly, the research participants might understand their challenges in research practices and barriers of institutional research management, which could stimulate them to debate necessary changes for national and institutional research policies. Additionally, whenever there are positive changes in research policies, they can be more motivated to engage in research activities. This possibly helped to expand their research networks and strengthen their professional knowledge and research capacity.

Despite efforts to address ethical issues in the research process, potential matters such as the reputation of institutions could be identified. Although selected institutions being identified in research is not a serious matter in the Vietnamese culture, I carefully removed any identifying details to protect the institutions' identity to respond to the 
formal ethical requirements of research at Victoria University of Wellington. Moreover, during interviews, if the participants suddenly felt uncomfortable answering questions on sensitive matters like dissatisfaction about their leaders' management styles, the participants had the right to refuse to answer any questions. Another possible problem about the confidentiality of participants and institutions was that there was the possibility of the researcher's peer reviewers identifying them.

\subsection{Chapter Summary}

This chapter provided the rationale for using interpretative qualitative research. It also gave a detailed description of method research designs, including process and procedures of data collection, the analytical framework and data analysis. Additionally, techniques used to enhance qualitative dependability, credibility, transferability and generalisations were provided. The chapter ended with the consideration of ethical issues in qualitative research. This chapter is followed by three chapters presenting the study findings. 



\section{CHAPTER 4. FINDINGS: CASE ONE}

\subsection{Chapter overview}

This chapter presents the findings of Case One, which was the first provincial multidisciplinary university established in southern Vietnam. As previously mentioned, this institution was developed from its local province's Teacher Training College.

The first section gives an overview of this case study. The second section presents the results of the document analysis. The third section presents the results of the survey. The fourth section describes the results of the interview. The last section is the chapter summary.

\subsection{Case One's documentary analysis results}

There were two different level documents used for analysis. Key national level documents included the regulation on Vietnamese university academics' working time in 2008, Vietnam University Charter in 2010, and Vietnam Education Law 2012. Institutional documents included the institution's website, institutional development project, scientific research workshop proceedings 2011, tasks in the academic year 2013-2014, and regulation on internal financial expense. The institutional documents of this provincial case seemed to indicate that this institution was in a phase of developing its qualified academics, training degrees and introducing academics to research activities.

\subsubsection{Case One' s academic staff}

In 2015, Case One has 429 academics (including 1 Associate Professor, 35 PhD degrees, and 350 MA degrees) out of a total of 841 staff $^{1}$. According to Vietnam Education Law 2012, Vietnamese university lecturers should minimally have MA degrees (Vietnam National Assembly, 2012). Contrasting with this legal document, there were 337 out of

\footnotetext{
${ }^{1}$ Case One's annual report 2015
} 
574 (58.71\%) lecturers in Case One who had qualified for MA degrees up to 2015 (see Table 4-1). This table also shows that Case One had few leading research and doctoraldegree academics. There was a limited number of doctoral academics in the faculties of Education and Agricultural and Natural Resources (A\&NR).

Table 4-1. Case One' academic and support staff ${ }^{2}$

\begin{tabular}{|c|c|c|c|c|c|c|c|c|}
\hline \multicolumn{9}{|c|}{$\begin{array}{c}\text { Case One's personnel } \\
841\end{array}$} \\
\hline \multirow{2}{*}{\multicolumn{3}{|c|}{ Supporting Staff (267) }} & \multicolumn{6}{|c|}{ Academic Staff (574) } \\
\hline & & & \multicolumn{2}{|c|}{ Faculty/School } & \multicolumn{4}{|c|}{ Degrees } \\
\hline Research staff & Supp & ive staff & & No. & $D$ & $M$ & $U$ & $\begin{array}{l}\text { Und } \\
\text { er-U }\end{array}$ \\
\hline 22 & & & Education & 162 & 10 & 116 & 36 & 1 \\
\hline \multicolumn{3}{|c|}{ Degrees } & E\&BA & 67 & 4 & 37 & 25 & 1 \\
\hline M & U & Under-U & A\&NR & 97 & 12 & 73 & 11 & 2 \\
\hline \multirow[t]{6}{*}{3} & 121 & 79 & IT\&Env & 59 & 5 & 34 & 18 & 2 \\
\hline & & & Poli Studies & 25 & 2 & 11 & 12 & \\
\hline & & & A\&C Studies & 40 & & 13 & 27 & \\
\hline & & & Phy Ed & 15 & & 7 & 8 & \\
\hline & & & ND Ed & 12 & & 3 & 7 & 2 \\
\hline & & & PP School & 97 & & 10 & 73 & 14 \\
\hline \multicolumn{9}{|c|}{$\begin{array}{l}\text { Notes: } \\
\text {-Degrees: D (Doctorate); M (Master); U (university); Under-U (under-university) } \\
\text {-Faculty \& School: E\&BA (Economics \& Business Administration); A\&NR (Agricultural and Natural Resources); } \\
\text { IT\&Env (Information Technology and Environment); Poli (Political); A\&C (Arts and Cultural); Phy Ed (Physical } \\
\text { Education); ND Edu (National Defence Education); Pedagogical Practice School }\end{array}$} \\
\hline
\end{tabular}

\subsubsection{Case One's scientific research operations and orientation Scientific research operation}

Case One' s research activities in recent years could be seen to be considerably improving thanks to an increase in the number of qualified staff from 2011 to 2014. However, the majority of the research projects conducted by this institution were at the institutional level. For instance, Case One had 765 staff, among whom were 265 holders of master degrees and 13 holders of doctoral degrees in 2011. In 2014, the time of this research conducted in this institution, there were 24 holders of doctoral degrees and 337 holders of master degrees (including academics and managerial staff) in various disciplines across the total number of 841 staff (see Table 4-1). In evaluating the

2 This table was extracted from Case One's week 5 report in the school year of 2014-2015, and translated into English. 
academics' research attitude in this institution, Case One's report ${ }^{3}$ documented that $^{\prime}$ generally its academics had strong determination in their professional career, and they also learnt their responsibilities as university lecturers. Thus, they actively participated in conducting institutional and provincial level research projects.

The report documented that the number of research projects conducted by this institution's academics was very limited. Only 78 institutional level research projects were conducted by its academics between 2006 and 2011. Most of these research projects were conducted by the academics in the Faculties of A\&NR, and Education. Among 78 research projects, there were 46 applied and 26 experimental development research projects.

In addition to its institutional research projects, Case One's academics have conducted some other research projects in recent times. They included six institutional, eight provincial level research projects and five research projects funded by the World Bank. Table 4-2 displays institutional ${ }^{4}$, provincial level, and international cooperation research projects conducted from 2006 to 2011.

Table 4-2. Case One's provincial level research projects in 2006-2011

\begin{tabular}{|c|c|c|c|c|c|c|}
\hline \multirow[t]{2}{*}{$\begin{array}{l}\text { Conducting } \\
\text { Units }\end{array}$} & \multicolumn{2}{|c|}{$\begin{array}{l}\text { Institutional level } \\
\text { research projects }\end{array}$} & \multicolumn{2}{|c|}{$\begin{array}{l}\text { Provincial level } \\
\text { research projects }\end{array}$} & \multicolumn{2}{|c|}{ TRIG projects } \\
\hline & $\begin{array}{c}\text { No. of } \\
\text { projects } \\
\text { approved }\end{array}$ & $\begin{array}{l}\text { No. of } \\
\text { projects } \\
\text { completed }\end{array}$ & $\begin{array}{l}\text { No. of } \\
\text { projects } \\
\text { approved }\end{array}$ & $\begin{array}{l}\text { No. of } \\
\text { projects } \\
\text { completed }\end{array}$ & $\begin{array}{l}\text { No. of } \\
\text { projects } \\
\text { approved }\end{array}$ & $\begin{array}{c}\text { No. of } \\
\text { projects } \\
\text { completed }\end{array}$ \\
\hline A\&NR & 7 & 1 & 5 & 2 & 16 & 5 \\
\hline SS\&HRC & 7 & 5 & 7 & 6 & & \\
\hline Education & 1 & 0 & & & & \\
\hline$E \& B A$ & & & 1 & 0 & & \\
\hline Rector Board & & & 1 & 0 & & \\
\hline Total & 15 & 6 & 14 & 8 & 16 & 5 \\
\hline
\end{tabular}

Additionally, the report documented that the academics actively participated in national and foreign conferences. Specifically, they submitted 51 papers to national and

\footnotetext{
${ }^{3}$ Case One's report of scientific research and technology transfer activities in 2011

${ }^{4}$ The institutional level research projects were funded from the provincial Department of Science and Technology
} 
international journals. Table 4-3 shows the academics' publications in Case One in recent years.

Table 4-3. Case One's publications in the period 2009-2011

\begin{tabular}{|c|c|c|c|c|c|c|}
\hline Faculties & $\begin{array}{l}\text { National } \\
\text { Journals }\end{array}$ & $\begin{array}{l}\text { Foreign } \\
\text { Journals }\end{array}$ & $\begin{array}{l}\text { Institutional } \\
\text { Journal }\end{array}$ & $\begin{array}{c}\text { Presentation } \\
\text { papers at } \\
\text { national } \\
\text { conferences }\end{array}$ & $\begin{array}{c}\text { Presentation } \\
\text { papers at } \\
\text { foreign } \\
\text { conferences }\end{array}$ & Total \\
\hline Education & 2 & 0 & 1 & 5 & 0 & 8 \\
\hline A\&NR & 2 & 4 & 6 & 4 & 11 & 27 \\
\hline IT\&Env & 0 & 1 & 0 & 4 & 0 & 5 \\
\hline $\mathrm{E} \& \mathrm{BA}$ & 0 & 1 & 0 & 0 & 0 & 1 \\
\hline $\begin{array}{l}\text { Support } \\
\text { offices }\end{array}$ & 6 & 0 & 4 & 0 & 0 & 10 \\
\hline Total & 10 & 6 & 11 & 13 & 11 & 51 \\
\hline
\end{tabular}

(Case One, 2011)

In conclusion, since 2000 as a newly established HEI from a pedagogical college, Case One in recent years has made, to some extent, considerable progress in regional and international HE integration. In addition, its research capacity has significantly improved thanks to its increase of the number of qualified staff and development of international relations affairs (the Teaching Research Innovation Grants Project namely TRIG project funded by the World Bank). However, research capacities among faculties were very different. It was apparent that the Faculties of Agriculture \& Natural Resources and of Education were stronger than others in research capacity, possibly because most qualified academics in this institution were in these two faculties. Moreover, the majority of its research projects were at institutional and locally provincial levels, and there were more applied and experimental development research projects than basic research projects.

\section{Scientific research orientation}

Case One's scientific research-orientation strategic development strategy to the year 2020 states that Case One plans to conduct research projects and apply S\&T advances in major fields such as training operation research and socioeconomic development research. For studies on training operation, the institution plans to modify and gradually 
perfect its current training curriculum and subject programmes, and updating knowledge to respond to society's demands. Also, it will add training programmes more suited to future development. For instance, teaching materials and monographic documents for new training programmes will be designed, and information technology and new teaching methods will be actively applied in teaching activities.

For studies on socioeconomic development issues, the institution will closely follow its local province's key research programmes and create a close link between research, training and practical manufacturing situations in the province, aiming at solving crucial provincial needs. Simultaneously, this institution aims to contribute to building a model for training and become a provincial research centre.

Specifically, Case One sets an objective for tasks of scientific research in the future. There will be an increase in the number of different level research projects domestically and internationally. It hopes that there will be at least one national, 10 ministerial, 30 provincial, and 300 institutional level research projects in the period 2011-2015. The predicted number for the period 2016-2020 is two national, 15 ministerial, 40 provincial, and 400 institutional research projects. Additionally, it will also expand its research cooperation. For instance, it predicts that there will be 104 national, 52 international cooperation, and 139 research projects for serving community's needs in the period 2011-2016. In the period 2016-2020, there will be 137 national, 69 international, and 183 community development research projects. For research finance, Case One hopes to seek various research funding sources domestically and internationally. Table 4-4 indicates various sources of research funding at Case One.

Table 4-4. Case One's expected sources of research funding

\begin{tabular}{|c|c|c|c|c|c|}
\hline $\begin{array}{c}\text { Years: } \\
\text { 2011-2015 }\end{array}$ & \multicolumn{2}{|c|}{$\begin{array}{c}\text { Total money: } 10,615 \mathrm{~m} \text { VND } \\
(530,750 \text { USD) }\end{array}$} & $\begin{array}{c}\text { Years: } \\
\text { 2016-2020 }\end{array}$ & \multicolumn{2}{|c|}{$\begin{array}{l}\text { Total money: } 13,980 \mathrm{~m} \\
\text { VND (699,000 USD) }\end{array}$} \\
\hline \multicolumn{3}{|c|}{ Sources } & \multicolumn{3}{|c|}{ Sources } \\
\hline $\begin{array}{l}\text { Institutional } \\
\text { research } \\
\text { funding }\end{array}$ & $\begin{array}{l}\text { Various } \\
\text { domestic } \\
\text { research } \\
\text { funding }\end{array}$ & $\begin{array}{l}\text { Foreign } \\
\text { cooperation } \\
\text { research } \\
\text { funding }\end{array}$ & $\begin{array}{l}\text { Institutional } \\
\text { research } \\
\text { funding }\end{array}$ & $\begin{array}{l}\text { Various } \\
\text { domestic } \\
\text { research } \\
\text { funding }\end{array}$ & $\begin{array}{c}\text { Foreign } \\
\text { cooperation } \\
\text { research } \\
\text { funding }\end{array}$ \\
\hline $\begin{array}{c}2,043 m \text { VND } \\
(102,150 \text { USD) }\end{array}$ & $\begin{array}{c}8,097 \mathrm{~m} \text { VND } \\
(404,850 \text { USD })\end{array}$ & $\begin{array}{c}475 \mathrm{~m} \text { VND } \\
(23,750 \text { USD) }\end{array}$ & $\begin{array}{c}2,690 \mathrm{~m} \text { VND } \\
(134,500 \text { USD })\end{array}$ & $\begin{array}{l}10,664 \mathrm{~m} \text { VND } \\
\text { (533,200 USD) }\end{array}$ & $\begin{array}{c}626 \mathrm{~m} \text { VND } \\
(31,300 \text { USD) }\end{array}$ \\
\hline
\end{tabular}

(Case One, 2014c) 


\subsubsection{Case One's staff development strategy}

In addition to its attention toward the task of scientific research development, Case One had concern for its human resources development. This institution is trying to make efforts to achieve its targets for staff development to respond to Vietnamese university academics' qualification standards after the year of 2015 according to Vietnam Education Law 2012 - "Vietnamese university academics must be minimally master degree holders"(Vietnam National Assembly, 2012). Its target is to have $84.2 \%$ of its academics holding master degrees at a minimum, which includes 1 Professor, 7 Associate Professors, 149 PhD holders, 436 MA holders in the year 2015. In 2020, all academics must at least be MA degree holders, among there will be 1 Professor, and 13 Associate Professors (Case One, 2014a). Table 4-5 shows the plan for upgrading academics' qualifications up to 2030.

Table 4-5. Case One's plan for staff development in the period 2012-2030

\begin{tabular}{|c|c|c|c|c|c|c|c|}
\hline \multirow[t]{4}{*}{ Academic Year } & \multirow{4}{*}{$\begin{array}{c}\text { Total } \\
\text { number } \\
\text { of staff }\end{array}$} & \multicolumn{6}{|c|}{ Academics } \\
\hline & & \multirow{3}{*}{$\begin{array}{l}\text { Total } \\
\text { number }\end{array}$} & \multicolumn{2}{|c|}{ Degrees } & \multicolumn{3}{|c|}{ Professional training courses } \\
\hline & & & \multirow[b]{2}{*}{ Master } & \multirow[b]{2}{*}{ Doctor } & \multirow{2}{*}{$\begin{array}{c}\text { Total } \\
\text { number } \\
\text { being } \\
\text { trained }\end{array}$} & \multirow[b]{2}{*}{ Master } & \multirow[b]{2}{*}{ Docto } \\
\hline & & & & & & & \\
\hline 2012 & 842 & 629 & 311 & 19 & 40 & 30 & 10 \\
\hline 2013 & 949 & 711 & 336 & 24 & 107 & 95 & 12 \\
\hline 2014 & 990 & 743 & 372 & 42 & 110 & 95 & 15 \\
\hline 2015 & 1030 & 772 & 458 & 77 & 112 & 95 & 17 \\
\hline $2015-2020$ & 1080 & 810 & 623 & 120 & 180 & 110 & 70 \\
\hline 2020-2025 & 1130 & 847 & 663 & 170 & 140 & 60 & 80 \\
\hline $2025-2030$ & 1193 & 895 & 573 & 304 & 147 & 30 & 117 \\
\hline
\end{tabular}

Additionally, the institution hopes to increase the number of Professors and Associate Professors in the future. Specifically, there is one professor and seven associate professors in 2015 . This number will be one, and thirteen respectively in 2020, and eight professors and forty associate professors in 2030. 


\section{Summary of documentary analysis}

At the time of this research, it seemed that Case One was in the phase of building its qualified academics, and developing training tasks. For research activities, it started to familiarise itself with the environment of scientific research at HE contexts in national and international integration. Therefore, in terms of the scope of domestic and foreign research cooperation, it had a very limited number of research projects, mainly at institutional and locally provincial levels. Also, its number of research publications was limited, too. It is possible that Case One had recently increased efforts to develop its staff as well as its research capacity, and develop a strategic research development plan for the future.

\subsection{Case One's survey results}

The survey results in Case One were collected from 37 master-degree participants and were grouped into six categories (academics' research perceptions; positive factors impacting academics' research engagement; negative factors impacting academics' research engagement; academics' satisfaction with PD activities organised by the institution; academics' satisfaction with PD activities organised by the faculty; academics' self-directed PD activities). Following are the details of Case One's survey results.

\subsubsection{Research perceptions}

The survey section on research perception comprised seven items with the aim of exploring the respondents' level of agreement. Overall, Table 4-6 shows that the respondents had high levels of agreement on seven statements related to research perceptions. Specifically, as seen from the table, the respondents were in high agreement on items $A 1, A 3, A 2, A 4, A 5, A 6$, and $A 7$ respectively. But nevertheless, it can be seen from the table that a great number of respondents show their neutral level of agreement on items $A 5, A 4, A 6, A 2, A 7$ respectively. Particularly, there were 13 out of 37 respondents (35\%) who disagreed on item A7 - research perceived as a way to fulfil academics' requirements. This appeared to denote that a considerable number of participants in this case study had not considered research to be part of their role as a 
university academic (although this is stated in Vietnam Education Law, 2012). Altogether, the findings indicated that most participants agreed positively with the research perceptions listed in the survey.

Table 4-6. Case One's results of academics' research perceptions

\begin{tabular}{|c|c|c|c|c|c|c|c|}
\hline \multirow[t]{2}{*}{ Item list } & \multirow[b]{2}{*}{ 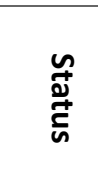 } & \multicolumn{5}{|c|}{ Scale of agreement } & \multirow{2}{*}{ 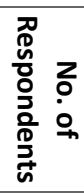 } \\
\hline & & SD & $\mathrm{D}$ & $\mathrm{N}$ & A & SA & \\
\hline \multirow{3}{*}{$\begin{array}{l}\text { A1. Research perceived as a process of discovering, } \\
\text { uncovering or creating understandable meanings }\end{array}$} & $M$ & & 0 & & 4 & 6 & \multirow{3}{*}{37} \\
\hline & $\mathrm{L}$ & 1 & & 1 & 10 & 15 & \\
\hline & total & 1 & 0 & 1 & 14 & 21 & \\
\hline \multirow{3}{*}{$\begin{array}{l}\text { A2. Research perceived as the creation of new } \\
\text { knowledge and innovative approaches to the } \\
\text { discovery of that knowledge }\end{array}$} & $M$ & & 1 & 3 & 3 & 3 & \multirow[t]{3}{*}{37} \\
\hline & L & 1 & & 5 & 8 & 13 & \\
\hline & total & 1 & 1 & 8 & 11 & 16 & \\
\hline \multirow{3}{*}{$\begin{array}{l}\text { A3. Research helps to develop one's personal } \\
\text { knowledge and research methods }\end{array}$} & $\mathrm{M}$ & 0 & & & 7 & 3 & \multirow[t]{3}{*}{37} \\
\hline & $\mathrm{L}$ & 1 & 1 & 1 & 8 & 15 & \\
\hline & total & 1 & 1 & 1 & 15 & 18 & \\
\hline \multirow{3}{*}{$\begin{array}{l}\text { A4. Research perceived as the process of data } \\
\text { collection, data analysis, then reporting its research } \\
\text { findings }\end{array}$} & $M$ & & & 1 & 5 & 4 & \multirow[t]{3}{*}{37} \\
\hline & $\mathrm{L}$ & 2 & 1 & 9 & 7 & 8 & \\
\hline & total & 2 & 1 & 10 & 12 & 12 & \\
\hline \multirow{3}{*}{$\begin{array}{l}\text { A5. Research means presenting new ways of seeing } \\
\text { the world, oneself or a problem }\end{array}$} & $\mathrm{M}$ & & & 2 & 6 & 2 & \multirow[t]{3}{*}{37} \\
\hline & $\mathrm{L}$ & 1 & & 10 & 9 & 7 & \\
\hline & total & 1 & 0 & 12 & 15 & 9 & \\
\hline \multirow{3}{*}{$\begin{array}{l}\text { A6. Research perceived as establishing oneself in the } \\
\text { field, and developing oneself personally }\end{array}$} & $M$ & 1 & 1 & 2 & 3 & 3 & \multirow[t]{3}{*}{37} \\
\hline & L & 1 & 4 & 7 & 12 & 3 & \\
\hline & total & 2 & 5 & 9 & 15 & 6 & \\
\hline \multirow{3}{*}{$\begin{array}{l}\text { A7. Research perceived as a way to fulfil academics' } \\
\text { requirements }\end{array}$} & $\mathrm{M}$ & 2 & 1 & 3 & 3 & 1 & \multirow[t]{3}{*}{37} \\
\hline & L & 5 & 5 & 5 & 9 & 3 & \\
\hline & total & 7 & 6 & 8 & 12 & 4 & \\
\hline
\end{tabular}

\subsubsection{Factors to motivate academics' research engagement}

Related to factors positively impacting on academics' research engagement, Table 4-7 illustrates positive motivators likely to impact on academics' research engagement at this institution. As shown in the table, the majority of respondents considered that items B5 to B11 were important to very important towards academics' research engagement whereas more respondents appeared to believe that items B2, B3, and B4 were little important or unimportant to academics' research engagement. For item B1 - become a (associate) Professor or receive promotion, the number of respondents (12) evaluating it to be unimportant and little important is nearly equal to the number of respondents (13) evaluating it to be important and very important. This finding may reflect the real 
situation in this institution where there was a very limited number of academics who had doctoral degrees. In particular, no questionnaire respondents in this study possessed a doctoral degree.

Table 4-7. Positive factors affecting academics' research engagement in Case One

\begin{tabular}{|c|c|c|c|c|c|c|c|}
\hline \multirow[b]{2}{*}{ Engaging in research to } & \multirow{2}{*}{ 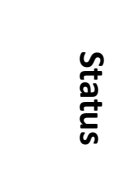 } & \multicolumn{5}{|c|}{$\begin{array}{l}\text { Scale of the Degree of } \\
\text { Importance }\end{array}$} & \multirow{2}{*}{ 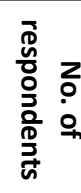 } \\
\hline & & $\mathbf{U}$ & $\mathbf{L}$ & $\mathbf{M}$ & $\mathbf{I}$ & VI & \\
\hline \multirow{3}{*}{$\begin{array}{l}\text { B1. Become a (associate) professor or receive } \\
\text { promotion. }\end{array}$} & M & 0 & 1 & 5 & 3 & & \multirow[t]{3}{*}{37} \\
\hline & $\mathrm{L}$ & 5 & 6 & 7 & 7 & 3 & \\
\hline & Total & 5 & 7 & 12 & 10 & 3 & \\
\hline \multirow[t]{3}{*}{ B2. Have better salary raises. } & $\mathrm{M}$ & 0 & 3 & 6 & 1 & & \multirow[t]{3}{*}{37} \\
\hline & $\mathrm{L}$ & 3 & 9 & 10 & 5 & & \\
\hline & Total & 3 & 12 & 16 & 6 & & \\
\hline \multirow[t]{3}{*}{ B3. Get promotion in the role of management. } & $\mathrm{M}$ & 3 & 2 & 2 & 3 & & \multirow[t]{3}{*}{37} \\
\hline & $\mathrm{L}$ & 6 & 11 & 7 & & 3 & \\
\hline & Total & 9 & 13 & 9 & 3 & 3 & \\
\hline \multirow[t]{3}{*}{ B4. Get a reduced teaching load. } & $\mathrm{M}$ & 3 & 5 & 2 & 0 & & \multirow[t]{3}{*}{37} \\
\hline & $\mathrm{L}$ & 6 & 8 & 8 & 4 & 1 & \\
\hline & Total & 9 & 13 & 10 & 4 & 1 & \\
\hline \multirow[t]{3}{*}{ B5. Gain a higher status in the professional career. } & $\mathrm{M}$ & & & 5 & 3 & 2 & \multirow[t]{3}{*}{37} \\
\hline & $\mathrm{L}$ & 2 & 3 & 5 & 10 & 7 & \\
\hline & Total & 2 & 3 & 10 & 13 & 9 & \\
\hline \multirow{3}{*}{$\begin{array}{l}\text { B6. Reflect research competence, improve } \\
\text { teaching skills, and find out better teaching } \\
\text { methods. }\end{array}$} & $M$ & & & 1 & 4 & 5 & \multirow[t]{3}{*}{37} \\
\hline & $\mathrm{L}$ & & 2 & 3 & 10 & 12 & \\
\hline & Total & 0 & 2 & 4 & 14 & 17 & \\
\hline \multirow{3}{*}{$\begin{array}{l}\text { B7. Get the respect and high evaluation from } \\
\text { students. }\end{array}$} & $\mathrm{M}$ & & 0 & 1 & 5 & 4 & \multirow[t]{3}{*}{37} \\
\hline & $\mathrm{L}$ & & 2 & 8 & 9 & 8 & \\
\hline & Total & 0 & 2 & 9 & 14 & 12 & \\
\hline \multirow{3}{*}{$\begin{array}{l}\text { B8. Satisfy need for contributing knowledge to the } \\
\text { professional field; need of discovery, and need of } \\
\text { creativity. }\end{array}$} & $\mathrm{M}$ & & & 1 & 5 & 4 & \multirow[t]{3}{*}{37} \\
\hline & L & & & 4 & 9 & 14 & \\
\hline & Total & 0 & 0 & 5 & 14 & 18 & \\
\hline \multirow{3}{*}{$\begin{array}{l}\text { B9. Contribute to the overall improvement of the } \\
\text { department and institution. }\end{array}$} & $\mathrm{M}$ & & & 2 & 4 & 4 & \multirow[t]{3}{*}{37} \\
\hline & $\mathrm{L}$ & & 3 & 4 & 11 & 9 & \\
\hline & Total & 0 & 3 & 6 & 15 & 13 & \\
\hline \multirow{3}{*}{$\begin{array}{l}\text { B10. Have better opportunities to study higher in } \\
\text { the country and abroad. }\end{array}$} & $\mathrm{M}$ & & 0 & 1 & 6 & 3 & \multirow[t]{3}{*}{37} \\
\hline & $\mathrm{L}$ & & 3 & 5 & 6 & 12 & \\
\hline & Total & 0 & 3 & 6 & 12 & 15 & \\
\hline \multirow{3}{*}{$\begin{array}{l}\text { B11. Have good collaboration from other } \\
\text { colleagues. }\end{array}$} & $M$ & & & 6 & 1 & 3 & \multirow[t]{3}{*}{37} \\
\hline & $\mathrm{L}$ & 2 & 6 & 6 & 9 & 4 & \\
\hline & Total & 2 & 6 & 12 & 10 & 7 & \\
\hline
\end{tabular}

In conclusion, the respondents had high evaluations of both internal and external factors that impact on academics' research engagement. For instance, they believed 
that they were involved in research because it could offer them a high status in the profession (B5), perfect their teaching and research knowledge (B6), get the respect from learners (B7), and satisfy their curiosity in research (B8). Additionally, in their view, research could help academics to fulfil their aspiration for the contribution of the institutional development (B9), to create better opportunities to improve their knowledge from their higher study (B10). Moreover, good collaborations in research (B11) were seen to be important for academics' research engagement, too. However, for respondents, elements such as better salary raises (B2), getting promotion in management (B3), and getting a reduced teaching load (B4) seemed to be unimportant to academics' research engagement.

\subsubsection{Factors hindering academics' research engagement}

The factors that were seen as having a negative impact on academics' research engagement are shown in Table 4-8. As can be seen from this table, the findings can be divided into two groups. Group One-agreement includes items C1, C4, C6, C9, and C10. Group Two-disagreement consists of ten other items (C2, C3, C5, C7, C8, C11, C12, C13, C14, and C15).

In group one, the respondents considered that items C1 (research is a waste of time), and C9 (the complicated procedures to get research grants) were the most negative factors that were likely to affect academics' research engagement. These two factors were followed by items $\mathrm{C} 10, \mathrm{C} 6$, and $\mathrm{C} 4$.

In group two, a majority of the respondents disagreed that items $\mathrm{C} 2, \mathrm{C} 14$, and $\mathrm{C} 15$ were the main factors that possibly hindered their research involvement. After these three items were items $\mathrm{C} 3, \mathrm{C} 8, \mathrm{C} 13, \mathrm{C} 5, \mathrm{C} 11$, and $\mathrm{C} 12$ respectively.

On the whole, the respondents seemed to consider that elements such as the complicated procedures to get research grants, a lack of research grants, a lack of research facilities, low income in research, and research as a waste of time were the main factors affecting their research engagement. Other elements like research 
environments, research collaborations, research supports, and academics' research competence seemed not to have a negative impact on their research engagement.

Table 4-8. Factors hindering academics' research engagement in Case One

\begin{tabular}{|c|c|c|c|c|c|c|c|}
\hline \multirow{2}{*}{$\begin{array}{l}\text { Factors that hinder me to engage in } \\
\text { scientific research activities }\end{array}$} & \multirow[b]{2}{*}{ 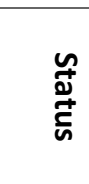 } & \multicolumn{5}{|c|}{ Scale of Agreement } & \multirow{2}{*}{ 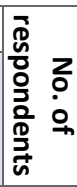 } \\
\hline & & SD & D & $\mathbf{N}$ & A & SA & \\
\hline \multirow[t]{3}{*}{ C1. Research is a waste of time } & $M$ & 1 & & 1 & 6 & 1 & \multirow[t]{3}{*}{37} \\
\hline & $\mathrm{L}$ & 2 & 5 & 3 & 16 & 3 & \\
\hline & Total & 3 & 5 & 4 & 22 & 4 & \\
\hline \multirow[t]{3}{*}{ C2. My job is teaching, not research } & $\mathrm{M}$ & 6 & 4 & & & & \multirow[t]{3}{*}{37} \\
\hline & $\mathrm{L}$ & 10 & 13 & 2 & 2 & & \\
\hline & Total & 16 & 17 & 2 & 2 & & \\
\hline \multirow{3}{*}{$\begin{array}{l}\text { C3. Research is a heavy extra burden towards university } \\
\text { academics }\end{array}$} & $\mathrm{M}$ & 4 & 6 & & & & \multirow[t]{3}{*}{37} \\
\hline & $\mathrm{L}$ & 10 & 8 & 3 & 4 & 2 & \\
\hline & Total & 14 & 14 & 3 & 4 & 2 & \\
\hline \multirow[t]{3}{*}{ C4. Research provides low salaries } & $\mathrm{M}$ & 1 & 3 & 2 & 4 & & \multirow[t]{3}{*}{37} \\
\hline & $\mathrm{L}$ & 1 & 4 & 7 & 11 & 4 & \\
\hline & Total & 2 & 7 & 9 & 15 & 4 & \\
\hline \multirow{3}{*}{$\begin{array}{l}\text { C5. There were few opportunities and conditions to } \\
\text { conduct research in the workplace }\end{array}$} & $\mathrm{M}$ & 2 & 4 & 1 & 3 & & \multirow[t]{3}{*}{37} \\
\hline & $\mathrm{L}$ & 7 & 9 & 3 & 5 & 3 & \\
\hline & Total & 9 & 13 & 4 & 8 & 3 & \\
\hline \multirow[t]{3}{*}{ C6. There is a lack of research grants } & $\mathrm{M}$ & & 1 & 2 & 4 & 3 & \multirow[t]{3}{*}{37} \\
\hline & $\mathrm{L}$ & & 4 & 8 & 12 & 3 & \\
\hline & Total & 0 & 5 & 10 & 16 & 6 & \\
\hline \multirow{3}{*}{$\begin{array}{l}\text { C7. Inadequate time available for research due to other } \\
\text { heavy duties }\end{array}$} & $\mathrm{M}$ & 2 & 3 & 1 & 3 & 1 & \multirow[t]{3}{*}{37} \\
\hline & $\mathrm{L}$ & 5 & 6 & 8 & 6 & 2 & \\
\hline & Total & 7 & 9 & 9 & 9 & 3 & \\
\hline \multirow[t]{3}{*}{ C8. There is a high pressure to publish } & $\mathrm{M}$ & 3 & 6 & 1 & & & \multirow[t]{3}{*}{37} \\
\hline & $\mathrm{L}$ & 5 & 11 & 6 & 5 & & \\
\hline & Total & 8 & 17 & 7 & 5 & & \\
\hline \multirow{3}{*}{$\begin{array}{l}\text { C9. The procedure to get research grants is very complex } \\
\text { and so time-consuming }\end{array}$} & $\mathrm{M}$ & & & 1 & 7 & 2 & \multirow[t]{3}{*}{37} \\
\hline & $\mathrm{L}$ & & 2 & 2 & 13 & 10 & \\
\hline & Total & 0 & 2 & 3 & 20 & 12 & \\
\hline C10. The lack of research facilities such as reference & M & 2 & 2 & & 4 & 2 & 37 \\
\hline books, experiment labs & $\mathrm{L}$ & 1 & 4 & 5 & 8 & 9 & \\
\hline & Total & 3 & 6 & 5 & 12 & 11 & \\
\hline C11. Lacking the leader's support and colleagues' & $\mathrm{M}$ & 4 & 4 & & 2 & & 37 \\
\hline collaborations & $\mathrm{L}$ & 2 & 10 & 11 & 4 & & \\
\hline & Total & 6 & 14 & 11 & 6 & & \\
\hline C12. Most colleagues not engaging in research & $\mathrm{M}$ & 5 & 2 & 1 & 2 & & 37 \\
\hline & $\mathrm{L}$ & 3 & 9 & 7 & 5 & 3 & \\
\hline & Total & 8 & 11 & 8 & 7 & 3 & \\
\hline C13. The university (workplace) not having specific & $\mathrm{M}$ & 5 & 2 & & 3 & & 37 \\
\hline research orientation and strategies & $\mathrm{L}$ & 8 & 9 & 6 & 4 & & \\
\hline & Total & 13 & 11 & 6 & 7 & & \\
\hline C14. Not understanding clearly the process of doing & $\mathrm{M}$ & 6 & 3 & & 1 & & 37 \\
\hline research & $\mathrm{L}$ & 8 & 15 & 4 & 1 & & \\
\hline & Total & 14 & 18 & 4 & 2 & & \\
\hline C15. Unconfident about research methods & $\mathrm{M}$ & 6 & 3 & & 1 & & 37 \\
\hline & $\mathrm{L}$ & 6 & 12 & 7 & 2 & & \\
\hline & Total & 12 & 15 & 7 & 3 & & \\
\hline
\end{tabular}




\subsubsection{PD activities}

The survey was also used to explore academics' PD activities for improving their research competence as well as professional knowledge. There were three subsections in the survey designed to investigate academics' professional activities. The first subsection was targeted to investigate the academics' evaluation about the activities' organised by the university. This subsection was followed by the second subsection - exploring academics' levels of satisfaction with activities held by the faculty. The open-ended subsection was given to the respondents to write about their PD activities and workshops they attended in the past 12 months. The findings of the respondents' PD activities are displayed below.

\section{PD activities organised by the institution}

The participants' level of satisfaction with activities organised by the institution is illustrated in Table 4-9. As seen in this table, the number of respondents that felt satisfied with the activities held by their institution was double the number of those unsatisfied. However, half of the respondents had evaluations on the PD activities organised by the institution that were barely acceptable.

Table 4-9. Academics' level of satisfaction with PD activities organised by the university

\begin{tabular}{|c|c|c|c|c|c|c|}
\hline \multirow{2}{*}{$\begin{array}{c}\text { No. of the } \\
\text { Respondents }\end{array}$} & \multicolumn{6}{|c|}{ Scale of quality evaluation } \\
\cline { 2 - 7 } & Very poor & Poor & $\begin{array}{c}\text { Barely } \\
\text { acceptable }\end{array}$ & Good & Very good & Not sure \\
\hline $\mathbf{3 6}$ & 1 & 5 & 18 & 10 & 2 & \\
\hline
\end{tabular}

\section{PD activities organised by the faculty}

In comparison with the activities organised by the institution, the number of respondents feeling satisfied, feeling unsatisfied with, and having neutral ideas on the activities organised by their faculties was nearly equal (see Table 4-10). In addition, there were two respondents who replied that they were not sure about the professional activities organised by their faculties. 
Table 4-10. Academics' level of satisfaction with PD activities organised by the faculty

\begin{tabular}{|c|c|c|c|c|c|c|}
\hline $\begin{array}{c}\text { No. of the } \\
\text { Respondents }\end{array}$ & \multicolumn{6}{|c|}{ Scale of quality evaluation } \\
\cline { 2 - 7 } & $\begin{array}{c}\text { Very } \\
\text { poor }\end{array}$ & Poor & $\begin{array}{c}\text { Barely } \\
\text { acceptable }\end{array}$ & Good & $\begin{array}{c}\text { Very } \\
\text { good }\end{array}$ & Not sure \\
\hline 37 & 2 & 9 & 12 & 9 & 3 & 2 \\
\hline
\end{tabular}

Academics' regular PD activities

In general, a majority of the respondents reported that they attended most institutional and provincial level workshops related to renewing training programmes (such as building a question bank for their teaching subjects, using open learning resources), and improving teaching methods. There were very few workshops related to developing research skills. For developing their professional knowledge, some respondents recorded that they submitted papers to conferences organised in provinces and in other universities.

\section{Summary of survey findings}

Key findings from the survey were as follows. First, most respondents agreed on seven research perceptions listed in the survey. However, they disagreed on item A7-research perceived as a way to fulfil academics' requirements. Second, the respondents seemed to consider the factors of teaching career related personal motivation important to academics' research engagement while it was not important for them to see that research brings them a high salary, a reduction of teaching loads, or a promotion in management positions. Third, a large number of the respondents believed that their research hindrances consisted of limited finance, time, facilities, and particularly a complicated procedure to receive research funding and payment when their research was completed. Furthermore, they had low evaluations toward research and PD activities run by their institution and faculties. Last but not least, they perceived that they did not have a variety of self-directed PD activities to improve their research skills, except for attending few institutional and provincial workshops related to renewing training programmes. 


\subsection{Case One's interview results}

Figure 4-1 delineates the interview participants in Case One. The code was given to each participant when reporting their responses in this study to protect the interviewees' identities, details about being identified their management positions were not explicitly presented. There were seven academic managers and four lecturers taking part in the interview. Two interviewees (MPro 2 and MPro 6) were PhDs.

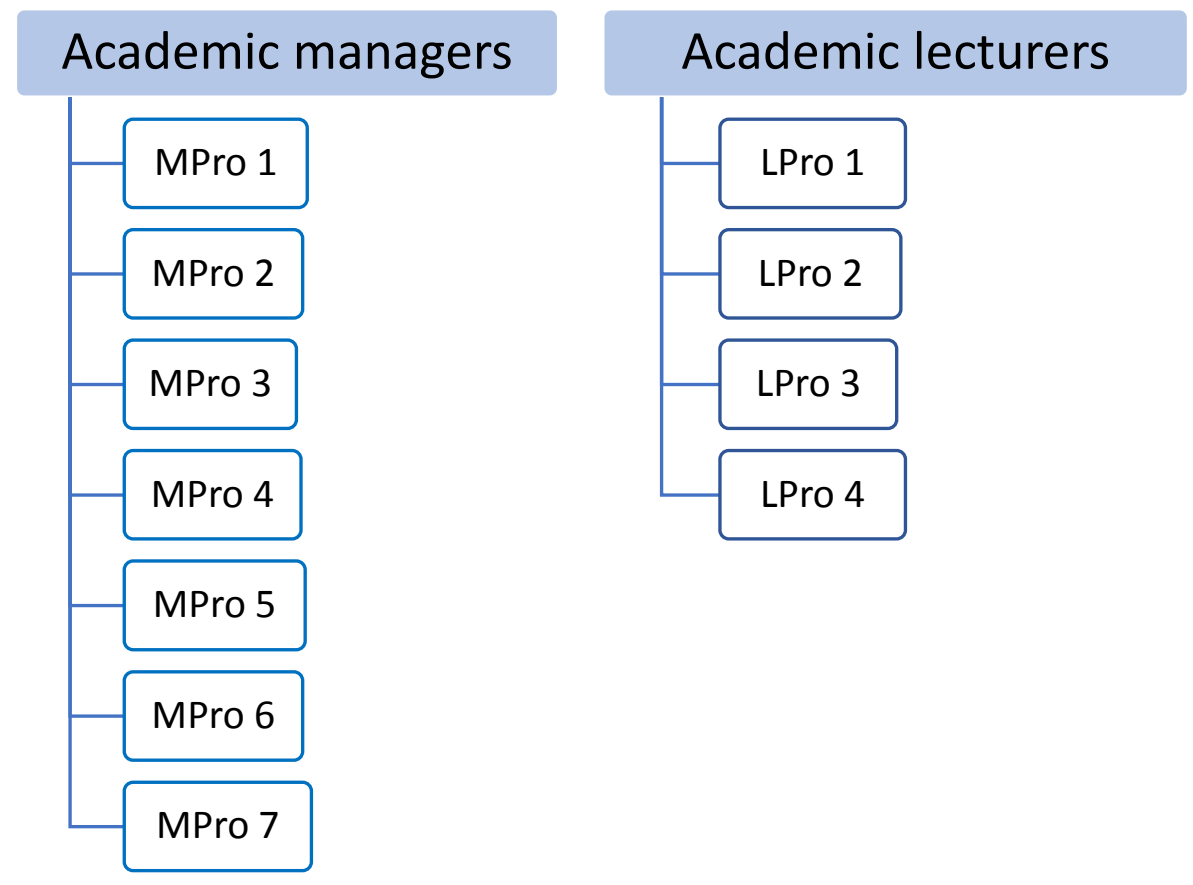

Figure 4-1. Case One's interview participants

Based on the conceptual framework for exploring the factors affecting Vietnamese academics' research capacity adapted from models of Bland et al. (2005), Chen et al. (2006), and Moore's (2015) as described in Chapter 3, the interview findings were analysed with the emerging factors including individual factors and institutional factors. These two factors appeared to be impacted by social contexts.

\subsubsection{Individual factors}

Some key individual factors impacting the academics' research engagement in Case One include their disciplinary knowledge, research experience, intrinsic and extrinsic 
motivation in research, foreign language competence, and research networks. The specific impacts of these elements on the academics' research engagement at Case One are presented in the following sections.

\section{Disciplinary knowledge}

The importance of good disciplinary knowledge is thought to help academics in their research activities. However, the participants' disciplinary knowledge seemed to be quite limited in terms of their qualification. There were only two PhD-degree participants who took part in some institutional and provincial research projects while other participants had recently completed their master's degrees. Thus, most participants were limited to concentrate on reading teaching materials to have a good understanding of their teaching subjects. There were two participants who expressed their disciplinary knowledge. One lecturer stated that:

I have not conducted any faculty or institutional research projects yet because I must focus on my MA course. And when I went back school for teaching, I had to concentrate on reading more materials to perform well my teaching subjects. (LPro 3)

Another lecturer said that:

So far I myself have not conducted any faculty and institutional level research projects. However, I have been reading quite a lot of research materials because I have just been assigned to teach two new subjects: university study skills and scientific research methods. (LPro 4)

In general, most academics in this institution were organised into disciplinary groups to design teaching materials for internal use in their faculties. This institution was in the process of developing its own teaching materials to reduce the use of other institutions' teaching materials and the employment of visiting lecturers.

In summary, Case One was considered to have a limited number of leading research academics and it was in the stage of strengthening its teaching staff and developing its training programmes. 
Research experience

The participants' research experience also seemed to be limited. The majority of the participants did not take part in research projects or become authors. However, there were some participants in research centres and in the Faculty of Agriculture and Natural Resources (A\&NR) who joined research projects funded by the TRIG Project. These participants were in the process of completing their projects for reporting and publishing in foreign journals, which was the TRIG Project's requirement. Moreover, many research projects conducted in this institution were only at institutional and provincial levels. One academic manager stated that:

As what I know about the TRIG project's requirement, now we have enough national publications but we have not yet achieved its required target because they required us to have 16 publications in foreign journals, but we have not completed yet. (MPro 1)

One lecturer stated that he had not ever been the author of any faculty or institutional research projects. He added that:

However, I supervised two students in writing their bachelor theses every year.

(LPro 2)

A lecturer of Economics stated that some of his colleagues in the faculty recently joined in provincial level research projects or were in the network with academics from big universities to implement research projects in other provinces. Nevertheless, this lecturer said that he had not taken part in any faculty or institutional research projects yet. Meanwhile, a lecturer of English reported that recently she had a presentation entitled An investigation into students' low interests in research activities and in conducting bachelor theses at the Department. She continued that:

Although it was not a faculty research project, I myself could have learned a lot of experiences in doing research, and of course it was very helpful for my new teaching subjects. (LPro 4)

Overall, it is possible to say that the academics' research experience in this institution was limited since there were very few leading, experienced research academics in this institution. Most research projects conducted by its academics were just at institutional and provincial levels. Moreover, most institutional research projects 
were related to improving teaching methods and developing training programmes. The majority of applied research projects were conducted at the Faculty of A\&NR.

\section{Intrinsic and extrinsic motivation}

It was found that despite limited research funding and complicated procedures to get research grants, the participants had intrinsic and extrinsic motivators to engage in research activities. First, many young academics in this institution engaged in research activities to improve their disciplinary knowledge for performing their teaching effectively. For instance, one young lecturer revealed that:

Although the research funding is quite limited - about 15 to 20 million VND (750 to $\$ 1000$ US) for a one-year length institutional research project, we still maintain our regular research activities such as supervising students' BA theses or collaborating with other colleagues to conduct research. (LPro 3)

This lecturer commented that with such a research grant, academics could not feel reasonably secure in research because research needed a lot of time and energy. Then, he suggested there should be an increase by three to five times the current amount of research grant so that academics would be more motivated to conduct research.

In the same manner, the lecturer of English would like to participate in research activities to supplement her teaching subject knowledge, motivate her students in research, and more importantly, for her to study abroad in the future. As she stated:

I would like to approach modern education systems in foreign countries and to learn what has been studied abroad. (LPro 4)

A senior academic manager commented that there were many barriers hindering academics being involved in research activities. This manager continued that:

I am sure that many of our colleagues, in their silent way of research, still want to do something to contribute to life and community. (MPro 7)

However, this manager stated that many academics in the institution seemed to have a low interest in research. By supporting his idea, he provided a figure: "there have been just ten research projects conducted by over 500 academic staff in the past 12 
years." He thought this indicated that a large number of academics ignored their research roles.

As seen above, like in most Vietnamese HEls, Case One had even more difficulties in official state-funded financial research and in attracting research funding from other national and foreign organisations. However, this institution was delighted to report that a few of its young and senior academics were greatly motivated in research to advance themselves and to contribute to the community. Moreover, there was an idea that a considerable number of academics in this institution lacked concern for their roles in scientific research.

\section{Confidence in research}

The survey findings about confidence in research (item C14 - C15) in Table 4-8 indicated that the majority of the respondents felt they had an understanding of research and confidence in research. In contrast, the interview results showed that the participants appeared to have little confidence in their own research. For example, one academic manager said that most research projects conducted in the institution were at the institutional level, not higher levels such as ministerial, and national. He added that:

It is possible to say that our institution's 12 -year-research activities were seen as an orientation to develop staff. In fact, to some extent, thanks to institutional research projects, some academics could be selected to study PhD courses in the country and abroad. (MPro 2)

To explain about the reasons for having a limited number of high level research projects conducted by its academics, academic managers from faculties of A\&NR, Economics \& Business Administration, and Culture \& Arts referred to the lack of leading research academics in their institution. For instance, one of these academic managers stated that:

We often fail to win the research projects funded by our provincial departments, not daring to mention to ministerial or national level research projects because we lack leading, experienced research academics. (MPro 2)

Similarly, another academic manager said that

Undergoing several provincial bidding competitions, I have recognised that we are often not selected to be the authors of provincial projects because we do not have leading research academics who have Professor or Associate Professor Doctorate holders as the chairpersons for research projects conducted by ourselves. (MPro 3) 
He added that they could not win research projects unless the local province gave them special priorities. In the same way, another academic manager said that:

In reality, the academics in this institution are not able to enter 'biển lớn' - meaning 'big ocean' in their research projects because we do not have enough well-known academics. (MPro 7)

This manager wanted to imply that the 'big ocean' was high level such as regional, ministerial, and national level research projects. On the whole, it seemed to be apparent that the academics' research experience at this institution was quite limited. For this reason, they were usually unsuccessful at winning research projects funded by provincial and national agents. The majority of research projects conducted were carried out within the institution. Therefore, it could be said that their research activities mainly relied on their limited institutional research funding.

\section{English language competence}

In addition to afore-mentioned institutional elements, English language barriers seemed to be a shortcoming for this institution's academics. A majority of academics had to selflearn foreign languages, especially the English language, to become qualified lecturers in the future. Moreover, some academics wished to develop their English language to follow higher study such as PhD courses in the country as well as abroad. It could be said that the Vietnamese National Foreign Language Project provided both good opportunities and challenges for the academics in this tertiary institution. For less experienced and recently completed MA course academics, this project would be considered as a supportive step for them to follow their respective careers. Nevertheless, it was also considerably stressful for senior academics in some faculties. As one participant explained:

It is apparent that foreign language competence, especially English language competence of the Vietnamese academics in general and academics here in this institution will improve a lot. This will create favourable conditions for them to selfstudy and approach the world's new knowledge, scientific and technological advancement, which strengthens their knowledge as well as betters their research and teaching competence. (MPro 1)

However, another academic manager had some concerns about unfavourable influences of this project on his faculty's senior academics, as he stated that: 
I consider that the NFL project, to some extent, has influenced considerably senior lecturers but it probably has positive impacts on junior lecturers such as having more good opportunities to improve their disciplinary knowledge and gaining scholarship to study abroad. (MPro 6)

Having the same concern as Participant MPro 6's, one young lecturer implied that the NFL project substantially stressed lecturers:

It now would be appropriate if we were in a favourable condition to study free or low-fee English courses organised in this university. Next, we should be provided better conditions of time and materials because right now our salaries are still low, and we feel insecure for our English study. (LPro 3)

Participant MPro 7 agreed that the NFL project added substantial pressure to academics. He acknowledged that it was vital to have this project for academics with low foreign language competence in doing research, and especially wanting to understand research materials written in foreign languages or wanting their studies translated was like 'thở bằng cái lổ mũi của người khác' (breathing by somebody else's nose).

To sum up, it appears that in addition to their limited research experience and capacity, the academics' foreign language competence at this institution was limited, so there was a very limited number of foreign cooperative research projects conducted in this university. Moreover, although the Vietnamese government planned to upgrade its university academics' quality and strengthen their research capacity by implementing the NFL Project, this project seemed to create a new pressure for this university's teaching staff.

\section{Research network}

The academics' domestic and foreign research networks in this institution were not considered to be strong. This could indicate why there were no ministerial or national level research projects conducted by its academics, except for some research projects funded by the TRIG project in recent times. Academics' research network being strong or weak depends on their institution's developmental strategy, policies and individual academics' reputation. There were possible reasons for the academics' weaknesses in research networks at this institution. 
First, due to being a newly established institution, Case One was making great efforts to develop its training programmes and developing staff's teaching competence. This would be a short-term developmental strategy, and it would probably shift to focus on its research capacity in the future. Secondly, in the initial phase of its developmental operation, there was a limited number of leading, and experienced research academics. Therefore, it was hard for this institution to create strong research networks or develop new research links. For this reason, its academics accessed limited research networks. Thirdly, it was found that there were just some qualified academics of agriculture who had their own research links since they had worked for a famous regional university. For instance, one participant revealed that:

Most academics in the Faculty of A\&NR come from the regional university which currently has many research projects related to agricultural engineering and aquaculture. Due to this good research network, they can cooperate with the academics from this university to conduct provincial research projects. (LPro 3)

In conclusion, the academics in Case One had limited research networks due to priorities in its recent developmental strategy, not yet being recognised as a prominent university in the region, and having very limited leading, experienced research academics. For these reasons, it seems to be apparent that academics' research capacity at this institution was quite limited.

\section{Summary of individual factors}

It is possible to conclude that there seemed to be numerous individual factors that were found to negatively impact the academics' research engagement in Case One. These included the academics' limitations in disciplinary knowledge, research experience, confidence in research, English language competence, and research networks. However, the academics in this institution still had strong internal motivation to engage in research. For instance, despite many financial difficulties, they had a good attitude towards self-studying in order to improve their disciplinary knowledge, and build research experience in the hope of contributing achievements to their university, life, and community. 


\subsubsection{Institutional factors}

In addition to the factors affecting individual academics, institutional factors may have an impact on their research involvement. In this case, the institutional factors affecting academics' research engagement included institutional policies, funding and structure, resources, teaching loads, leadership, and the research environment.

\section{Institutional policies}

In line with the trend to refresh Vietnamese HEls in order to improve regional and international integration effectively, raised by the Vietnamese Government and Ministry of Education and Training (MOET), Case One had supplemented and perfected its institutional policies to improve its research capacity in recent times. Specifically, it promulgated some regulations such as the internal expense regulations in the year 2014, tasks in the academic year 2014, and its developmental strategy in the period 2011-2020 and vision until 2030, which were much related to academics' PD and research activities.

However, the payment for institutional research projects, according to this provincial institution's internal expense regulation 2014 (Case One, 2014b), is still unchanged in comparison with the amended internal expense regulation $2012^{5}$. Table 4-11 shows the research payment for its academics. The internal expense regulation 2014 had not updated the exchange from standard research hours to standard teaching hours. It did not have a specific convertible table for teaching and research hours if academics had conducted their higher level research projects or had their papers published in national and foreign journals. It also did not provide a clear instruction on how many hours of research are needed to be done by individual academics with different degrees. A new thing that could be found in this document is to have an increase in payment for teaching hours for all academics in terms of their qualifications and seniority at work. For instance, lecturers with a salary code plus management position allowance (2.34 - 3.33) in 2012 were paid 60,000 VND (equivalent to \$3 USD), and in 2014 they were paid 75,000 VND. However, the teaching payment for lecturers

\footnotetext{
${ }^{5}$ Case One's amended internal expense regulation 2012
} 
done before the year 2014 generally relied on an academic's salary code and management position allowance, not on their academic degrees. The form of payment was a barrier to encouraging academics to upgrade their qualifications and to engage in research activities.

Table 4-11. Case One's comparison of research payment in 2007-2014

\begin{tabular}{|c|c|c|c|c|c|c|c|c|c|}
\hline \multicolumn{2}{|c|}{$\begin{array}{l}\text { Internal Expense } \\
\text { Regulation } 2007\end{array}$} & \multicolumn{4}{|c|}{$\begin{array}{c}\text { Amended Internal Expense } \\
\text { Regulation } 2012\end{array}$} & \multicolumn{4}{|c|}{$\begin{array}{l}\text { Internal Expense } \\
\text { Regulation } 2014\end{array}$} \\
\hline $\begin{array}{c}\text { Faculty } \\
\text { level } \\
\text { Project }\end{array}$ & $\begin{array}{l}\text { Institutional } \\
\text { level Project }\end{array}$ & $\begin{array}{c}\text { Faculty } \\
\text { level } \\
\text { Project }\end{array}$ & \multicolumn{3}{|c|}{$\begin{array}{l}\text { Institutional level } \\
\text { Project }\end{array}$} & $\begin{array}{c}\text { Faculty } \\
\text { level } \\
\text { Project }\end{array}$ & \multicolumn{3}{|c|}{$\begin{array}{l}\text { Institutional level } \\
\text { Project }\end{array}$} \\
\hline \multirow[t]{4}{*}{10} & \multirow[t]{4}{*}{20} & \multirow[t]{4}{*}{10} & & 30 & & \multirow[t]{4}{*}{10} & \multirow{2}{*}{\multicolumn{3}{|c|}{$\begin{array}{c}30 \\
\text { Ranked Type }\end{array}$}} \\
\hline & & & \multicolumn{3}{|c|}{ Ranked Type } & & & & \\
\hline & & & $A$ & $B$ & $\mathrm{C}$ & & $A$ & B & $\mathrm{C}$ \\
\hline & & & 30 & 28 & 25 & & 30 & 28 & 25 \\
\hline
\end{tabular}

In summary, Case One was in the phase of perfecting its document policies at the time of this research. It started to introduce some documents related to its future development strategy. However, most changes in these policies concentrated on teaching payments, not on research payments. It did not have specific reward policies although it did encourage academics to participate into research activities as mentioned in its academic tasks in 2013-2014. It was documented in this institutional plan that academics were encouraged to conduct provincial, and ministerial level research projects, and participate in cooperative research projects. The institution continued to amend and supplement previously issued documents related to research activities in order to create favourable conditions for academics to engage in research. Research would soon be considered as a criterion for evaluating academics' capacity (Case One, 2013). For these reasons, it could be implied that Case One's research capacity was still limited.

\section{Funding and structure}

Research funding is a vital element contributing to a university's research strength. However, the finding seemed to indicate that this institution's research funding was 
limited, and procedures to get research grants was problematic. It seemed apparent that this institution relied on its own institutional research funding. Based on the Vietnamese Government Decree 43/2006, Vietnamese HEls have to allocate 4 million VND per annum (equivalent to 200 USD) for each academic to undertake his or her own research (Vietnam Government, 2006). Therefore, the local government annually provided the research funding for the institution with the approximate amount of 3 billion VND because the total number of staff was 765 (see Table 4-1). This institution seemed not to have any other sources of research funding because the finding indicated that for nearly 15 years of operating as a university, it did not have any provincial, ministerial, and national level research projects. There were just eight completed local research projects, and five projects funded by TRIG Project. As seen from Table 4-12, there were 78 institutional research projects conducted from 2006 to 2011, which meant Case One spent around 1.5 billion $\mathrm{VND}^{6}$ - half of the annual research funding provided.

Table 4-12. Case One's research funding spent in 2006-2011 ${ }^{7}$

\begin{tabular}{|l|c|c|c|c|c|c|c|}
\hline \multicolumn{1}{|c|}{$\begin{array}{l}\text { Year } \\
\text { Budget }\end{array}$} & $\mathbf{2 0 0 6}$ & $\mathbf{2 0 0 7}$ & $\mathbf{2 0 0 8}$ & $\mathbf{2 0 0 9}$ & $\mathbf{2 0 1 0}$ & $\mathbf{2 0 1 1}$ & $\begin{array}{c}\text { Total } \\
\text { Spending }\end{array}$ \\
\hline $\begin{array}{l}\text { Expected budget } \\
\text { for research }\end{array}$ & $\mathbf{3}$ & $\mathbf{3}$ & $\mathbf{3}$ & $\mathbf{3}$ & $\mathbf{3}$ & $\mathbf{3}$ & $\mathbf{1 8}$ \\
\hline Real Spending & $\begin{array}{l}78 \text { research projects X } 30 \text { million VND/1 research project = } \\
\text { 2.34 billion VND. On average, annual research spending was } \\
\text { 0.39 billion VND }\end{array}$ & 2.34 \\
\hline
\end{tabular}

This finding indicates that this institution did not effectively use its research funding in recent years. However, surprisingly, a majority of participants (both academics and academic managers) commented that they felt unhappy with ways to access research grants, and to get research payment for their finished projects. For example, one academic manager participant admitted that:

One reason that causes academics not to actively engage in research activities is the grant for a research project is limited (30 million VND/a project). In addition, the complicated financial procedures to pay for researchers may make them disappointed. (MPro 1)

\footnotetext{
${ }^{6}$ Each institutional research project is granted with 30 million VND. 78 research projects $\times 30$ million VND $=2.34$ billion VND

${ }^{7}$ Case One's report on the management of scientific research activities
} 
Another academic manager considered that there should be a change in the approach for the financial research allocation. He suggested that:

There is only 30 million VND funded for a project. How can academics want to conduct such a research project? If conducting research due to their duties, they may implement a project with that amount of money, but surely with a low quality project. (MPro 2)

Sharing the idea of MPro 2, LPro 2 suggested that the grant for a yearly institutional research project should be increased by four or five times.

Related to procedures for getting research grants, the result from Table 4-8 indicated that 32 out of 37 respondents strongly agreed that the procedures were complicated and time consuming. MPro 7 commented that it was strange that researchers had to buy expense receipts to give to the Office of Finance to indicate that they had conducted research. He questioned how academics had to do 'such strange things'. Similarly, MPro 5 expressed that although he often conducted research projects, and often worked with the staff in the Office of Finance, he still felt disappointed about how they operated. He believed that other academics who started conducting research would also feel disappointed. He commented that:

We are academic researchers. We feel heavy headed with our research work. It would be appropriate for them to give us specific guidance about the procedures, but in practice they often have a negative attitude to create more difficulties for us. (MPro 5)

To summarise, Case One had limited research funding as it relied on its own institutional research funding. There were no other financial sources. It seemed difficult for academics to gain research grants and receive reasonable research payments. The finding showed that annually it did not use up all its research funding. This could be because the institution made use of such research funding for other institutional activities such as to upgrade its teaching facilities and improve training programmes.

\section{Resources}

Research resources in this institution were believed to be limited. Thanks to the TRIG Project (2008-2012), laboratories for the Faculties of Education and Agriculture and Natural Resources were built and other research equipment was provided. However, 
identifying the important role of the library to teaching and research activities, the institution's leading board made efforts to build its 'E-Library', a network of computers connected with the Internet. It was seen as the second university in the region to have a modern library. Nevertheless, some participants considered that this e-library did not provide enough research books and materials for its academics to research. For instance, MPr 7 stated that although the library annually bought books according to its purchase plan, and necessary books for research could not be found in the library. Related to research facilities, the survey result shows that 33 out of 37 respondents agreed that their institution had few research facilities (see Table 4-8).

In conclusion, it is apparent that sufficient research facilities greatly contribute to a university's research strength. Yet, Case One's research resources were quite limited. Therefore, it is doubtless that the shortage of research resources had a negative impact on its research capacity.

\section{Teaching loads}

Teaching loads was seen as a negative factor for the institution's research capacity. In general, Case One's academics had heavy teaching loads. They not only taught regular classes at university but also classes of continuing education - namely in a work and study (part time) form. Many academics agreed to have more teaching hours to increase their income and to replace their compulsory research hours. The MOET's regulation $64 / 2008$ on university academics working time states that academics have to fulfil their standard teaching and research hours in an academic year. Their research hours equal half of their teaching hours. This document also mentions that if academics do not conduct research, they have to do extra teaching to substitute for their research hours. It means that lecturers must teach for an extra 140 hours if they have no research project in that year. Table 4-13 shows academics' standard work hours in a year. 
Table 4-13. Vietnamese HE academics' workload framework

\begin{tabular}{|l|c|c|}
\hline \multicolumn{1}{|c|}{ Lecturers' Titles } & \multicolumn{2}{|c|}{ Framework for standard teaching hours } \\
\hline & $\begin{array}{c}\text { General requirement } \\
\text { for all disciplines }\end{array}$ & $\begin{array}{c}\text { Physical Education and } \\
\text { National Defence \& Security } \\
\text { for non-majoring institutions }\end{array}$ \\
\hline Professors \& Advanced Lecturers & 360 & 500 \\
\hline $\begin{array}{l}\text { Associate Professors \& Senior } \\
\text { Lecturers }\end{array}$ & 320 & 460 \\
\hline Lecturers & 280 & 420 \\
\hline
\end{tabular}

(Vietnam Ministry of Education and Training, 2008b)

In this institution, a large number of academics had heavy teaching loads. A very small number of academics engaged in research. Most participants thought that it would be simpler and more comfortable to perform extra teaching hours than to conduct research because when conducting research, they faced lots of difficulties such as low research income, hard to gain research grants, complicated procedures for receiving research payment, and lack of research facilities.

Another reason for their heavy teaching load was their institution's development strategy for the previous 10 years. It seemed that this university had more of a focus on expanding its scope for training than on research activities. For instance, in the first academic year of 2000-2001, it had only five university-level disciplinary training programmes, but presently it had 29 regular university-level disciplinary and 12 collegelevel disciplinary training programmes ${ }^{8}$. Additionally, it had eight university-level disciplinary training programmes and four master-level disciplinary cooperation training programmes. Therefore, academics had to perform more teaching hours than before to increase their income, so they had limited time for research and this seemed to impact on their research motivation.

To sum up, academics' heavy teaching loads in Case One negatively affected both their research engagement and the institution's research capacity. Reasons for their heavy teaching loads came from the view that earning money from teaching was easier than from research. In addition, some barriers such as unavailable research grants, insufficient research facilities, and complex research payment procedures hindered

${ }^{8}$ Case One's development strategy in the period 2011-2020, and its vision towards 2030 (a draft version) 
them from engaging in research. To some extent, it seemed that they agreed to have more teaching hours than usual in order to meet their personal income needs and their institution's short-term developmental strategy.

\section{Leadership}

According to the participants, leadership was seen as another negative impact on their research engagement. They said that faculty leaders should be qualified, knowledgeable, experienced, active, and exemplary in research so that the leaders could give helpful advice and have a strong voice in encouraging their academics in research. In practice, many faculty leaders in this institution were not qualified according to the Charter of Vietnamese HEls issued on $22 / 09 / 2010$. The document states that faculty Deans and department Heads at universities must be PhD holders who are respected and experienced in teaching, research and management (Vietnam Government, 2010a). For example, one participant commented that:

The Faculty of A\&NR is stronger in research than other faculties because it had qualified leaders and many doctorate degree academics graduating from foreign universities. Our faculty does not have such conditions. (LPro 2)

At a higher leadership level, MPro 2 considered that the advisory function for the institution's research strategy was not good, although the institution had the Scientific Committee and the Office of Research Management and International Relations. He stated that his institution really lacked a force who could scrutinise research problems. Similarly, MPro 3 considered that this office only performed well in its affairs of international relations and administrative management. He said that:

The Office of Research Management \& International Relation needs a person who is experienced in research. This will help the office work better. (MPro 3)

To sum up, in the previous short-term developmental strategy, Case One's leading management board focused on expanding its training programmes and encouraged its academics to be responsible for extra teaching hours. As a result, its recent research capacity was quite limited. Moreover, for some participants, their faculty leaders and head of the Research Management and International Relation Office were still not qualified in terms of their academics' titles and research experience. This did not, to some extent, motivate academics to engage in research. Therefore, for leadership to 
enhance its research capacity, its leaders needed to pay attention to the aforementioned issues.

\section{Research environment}

The research environment in this university was not considered to be positive for involving its academics in research. There were several causes. First, as afore-mentioned, it did not have many qualified, leading, and experienced academics in research. Thus, it rarely won any important provincial, ministerial, or national research projects. It seemed that the provincial authority gave this institution some priorities to conduct provincial research projects. In addition, due to a very small number of experienced research academics, it had not been able to attract private and state enterprises to invest in its research activities in recent years. This greatly weakened its research networks.

Secondly, it appeared that the local authority had little confidence in its academics' research capacity. Therefore, the officials in charge of scientific research affairs in this province mostly invited academics from other major universities to conduct its important provincial socioeconomic development research projects. For this reason, this university's research funding seemed to be very limited.

Thirdly, due to limited finance and networks in research, it seemed that academics had no choice but to accept heavy teaching loads instead of research. As a result, they had very little time for research and their research competence, by nature, was not strong; in fact, it became weaker.

Furthermore, this institution had organised very few workshops and conferences related to research development activities in recent years. It did not create good opportunities for its academics to participate in related research conferences held in other institutions so that they could improve their research competence. This issue was shared by one participant:

The university has not given financial support for academics to take part in conferences organised in other universities for two recent years. Academics have to use their own money to attend such conferences. By such doing, the university has reduced opportunities for academics to address new research ideas. (LPro 2) 
To sum up, like other institutional factors, the research environment in this institution was in fact not good for its academics to engage in research. This was caused by unfavourable conditions in relation to the number of qualified academics, research networks, and research finance.

\section{Summary of institutional factors}

The study findings show that several institutional factors had negatively impacted the academics' research engagement at this university. It was noted that elements such as not updating institutional policies, limited leadership, inexperienced research workforce, limited financial research and research links, complicated research payment procedures, and heavy teaching loads were major institutional factors that possibly weakened its academics' research capacity. Therefore, to enhance its research capacity, there should be positive changes towards such institutional factors.

\subsection{Chapter summary}

Some key findings from Case One suggest that this institution was considered weak in research capacity due to the following reasons. Firstly, as Case One was developed from a teacher training college, in its initial phase of working as a university, it was making efforts to survive in a new competitive environment of the Vietnamese HE context. It focused mainly on developing and expanding cooperative training programmes. This institution put emphasis on developing its teaching staff to qualify for lots of training programmes. In other words, between the two main tasks of a university - research and teaching - Case One only had dominant teaching performance. Secondly, this institution did not have many qualified academics with good research experience and practice. Thirdly, it had limited research funding and research networks. As a HEI under the provincial level management, it hardly received research funding from the central government and related ministries. Due to the lack of well-known, leading research academics, it was hard to attract research finance from other domestic and foreign organisations.

The research environment was not good enough for its academics to engage in research although they were motivated towards research activities. For instance, this 
institution had very few leading, experienced researchers, limited research facilities and research funding, and complicated research payment procedures. Additionally, few conferences related to research development activities were organised in the institution, and academics received restricted financial support to attend conferences held in other institutions. Therefore, the academics accepted extra teaching loads to substitute their compulsory research hours, resulting in a deterioration in their research competence. In summary, those afore-mentioned causes actually hindered this institution's research capacity as well as its academics' research engagement. 



\section{CHAPTER 5. FINDINGS: CASE TWO}

\subsection{Chapter overview}

Case Two was seen as the largest public multidisciplinary HEI in the southwest of Vietnam. This institution was known as one of the strongest Vietnamese HEls in the domain of agricultural science. It was ranked at the third position in the Universities Web Ranking in Vietnam (4International Colleges \& Universities, 2013).

In this chapter, the first section presents an overview of this case study. The second section presents the findings of document analysis. The third section describes the survey results, which is followed by the fourth section that presents the interview results. This chapter ends with the chapter summary.

\subsection{Case Two's documentary analysis results}

The documents collected for analysing in this case also included two different level documents: national and institutional. The national documents collected in Case One were also used to analyse this case. The institutional documents collected for analysis in Case Two included its website, its five-year report on scientific and technological activities (2006-2010), its five-year plan (2011-2015) for building orientation and strategies for scientific and technological activities, and some relevant research-related documents. The aim of the documentary analysis was to gain an insight of this institution's academic staff and research strategies and orientations.

\subsubsection{Case Two' s academic staff}

Case Two's 2014 report on its academic staff documented that this institution had 1,206 academic lecturers and out of a total of 1,908 staff, including 7 Professors, 79 Associate Professors, 199 doctoral degree holders, 687 master degree holders, and 234 bachelor 
degrees $^{9}$. Based on Vietnam Education Law 2012 and Vietnam University Charter 2010, $80.59 \%(972 / 1206)$ of the academics in this regional institution are qualified.

Its strategy for human resources development is clearly stated in its mission and vision. For instance, by the year 2020 , this institution targets to achieve between $50 \%$ and $60 \%$ of academics with PhD degrees and they will be fluent in a foreign language, preferably English (Case Two, 2014e). It can be said that it will not be difficult for this institution to reach this objective because from now until 2020 , nearly 1,000 nondoctoral degree holders will get their PhD degrees thanks to current national projects for sending academics to study abroad. Additionally, this institution aims to reach from $30 \%$ to $40 \%$ of teaching staff who will publish their papers in international peer reviewed journals to show its proactivity in the process of international HE integration.

\subsubsection{Case Two's evaluation of research activities in $2006-2010$}

The evaluation of research activities in the five years 2006-2010 was based on its objectives (improving training quality and academics' research ability; implementing to conduct key projects the development of the institution, the region, and the country; expanding research cooperation with other institutions and enterprises; and developing publications, technology transfer and protecting intellectual property) ${ }^{10}$ and the number of research projects conducted. The figures for research projects, journal papers, and conference papers were illustrated in Table 5-1.

Table 5-1. Case Two's publications in the period 2006-2010

\begin{tabular}{|c|c|c|c|c|c|c|c|}
\hline \multicolumn{3}{|c|}{ Projects } & \multicolumn{2}{c|}{ Journal papers } & \multicolumn{2}{c|}{ Conference papers } & Institutional \\
Papers \\
\begin{tabular}{c|c|c|c|c|c|} 
Insti. \\
level
\end{tabular} & $\begin{array}{c}\text { Minis. } \\
\text { level }\end{array}$ & Intl.level & National & Foreign & National & Foreign & 534 \\
\hline 394 & 229 & 30 & 332 & 56 & 65 & 3 & \\
\hline
\end{tabular}

\footnotetext{
${ }^{9}$ Case Two's fiscal report 2014

${ }^{10}$ Case Two's Summary Report: Evaluation of S\&T activities in the period 2006-2010, and building and orienting the S\&T plan in the period 2011-2015
} 
The report documented that:

First, the achievement results that were gained comparatively responded to the plan. The number of national, ministerial-level, and provincial-level projects performed was higher than the planned number (342/285). Secondly, there were more conducted research projects after issuing five internal documents related to research operation. (Case Two, 2011, p. 9)

However, it also reported that few ministerial-level research projects were chaired by doctoral-degree academics under the age of 45 whereas most institutional-level projects were conducted by academics under the age of 45 . This was because the institution did not prioritise doctoral-degree academics conducting institutional-level research projects. It can be hard for young academics and academics who are MA holders to be chosen to be a chairperson of provincial, ministerial or national research projects. Due to the institution's prestige, before submitting individuals' research proposals to the outside selection committee, the institution's selection board first reviews its academics' research proposals. Moreover, the selection board in the higher level management appears to first review the scientific curriculum vitae of the chairperson of the research projects before reviewing other issues and checking against the criteria of the research projects. For these reasons, this institution selected the research projects chaired by $\mathrm{PhD}$ degree academics.

It was possible that Case Two's research management board wanted its young and master degree academics first to become familiar with the environment and procedure of research activities at the institution before they entered more competitive research environments. However, by doing so, it partly limited individuals' research freedom and hindered young academics' creativity in research activities. Sometimes it is necessary for individuals to be flexible, creative, and independent in scientific research and make decisions for their own research activities. Rather, there needs to be a balance between institutional organisation's management decisions and individuals' decisions.

The report remarked that there were still several difficulties in organising institutional research activities:

First, few research projects on the domain of agriculture and fishery were not completed in the planned time due to objective factors such as environment, and 
climate. Second, some authors of projects were still less strong in their presentation skills. Third, many institutional-level projects were not allowed to be conducted due to lacking funds. Next, the payment procedure and income of research did not sufficiently attract academics to engage in research. Lastly, the support for research affairs from faculties was also limited. (Case Two, 2011, p. 13)

The report showed a range of both objective and subjective factors which may influence the institution's research activities. Objective factors such as environment and climate affected the completion of research projects in applied engineering whereas some individuals' shortcomings, such as their ineffective presentation skills, limited their projects being approved by the examination board of higher level management. In addition, it was reported that institutional factors, including limited research funds, complicated research payment procedures, unattractive research wages, and less effective research support from faculties greatly hindered academics' research engagement in this institution. This report seemed to provide a means for the leaders of this institution to review their strengths and weaknesses in research activities, and make a specific plan for strategic research development of their institution.

\subsubsection{Case Two's plan of S\&T activities in 2011-2015}

According to this institution's mission and vision, S\&T activities in the 2011-2015 phase were to focus on training, conducting scientific research, and transferring technology to advance the socioeconomic development for the region. As stated in its strategic vision to 2020 , the institution would not only become the best university in Vietnam but also be recognised as one of the leading HEls in education, research, and development throughout the Asia-Pacific region. The message of its vision stated that it would expand human knowledge and benefit society through its research, teaching and strategic partnerships, and importantly the institution would develop within the framework of global integration and mutual cooperation. Noticeably, one of the five goals of this institution was to be in the top 250 universities in the Asia-Pacific region by the year 2020 (Case Two, 2014e).

The above information indicates that Case Two desired to be highly integrated into the global HE. Maybe, recognised as a premier university in the Mekong Delta region of Vietnam, this institution was nationally selected to be one of 16 key universities in 
Vietnam (out of $400 \mathrm{HEls}$ across the nation) by the MOET (Toan, 2013). Recently, with an aim for regional and international integration for the HE system, the Government of Vietnam made a big investment in its tertiary education system, especially in Vietnam's key universities. Therefore, this institution received a big investment for its development strategy.

\section{Summary of the documentary analysis}

It could be concluded from the documentary analysis that Case Two was a Vietnamese $\mathrm{HEl}$ strong in research and training due to its current highly qualified staff. It also had a specific long-term strategy for its human resources development. In addition to its focus on human resources development, Case Two planned its relevant mission and vision for research development in the age of regional and global integration of the HE system. Last but not least, one of its benefits was to receive considerable investment from the Government as one of the key national universities of Vietnam. Therefore, based on its research documents, its mission and vision, it was identified that Case Two's research activities were active and strong.

\subsection{Case Two's survey results}

The survey findings of Case Two were collected from 15 participants (12 PhD degree holders and 3 MA degree holders). Similarly, the survey findings in this case were grouped into six categories: academics' research perceptions; positive factors impacting academics' research engagement; negative factors impacting academics' research engagement; academics' satisfaction with PD activities organised by institution; academics' satisfaction with PD activities organised by faculty; academics' regular PD activities. The following section discusses in further detail these six categories.

\subsubsection{Research perceptions}

This section of the survey had seven items designed to explore the participants' level of agreement. Table 5-2 illustrates the research perceptions of the participants in Case Two. Overall, most participants in Case Two agreed with the first two items of the survey (A1: research perceived as a process of discovering, uncovering or creating understandable 
meanings, and A2: research perceived as the creation of new knowledge and innovative approaches to the discovery of that knowledge). However, some participants disagreed with statements $A 3$ to $A 7$. For instance, seven of sixteen participants replied disagree and strongly disagree with item A7 (research perceived as a way to fulfil academics' requirements), and five participants did not agree with item A4 (research perceived as the process of data collection, data analysis, then reporting its research findings). Specifically, two participants with an MA degree responded 'disagree and strongly disagree' with item A3 (research helped to develop one's personal knowledge and research methods). Perhaps, these two participants did not engage in as much research as other participants (PhD holders), so it seemed that the two academics did not recognise the benefits of research involvement for developing researchers' disciplinary knowledge and research methods.

Table 5-2. Case Two's results of academics' research perceptions

\begin{tabular}{|c|c|c|c|c|c|c|c|}
\hline \multirow[t]{2}{*}{ Item list } & \multirow[b]{2}{*}{ 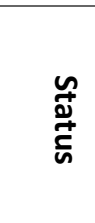 } & \multicolumn{5}{|c|}{ Scale of agreement } & \multirow{2}{*}{ 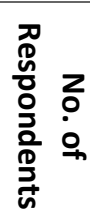 } \\
\hline & & SD & $\mathrm{D}$ & $\mathrm{N}$ & $A$ & SA & \\
\hline \multirow{3}{*}{$\begin{array}{l}\text { A1. Research perceived as a process of discovering, } \\
\text { uncovering or creating understandable meanings }\end{array}$} & $M$ & & & 1 & 2 & 8 & \\
\hline & $\mathrm{L}$ & & 1 & 1 & 2 & & \\
\hline & total & 0 & 1 & 2 & 4 & 8 & 15 \\
\hline \multirow{3}{*}{$\begin{array}{l}\text { A2. Research perceived as the creation of new } \\
\text { knowledge and innovative approaches to the } \\
\text { discovery of that knowledge }\end{array}$} & $M$ & & & 1 & 2 & 8 & \\
\hline & $\mathrm{L}$ & & 1 & & 3 & & \\
\hline & total & 0 & 1 & 1 & 5 & 8 & 15 \\
\hline \multirow{3}{*}{$\begin{array}{l}\text { A3. Research helped to develop one's personal } \\
\text { knowledge and research methods }\end{array}$} & $\mathrm{M}$ & & & & 5 & 6 & \\
\hline & $\mathrm{L}$ & 1 & 1 & 1 & & 1 & \\
\hline & total & 1 & 1 & 1 & 5 & 7 & 15 \\
\hline \multirow{3}{*}{$\begin{array}{l}\text { A4. Research perceived as the process of data } \\
\text { collection, data analysis, then reporting its } \\
\text { research findings }\end{array}$} & $M$ & & 3 & 2 & 5 & 1 & \\
\hline & $\mathrm{L}$ & & 1 & 1 & 1 & & \\
\hline & total & 0 & 4 & 3 & 6 & 1 & 14 \\
\hline \multirow{3}{*}{$\begin{array}{l}\text { A5. Research means presenting new ways of } \\
\text { seeing the world, oneself or a problem }\end{array}$} & $M$ & 1 & 1 & 2 & 5 & 2 & \\
\hline & L & & & 1 & 3 & & \\
\hline & total & 1 & 1 & 3 & 8 & 2 & 15 \\
\hline \multirow{3}{*}{$\begin{array}{l}\text { A6. Research perceived as establishing oneself in } \\
\text { the field, and developing oneself personally }\end{array}$} & $M$ & 1 & 2 & 1 & 4 & 3 & \\
\hline & $\mathrm{L}$ & 1 & 1 & & 1 & 1 & \\
\hline & total & 2 & 3 & 1 & 5 & 4 & 15 \\
\hline \multirow{3}{*}{$\begin{array}{l}\text { A7. Research perceived as a way to fulfil } \\
\text { academics' requirements }\end{array}$} & $\mathrm{M}$ & 1 & 3 & 4 & 1 & 2 & \\
\hline & $\mathrm{L}$ & 1 & 2 & 1 & & & \\
\hline & total & 2 & 5 & 5 & 1 & 2 & 14 \\
\hline \multicolumn{8}{|c|}{$\begin{array}{l}\text { Notes: - SD (strongly disagree), D (disagree), N (neither agree nor disagree), A (agree), and SA } \\
\text { (strongly agree) }\end{array}$} \\
\hline
\end{tabular}


For item A4 (research perceived as the process of data collection, data analysis, then reporting its research findings), the number of participants who did not agree with it was nearly equal to the number of participants who agreed. This finding seemed to be reasonable because the participants came from different disciplines of engineering, applied sciences, and basic sciences. Thus, they may have different research processes in their studies. The result of item A6 (Research perceived as establishing oneself in the field, and developing oneself personally) seemed to illustrate that more participants in this institution wished to engage in research to develop themselves and even establish themselves in the field. Interestingly, four participants (1 MA, $2 \mathrm{PhD}$, and 1 Ass Prof) who did not agree with item A6 were from applied agricultural science and engineering whereas all participants from domains of social sciences and education agreed with this item. This finding may reveal that academic researchers in the domain of social sciences have the tendency to have a broader perspective than academic researchers in applied engineering domains. In reality, research projects in applied sciences are able to be subdivided into branches of study. Therefore, many academic researchers in applied sciences can cooperate to study together for one 'mother' project. Yet, it seemed to be rare for basic and theoretical researchers.

Engagement in research was officially a compulsory task for Vietnamese university academics. However, related to item A7 (research perceived as a way to fulfil academics' requirement), there were seven participants who replied disagree and strongly disagree, and four participants who replied neither agree nor disagree. Perhaps, these participants might think that this policy was not strictly applied in this university. Therefore, many university academics seemed to choose more teaching hours in an academic year for the replacement of their required standard research hours. For instance, if university academics with a salary code $(2.34-3.00)$ did not have any research projects in an academic year, they had to teach 60 hours in that academic year on top of their standard teaching time of 220 hours. Depending on their salary code, degree, and title, university academics had to perform their teaching hours to replace their standard research hours equivalently. Table 5-3 shows the convertible teaching hours and research hours in Case Two. 
Table 5-3. Case Two's convertible table of teaching and research time

\begin{tabular}{|c|l|c|c|c|}
\hline No. & \multicolumn{1}{|c|}{ Academics' titles and degrees } & $\begin{array}{c}\text { Standard } \\
\text { teaching } \\
\text { hours }\end{array}$ & $\begin{array}{c}\text { Standard } \\
\text { research } \\
\text { hours }\end{array}$ & $\begin{array}{c}\text { Total hours } \\
\text { of in charge }\end{array}$ \\
\hline 1 & Professor, Advanced Lecturer & 340 & 170 & 510 \\
\hline 2 & Associate Professor & 320 & 140 & 460 \\
\hline 3 & Senior lecturers with a salary code $\geq 5.76$ & 310 & 130 & 440 \\
\hline 4 & $\begin{array}{l}\text { Senior lecturers with a salary code (4.40- } \\
5.42) \text { and lecturers with a doctoral degree }\end{array}$ & 300 & 120 & 420 \\
\hline 5 & Lecturers with a salary code ( $\geq 4.32)$ & 280 & 100 & 380 \\
\hline 6 & $\begin{array}{l}\text { Lecturers with a salary code (3.33-3.99) and } \\
\text { lecturers with MA degrees }\end{array}$ & 250 & 80 & 330 \\
\hline 7 & Lecturers with a salary code (2.34-3.00) & 220 & 60 & 280 \\
\hline 8 & $\begin{array}{l}\text { Probationary lecturers (receive 85\% of the } \\
\text { starting point salary) }\end{array}$ & 50 & 10 & 60 \\
\hline
\end{tabular}

(Case Two, 2010)

In addition to the closed part, the open-part of this questionnaire section was received from five questionnaire respondents. There were two perceptions that had similar meanings with items A6 (Research perceived as establishing oneself in the field, and developing oneself personally) and A7 (Research perceived as a way to fulfil academics' requirements). The three new perceptions of research provided by the participants were as follows:

Perception 1: Scientific research is conducted to solve problems arising in practical life. (QRespt 1)

Perception 2: Scientific research is conducted to develop science and community. (QRespt 2)

Perception 3: Doing scientific research to add into the improvement of undergraduate and postgraduate training courses. (QRespt 3)

Perception 1 and Perception 2 provided a general scientific significance of research toward community life while Perception 3 gave a practical significance of research toward the university training duty. The participant who provided perception 3 seemed to emphasise the importance of the teaching-research link at the university.

In conclusion, most questionnaire participants agreed with seven research perceptions listed in this questionnaire section. However, a few of the participants showed their disagreement with 'research perceived as process' (item A4), 'research 
perceived as establishing oneself in the field, and developing oneself personally' (item A6), and 'research perceived as a way to fulfil academics' requirements' (item A7) because the participants in Case Two came from both the domain of engineering, applied sciences and social sciences considered as theoretical sciences. Particularly, one participant provided his/her research perception by emphasising the important link between research and training at university.

\subsubsection{Positive factors impacting academics' research engagement}

The data for factors that have positive impacts on academics' research engagement are shown in Table 5-4.

Table 5-4. Positive factors impacting academics' research engagement in Case Two

\begin{tabular}{|c|c|c|c|c|c|c|c|}
\hline \multirow[b]{2}{*}{ Engaging in research to } & \multirow{2}{*}{ 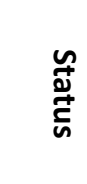 } & \multicolumn{5}{|c|}{$\begin{array}{l}\text { Scale of the Degree of } \\
\text { Importance }\end{array}$} & \multirow{2}{*}{ 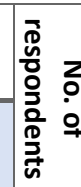 } \\
\hline & & $\mathbf{U}$ & $\mathbf{L}$ & M & $\mathbf{I}$ & VI & \\
\hline \multirow[t]{3}{*}{ B1. Become a (associate) professor or receiving promotion. } & M & & 1 & 7 & 3 & 1 & \\
\hline & $\mathrm{L}$ & 1 & 2 & & & & \\
\hline & Total & 1 & 3 & 7 & 3 & 1 & 15 \\
\hline \multirow[t]{3}{*}{ B2. Have better salary raises. } & M & 1 & 4 & 3 & 4 & & \\
\hline & $\mathrm{L}$ & & 2 & 1 & & & \\
\hline & Total & 1 & 6 & 4 & 4 & 0 & 15 \\
\hline \multirow[t]{3}{*}{ B3. Get promotion in the role of management. } & M & 3 & 5 & 3 & 1 & & \\
\hline & $\mathrm{L}$ & 1 & 2 & & & & \\
\hline & Total & 4 & 7 & 3 & 1 & 0 & 15 \\
\hline \multirow[t]{3}{*}{ B4. Get a reduced teaching load. } & M & 5 & 2 & 3 & 2 & & \\
\hline & $\mathrm{L}$ & 1 & 2 & & & & \\
\hline & Total & 6 & 4 & 3 & 2 & 0 & 15 \\
\hline \multirow[t]{3}{*}{ B5. Gain higher status in the professional career. } & M & & 2 & 3 & 6 & 1 & \\
\hline & $\mathrm{L}$ & & & 2 & & & \\
\hline & Total & & 2 & 5 & 6 & 1 & 14 \\
\hline \multirow{3}{*}{$\begin{array}{l}\text { B6. Reflect research competence, improve teaching skills, } \\
\text { and find out better teaching methods. }\end{array}$} & M & 1 & & 1 & 6 & 4 & \\
\hline & $\mathrm{L}$ & & & & 3 & & \\
\hline & Total & 1 & 0 & 1 & 9 & 4 & 15 \\
\hline \multirow[t]{3}{*}{ B7. Get the respect and high evaluation from students. } & $\mathrm{M}$ & & & 6 & 4 & 2 & \\
\hline & $\mathrm{L}$ & & 1 & & 2 & 1 & \\
\hline & Total & 0 & 1 & 6 & 6 & 3 & 15 \\
\hline \multirow{3}{*}{$\begin{array}{l}\text { B8. Satisfy the need for contributing knowledge to the } \\
\text { professional field; the need of discovery, and need for } \\
\text { creativity. }\end{array}$} & $M$ & & & 3 & 4 & 4 & \\
\hline & $\mathrm{L}$ & & & & 2 & 1 & \\
\hline & Total & 0 & 0 & 3 & 6 & 5 & 14 \\
\hline \multirow{3}{*}{$\begin{array}{l}\text { B9. Contribute to the overall improvement of the } \\
\text { department and institution. }\end{array}$} & $\mathrm{M}$ & & & 1 & 8 & 3 & \\
\hline & $\mathrm{L}$ & & & 2 & & 1 & \\
\hline & Total & 0 & 0 & 3 & 8 & 4 & 15 \\
\hline \multirow{3}{*}{$\begin{array}{l}\text { B10. Have better opportunities to study higher in the } \\
\text { country and abroad. }\end{array}$} & $M$ & & & 3 & 7 & 2 & \\
\hline & $\mathrm{L}$ & & 1 & 1 & & 1 & \\
\hline & Total & 0 & 1 & 4 & 7 & 3 & 15 \\
\hline \multirow[t]{3}{*}{ B11. Have good collaboration from other colleagues. } & M & & 1 & 4 & 4 & 3 & \\
\hline & $\mathrm{L}$ & & 1 & 1 & & 1 & \\
\hline & Total & 0 & 2 & 5 & 4 & 4 & 15 \\
\hline
\end{tabular}


The table shows that most participants in Case Two considered items B6 to B11 as important factors that encouraged them to engage in scientific research activities at universities whereas items B2 to B5 were seen as unimportant factors in motivating them towards research engagement. For item B1 (become a [associate] professor or receiving promotion), the number of participants who considered it as an important motivator to their research engagement was equal to the number of participants who considered it as an unimportant motivator, and half of the participants evaluated it as a moderately important factor.

The findings seemed to show that the participants' internal factors like reflection of research competence and improvement of teaching methods (B6), obtaining the respect of students (B7), satisfaction of contributing knowledge to the field, of discovery, and of creativity (B8), contribution to the development of university (B9), good opportunities to deepen disciplinary knowledge in the country or foreign countries (B10) were important motivators to their research engagement. Besides, good relationships and collaboration with colleagues (B11) was also considered as an important factor for their research engagement. However, external factors like better salary raises (B2), getting promotion in the management role (B3), getting reduced teaching loads (B4), and obtaining high status in professional careers were not considered as important motivators for the participants to engage in research activities.

Additionally, three participants provided their personal viewpoints about factors that may have a positive impact on academics' research engagement. As they wrote in the survey:

Engaging in scientific research activities is a compulsory task for all university academics and staff. (QRespt 1 )

Engaging in scientific research activities to satisfy their personal needs and to occupy an important status in their disciplinary domain. (QRespt 2)

Engaging in scientific research activities to contribute to the overall development of the college and the university. (QRespt 3) 
QRespt 1 seemed to suggest that in order to encourage academics to actively participate in research, there should be a policy to this effect that requires all university academics to engage in research. In fact, Vietnam Education Law states that:

University academics are dutiful to develop research, to apply and transfer S\&T, and ensure training quality (Vietnam National Assembly, 2005).

QRespt 2 appeared to suggest that engaging in research partly depended on individuals' internal motivation because some individuals wanted to be highly recognised in the community. Particularly, it seems that well-educated individuals such as scientists, research experts, and academic experts have a desire to be respected and recognised by the community. In some hierarchical societies, like the Vietnamese society, the fact that intellectuals' need to be recognised by the community is clearly understood.

Dissimilar to QRespt 2's statement, QRespt 3's viewpoint seemed to suggest a more collective contribution. This seems to indicate that the academics of social sciences in this institution have more collectivism thinking than those of engineering sciences.

In summary, the participants in this case evaluated internal motivators and the relationships among academics in research activities more highly than external motivators such as finance, management positions, and reduced teaching loads in their research engagement. Moreover, there were three extra ideas provided by the participants about factors motivating academics to engage in research activities, which include a need to have a compulsory requirement for university academics to fulfil their research duty, the individual satisfaction with a respected position in their professional area, and the need for the contribution to the overall development of their institution.

\subsubsection{Negative factors impacting academics' research engagement}

Data related to factors that may have negative impacts on academics' research engagement are displayed in Table 5-5. 
Table 5-5. Factors negatively affecting academics' research engagement in Case Two

\begin{tabular}{|c|c|c|c|c|c|c|c|}
\hline \multirow{2}{*}{$\begin{array}{l}\text { Factors that hinder me to engage in } \\
\text { scientific research activities }\end{array}$} & \multirow[b]{2}{*}{ 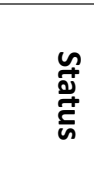 } & \multicolumn{5}{|c|}{ Scale of Agreement } & \multirow{2}{*}{ 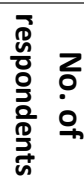 } \\
\hline & & SD & $\mathrm{D}$ & $\mathrm{N}$ & A & SA & \\
\hline \multirow[t]{3}{*}{ C1. Research is a waste of time } & $M$ & 1 & 2 & 3 & 6 & & \\
\hline & $\mathrm{L}$ & 2 & & 1 & & & \\
\hline & Total & 3 & 2 & 4 & 6 & 0 & 15 \\
\hline \multirow[t]{3}{*}{ C2. My job is teaching, not research } & $\mathrm{M}$ & 4 & 4 & 4 & & & \\
\hline & $\mathrm{L}$ & 1 & 2 & & & & \\
\hline & Total & 5 & 6 & 4 & 0 & 0 & 15 \\
\hline \multirow{3}{*}{$\begin{array}{l}\text { C3. Research is a heavy extra burden towards university } \\
\text { academics }\end{array}$} & $\mathrm{M}$ & 4 & 7 & 1 & & & \\
\hline & $\mathrm{L}$ & 2 & 1 & & & & \\
\hline & Total & 6 & 8 & 1 & 0 & 0 & 15 \\
\hline \multirow[t]{3}{*}{ C4. Research provides low salaries } & M & 1 & 5 & 2 & 4 & & \\
\hline & $\mathrm{L}$ & 2 & 1 & & & & \\
\hline & Total & 3 & 6 & 2 & 4 & 0 & 15 \\
\hline \multirow{3}{*}{$\begin{array}{l}\text { C5. There were few opportunities and conditions to } \\
\text { conduct research in the workplace }\end{array}$} & M & 1 & 7 & & 4 & & \\
\hline & $\mathrm{L}$ & 2 & 1 & & & & \\
\hline & Total & 3 & 8 & 0 & 4 & 0 & 15 \\
\hline \multirow[t]{3}{*}{ C6. There is a lack of research grants } & $\mathrm{M}$ & 1 & 3 & 6 & 2 & & \\
\hline & $\mathrm{L}$ & 2 & & & 1 & & \\
\hline & Total & 3 & 3 & 6 & 3 & 0 & 15 \\
\hline \multirow{3}{*}{$\begin{array}{l}\text { C7. Inadequate time available for research due to other } \\
\text { heavy duties }\end{array}$} & M & 1 & 4 & 3 & 4 & & \\
\hline & $\mathrm{L}$ & 1 & 1 & 1 & & & \\
\hline & Total & 2 & 5 & 4 & 4 & 0 & 15 \\
\hline \multirow[t]{3}{*}{ C8. There is high pressure to publish } & M & 2 & 6 & 3 & & 1 & \\
\hline & $\mathrm{L}$ & 1 & 2 & & & & \\
\hline & Total & 3 & 8 & 3 & 0 & 1 & 15 \\
\hline \multirow{3}{*}{$\begin{array}{l}\text { C9. The procedure to get research grant is so complex and } \\
\text { so much time consuming }\end{array}$} & $M$ & & 2 & 1 & 7 & 2 & \\
\hline & L & & & & 2 & 1 & \\
\hline & Total & 0 & 2 & 1 & 9 & 3 & 15 \\
\hline \multirow{3}{*}{$\begin{array}{l}\text { C10. The lack of research facilities such as reference } \\
\text { books, experiment labs }\end{array}$} & $M$ & & 5 & 3 & 4 & & \\
\hline & $\mathrm{L}$ & 1 & 1 & & 1 & & \\
\hline & Total & 1 & 6 & 3 & 5 & 0 & 15 \\
\hline \multirow{3}{*}{$\begin{array}{l}\text { C11. Lacking the leader's support and colleagues' } \\
\text { collaborations }\end{array}$} & $M$ & & 10 & 2 & & & \\
\hline & L & 1 & 2 & & & & \\
\hline & Total & 1 & 12 & 2 & & 0 & 15 \\
\hline \multirow[t]{3}{*}{ C12. Most colleagues not engaging in research } & $\mathrm{M}$ & 5 & 2 & 4 & & 1 & \\
\hline & $\mathrm{L}$ & 3 & & & & & \\
\hline & Total & 8 & 2 & 4 & 0 & 1 & 15 \\
\hline \multirow{3}{*}{$\begin{array}{l}\text { C13. The university (workplace) not having specific } \\
\text { research orientation and strategies }\end{array}$} & M & 7 & 3 & 2 & & & \\
\hline & $\mathrm{L}$ & 3 & & & & & \\
\hline & Total & 10 & 3 & 2 & 0 & 0 & 15 \\
\hline \multirow{3}{*}{$\begin{array}{l}\text { C14. Not understanding clearly the process of doing } \\
\text { research }\end{array}$} & M & 4 & 7 & & & & \\
\hline & $\mathrm{L}$ & 2 & 2 & & & & \\
\hline & Total & 6 & 9 & & 0 & 0 & 15 \\
\hline \multirow[t]{3}{*}{ C15. Unconfident about research methods } & M & 6 & 4 & 2 & & & \\
\hline & L & 1 & 2 & & & & \\
\hline & Total & 7 & 6 & 2 & 0 & 0 & 15 \\
\hline
\end{tabular}

Notes: - SD (strongly disagree), D (disagree), N (neither agree nor disagree), A (agree), and SA (strongly agree) - M: Academic Manager; L: Lecturer

It can be seen from Table 5-5 that overall, most participants disagreed with the items listed in this survey section. Specifically, most participants strongly disagreed with common sayings about research at university like academics' duty is teaching, not 
research (C2), research is a heavy extra burden towards university academics (C3), and research provides low salaries (C4). Related to elements of university research environments such as 'there were few opportunities and conditions to conduct research in the workplace (C5), 'there is a high pressure to publish' (C8), 'lacking the support from leaders' and colleagues' collaboration (C11), most colleagues not engaging in research (C12), the university (workplace) not having specific research orientation and strategies (C13), most participants strongly disagreed with those items. Associated with research knowledge and capacity, many participants considered themselves to be strong in understanding clearly the process of doing research (C14), and great confidence about research methods (C15). However, a large number of participants agreed with items C1 (Research is a waste of time) and C9 (The procedure to get a research grant is complex and time consuming). The number of participants (3) indicating their agreement was much smaller than the number of participants (6) showing their disagreement and strong disagreement with items $\mathrm{C} 6$ (There is a lack of research grants). For $\mathrm{C} 10$ (The lack of research facilities such as reference books, experiment labs), there were more participants (6) who disagreed with it than those (5) who agreed with.

Noticeably, the environmental-related elements (from C6 to C10) showed the contrasting ideas of academics in social sciences and academics in applied engineering sciences, and between experienced academic participants and less experienced academic participants. For instance, many academic participants in the domain of applied engineering sciences considered the research environment at this institution to be relatively good such as many opportunities and conditions to conduct research (C5), enough research grants (C6), enough research time (C7), and enough research facilities. On the other hand, the academic participants of social sciences considered those elements limited. This finding possibly reflected the real situation of teaching and research operations in different colleges. The academics in the colleges of social sciences like education, economics, and social sciences and humanities generally had heavier teaching loads than the academics in the colleges of applied engineering sciences. Consequently, some academic participants in the field of applied engineering sciences in this institution seemed to be accustomed to research activities and research payment procedures, and to be under less pressure for publication than their colleagues in the 
colleges of social sciences. It was possible that less experienced academics felt more uncomfortable with institutional research payment procedures in their initial research operations.

Additionally, it probably confirmed some specific research engagement hindrance that the academic participants in this institution underwent. For instance, two participant respondents provided their ideas by writing into the open-part of this survey section:

Some factors that hindered me to participate in research activities include the lack of document references (especially new published documents), the lack of modern research equipment (machinery), and very limited research funding for research projects. (R1)

One factor hindering me to engage in research activities is the problem of spending much time dealing with research payment procedure. (R2)

In summary, the study findings seemed to show that the participants felt satisfied with their institutional research environment such as good opportunities and conditions to conduct research in the workplace, not having high pressure on publication, good support from leaders and collaboration with colleagues in research activities, most colleagues engaging in research activities, and having specific institutional research strategies. Besides, it seemed to indicate that the participants had a good understanding of research knowledge and confidence in research methods. However, other elements of the research environment such as the lack of research grants and the lack of research facilities were not a big concern for some participants. Meanwhile, other elements like research is a waste of time, and the procedure to get research grants is complex and time consuming were considerable concerns in research activities for many participants in this institution.

\subsubsection{PD activities}

The survey results related to the PD activities performed by the academics in Case Two are outlined the same as those in Case One. Specifically, the results are grouped into: PD activities organised by the institution, PD activities organised by the faculty, and 
academics' regular PD practices. The results of the academics' PD activities in this case study are shown below.

\section{PD activities organised by the institution}

A high number of the participants in general felt satisfied with the PD activities held by the university. The activities organised by the university were evaluated with 'good' and 'very good' levels by 13 out of 15 participant respondents while two participants evaluated the activities with a barely acceptable level (see Table 5-6).

Table 5-6. Academics' level of satisfaction with activities organised by the university

\begin{tabular}{ccccccc}
\hline No. of the & \multicolumn{5}{c}{ Scale of quality evaluation } \\
\cline { 2 - 6 } Respondents & Very poor & Poor & $\begin{array}{c}\text { Barely } \\
\text { acceptable }\end{array}$ & Good & Very good & Not sure \\
\hline 15 & 0 & & 2 & 6 & 7 & 0 \\
\hline
\end{tabular}

\section{PD activities organised by the faculty}

Similarly, the PD activities organised by the faculty received good evaluations from the participants, but not as good as evaluations for the PD activities organised by the university. For instance, 10 of 15 participants considered that they felt satisfied with 'good and very good levels' with the PD activities organised in their faculties, and five of the participants evaluated the PD activities organised in their faculties with a barely acceptable level (see Table 5-7).

Table 5-7. Academics' level of satisfaction with activities organised by the faculty

\begin{tabular}{ccccccc}
\hline \multirow{2}{*}{$\begin{array}{c}\text { No. of the } \\
\text { Respondents }\end{array}$} & Very poor & Poor & $\begin{array}{c}\text { Scale of quality evaluation } \\
\text { Bacceptable }\end{array}$ & Good & Very good & Not sure \\
\cline { 2 - 6 } & 0 & & 5 & 3 & 7 & 0 \\
\hline
\end{tabular}

In general, it seemed that the participants in Case Two had better evaluations for the PD activities organised by the university than the PD activities organised by the faculty. This could be explained by the operation of research activities in different faculties with some faculties having more active research activities than other faculties. As documented in this institution's evaluation report on research activities in the period of 2006-2010, the domains of applied bio-technology and high technology belonging to 
the College of Agriculture and Applied Biology, the College of Aquaculture and Fisheries, the College of Engineering Technology, and The College of ICT had more national level research projects than the domain of basic sciences belonging to the School of SS\&H, the School of Education, the School of Political Science, and the School of Law. The research projects in the domain of basic sciences in this institution were mainly at the institutional level (Case Two, 2011). Additionally, the scope and value of institutional PD and research workshops/conferences were generally more substantial than those of faculty PD and research activities. Moreover, institutional conference participants had better opportunities to widen their research networks with academics and research experts from different disciplines than in workshops/conferences organised by the faculty. In summary, the participants in this study were more satisfied with activities organised by the university.

\section{Academics' regular PD activities}

The data showed that in the past twelve months the participants in Case Two had a wide range of frequent PD activities. Firstly, they attended different conferences at international, national, institutional, and faculty levels. In addition, the participants conducted institutional, ministerial, and national research projects. Some of the participants joined in research groups for this institution's international cooperation projects. They also wrote scientific articles for scientific journals, designed teaching materials, read research documents to update disciplinary and research knowledge, and supervised undergraduate and postgraduate students' theses.

\section{Summary of survey results}

There are some key findings from the questionnaire. First, for research perceptions, it seemed that the participants in the domain of social sciences and humanities had greater ambition in establishing and developing themselves in their disciplinary area than the participants in the domain of applied engineering like agricultural sciences, biotechnology, engineering technology, etc. Moreover, many participants considered that scientific research needed to be a compulsory task for university academics and it was 
necessary to have a strong link between research and training in the Vietnamese tertiary education system.

For factors that motivate academics' research involvement, the participants seemed to have higher evaluations for academics' relationships in research activities than other factors like finance, management positions, and reduced teaching loads. In addition, three extra ideas suggested that research should be compulsory for all university academics in their roles.

For the factors that hinder academics' research engagement, the participants seemed to have great concerns about research being a waste of time, complexity of gaining research grants, and payment processes for research projects. Yet, they had positive evaluations for their institutional research environment and colleagues' support and collaborations in research activities. Last but not least, for PD activities, the participants performed various PD activities (participating in international and national research projects, attending and writing papers for research conferences, self-learning, and supervising undergraduate and postgraduate students' theses) to improve their research knowledge and competence.

\subsection{Case Two's interview results}

In Case two, there were six academic managers who agreed to participate in the interviews. All of them were doctorate holders. Among these participants, there was one participant with the academic title of Professor, and one participant with the title of Associate Professor. It was believed that the participants would provide a great deal of important information for this case study, from their background knowledge and experiences in the position of management and research activities. Figure 5-1 shows the codes given to these six manager interviewees in Case Two. As in Case One, details about the participants' management positions were not presented to protect their identities. 


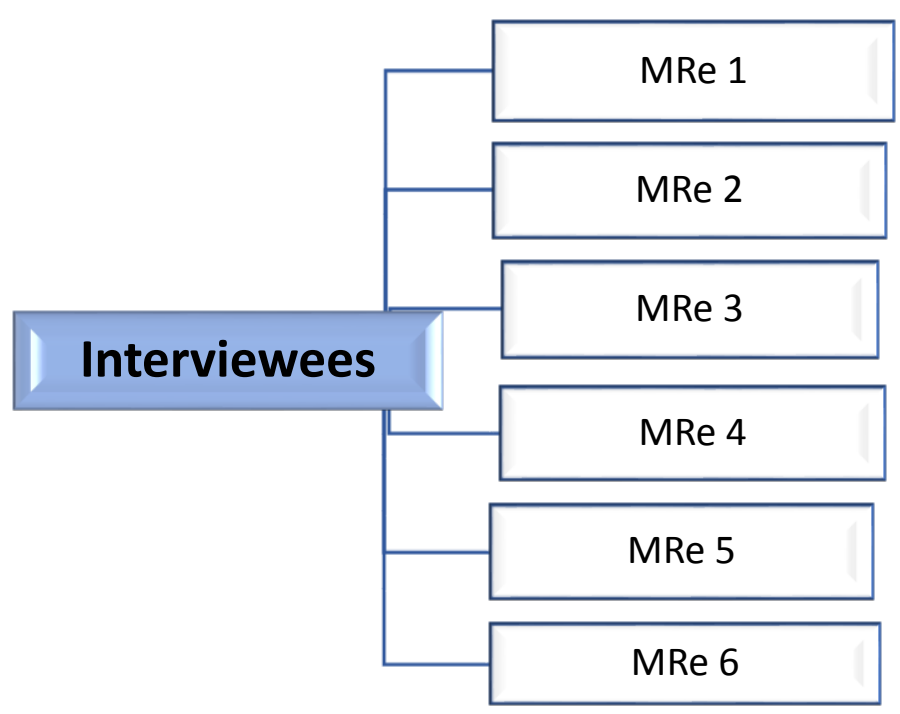

Figure 5-1. Case Two's interview participants

The interview results in Case Two were analysed, based on the framework for exploring factors affecting the Vietnamese academics' research engagement in Chapter 3. The emerging factors impacting on academics' research engagement capacity in the study comprised individual factors, and institutional factors, which both seemed to be affected by social contexts.

\subsubsection{Individual factors}

Several individual factors were considered to have an impact on academics' research engagement. They included their disciplinary knowledge, research experience, research motivation, confidence in research, English language competence, and research network. The following subsections will provide more detail about specific individual factors that influence the research engagement of Case Two's academics.

\section{Disciplinary knowledge}

The interview participants had good qualifications and academic titles; thus, they seemed to have good knowledge in their disciplinary fields. Moreover, most of these participants undertook many years of teaching in their colleges and professional departments prior to their current management positions. They also designed teaching materials and translated professional materials from foreign languages into Vietnamese 
as internal teaching materials for their colleges. For instance, MRe 2, MRe 3, and MRe 4 had participated in many national and foreign research projects. MRe 3 had 14 international papers in his discipline from 2006 to $2013 .{ }^{11}$ MRe 4 had 13 national and international papers between 2006 and $2011^{12}$. In addition, because of good disciplinary knowledge, these academic managers were invited to supervise students' theses as university academics' roles. Therefore, it is likely to say that they had a lot of experience in teaching, research and management knowledge.

\section{Research experience}

Most interview participants had a great wealth of research experience. For example, academic manager MRe 1 was the author of two national level research projects and had two papers published in foreign journals from 2006 to 2011 (Case Two, 2011). MRe 2 had 14 international papers, among which he was the chief author of five papers. ${ }^{13}$ In addition, other academic managers had conducted some institutional and national level projects and had their papers published in many journals in the country.

However, when referring to the institution's academics' research experience, some academic managers commented that academics' research experience in the institution was a lot different due to the length of their time working and their disciplines. For instance, MRe 1 considered that the academics in the Schools of Education, SS\&H, Political Sciences, and Law, and the College of Economics and Administration seemed to have less research experience than those in applied engineering disciplines in the Colleges of Environment and Natural Resources, Agriculture and Bio-Technology, Aquaculture, and ITC. MRe 1 added that this was because most schools and colleges belonging to the domain of SS\&H were newly established or separated. He continued that the academics in those schools and colleges had more teaching hours, and those colleges seemed not to have experienced research leaders. Thus, they had not

\footnotetext{
11 MRe 3's publications were recorded in (Case Two, 2011)

12 MRe 4's publications were shown on the website of Case Two's college of ITC

13 MRe 2's curriculum vitae
} 
completed many research projects in recent years. They just had a few institutional level research projects. MRe 1 commented that:

Whichever college/school is strong in international cooperation and had leaders strong in research activities, that college/school will be strong in research. (MRe 1)

MRe 1 said that besides the afore-mentioned causes, most non-engineering colleges in his institution were not strong in international cooperation and relations in comparison with applied engineering colleges. As a result, the non-engineering colleges did not have many research projects. Their academics, thus, had fewer opportunities to engage in research, so their research experience was limited. MRe 1 stated: "cái gì cũng vậy, có làm nhiều thì mới quen."

This saying can have an equivalent translation in English [the more you do something, the more experienced you become in doing it]. The English idiom 'practice makes perfect' fits with MRe 1's saying. It seems that MRe 1 implied that some academics in this institution were able to improve their research experience and capacity thanks to their frequent participation in international research projects from the college's international relations.

Similarly, MRe 2 considered that research experiences among colleges and schools were much different. He said in this institution the academics in the colleges of applied engineering fields were much stronger in research experience than those in other colleges. He added that senior lecturers were more research experienced than young lecturers. Every year, the institution recruited several excellent students to become future lecturers. However, he stated: "we mostly have to train their research skills again because, after graduation, their research skills are limited, nearly zero." He continued that:

But that is not students' faults. That is because our current university programmes are not appropriate. Our programmes are heavily theoretical and students even learn many irrelevant subjects. (MRe 2) 
It was possible that MRe 2 wanted to imply that Vietnamese university students learn many 'irrelevant subjects' ${ }^{14}$ related to politics. In fact, generally, Vietnamese university students have to take four years to complete their university bachelor degrees while students in foreign countries may only take three years.

In summary, insights into the experiences of the managers in Case Two suggests that they had good research experience because they had participated in lots of different level research projects. However, they confirmed that the academics' research experience in the institution varied a lot between colleges such as long established colleges and newly established colleges, between applied engineering colleges and nonengineering colleges, and between senior academics and junior academics.

\section{Research motivation}

Academic managers' motivation in research activities seemed to be seen in their frequent engagement in research activities at their college despite existing difficulties in Vietnamese HE research operation polices in general and in this institution's policies in particular. For instance, MRe 3 commented that the national policy for financial support in research seemed to be very out of step with the current situation, but a few academics in this institution still actively joined research activities. They even used their research experience to build up junior academics as strong research human resources for their colleges and institutes by organising basic research skill courses for inexperienced academics. Other participants said that they had to sacrifice their leisure time and family time for their research activities. For example, MRe 4 stated that:

As a university lecturer, especially for academic managers, we have to leave much of our leisure time and family time aside for our research work. (MRe 4)

Similarly, MRe 5 stated that most university academics generally seem to sacrifice a lot (such as receiving low wages, not much time for family) for their professional careers. He continued that:

\footnotetext{
${ }^{14}$ MRe 2 referred to subjects related to politics at university in Vietnam , including Vietnam Communist Party History, Ho Chi Minh's Ideology, Marxist-Leninist Philosophy, etc.
} 
For the task of research, we even sacrifice more of our material needs. It can say that we are showing our love for the country. We are like soldiers within peace time to use our brain power to build the country stronger. (MRe 5)

In addition to the participants' intrinsic motivation in research engagement, one academic manager said that some academics in this institution had some extrinsic motivation in their research engagement. For example, he said that:

In reality, the income we can earn from conducting research is nearly nothing, but what academics like me to follow research activities is to achieve higher academic titles or to be recognised in the field. (MRe 2)

To sum up, most participants considered that generally university academics had a strong intrinsic motivation to research and teach. Some academics were extrinsically motivated to achieve high academic titles, and external factors of finance and management positions, in their professional life. Although there were still some limitations in the government's financial support for research activities at university, university academics kept on sacrificing their daily leisure time and family time for their journey of research.

\section{Confidence in research}

The participants' confidence in research was seen in their research activities. Some participants not only joined many national and international research projects, but also organised many research conferences to share their research results, experiences with colleagues and young academics within the college, research institute and university. For instance, MR1 shared that previously, as a lecturer, he often actively participated in research activities but did not have opportunities to share his research experiences. He continued that now in the role of the head office, in addition to helping the university construct the directive frames for research operation, he had chances to attend many national and international conferences related to $\mathrm{HE}$ research activities. Then he said:

Thus, I have more opportunities to work and share my research experiences with my colleagues, especially young ones. (MRe 1)

Similarly, another participant shared his research confidence by stating that:

I have had some opportunities to join regional, national and international projects. I could learn the world's current research needs in my discipline. Then, I could share my experience with my colleagues and young academics in this institution. (MRe 2) 
Moreover, MRe 2 said "in addition to my responsibilities in my research institute, I participate in supervising MA and PhD students' theses and contribute ideas for innovating and improving the quality of training programmes."

Meanwhile, in addition to mentioning his frequent activities of supervising postgraduate students' theses as his research confidence and experience grew, MRe 3 compared the Vietnamese HE system's research management with that of a Dutch university that he used to work with. He said:

As I know it seems that Vietnam has not yet a model of Research University so far, but Holland has such a well-known research university called Wageningen University. (MRe 3)

Besides reflecting on his good research experience, MRe 3 indicated his understanding of the Vietnamese tertiary education system's management of research activities. He considered that leaders of Vietnamese HEls had a quite strange viewpoint on teaching and research at university. He gave an example of his research institute. He said at first his research institute was not allowed to perform the task of training. He continued that:

'Chúng tôi phải sáng tạo để bổ sung thêm một nhiệm vụ cho viện nghiên cứu. Chức năng nhiệm vụ của viện là đào tạo song song với nghiên cứu khoa học.' (MRe 3)

[We have to be 'creative' to add into our research institute's regulation. The institute's function is to perform the task of training and scientific research in parallel].

He seemed to be critical that it was, in fact, a redundancy of legal documents because the university's role was to perform the tasks of training and research and he meant to question why a research institute within a university was not permitted to do the task of training and teaching. Therefore, MRe 3 seemed to imply that the leaders of Vietnamese HEls had out-of-date thinking about management which originated from the Soviet Union by separating the task of research for institutes and the task of teaching or training for universities.

Furthermore, the participants' confidence in research could be found in the questionnaire. For instance, the findings of the factors related to the hindrance of academics' research engagement like C14 - not understanding clearly the process of 
doing research and C15 unconfident about research methods (see Table 5-5) show that 13 out of 15 participants disagreed with their misunderstanding of the process of doing research, and 13 out of 15 participants disagreed that they were not confident about research methods.

In summary, the interview data indicated that the participants not only had good research experience and competence but also good experiences of research management. They had deep insights into their disciplinary majors, being shown by their participation in research projects and their supervision of postgraduate students' theses.

\section{English language competence}

In contrast to university academics in English-speaking countries, Vietnamese university academics' English language competence doubtlessly seems to affect their research engagement. For this reason, the State of Vietnam has provided its national scholarships such as Project 322, and Project 911 for young Vietnamese university academics to study abroad, especially in English-speaking countries. In fact, most Vietnamese university academics also consider that incompetence in the English language is a considerable factor that causes their research capacity to be hindered.

In this institution, academics' English language competence was considered as a factor hindering their research engagement. For instance, MRe1 considered generally in this university, social sciences academics had weaker English competence than their colleagues in applied engineering colleges. This weakened their international relations, and it meant that they did not have as many international cooperation research projects as those in applied engineering colleges.

Similarly, MRe 2 believed that many academics in this university needed to improve their English competence for enhancing their research capacity. He wondered why some junior academics and students in this institution had weak English language competence, limiting their research work. He continued to say that: 
Now it would be rational for young academics to have better English competence than our generation - we experienced many difficulties in studying in the wartime before because now they have many good opportunities to study English. (MRe 2)

Likewise, MRe 5 admitted that English language barriers seemed to be a limiting factor towards academics' research capacity, especially towards the academics in the social sciences field in Vietnam in general and in this institution in particular. He continued that:

English as a foreign language (EFL) in China, and in Thailand where I used to study is like in Vietnam, but they have more research projects in this field than we do because their English language competence is better and it is perhaps that they have more masterpieces of literature works than us. (MRe 5)

To sum up, English language barriers were believed to be one of the weak points in academics' research engagement. Also, academics' English language competence was not good enough in colleges. In particular, according to some participants, the academics in the schools of SS\&H and Education seemed to have worse English language competence than their colleagues in the colleges of applied engineering fields. Thus, it could be concluded that English language barriers were somehow considered to be a negative factor that impacts academics' research capacity in this institution.

\section{Research network}

A wide research network is considered to be a good enabler for a university's research competence. The academics in this institution were considered to have broad research networks, thanks to this institution's wide research networks. For instance, from 2006 to 2010, Case Two had 30 cooperation projects thanks to international relations, with the total funding of 14 billion VND - half of this funding was used for research projects (approximately 350,000 USD). The research projects mainly centred on the fields of agriculture, aquaculture, bio-technology, environment, and agro-economics. Its foreign partnerships came from Belgium, Germany, Holland, Denmark, Italy, The United States, Australia, Japan, and the Philippines (Case Two, 2011). In addition to the international relations, Case Two had strong research links with many provincial and national research affairs departments. For example, accoriding to Case Two's report in 2011, there were 
21 research and technology transfer projects conducted in research centres and departments in the Mekong Delta region in the same period of time.

In addition, other research institutes and colleges had good international relations and research links. For example, the Mekong Delta Development Research Institute had 45 research links with international organisations, non-governmental organisations, and foreign universities (Case Two, 2014b). The College of Environment and Natural Resources had cooperation research links with 14 international and non-governmental organisations (Case Two, 2014c).

In brief, it could be said that Case Two was quite strong in both national and foreign research links. Also, some of its colleges and research institutes had wide domestic and foreign cooperation and research links. Thus, it was reasonable that to some extent these institutional research links helped their academics to gain much confidence and experience in research activities.

\section{Summary of individual factors}

In summary, among the individual factors impacting on the academics' research engagement in this institution, it seemed that there were more positive individual factors than negative ones. For example, the positive individual factors of Case Two's academic lecturers included good disciplinary knowledge, good research experience, highly intrinsic and extrinsic motivation, confidence in research, and wide research networks whereas one individual factor negatively affecting their research capacity seemed to be their limited English language competence. Moreover, from the participants' viewpoints, it could be interpreted that applied engineering academics' research experience, research confidence, research competence, and English language competence seemed to be much better than those of the academics in domains of education and social sciences and humanities. This finding might surprise many people with the assumption that Vietnamese academics of social sciences and humanities appear to be better at foreign languages than Vietnamese academics of natural sciences. 


\subsubsection{Institutional factors}

Like other Vietnamese HEls, the institutional factors of this regional institution were being impacted by some recent policies of the Vietnamese Government which all aimed to develop the Vietnam HE system. These policies were specified in documents such as the Vietnam Education Development Strategy for 2001-2010 approved by the Prime Minister in December 2001 (Vietnam Government, 2001), the Government Resolution on substantial and comprehensive renovation of Vietnam's HE in the period of 20062020 (Vietnam Ministry of Education and Training, 2005), Project 322 (Vietnam Government, 2000) , Vietnam NFL Project (Vietnam Government, 2008), and Project 911 (Vietnam Government, 2010b).

Specifically, The Educational Development Strategy for 2001-2010 stated that:

Training must be linked with research, application, implementation and technology transfer" and "partnership between training and research institutions and the business sector shall also be formed to solve problems arise out of the labour market and technology market through training contracts, joint research contracts, development of university enterprises, etc.

(Vietnam Ministry of Education and Training, 2006)

Therefore, every Vietnamese HEI was to carry out its own institutional developmental strategy and policies to respond to national and international changes related to the HE system. Its institutional policies relating to the scientific research development strategy are mentioned in the following subsection.

\section{Institutional policies}

Case Two determined that scientific research was one of its main duties, aiming at enhancing training quality and serving socioeconomic development for the region and for the whole country. Thus, based on the governmental policies for the development of Vietnam's HE system, it constructed and issued its institutional policies. For instance, Case Two's orientations on the activities of scientific research and technology by the year 2020 documented that: 
Its strategic vision to 2020 is not only to become the best university in Viet Nam but also to be recognised throughout Asia-Pacific as one of the leading universities in education, research, and development. It will expand human knowledge and benefit society through its research, teaching and strategic partnerships, all the while developing itself within the framework of global integration and mutual cooperation (Case Two, 2014e).

It could be said that with a specific strategic vision, Case Two highlighted its important task of S\&T operation in the age of global integration of HE system. It was possible that its academics' research engagement needed to be more active and dynamic than before because they were expected to improve themselves and support the university's overall goals.

In addition to its research strategic plan, Case Two recently issued and adjusted a series of internal policies to suit social changes and to develop its human resources' research capacity. It activiated the Regulation of Monitoring Academics' Professional Work in 2013 to replace the former regulation issued in 2010. One amendment that was considered to encourage academics to participate in research activities is to increase the financial reward for researchers. For example, according to the 2010 Regulation, the author of a national level research project with the value of over one billion VND (approximately 50,000 USD) was awarded 100 standard teaching hours whereas according to the 2013 Regulation, the author of this research project was awarded as much as double the money in the 2010 Regulation (Case Two, 2010, 2013b) . In general, according to the 2013 Regulation, all financial rewards given to academics towards their research activities increased greatly. Moreover, related to its human resources development, Case Two had a decision documented that all academics had to obtain a higher academic degree than their current degrees within four years. Furthermore, if academics had English and IT certificates, they would receive some financial reward. All academics with doctoral degrees in the university were also expected to be competent in English - equivalently the score of $\geq 5.5$ IELTS (Case Two, 2009).

It is likely that in accordance with national policies related to the Vietnamese HE development, Case Two was well prepared for its development of human resources in the process of global HE integration. Particularly, related to its task of research activities, it seemed that due to its open-minded leaders who used to study abroad and often 
worked with international organisations, it was often proactive in modifying national and institutional documents related to their research operation so that they could most benefit academics in their research engagement. Briefly, based on the general national guidance documents related to scientific research activities, this institution seemed to have more financial autonomy by going ahead in modifying and issuing its internal documents and policies in comparison with other institutions, which enabled the best conditions for its academics to be involved in research.

\section{Funding and structure}

It can be said that in addition to the element of human resources, a university's financial resource and structure play an important role in determining its research competence. Due to a big multi-branch university, Case Two received the state budget for the operation of technology and science activities of approximately 4 billion VND per annum - equivalent to 200,000 USD (Case Two, 2011). This can be explained by the Vietnamese government's decree which stated that Vietnamese HEls distributed the amount of 4 million VND per year (approximately 200 USD) for their research activity (Vietnam Government, 2006).

In addition, thanks to its broad national and international research networks, especially from the research links of the Department of Research Affairs and the Department of International Relations between 2006 and 2010, this institution annually received nearly 7.5 million USD (see Table 5-8). It was apparent that this huge funding for research was a good condition to developing its research activities and research competence. Moreover, because it was directly under ministerial management, Case Two received directly the state' s research funding as well as other sources of research grants. Thus, its academics did not necessarily have to ask for research funding from other high management levels. All they could do was contacting the supportive offices within the university in case their research projects were approved. 
Table 5-8. Case Two's funding resources and research outcomes in 2006-2010

\begin{tabular}{|l|c|c|c|}
\hline \multicolumn{1}{|c|}{ Sources } & $\begin{array}{c}\text { Number of research } \\
\text { projects }\end{array}$ & Amount (mil VND) & $\begin{array}{c}\text { Amount } \\
\text { (thousand USD) }\end{array}$ \\
\hline State-level Projects & 5 & 5250 & 262.5 \\
\hline $\begin{array}{l}\text { Basic Research+ } \\
\text { National Genes } \\
\text { Preservation Research }\end{array}$ & 1 & 650 & 3.25 \\
\hline MOET Projects & 184 & 16151 & 8075.5 \\
\hline MARD Projects & 2 & 1062 & 5.31 \\
\hline Provincial Level Projects & 156 & 44346 & 221.73 \\
\hline $\begin{array}{l}\text { International } \\
\text { Cooperation Projects }\end{array}$ & 30 & 6588 & 32.94 \\
\hline NAFOTED & 379 & 978 & 4.98 \\
\hline \multicolumn{2}{|c|}{ Total } & 75025 & 3751.25 \\
\hline $\begin{array}{l}\text { Note: - MOET: Ministry of Education and Training; MARD: Ministry of Agriculture \& Rural } \\
\text { Development; NAFOTED: National Foundation for Science \& Technology Development. }\end{array}$ \\
\hline
\end{tabular}

(Case Two, 2011)

However, there were still some limitations in gaining research funding. For example, MRe 1 reported difficulties related to research funding:

At present, the payment for each research project is very limited. Also, academics participating in research projects have to provide expense receipts as proof, which is complicated. (MRe 1)

In the same way, MRe 3 mentioned the difficulty of gaining the funding for ministerial and national research projects. He said that:

For research projects with the cost of over 400 million VND (20,000 USD), the project author has to go to Hanoi Capital to present his/her project. The problem here is that we are not provided with travel fares and other things. (MRe 3)

Meanwhile, MRe 6 said that the research funding in this institution was limited because:

Most of the university's financial expenses were allocated for the activity of training. (MRe 6)

However, other participants had a relatively positive view on research funding and research payment procedure. For instance, MRe 2 considered that (after the year 2012) there was a little increase in the institution's research funding, about nearly 10 billion VND per annum (approximately 500,000 USD/pa) after the adjustment of the institution's internal expense regulation in 2012. Likewise, MRe 4 revealed that there was a big change in the university's budget allocated for research activities. He said that: 
Five years ago, the university only distributed 3 or 4 billion VND for scientific research, but presently the sum of money is about 9 or 10 billion VND. Moreover, the procedure for obtaining research grants is much simpler. (MRe 4)

Similarly, MRe 5 revealed that at the moment the payment procedure for research at the Department of Financial Affairs was much simpler. He continued:

The staff in the Department of Financial Affairs can provide necessary guidance for us about making research expense claims. (MRe 5)

In conclusion, Case Two's budget for research was much more limited before 2007, and the procedure for obtaining research funds was complicated. However, since then, its research budget has more than doubled (from 4 billion VND to 10 billion VND). Moreover, there seemed to be a simpler way for academics to obtain the institution's research funding. However, one academic manager in the discipline of social sciences and humanities considered that the funding for research was still limited. There seemed to be some possible reasons for this problem. It was first possible that this institution's research selection board seemed to prefer to choose applied engineering research projects before social sciences projects. The second possibility seemed to be that social sciences academics' ability to conduct research projects and their presentation skills for research projects were limited. This matched with the report that from 2006 to 2011 there were 66 research projects in social sciences disciplines conducted out of a number of 785 research projects, but nearly 50 social sciences research projects were institutional-level ones, with no foreign cooperative research projects of social sciences (Case Two, 2011). These data also suited MRe 1's statement as he revealed that:

The colleges of applied-engineering domains such as agriculture \& bio-technology, aquaculture, and ITC are much stronger in research activities and in international relation affairs than the colleges of social sciences. (MRe 1)

In summary, it can be said that despite its limited state budget research funding, Case Two seemed to be quite successful in widening its own research funding thanks to its broad international cooperation. Moreover, it made efforts to simplify the procedures for academics to obtain research funding as easily as possible. In so doing, this has reduced some intangible barriers towards academics' intentions to participate in research activities. 


\section{Resources}

Good resources for research such as a good library, and good research facilities were considered a vital element to enhance a university's research capacity. Case Two's research resources were considered rather good and were often being much upgraded and updated day by day. For example, this institution had its Learning Resources Centre - previously called the Central Library, established in 2006 with a grant of 9.2 million USD by the Atlantic Philanthropies. This Learning Resources Centre was considered to be a world-class library in Vietnamese HEls. This Centre was equipped with lots of modern facilities supporting students' and academics' studies. The Centre was also seen as an integral part in this institution's strategic plan to enhance the quality of training and research (Case Two, 2014d). Besides, some of this institution's international cooperation projects such as the TRIG project helped to increase its research facilities as well as enhance academics' research capacity for some of its colleges.

However, the lack of research facilities was partly seen as one hindrance towards academics' research engagement in some colleges. For instance, MRe 4 considered that the lack of research facilities reduced individuals' research drive as he said:

Generally, our university's research facilities have recently been improved a lot. However, we have suggested buying some devices for research support in my college several times but we have not received them yet, which demotivates our research group. (MRe 4)

Similarly, the survey's findings indicated that five out of fifteen participants agreed that the lack of research facilities was seen as one of their institution's shortcomings in research capacity and one questionnaire respondent added his idea by writing:

Some factors that hindered me to participate in research activities include the lack of document references (especially new published documents), the lack of modern research equipment (machinery), and very limited research funding for research projects. (R1)

In summary, research facilities seemed not to be a problematic issue for this institution because it had a modern Learning Resource Centre that greatly assisted a lot of its academics in conducting research. Additionally, in the past, many of its research facilities had been upgraded and supplemented. Thus, its academics had better 
opportunities to follow their research. However, a few academics expected to have access to more updated resources and modern equipment.

\section{Teaching loads}

Teaching loads was believed to have negative impact on academics' research engagement in Case Two. MRe 1 commented:

One reason that some units in this university such as the school of Education, SS\&H, Natural Sciences are not as strong in research as others is because they have heavy teaching loads. (MRe 1)

Meanwhile, another academic manager, in his macro-level view, thought that heavy teaching loads were caused by the MOET's current requirement. He stated that the MOET required academics to fulfil lots of teaching and research hours per annum. He continued:

It is hard for academics to finish all their required teaching hours. (MRe 2)

In fact, according to the MOET's decision on academics' work/teaching hours, as indicated in Table 5-9 (Vietnam Ministry of Education and Training, 2008a), university academics annually have to fulfil 280 teaching hours and half of the number of teaching hours for research (equivalent to 140 hours for research). The following table shows detail of what academics with different titles have to do to fulfil their teaching hours:

Table 5-9. Framework for standard teaching hours for Vietnamese academics

\begin{tabular}{|l|c|c|}
\hline \multicolumn{1}{|c|}{ Academics' Titles } & \multicolumn{2}{|c|}{ Framework for standard teaching hours } \\
\hline & $\begin{array}{c}\text { General framework for all } \\
\text { subjects }\end{array}$ & $\begin{array}{c}\text { Framework for subjects of } \\
\text { Physical Education, National } \\
\text { Security \& Defence (at non- } \\
\text { majoring institutions) }\end{array}$ \\
\hline $\begin{array}{l}\text { Professors and Advanced } \\
\text { Lecturers }\end{array}$ & 360 & 500 \\
\hline $\begin{array}{l}\text { A/Professors and Senior } \\
\text { Lecturers }\end{array}$ & 320 & 460 \\
\hline Lecturers & 280 & 420 \\
\hline
\end{tabular}

(Vietnam Ministry of Education and Training, 2008a)

Moreover, MRe 6 believed that academic managers had more difficulties in engaging in research activities than academics because: 
Besides their duties of teaching as academics, they have less time for research as they have to do many other things. (MRe 6)

However, MRe 4 considered that, in terms of management, academic managers had more advantages in undertaking research because they knew well their daily work such as management, research, and teaching. He went on to say that:

Academic managers have better visions, organisational skills, and evaluation skills than academics. (MRe 4)

In conclusion, many academic managers believed that heavy teaching loads in Vietnamese HE system in general and in Case Two in particular were the main cause for academics' limited engagement in research. For instance, MRe 6 commented that academic managers generally had more difficulties in research due to their other tasks and responsibilities. Nevertheless, MRe 5 stated that academic managers could have more advantages than academics in research since academic managers had broader views and better skills in organisation and evaluation.

\section{Leadership}

Leadership played an important role in enhancing research capacity for a HEI. The leadership role could be influenced by the leadership skill, the leader's reputation, vision, social relationships, personnel organisation and care. For the leadership skill, MRe 1 revealed that:

Our leader cares so much for the institution's research task. In most institutional meetings, he often pushes and asks all units to be proactive in looking for various sources of research funding. (MRe 1)

MRe 1 reported that as for the responsibility for enhancing all the university's research activities, his department had to actively look for institutional research funding from various sources. He added that his department coordinated with other departments and contributed ideas to modify national research policies (e.g. to simplify administrative procedures for research activities so that academics were encouraged to undertake research. This interviewee continued:

We are proactive to widen our research networks by building partnerships with provincial Departments of S\&T, and international organisations. (MRe 1) 
Additionally, MRe 5 believed that once a leader's management skills and knowledge won academics' hearts, the leader could successfully encourage academics and staff to join in research. He commented that

Moreover, as we know, our country operates according to the manner of centred democracy, once the leader asks his employees to do something, then they will do it. And if the leader has some encouraging words, they will do it better. (MRe 5)

MRe 5 also commented that the leader's reputation and ability to build social relationships had a considerable influence on the institution's research capacity. He stated:

Though there was an equality of research care and research vision between the preceding Rector and the current Rector, our institution's research capacity is much better than before since we have larger research funding thanks to the current Rector's good social relationships. (MRe 5)

MRe 5 added that, besides the annual research funding received from the MOET, the institution could receive research grants from provinces in the region, from other ministries, and international as well as non-governmental organisations. He believed that many national, international and non-governmental organisations established partnerships with the institution, which was partly thanks to his leader's reputation and good relationships. This interview respondent also acknowledged that his leader was good at selecting personnel for the managers of the Department of Scientific Affairs and International Relations. He believed the heads of those departments helped the institution to broaden its research networks as well as enlarge its research funding.

However, MRe 5 also revealed that the institutional research funding for his school was quite limited. He added that consequently his school had fewer research projects than other colleges. He believed that this was a consequence of his school receiving little support from the rector. He thus stated that his school's research capacity was considered not strong.

To conclude, in the academic managers' viewpoints of this regional institution, the role of leadership at university, particularly in Vietnamese tertiary education institutions, had a greatly positive impact on its research capacity. More specifically, it included the 
leadership skills, ability of personnel organisation, reputation, and relationships of a university's rector.

\section{Research environment}

Case Two appeared to have a supportive environment for its academics in research activities. Firstly, it was regarded as a key $\mathrm{HEl}$ in the Mekong Delta region as well as one of the sixteen key national universities in Vietnam (Toan, 2013), and was paid considerable attention by the State and the Government of Vietnam. Specifically, many international investment projects on the Vietnamese HE system such as Vietnam - First Higher Education Project (HEP1) (with the amount of US\$ 83.3 million) and Vietnam Second Higher Education Project (HEP2) (with the amount of US\$ 70.5) were carried out to enhance Vietnamese universities' quality of teaching and their research capacities that this regional institution benefited from this project (Zanetta, 2012).

In addition, due to its large number of staff, Case Two had a state budget for its S\&T activities annually - over 5,700 million VND (approximately 285,000 USD) per year (Case Two, 2014e). For instance, according to Vietnam Government Decree 43/2006, each Vietnamese academic at HEls was provided 4 million VND (equivalent to 200 USD) per year for research activities (Vietnam Government, 2006). This institution was proactive about modifying this important document so as to encourage its academics to be actively involved in research activities by amending its internal expense regulation twice. For the first amendment in 2010, every academic was provided 5 million VND (250 USD) per annum for their research activities. For the second amendment in 2013, this amount of money increased 6 million VND (300 USD) per year (Case Two, 2013a).

Moreover, this institution had a large number of qualified academics with high degrees. There were 929 out of the total of 1,197 staff who held at least MA degrees. Among this number of qualified staff, there were 7 Professors, 78 Associate Professors, and 177 doctoral degree holders (Case Two, 2014f). For this reason, leading specialised staff would probably share and guide young staff in research activities. Furthermore, thanks to its strong research networks, it annually obtained a considerable amount of 
money from domestic and foreign organisations for its research activities approximately 7.5 million USD per year (Table 5-8).

However, the research environment at all colleges in this institution was different. It seemed that the research environment in applied engineering colleges was much better than in social sciences and humanities colleges. For instance, there were more leading research lecturers in applied engineering colleges, and their international cooperation and research links were also stronger. As a result, the applied engineering colleges' research capacity was much stronger. One academic manager participant stated that there were some reasons for weak research capacity in the field of SS\&H. He said that:

First, generally the society has not criticised on teaching and research activities in the field of SS\&H yet. Secondly, for a long time, Vietnamese university academics are accustomed with the 'dạy chay' style - a Vietnamese common saying for teaching without research. (MRe 3)

MRe 3 continued that they were familiar with that routine; thus, when they were told to do research, they could not do it. He went on to state that it was due to the top management's requirement. He said:

For a long time, there have not been concerns for the social sciences field. They seem just to focus on politics, studies on Ho Chi Minh's Ideology. Now, they are startled with the rapid economic development accompanied with the deterioration of social morals. (MRe 3)

In summary, its research environment was good, which was thanks to its qualified, strong research experienced staff, its various research links and strong international relations. However, there was still a big difference between the research environment in colleges, especially between applied engineering colleges and basic, social sciences and humanities colleges.

\section{Summary for institutional factors}

Together with Vietnamese national policies for enhancing its tertiary institutions' research capacity, Case Two was proactive in modifying and issuing its internal policies with the purpose of developing its research capacity to achieve its strategic mission for 
regional and global integration. By so doing, Case Two had strong research facilities, various research links, and sources for research grants. Therefore, its staff had good opportunities for research in an active research environment. For those reasons, this institution seemed to be quite strong in its research capacity. However, despite great efforts for reducing existing difficulties in research activities by the management staff, some academics still had concerns about limited research funding and the way to obtain research grants. One other thing that was identified is the research environment which was not equal between its colleges.

\subsection{Chapter summary}

From the data collected, it could indicate that Case Two was strong in its research capacity. This originated from the following elements. First, it was a multi-disciplinary university with many leading qualified staff with good experience in research and management. Secondly, its leading staff had a broad mission of strategic development. Thirdly, it had good research funding and research facilities thanks to its strong research networks and international relations. More importantly, this institution seemed to be the pioneers in modifying national financial and research policies to meet its practical situation in order to stimulate its academics to engage in research activities. However, research capacity in its colleges of basic research, social sciences and humanities was still limited due to a lack of leading researchers, of research grants, and lack of foreign languages and international relations. 


\section{CHAPTER 6. FINDINGS: CASE THREE}

\subsection{Chapter overview}

Case Three was an institution member of Vietnam National University (VNU). This institution was well known in the field of social sciences and humanities (SS\&H) in Vietnam. It held number one ranking in the research field of SS\&H and ranked 12 in the Universities Web Ranking 2013 in Vietnam (4International Colleges \& Universities, 2013).

The findings of this case study are presented in four sections. The first section gives an overview of the case study. The second section presents the results of documentary analysis, which is followed by the third section - the results of the survey. The fourth section describes the results of the interviews. The chapter ends with a summary of Case Three's findings.

\subsection{Case Three's documentary analysis results}

Major documents used for analysis in this case include two national legal documents and institutional documents. The two national documents include Vietnam Education Law 2005, and Vietnam University Charter 2010. The institutional legal documents consiste of the website of this HEI, and the five year report of this institution's research activities. The purpose of this documentary analysis is to get insight of this institution's academic staff and research strategies and orientations.

\subsubsection{Case Three's academic staff}

According to Vietnam Education Law, Article 77, Section 2 - Education and Training for Teachers, Chapter IV - Teachers, teachers at colleges and universities must possess a university degree or higher..."(Vietnam National Assembly, 2005, p. 25). Similarly, Chapter 6 - Rights and Responsibilities of Academic Staffs, Clause 2 of Article 24 of the Vietnam University Charter (Vietnam Government, 2010a), stating the standard requirements of university academics, says that university academics must have at least university degrees and certificates of pedagogy. 
From this information it can be concluded that Case Three has strong academic staff in both teaching and research because when being contrast to the Vietnam Education Law and Vietnam University Charter, all academic lecturers of Case Three met the general requirements towards the standards of Vietnamese university academics.

Additionally, Vietnam Educational Development Strategy 2011 - 2020 (Vietnam Government, 2012b, p. 10) states that one hundred percent of Vietnamese university lecturers must be at least MA holders and competent in one foreign language by the year 2020. Presently, this institution has 577 academic staff (3 Professors, 41 Associate professors, $150 \mathrm{PhD}$ degrees and 372 master degrees, 11 bachelor degrees) out of a total of 890 staff $^{15}$. There are 11 unqualified academics. Except for the criterion of the foreign language requirement, it seems that the academic lecturers of this institution have thus currently fulfilled the requirement of this important strategy. Moreover, this institution has had over 150 doctorate degree holders, many of whom have been visiting lecturers at international universities. Therefore, this university is seen to be one of the two major HEls having the biggest number of Professors, Associate Professors and PhD holders in the domain of social sciences and humanities in Vietnam.

\subsubsection{Case Three's research strategies and orientation}

This institution has visions and missions in its future developmental strategy. Its visions and missions are posted on its website. One of its vision statements is to diversify disciplines and to develop scientific research centres towards a research-based university to reach international standards (Case Three, 2013). As a member of VNU, Case Three commits to being one of the leading institutions of Vietnam in training and research in SS\&H. Specifically, in its mission for scientific research activities, Case Three has outlined its orientation for the developmental strategy in S\&T in the domain of SS\&H, focusing on three major fields:

15 Case Three's fiscal report 2014 
The field of municipality: programmes on social-humanity issues in urban development in Southern Vietnam.

The field of culture: programmes on conserving and developing Southern Vietnam ethnic groups' cultures in the era of integration.

The field of ethnicity and religions: programmes on ethnicity and religions in urban development in Southern Vietnam.

(Case Three, 2012)

The three key fields aim to concentrate on the research projects at different levels: national, VNU, and provincial. The five year report of research output in the period 2006-2010 shows that the institution organised many S\&T activity workshops that align with its research and development mission. Its activities of S\&T development substantially contributed to solving problems of socioeconomic development in different provinces and the whole country (Case Three, 2012). Table 6-1 shows the results of Case Three's research outcome in the period of 2006-2010.

Table 6-1. Case Three 's research outcome in the period 2006-2010

\begin{tabular}{|c|c|c|c|c|c|c|c|c|c|}
\hline \multirow[t]{2}{*}{ Year } & \multicolumn{4}{|c|}{ No. of projects approved (A) } & \multicolumn{4}{|c|}{$\begin{array}{l}\text { No. of projects completed on time } \\
\text { (B) }\end{array}$} & \multirow[t]{2}{*}{$\begin{array}{l}\text { Ratio } \\
\text { of } A / B\end{array}$} \\
\hline & State & $\begin{array}{c}\text { Ministry } \\
\text { Ntl. Ui }\end{array}$ & Province & Uni. & State & $\begin{array}{c}\text { Ministry/ } \\
\text { Ntl. Ui }\end{array}$ & Province & Uni. & \\
\hline 2006 & 0 & 7 & 3 & 17 & 0 & 4 & 3 & 16 & $85 \%$ \\
\hline 2007 & 3 & 12 & 3 & 36 & 3 & 11 & 3 & 25 & $77.7 \%$ \\
\hline 2008 & 0 & 12 & 2 & 40 & 0 & 10 & 2 & 25 & $68.5 \%$ \\
\hline 2009 & 0 & $13^{*}$ & 2 & 19 & 0 & & 2 & 16 & $85.7 \%$ \\
\hline 2010 & 0 & $13^{*}$ & & 21 & 0 & & & $\left(15^{*}\right)$ & \\
\hline
\end{tabular}

Notes: Projects $\left({ }^{*}\right)$ were carrying out, not completed yet.

As can be seen, the number of ministerial and national university-level projects approved in the last four years (2007-2010) doubled the number in 2006. Yet, the number of university level projects has declined in the last two years, and the percentage of projects not completed on time has also been high. Table 6-1 indicates that in the past five years, the percentage of research projects successfully completed was quite high at $79.2 \%$. 
The report also documents that Case Three's academics published 25 papers in international scientific journals, 157 papers in national scientific journals, and 163 papers in this national institution's scientific journal. There were 191 papers presented at international conferences, 344 papers presented in national conferences, and 338 papers presented at its institutional conferences.

Most research activities in this institution have related to training activities. They include research activities for undergraduate and postgraduate students, scientific conferences for postgraduate students and young academics, studies on educational methodologies, designing new training programmes, designing teaching materials, educational assurance, and assessments (Case Three, 2012).

For its on-going operational orientations toward the activities of scientific research and technology development, this institution also has encouraged academics and staff to engage in research activities through the announcement for registering new research projects with the aim of contributing to basic theoretical research on SS\&H. It is documented that these research orientations would help to solve issues of practical life in Southern Vietnam, the Central Highland, and Ho Chi Minh City. Moreover, there are also many projects whose authors have cooperated with the provincial service of S\&T to solve the socioeconomic issues in the provinces. One of its new research orientations is to increase its revenue through scientific research and technology transfer. This operation has contributed to its revenue of 23 billion VND (approximately 1.115 million USD) over the past five years.

To promote scientific research activities, it was documented that Case Three made its SWOT analysis (strengths, weaknesses, opportunities, and threats) and withdrew lessons in the previous five years of research activities provided by academic lecturers. Then, it has outlined the plan for its developmental strategy in the period of 2011-2015, which focuses on six solutions: personnel organisation, scientific management, promotion of publications, project management, taking advantages of intellectual rights, and raising sponsorships. 
In summary, Case Three seems to have strong scientific research activities in the past five years because it has well qualified academic lecturers and some academics are leading researchers in their disciplines. Moreover, as a member of VNU, the staff in this institution believe that there are sufficient research facilities, and multiple research links for them to engage in research. Finally, the institution has a specific future strategy for research development orientations in the future.

\subsection{Case Three's survey results}

Similar to the survey results of Case One and Case Two, the survey results of Case Three were grouped into six categories: academics' research perceptions, positive factors impacting academics' research engagement, negative factors impacting academics' research engagement, academics' satisfaction towards PD activities organised by institution, academics' satisfaction towards PD activities organised by faculty, and academics' regular PD activities. The details of these categories are discussed in the following sections.

\subsubsection{Research perceptions}

The survey has seven items of research perceptions for exploring respondents' level of agreement. Table 6-2 presents the results of the perception of the academics in Case Three. This table shows that the majority of respondents strongly agreed with seven research perceptions in the survey. However, the number of respondents that stated 'neither agree nor disagree', 'disagree', and 'strongly disagree' for items A4, A5, A6, A7 was quite high, nearly one-third of the respondents in the study.

For item A4 - research perceived as process, there was agreement that the process of qualitative research is different to the process of quantitative research. Also, the process of research in different disciplines is not the same. The result of item A4 showed that seven participants answered strongly disagree and disagree and five participants answered neither agree nor disagree. This finding seemed to be acceptable because the participants in this study were from different disciplines and they might use different research processes in their studies. 
Table 6-2. Case Three's results of academics' research perceptions

\begin{tabular}{|c|c|c|c|c|c|c|c|}
\hline \multirow[t]{2}{*}{ Item list } & \multirow{2}{*}{ 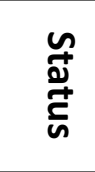 } & \multicolumn{5}{|c|}{ Scale of agreement } & \multirow{2}{*}{ 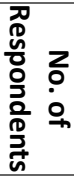 } \\
\hline & & SD & $\mathrm{D}$ & $\mathrm{N}$ & A & SA & \\
\hline \multirow{3}{*}{$\begin{array}{l}\text { A1. Research perceived as a process of discovering, } \\
\text { uncovering or creating understandable meanings }\end{array}$} & $\mathrm{M}$ & 1 & & 1 & 4 & 11 & \\
\hline & $\mathrm{L}$ & 1 & & 4 & 8 & 11 & \\
\hline & total & 2 & 0 & 5 & 12 & 22 & 41 \\
\hline \multirow{3}{*}{$\begin{array}{l}\text { A2. Research perceived as the creation of new } \\
\text { knowledge and innovative approaches to the } \\
\text { discovery of that knowledge }\end{array}$} & $M$ & & & & 8 & 9 & \\
\hline & $\mathrm{L}$ & 1 & 1 & 4 & 10 & 9 & \\
\hline & total & 1 & 1 & 4 & 18 & 18 & 42 \\
\hline \multirow{3}{*}{$\begin{array}{l}\text { A3. Research helped to develop one's personal } \\
\text { knowledge and research methods }\end{array}$} & $\mathrm{M}$ & 1 & & & 8 & 8 & \\
\hline & $\mathrm{L}$ & 1 & & 2 & 7 & 14 & \\
\hline & total & 2 & & 2 & 15 & 22 & 41 \\
\hline \multirow{3}{*}{$\begin{array}{l}\text { A4. Research perceived as the process of data } \\
\text { collection, data analysis, then reporting its } \\
\text { research findings }\end{array}$} & $M$ & 1 & 1 & 1 & 11 & 3 & \\
\hline & $\mathrm{L}$ & 1 & 4 & 4 & 8 & 8 & \\
\hline & total & 2 & 5 & 5 & 19 & 11 & 42 \\
\hline \multirow{3}{*}{$\begin{array}{l}\text { A5. Research means presenting new ways of } \\
\text { seeing the world, oneself or a problem }\end{array}$} & $M$ & & & 1 & 13 & 3 & \\
\hline & $\mathrm{L}$ & & 1 & 8 & 13 & 4 & \\
\hline & total & 0 & 1 & 9 & 26 & 7 & 43 \\
\hline \multirow{3}{*}{$\begin{array}{l}\text { A6. Research perceived as establishing oneself in } \\
\text { the field, and developing oneself personally }\end{array}$} & $M$ & 1 & 1 & 1 & 6 & 6 & \\
\hline & $\mathrm{L}$ & 1 & 4 & 3 & 9 & 8 & \\
\hline & total & 2 & 5 & 4 & 15 & 14 & 40 \\
\hline \multirow{3}{*}{$\begin{array}{l}\text { A7. Research perceived as a way to fulfil } \\
\text { academics' requirements }\end{array}$} & $\mathrm{M}$ & 2 & 2 & 2 & 6 & 5 & \\
\hline & $\mathrm{L}$ & 1 & 3 & 3 & 11 & 7 & \\
\hline & total & 3 & 5 & 5 & 17 & 12 & 42 \\
\hline
\end{tabular}

Like the case of item A4, the respondents had a similar scale of agreement for the cases of item A5 (Research means presenting new ways of seeing the world, oneself or a problem), A6 (Research perceived as establishing oneself in the field, and developing oneself personally), and A7 (Research perceived as a way to fulfil academics' requirements). It appears that academics' purposes for research engagement are different; some academics are not as motivated to research new ways of seeing the world as others. Some academic lecturers, especially the junior ones, may not wish to establish themselves in the research field because they may wish to have a better material life by taking on extra jobs instead of engaging into research which is poorly paid. The intention of establishing oneself in a specific academic community perhaps only suits senior, experienced, leading national and international research experts.

Research is a compulsory requirement for university lecturers in the Vietnam HE system. Therefore, it is surprising to find that eight respondents stated strongly disagree 
and disagree and four respondents stated neither agree nor disagree for item A7 (see Table 6-2). Meanwhile, this institution stated that its goal is to become a researchoriented university. Therefore, it may suggest that it is a surprising finding.

Interestingly, there was one respondent in this case that provided his/her own perception or definition of research as scientific research should be practically applied in teaching and it should avoid the disease of high achievement. Currently the terms the disease of negativeness and the sickness of high achievement in education are often mentioned by Vietnamese government officials, educational managers and educators. The sickness of negativeness and sickness of high achievement in education include cheating in examinations in offering and using false certificates, wasting the state budget and reporting a better result for performance (Borg \& Alshumaimeri, 2012). As a result, the MOET implemented the Government's Directive $33 / 2006^{16}$ about an initiative saying no with negativeness and the sickness of high achievement in education. Currently, the Government has focused on huge financial investments in research activities in the HE system. Therefore, this senior lecturer would prefer to add his idea of research perception in the current context of the Vietnamese tertiary system.

In summary, most academics in this institution had as positive a perception of research as their foreign colleagues in previous studies such as a study by Bai et al. (2012), Borg (2009), and Borg and Alshumaimeri (2012). Interestingly, the perception of one Vietnamese senior academic lecturer scientific research should be practically applied in teaching and it should avoid the sickness of high achievement could seem to be not just a part of the current dominant ethos in the West.

\subsubsection{Positive factors impacting academics' research engagement}

Table 6-3 shows positive factors affecting academics' research engagement in Case Three. The table shows that three items (B2, B3, and B4) received more negative evaluations from 'unimportant' to 'moderately important' in the scale of the degree of importance 1 (unimportant) - 5 (very important).

\footnotetext{
16 The Government Directive 33/2006 CT-TTg on struggling the negativeness and achievement disease in education (Chỉ thị số 33/2006/CT-TTg về chống tiêu cực và khắc phục bệnh thành tích trong giáo dục)
} 
Table 6-3. Positive factors impacting the academics' research engagement in Case Three

\begin{tabular}{|c|c|c|c|c|c|c|c|}
\hline \multirow[b]{2}{*}{ Engaging in research to } & \multirow{2}{*}{ 导 } & \multicolumn{5}{|c|}{$\begin{array}{l}\text { Scale of the Degree of } \\
\text { Importance }\end{array}$} & \multirow{2}{*}{$\begin{array}{l}2 \\
? \\
0 \\
0\end{array}$} \\
\hline & & $\mathbf{U}$ & $\mathbf{L}$ & M & I & VI & \\
\hline \multirow{3}{*}{$\begin{array}{l}\text { B1. Become a (associate) professor or receiving } \\
\text { promotion. }\end{array}$} & $\mathrm{M}$ & 3 & 3 & 4 & 5 & 2 & \\
\hline & $\mathrm{L}$ & 7 & 3 & 8 & 4 & 2 & \\
\hline & Total & 10 & 6 & 12 & 9 & 4 & 41 \\
\hline \multirow[t]{3}{*}{ B2. Have better salary raises. } & $\mathrm{M}$ & 2 & 7 & 4 & 4 & 1 & \\
\hline & $\mathrm{L}$ & 4 & 4 & 12 & 1 & 2 & \\
\hline & Total & 6 & 11 & 16 & 5 & 3 & 41 \\
\hline \multirow[t]{3}{*}{ B3. Get promotion in the role of management. } & M & 8 & 6 & 1 & 1 & 1 & \\
\hline & $\mathrm{L}$ & 9 & 6 & 3 & 2 & 1 & \\
\hline & Total & 17 & 12 & 4 & 3 & 2 & 38 \\
\hline \multirow[t]{3}{*}{ B4. Get a reduced teaching load. } & M & 3 & 9 & 3 & 1 & 1 & \\
\hline & $\mathrm{L}$ & 5 & 9 & 6 & 1 & & \\
\hline & Total & 8 & 18 & 9 & 2 & 1 & 38 \\
\hline \multirow[t]{3}{*}{ B5. Gain a higher status in professional career. } & $M$ & & 2 & 2 & 10 & 3 & \\
\hline & $\mathrm{L}$ & 1 & 1 & 5 & 7 & 7 & \\
\hline & Total & 1 & 3 & 7 & 17 & 10 & 38 \\
\hline \multirow{3}{*}{$\begin{array}{l}\text { B6. Reflect research competence, improve } \\
\text { teaching skills, and find out better teaching } \\
\text { methods. }\end{array}$} & $\mathrm{M}$ & 1 & & 2 & 7 & 8 & \\
\hline & $\mathrm{L}$ & & & 1 & 9 & 14 & \\
\hline & Total & 1 & 0 & 3 & 16 & 22 & 42 \\
\hline \multirow{3}{*}{$\begin{array}{l}\text { B7. Get the respect and high evaluation from } \\
\text { students. }\end{array}$} & $\mathrm{M}$ & 2 & 2 & 4 & 5 & 4 & \\
\hline & $\mathrm{L}$ & 1 & 2 & 6 & 4 & 9 & \\
\hline & Total & 3 & 4 & 10 & 9 & 13 & 39 \\
\hline \multirow{3}{*}{$\begin{array}{l}\text { B8. Satisfy the need of contributing knowledge to } \\
\text { my professional field, need of discovery, and need } \\
\text { for creativity. }\end{array}$} & $M$ & 1 & & & 7 & 10 & \\
\hline & $\mathrm{L}$ & & & 1 & 12 & 9 & \\
\hline & Total & 1 & 0 & 1 & 19 & 19 & 40 \\
\hline \multirow{3}{*}{$\begin{array}{l}\text { B9. Contribute to the overall improvement of the } \\
\text { department and institution. }\end{array}$} & $\mathrm{M}$ & & & 3 & 8 & 6 & \\
\hline & $\mathrm{L}$ & 1 & 1 & 6 & 9 & 5 & \\
\hline & Total & 1 & 1 & 9 & 17 & 11 & 39 \\
\hline \multirow{3}{*}{$\begin{array}{l}\text { B10. Have better opportunities to study higher in } \\
\text { the country and abroad. }\end{array}$} & $\mathrm{M}$ & 1 & 1 & 4 & 5 & 6 & \\
\hline & $\mathrm{L}$ & 1 & 1 & 5 & 9 & 6 & \\
\hline & Total & 2 & 2 & 9 & 17 & 12 & 42 \\
\hline \multirow{3}{*}{$\begin{array}{l}\text { B11. Have good collaboration from other } \\
\text { colleagues. }\end{array}$} & $M$ & 1 & 1 & 7 & 4 & 3 & \\
\hline & $\mathrm{L}$ & 1 & 1 & 7 & 10 & 4 & \\
\hline & Total & 2 & 2 & 14 & 14 & 7 & 39 \\
\hline
\end{tabular}

Notes: - U (unimportant); L (little important); M (moderately important); I (important); VI (very important) - M: Academic Manager; L: Lecturer

This finding shows that Case Three's academics did not consider the factors of getting promotion in administrative management, having better salary raises, and reduction of teaching loads to have great impacts on their research involvement. In other words, the external factors of promotion to management, finance, and teaching hours did not hugely affect the academic lecturers. 
However, for item B1 (becoming a (associate) professor or receive promotion), nearly two-thirds of respondents in the study evaluated this item from 'moderately important to very important'. This finding seemed to imply that the external factor of high academic titles was an important motivator for the academics in the study to engage actively in research. Getting high academic titles seemed to be preferred to getting promotion in management by the respondents. Maybe, the respondents felt afraid of spending too much time in political meetings instead of academic meetings and they might feel somehow uncomfortable with this way of getting promotion in management. There are 'political' elements in many public universities in Vietnam presently.

In contrast, the factors from B5 (offering a higher status in professional careers) to B11 (good collaborations from other colleagues) appeared to be considered important to the respondents. They wanted to gain a higher status in professional careers, improve and discover better teaching methods, gain respect from students, satisfy the need for discovery and creativity, contribute to the development of their working places, opportunities to study higher in the country and abroad, and good collaboration with colleagues. These findings appeared to suggest that the academic lecturers in this university were highly motivated to contribute knowledge to the community and discover knowledge for themselves. They were also influenced by the working environment. When the working environment fosters collaborations and creates good opportunities to study, these factors appear to have a great impact on academics' research engagement.

In summary, it can be stated that the respondents' research engagement capacity seemed to be influenced by internal factors (B8) - satisfying the need for contributing knowledge to profession, the need of discovery and for creativity, (B9) - contributing to the overall development of the workplace. However, their research engagement capacity appeared not to be greatly impacted by external factors of having high salaries (B2), getting promotion in management (B3), and heavy teaching loads (B4). In contrast, the external factor of getting a high status in academic titles such as becoming A/Prof or Professor (B1) seemed to be considered as a motivator to their research engagement. 
Similarly, other external factors related to an academic research environment such as having opportunities to study higher (B10), and good collaboration from colleagues (B11), being respected by the academic community (B5) and respected by students (B6) were believed to be positive motivators to the respondents' research engagement.

\subsubsection{Negative factors impacting academics' research engagement}

Table 6-4 indicates the findings of negative factors impacting academics' engagement in research. In the four first factors of negative research perceptions (C1: research is a burden towards university academics; C4: research provides low salaries), more participants had low levels of agreement for factors C2 and C3 than for factors C1 and C4. Two participants from the Faculty of Literature \& Linguistics and one participant from the Faculty of Journalism \& Communication responded 'agree' and 'strongly agree' to factor $\mathrm{C2}$. These two faculties were considered to be less strong in scientific research activities in recent years by one leader from the office of research project management. It was noted that seven participants from the Faculty of English Linguistics \& Literature and the Faculty of Oriental Studies agreed with factor C3. It was possible that the academics in these faculties had more teaching hours (including teaching hours in and out of the institution) than academics in other faculties. Nineteen out of 44 participants agreed with factor C4 (research provides low salaries) whereas seven participants with doctoral degrees had opposite ideas. Perhaps, the seven doctoral participants became familiar with research work and procedures for research grants. 
Table 6-4. Factors negatively affecting the academics' research engagement in Case Three

\begin{tabular}{|c|c|c|c|c|c|c|c|}
\hline \multirow{2}{*}{$\begin{array}{l}\text { Factors that hinder me to engage in scientific } \\
\text { research activities }\end{array}$} & \multirow[b]{2}{*}{ 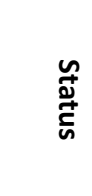 } & \multicolumn{5}{|c|}{ Scale of Agreement } & \multirow{2}{*}{ 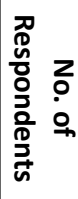 } \\
\hline & & SD & D & $\mathbf{N}$ & A & SA & \\
\hline \multirow[t]{3}{*}{ C1. Research is a waste of time } & $M$ & 1 & 5 & 1 & 3 & 5 & \\
\hline & $\mathrm{L}$ & 4 & 1 & 3 & 9 & 10 & \\
\hline & Total & 5 & 6 & 4 & 12 & 15 & 42 \\
\hline \multirow[t]{3}{*}{ C2. My job is teaching, not research } & $\mathrm{M}$ & 6 & 4 & 3 & & & \\
\hline & $\mathrm{L}$ & 9 & 9 & & & 1 & \\
\hline & Total & 15 & 13 & 3 & 0 & 1 & 32 \\
\hline \multirow{3}{*}{$\begin{array}{l}\text { C3. Research is a heavy extra burden towards university } \\
\text { academics }\end{array}$} & $\mathrm{M}$ & 5 & 4 & 4 & 1 & & \\
\hline & $\mathrm{L}$ & 4 & 9 & 8 & 4 & 2 & \\
\hline & Total & 9 & 13 & 12 & 5 & 2 & 41 \\
\hline \multirow[t]{3}{*}{ C4. Research provides low salaries } & $\mathrm{M}$ & 2 & & 3 & 2 & 8 & \\
\hline & $\mathrm{L}$ & & 7 & 3 & 10 & 6 & \\
\hline & Total & 2 & 7 & 6 & 12 & 14 & 41 \\
\hline \multirow{3}{*}{$\begin{array}{l}\text { C5. There were few opportunities and conditions to conduct } \\
\text { research in the workplace }\end{array}$} & $\mathrm{M}$ & 3 & 4 & 2 & 4 & 1 & \\
\hline & $\mathrm{L}$ & 3 & 10 & 6 & 5 & 1 & \\
\hline & Total & 6 & 14 & 8 & 9 & 2 & 39 \\
\hline \multirow[t]{3}{*}{ C6. There is a lack of research grants } & M & & 4 & 1 & 4 & 3 & \\
\hline & L & 1 & 5 & 4 & 9 & 5 & \\
\hline & Total & 1 & 9 & 5 & 13 & 8 & 36 \\
\hline \multirow{3}{*}{$\begin{array}{l}\text { C7. Inadequate time available for research due to other heavy } \\
\text { duties }\end{array}$} & $\mathrm{M}$ & & 4 & 1 & 6 & 4 & \\
\hline & $\mathrm{L}$ & & 12 & 9 & 4 & & \\
\hline & Total & 0 & 16 & 10 & 10 & 4 & 40 \\
\hline \multirow[t]{3}{*}{ C8. There is a high pressure to publish } & $M$ & 3 & 4 & 4 & 3 & & \\
\hline & $\mathrm{L}$ & 2 & 12 & 5 & 5 & 1 & \\
\hline & Total & 5 & 16 & 9 & 8 & 1 & 39 \\
\hline \multirow{3}{*}{$\begin{array}{l}\text { C9. The procedure to get research grant is complex and time } \\
\text { consuming }\end{array}$} & $\mathrm{M}$ & & 4 & 4 & 3 & 2 & \\
\hline & $\mathrm{L}$ & 2 & & 6 & 11 & 7 & \\
\hline & Total & 2 & 4 & 10 & 14 & 9 & 39 \\
\hline \multirow{3}{*}{$\begin{array}{l}\text { C10. The lack of research facilities such as reference books, } \\
\text { experiment labs }\end{array}$} & $\mathrm{M}$ & 1 & 3 & 2 & 6 & 4 & \\
\hline & $\mathrm{L}$ & 0 & 5 & 5 & 5 & 9 & \\
\hline & Total & 1 & 8 & 7 & 11 & 13 & 40 \\
\hline \multirow{3}{*}{$\begin{array}{l}\text { C11. Lacking the leader's support and colleagues' } \\
\text { collaborations }\end{array}$} & $\mathrm{M}$ & 2 & 4 & 2 & 7 & & \\
\hline & $\mathrm{L}$ & 6 & 8 & 7 & 2 & & \\
\hline & Total & 8 & 12 & 9 & 9 & 0 & 38 \\
\hline \multirow[t]{3}{*}{ C12. Most colleagues not engaging in research } & M & 2 & 2 & 7 & 4 & & \\
\hline & $\mathrm{L}$ & 6 & 10 & 6 & 1 & 1 & \\
\hline & Total & 8 & 12 & 13 & 5 & 1 & 39 \\
\hline \multirow{3}{*}{$\begin{array}{l}\text { C13. The university (workplace) not having specific research } \\
\text { orientation and strategies }\end{array}$} & $\mathrm{M}$ & 5 & 2 & 6 & 2 & & \\
\hline & $\mathrm{L}$ & 7 & 6 & 7 & 3 & 1 & \\
\hline & Total & 12 & 8 & 13 & 5 & 1 & 39 \\
\hline \multirow[t]{3}{*}{ C14. Not understanding clearly the process of doing research } & M & 7 & 5 & 1 & 1 & & \\
\hline & $\mathrm{L}$ & 12 & 7 & 3 & & 1 & \\
\hline & Total & 19 & 12 & 4 & 1 & 1 & 37 \\
\hline \multirow[t]{3}{*}{ C15. Unconfident about research methods } & $\mathrm{M}$ & 3 & 7 & 3 & 1 & 1 & \\
\hline & $\mathrm{L}$ & 9 & 6 & 5 & 4 & & \\
\hline & Total & 12 & 13 & 8 & 5 & 1 & 39 \\
\hline
\end{tabular}

Notes: - SD (strongly disagree), D (disagree), $N$ (neither agree nor disagree), A (agree), and SA (strongly agree) - M: Academic Manager; L: Lecturer

The factors from C5 to C13 in Table 6-4 were considered as factors of the research environment. The respondents' evaluations of the factors are varied. For instance, most respondents assumed that factor C5 (few opportunities and conditions to 
conduct research), factor $\mathrm{C} 6$ (insufficient research grants) and factor $\mathrm{C7}$ (insufficient time for research) were the important factors blocking their research engagement. Meanwhile, about one-third of the respondents did not agree with these three factors as vital obstacles. This result could reflect that academics in different disciplines and faculties would have different opportunities, conditions, and ways to approach research grants for their research. It seems that having good opportunities, conditions, and sufficient funds for research depends greatly on academics' proactivity, and flexibility in research, and their clear understanding of how to obtain research grants. Although the respondents are in the same university, their faculties' operation and administration are different.

However, many respondents disagreed that factors C8 (there was a high pressure to publish), C10 (the lack of research facilities), C11 (the lack of leader's support and coworkers' collaborations), C12 (most colleagues not engaging in research), and C13 (the university not having specific research orientations and strategies) were big hindrances. These findings seemed to be a positive signal for this university because most other universities in Vietnam do not often have good and sufficient research infrastructure. The good relationship of multi-dimensions (leader-academics relationship; academicacademic relationship) is a favourable condition in this institution to develop its research capacity. Significantly, factor C9 (the complexity and time consuming in obtaining research grants) was considered as a big negative factor impacting on academics' research involvement with 32 out of the total of 44 respondents agreeing. The two remaining factors of understanding the research process (C14) and confidence in research methods (C15) were not seen as negative factors by the academics in this institution. This is not surprising as all the respondents were at least MA holders, and they are from a university with strong research activities in the field of SS\&H.

To sum up, the factors of finance (low salary), time, heavy teaching hours, and research experiences were considered as motivators for academics' research engagement in this case study. Additionally, the factors related to research environment in this institution were not viewed as negative factors in their research environment. Nevertheless, it is noticeable that the factor of a slow and complex process to get 
research grants and limited opportunities and conditions to conduct research are believed to be unfavourable factors for academics to engage in research activities in this institution.

\subsubsection{PD activities}

The outline of the survey results of the PD activities in Case Three is structured the same as that of Case One and Case Two. The results of the PD activities organised in Case Three are presented as follows.

\section{PD activities organised by the institution}

Table 6-5 shows that the number of respondents who evaluated the activities held by the institution as good and very good is nearly equal to the number of respondents who evaluated them as barely acceptable. It is quite strange that there were three respondents recording not sure whereas three respondents evaluated them with a poor level. Overall, the majority of the respondents highly rated the activities organised by the institution.

Table 6-5. Academics' level of satisfaction with PD activities organised by the institution

\begin{tabular}{ccccccc}
\hline $\begin{array}{c}\text { No. of the } \\
\text { Respondents }\end{array}$ & Very poor & Poor & $\begin{array}{c}\text { Scale of quality evaluation } \\
\text { Barely } \\
\text { acceptable }\end{array}$ & Good & Very good & Not sure \\
\hline 41 & 0 & 3 & 18 & 11 & 6 & 3 \\
\hline
\end{tabular}

PD activities organised by the faculty

The data in Table 6-6 illustrate that more respondents rated activities organised by the faculty more highly than activities organised by the institution. However, the number of respondents (6) who gave negative evaluations of the activities organised by the faculty was also higher than the number of respondents (3) who evaluated the activities organised by the institution. It seemed that some PD and research activities organised in the faculty did not meet academics' expectations.

Table 6-6. Academics' level of satisfaction with PD activities organised by the faculty

\begin{tabular}{cccccccc}
\hline $\begin{array}{c}\text { No. of the } \\
\text { Respondents }\end{array}$ & Very poor & Poor & $\begin{array}{c}\text { Scale of quality evaluation } \\
\text { acceptable }\end{array}$ & Good & Very good & Not sure \\
\cline { 2 - 7 } & 2 & 4 & 12 & 16 & 17 & 1 \\
\hline
\end{tabular}




\section{Academics' regular professional activities}

Most participants in the study stated that in the past twelve months they attended seminars/workshops related to their disciplines to improve their scientific research methods and skills that were organised by their faculty or other faculties in the university. They also participated in all academic meetings and conferences organised by the faculty. They often arranged their time to be able to attend the talks from key national and foreign presenters invited by the university.

The participants practised various individual PD activities. They read many research materials in Vietnamese and foreign languages related to their disciplines to update their professional and research knowledge. Some conducted their own research projects or joined in institutional research groups and networks to learn, share and update research knowledge and experiences. Some even were teaching in foreign cooperative universities as visiting lecturers. They also designed teaching materials, instructing students to conduct scientific research projects, and supervised undergraduate and postgraduate students' theses. In the Vietnam tertiary institutions these are considered to be scientific research activities.

\section{Summary of the survey results}

The findings of the survey reflected academics' research perceptions, factors impacting academics' research engagement, academics' levels of satisfaction with the activities organised by the institution and the faculty, and their own regular practices for improving their research competence. Firstly, for research perceptions, the findings seemed to show that most respondents had a good understanding of the research role, procedures and processes to conduct research, and benefits of research activities to academics' professional careers and to the community. Yet, one respondent who had a lot of experience in the Vietnamese HE system desired others to be aware that Vietnamese tertiary educators should avoid 'the achievement disease' in participating in scientific research activities as other activities in the Vietnam educational system recently reported. 
Secondly, for factors affecting research engagement, the survey shows that internal factors (such as the improvement of personal knowledge, and the satisfaction of curiosity for discovering new things and contributing knowledge to the community) seemed to be considered to sufficiently motivate academics to be involved in research activities. The external factors including institutional working environment (having opportunities to study higher and collaboration from colleagues, being supported by the leader, specific institutional research goals), and personal ambitions (gaining a high academic title, being respected by the academic community and by the students) appeared to have positive influences on their research engagement. It is possible to say that external factors are weighted more than internal factors.

For factors hindering academics' research involvement, they included limited research time, insufficient research facilities, low research payment, and complicated procedures to obtain research grants. Interestingly, the survey shows that the factors of heavy teaching loads, getting promotion to management seemed not to be considered as important factors impacting their research engagement.

Thirdly, the survey also indicates that academics did not regard research and PD activities organised by the institution as being better than those held by the faculty. Finally, the respondents had a wide range of regular PD activities such as participating in departmental, institutional seminars and workshops, domestic and foreign conferences, reading research materials, conducting research projects, joining in institutional research groups and networks, writing teaching materials, teaching in foreign universities as visiting lecturers, supervising undergraduate and postgraduate students' theses, and instructing students to do research.

\subsection{Case Three's interview results}

There were nine participants taking part in the interview. Six of them were academic managers and the three others were academic lecturers. The qualifications of the interview participants included seven PhD holders, two of whom were Associate Professors. Two other interviewees who had more than five years' experience in 
managing research affairs in this university held MA degrees. The contribution of deep insights into research knowledge and practice of the participants in the interviews was valuable for this research. Figure 6-1 delineates the interview participants in Case Three.

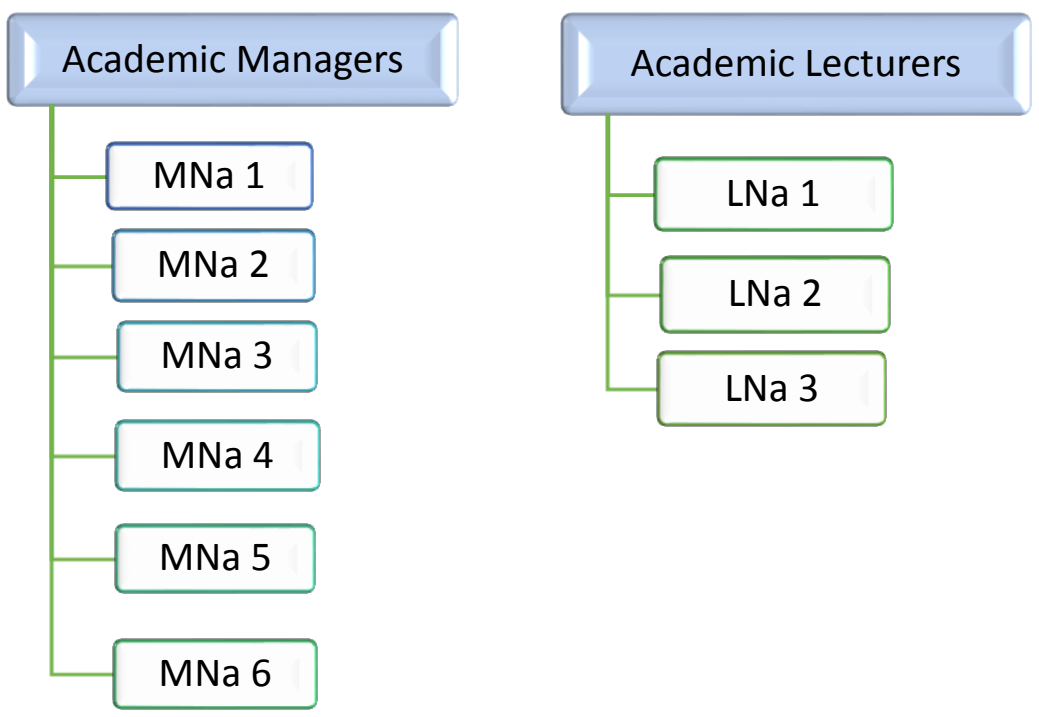

Figure 6-1. Case Three's interview participants

Similarly, the interview results of Case Three were presented into two main groups of factors: individual factors and institutional factors. These two groups of factors were impacted by social contexts. Details of individual and institutional factors affecting the research engagement of the academics in this case study were described below.

\subsubsection{Individual factors}

Like the two previous cases, individual factors affecting the academics' research engagement in Case Three were analysed according to their disciplinary knowledge, research experience, research motivation, research confidence, research network, foreign language competence, and familiarisation with the journals needed for publication.

\section{Disciplinary knowledge}

The participants' disciplinary knowledge was very different. Table 6-7 indicates the survey participants' disciplinary knowledge in terms of their academic titles. 
Table 6-7. Case Three's survey participants' degrees and titles

\begin{tabular}{|c|c|c|c|c|c|c|}
\hline & \multicolumn{3}{|c|}{ MA Degrees } & \multicolumn{3}{|c|}{ PhD Degrees } \\
\hline \multirow[t]{2}{*}{ Academic Titles } & & & & A/Prof & \multicolumn{2}{|c|}{ Prof } \\
\hline & & & & 7 & \multicolumn{2}{|c|}{0} \\
\hline \multirow[t]{2}{*}{ Types of lecturers } & L & SL & $A L$ & L & SL & $A L$ \\
\hline & 21 & 1 & 0 & 7 & 14 & 0 \\
\hline Total Number & \multicolumn{3}{|c|}{22} & \multicolumn{3}{|c|}{21} \\
\hline Notes: & Lec & : S & ctur & Advanc & urers & \\
\hline
\end{tabular}

A majority of the participants joined in teaching undergraduate courses. For the participants with doctorate degrees, they also taught master's courses, and doctorate courses in disciplines of history, anthropology, culturology, and Vietnamese language and literature. It could be stated that all participants in Case Three had more than sufficient knowledge in their disciplines. Some of them even could be considered as leading academic researchers in their disciplines.

\section{Research experience}

It could be stated that the participants in Case Three had good research experience. The data from the open-question part of the questionnaire showed that doctoral degree participants, in the past two years, frequently supervised master and doctorate students, wrote course books for their teaching subjects, and were invited to teach in some foreign universities in Japan and South Korea. They also attended and presented at domestic and international conferences related to their disciplines. Additionally, some were organisers of scientific research conferences for junior academics and students in their faculties every year. Moreover, four participants in this group were the chairpersons of national-level and National University-level research projects. Master's participants joined groups for writing their teaching course books and their teaching materials. A great majority of the participants reported that they often participated in research conferences organised at their institution and at VNU. Many participants wrote papers for these conferences and even for foreign conferences and journals. To sum up, all the activities reported in the survey showed that Case Three's participants seemed to have good research experiences in their disciplines. 


\section{Research motivation}

The participants' research motivation could be recognised from their research awareness and research passion. For research awareness, it seemed that most of Case Three's academics had positive research awareness. Many interview participants considered that when having good research awareness, academics would become more active in research activities. For instance, $\mathrm{MNa} 1$ stated that research awareness originated from academics' awareness of responsibilities, including the role of university lecturers, and responsibilities for communities such as workplaces, and the country.

He commented that if academics did not fully commit themselves to being university lecturers, they would not have actively been involved in research activities. However, he pointed out one negative signal by stating that:

Unfortunately, it seems that many academics, especially the young ones in this institution are not active enough to participate in research due to not having a full awareness of their role as university lecturers. (MNa1)

He continued by saying that most of them just performed their role of teaching, not for the role of research. He confirmed that such a lack in performance would not meet the requirement for university lecturers. $\mathrm{MNa} 1$ seemed to imply that many academics in his institution simply ignored their duty to research. He stated that:

As university lecturers, besides the duty of teaching, we have the other important duty - that is the duty of research, which is clearly stated in the Vietnam Education Law. (MNa 1)

Similarly, LNa 1 commented that many academics in Case Three were just like high school teachers (the third level in the Vietnamese education system). They just performed the role of teaching, not of research. He concluded that teaching well was not enough for university lecturers. He confirmed that

University lecturers must do research, otherwise, they would be considered as teachers of level four, not university lecturers at all. (LNa 1)

LNa 1 added that in reality many teachers at high school now were also conducting research to improve their knowledge and to help renew their teaching methods. LNa 1 confirmed that in order to become competent in research, it was important that university academics know about their role as a lecturer. 
In addition to research awareness, research passion was considered an essential element of research motivation that enables academics to be competent in research. For the participants, research passion could be seen in academics' self-learning and selfdiscovery, their ambition to develop themselves, and to contribute to the development of the community.

\section{Attitudes of self-learning and self-discovery}

The participants revealed that the majority of academic researchers and research experts had a great research passion. If they did not have research passion, they could not become good and active researchers. For the participants, research passion was understood as the attitudes of self-learning and self-discovery. For instance, LNa 1 stated that:

Research passion can be seen from the academics' attitudes of self-learning and self-discovery although conditions for conducting research in Vietnam were not as good as in foreign countries. (LNa 1)

The attitude of self-learning was shared by LNa 2 when he mentioned the issue of being strong in research, stating that:

Academics themselves need to read as many research documents as possible and do not stop learning from other good people and colleagues. (LNa 2)

LNa 2 continued to explain that once academics spent time reading materials, they would find gaps in their research fields. Then, they would have some ideas to develop and to write about. Thus, he ascertained that the necessity of reading, self-learning, and self-discovering may help academics be active in research:

As academic lecturers, we must know what gaps are in our research fields. By doing that, we must read and read more. (LNa 2)

Meanwhile, MNa 6 considered that it should be common for university lecturers to have the attitude of self-learning and self-discovery in their personalities. She said:

As academic lecturers, they must always learn more and more. It does not mean that once they get some type of degree in their field such as MA or PhD degrees then they stop learning. (MNa 6)

To emphasise self-learning, $\mathrm{MNa} 6$ revealed her negative feeling about a misconception - 'it is enough for Vietnamese university academics to hold a PhD degree' 
currently held by many Vietnamese HE academics. She believed that many university academics misunderstood the Government's requirement. She explained that our government, in fact, required Vietnamese university academics from now on to have a $\mathrm{PhD}$ degree because gaining a PhD degree is just a step on the journey to research. Perhaps, after spending her years of studying in England, MNa 6 was open-minded and would understand the differences between western academics' views and Vietnamese academics' views about the significance of studying for a PhD and obtaining a PhD degree. She said that:

It is completely wrong at tertiary level when saying that it is enough for academics to get $\mathrm{PhD}$ degrees, and then there is no need to study higher...Research is so vast and learning is unlimited. ( $\mathrm{MNa} 6$ )

To confirm the benefits of being involved in research, MNa 6 stated that research would enable academic lecturers to nurture and obtain new knowledge that they had learned, and simultaneously, this knowledge would be more enlightening. Then, she concluded that academics must research and gain some achievement in research to update their knowledge.

\section{Ambition to develop themselves and to develop the community}

MNa 1 considered that academic researchers always had ambitions to discover new things for themselves and for communities. They tried to overcome difficulties in achieving research ambitions. MNa 1 affirmed that:

Senior academic researchers in this university had a better devotion to professional careers and scientific research than young academic researchers although the young ones presently have better research conditions. (MNa 1)

MNa 1 complained that the academics now appeared to have so many demands in their jobs for their research involvement. He took himself as an example for overcoming difficulties to gain certain achievements in his career. He wondered whether the younger generation in general and young university academics in particular were now being affected by the emergence of a market economy in Vietnam.

LNa 2 revealed that young academics seemed not to have the spirit of overcoming hardships and they did not have ambitions for their professional careers. As their 
priorities, they seemed first to seek earning money by rushing into having as many classes to teach as possible. The consequence of this choice was that they had limited time for their scientific research activities. Then, when waking, they would have little time to redeem what they have done. LNa 2 concluded:

As university academics, we need to have a great will. Instead of having a minor think like 'cooked rice, clothes, rice, money' (cơm, áo, gạo, tiền), we need to have a big think for our future achievement, for organisation and university, and for our country. (LNa 2)

LNa 2 also perceived that academics' research passion could be seen from their regular PD activities. He said that he had a great passion for scientific research activities. He always saved time for research in his limited time. He added that by so doing, he had to sacrifice his personal leisure time and his time for family. Besides, he said that he created his own research document library at home. He ascertained that:

I have no difficulties about research documents and materials; I am afraid of having little for my research. For this reason, I am feeling isolated among my colleagues. (LNa 2)

When comparing the result of item $\mathrm{C} 4$ (research provides low salaries) in Table 64 as one of the factors hindering academics to engage in research, the result showed that the number of the respondents agreeing with item C4 was three times higher than the number of respondents who disagreed. For this reason, it can be said that when academics have great ambition in research, they will overcome the difficulty of items like money and sacrificing their family and leisure time for their research passion.

In conclusion, the academics, particularly the young ones in Case Three, were considered to have a negative research awareness. They spent limited time on research. Perhaps the recently emerging market economy in Vietnam caused them to be more practical about life by seeking more teaching hours rather than being devoted to research and being respected in the academic world.

\section{Confidence in research}

Confidence in research can be seen in the understanding of research processes, employing research methods, and administrative procedures for research activities. The participants in this study appeared to have great confidence in their scientific research 
activities. The background information from the interview participants indicated this. As mentioned above, the interview participants included seven PhD degree holders (2 A/Profs) and two master degree holders who had much experience in their supportive administration. Most of these participants were supervising their students' theses. Two of them were conducting a national-level research project. LNa 1 shared his confidence in research by stating that when he was a faculty Dean, he supported and instructed junior academics in his faculty to do research. He helped them with editing their papers for submission. He said that he was also a leading member in the faculty's research group. He went on to state that:

In order to be a good example in research for young academics in the faculty, as a senior lecturer without management jobs, I have more time for research and am in the progress of conducting a research project. (LNa 1)

Likewise, LNa 2 said that he attended and submitted his papers to plenty of national and foreign conferences. He added that he often submitted articles to many domestic and foreign journals related to his discipline. He said that:

By doing that, I have to read a lot and have a deep insight into my discipline. More importantly, I can learn what conferences and journals need in our papers. (LNa 2)

Meanwhile, MNa 1 shared that in comparison with other colleagues, he was lucky to have good opportunities to keep in touch with his foreign supervisors and to work with many leading experts and professors in his disciplines. This could imply that this participant had confidence in research in general and in other research activities in particular. With his confidence in research and good relationships with foreign famous experts, MNa 1 was designated to be a leader in his department.

Additionally, the participants' confidence in research could be seen in the findings of the survey. For instance, the results of items C14 (Not understanding clearly the process of doing research) and C15 (Unconfident about research methods) in Table 6-4 show that a majority of questionnaire participants had great confidence in their research methods and had a good understanding of the research process. There were only 4 out of 19 MA participants who did not seem to be confident in research methods. Most of these MA participants were from the Faculty of English Linguistics \& Literature, and the Faculty of Oriental Studies. The academics in these two faculties were considered to 
have the heaviest teaching loads in this institution. Therefore, it seemed that the participants had few opportunities and little time for their research activities.

\section{Research network}

It can be considered that the participants in the study had a wide range of research networks. Their research network was from their institution's research network and from their own relationships. This institution and its faculties had a variety of domestic and foreign research networks. Their foreign research links were mainly from their faculty or others in the institution. It was documented that this university had over twenty training and research links with foreign universities and non-governmental organisations (Case Three, 2014a). Besides, this institution had good research links with provincial departments of S\&T. For this reason, whenever there were new announcements of local research projects from these provincial departments, the announcements were updated and uploaded on the website of the Department of Research and Project Management in this institution. This wide range of research links helped its academics by creating and expanding their personal research networks. For instance, LNa 1 said that he had good relationships with some domestic journals in his discipline and officials in some provincial departments of S\&T. Thus, he became a regular writer in such journals and he was also informed of new research announcements related to his discipline from the officials. LNa 3 said that he frequently attended all the domestic and international conferences held in his institution and neighboring institutions to update knowledge and expand his research links. MNa 4 said that she often invited famous research experts whom she met at conferences to share their research experiences with the staff in her faculty.

\section{Foreign language competence}

Interestingly, one important element of individual factors found in this study that seemed to greatly affect academics' research engagement was foreign language barriers, especially English language barriers. MNa 1 said that foreign language barriers were a big obstacle for Vietnamese academics, especially for academics' research competence in the domain of social sciences and humanities as he said that: 
The barriers of foreign languages, especially English, greatly obstruct Vietnamese academics with their publications in foreign journals. ( $\mathrm{MNa} 1$ )

Meanwhile, MNa 6 admitted that foreign language barriers greatly limited academics' research ability, especially when they wished to submit to foreign journals. She added that in fact presently her institution required academics to have more publications in international journals. She continued to say that there was a big paradox between academics' research skills and knowledge and their English language competence in the university. She stated:

Some academics who are strong and have profound knowledge in their research fields but are still limited in their English language competence and vice versa. This paradox restricts academics much in submitting their papers in foreign journals. (MNa 6)

Additionally, LNa 1, as a senior researcher in the field of history, asserted that the weak competence in English language hugely hindered academics to publish their papers in foreign journals. Taking his own example, he stated:

I myself wish to have my papers published in foreign journals but I cannot express my thoughts with my current English language competence. That is a big obstruction. And if you want your papers to be translated, its meaning will not be exactly correct because the translators do not have a good understanding in our discipline. (LNa 1)

Similarly, LNa 3 acknowledged that one important difficulty for Vietnamese academics of SS\&H to have their papers published in foreign journals was the English language barrier.

It is apparent that foreign academics still have some difficulties in writing scientific papers for submitting to journals. For Vietnamese academics, there is no doubt that they would have more difficulties. Especially, the written language used in scientific papers is an academic English language that is more difficult than normal English language.

\section{Familiarisation with journals' format requirements}

The fact of whether to be familiar with a journal's format requirements or not was considered as an important hindrance for academics' expectation to publish their papers in journals. For instance, LNa 3 commented that the format requirement of foreign journals when being accepted for publication was actually a big problem. He continued 
that foreign journal formats were different from Vietnamese journal formats, and the journal formats were also different in different disciplines. He considered that despite having English writing competence and not being familiar with the journal's format needed for publication, academics would surely meet difficulties in their publications.

Likewise, $\mathrm{MNa} 6$ admitted that being familiar with the journal's format requirements needed for publication was important, so academics needed time to learn its required format. She stated:

Obviously, besides the problem of foreign language barriers, academics need to have time for observing and understanding the format requirement of the journal which they want for their published articles. ( $\mathrm{MNa} 6$ )

\section{Summary of individual factors}

In conclusion, all individual factors identified to have impacts on the participants' research engagement in Case Three could be categorised into two groups: positive impacts and negative impacts. For positive impacts, they included disciplinary knowledge, research experience, intrinsic motivation, confidence in research, and research networks. It could be said that the participants in this institution had a strong disciplinary knowledge, research experience, intrinsic motivation, confidence in research, and research networks. Negative individual factors consisted of foreign language barriers, negative research awareness from a few academics, and unfamiliarisation with the journals' formats needed for publication. These factors seemed to greatly inhibit their research engagement.

\subsubsection{Institutional factors}

In addition to individual elements, institutional factors were considered to have a considerable impact on academics' research engagement. These institutional factors included governmental policies, its funding and structure, its resources, and its research environment. 


\section{Governmental policies}

The institutional factors are impacted by Vietnam's recent policies for the development of its HE system such as the Education Development Strategy for 2001-2010 approved by the Prime Minister in December 2001, and the Government Resolution on Substantial and Comprehensive Renovation of Vietnam HE in the period of 2006-2020 which all aimed to improve and update Vietnam's HE quality and research. Specifically, it was stated in the Educational Development Strategy for the 2001-2010 period that:

Training must be linked with research, application, implementation and technology transfer" and "partnership between training and research institutions and the business sector shall also be formed to solve problems arise out the labour market and technology market through training contracts, joint research contracts, development of university enterprises etc.

(Vietnam Ministry of Education and Training, 2006, p. 2)

Related to the development of research activities in HEls, the Government Resolution on substantial and comprehensive renovation of Vietnam HE in the period 2006-2020 stated that the State shall invest in upgrading existing capable research institutes in tertiary education institutions and building a number of new ones, with investment being concentrated on key universities for the immediate future. Simultaneously, the research tasks of lecturers must be actively intensified (Vietnam Government, 2005)

Besides these two important governmental policies, Vietnam's Government focused on developing high-quality human resources for its HE system by issuing Project 322 - Training scientific and technical staff overseas by the state budget (Vietnam Government, 2000), Project for Teaching and learning foreign languages in the national education system, period 2008-2020 (Vietnam Government, 2008), and Project 911 (Training Vietnamese academics at HEls to obtain PhD degrees abroad for the period 2010-2020) (Vietnam Government, 2010b).

Based on these important government directives, Case Three aimed to become a strong research-oriented university in the country and the region by stipulating its research tasks to achieve its strategic development towards 2020. It was documented 
that research was an important field of activity in this institution's academic life. Its academics were required to regularly conduct research as part of their duties. Its students were also encouraged to participate in research activities annually (Case Three, 2012). This stipulation about research activities seemed somehow to challenge newly established faculties and departments and lecturers with heavy teaching loads. This institution's Rector Board perceived the important role of a foreign language, especially English, to academics' research capacity. For this reason, many intensive English training courses have regularly been opened to train the academics in this institution in the past years. MNa 2 said, his Rector confirmed that the institution would become a strong research-oriented university by 2015 . Thus, all lecturers needed to actively participate in research activities. Especially, there should be an increase in the number of international publications from the lecturers. However, $\mathrm{MNa} 2$ had a concern that it was hard to encourage the lecturers from newly established faculties like the Faculty of Oriental Studies and the Faculty of International Studies, and even the Faculty of English Linguistics \& Literature, because they had heavy teaching loads. For an increase in foreign journal publications, MNa 2 considered that the difficulty was the lecturers' foreign language competence, especially the English language barrier. Having the same ideas as $\mathrm{MNa} 2, \mathrm{MNa} 4$ stated that:

There is a big disparity about academics' foreign language competence in our institution. Many young academics from the faculties teaching foreign languages are good at foreign languages but have limited research experiences and a limited ability to write scientific papers while many senior academics having good research abilities are not good at foreign languages. (MNa 4)

In summary, even though there is an appropriate policy for the development of institutional research activities without synchronising effective measures to solve longexistent problems of foreign language barriers and of the imbalance of research and teaching time, such a policy seemed to cause some pressure for academics in engaging in research.

\section{Funding and structure}

It can be stated that research funding and its funding mechanism plays an important role in enhancing institutional research activities. However, it seemed that the 
mechanism of research funding and the limited resource of finance generally had a negative impact on academics' research engagement at this institution. MNa 2 commented that they had more limited autonomy for research finance than before (the time this institution became a university member of the National University).

Another reason is that it is hard to get the research fund from The National University because most our research projects are basic research whereas the National University prioritises to finance for applied research. (MNa 2)

In fact, the information shared by MNa 2 was in line with the state's policy of a higher priority for the financial investment into applied research than basic research (Khanh, Ly, and Tuan, 2012). Recently, Decision 418 by the Prime Minister 'Strategic Plan on S\&T Development in the 2011-2020 Period' does not even mention the focus for basic research investment. There is one line saying that "enhancing HEIs' research capacity on basic research" (p. 5). The important question posed is how to invest and enhance institutions' research capacity (Khanh et al., 2012). MNa 2 admitted that her institutional research fund was also lower than before due to the economic difficulty of the country; thus, it greatly affected the whole institution's research activities. Besides, this interviewee had a concern about the administrative mechanism from the VNU. She said that she had worked here for a long time but sometimes she did not understand what some directive documents said. Those documents contained many spelling mistakes and technical errors causing a difficulty in understanding them. She said that she and other academics from other institution members of VNU repeatedly complained about that problem. She believed that those documents were typed by junior staff but their managers did not have time to review them.

In addition to the limited research funding, some participants complained about complicated procedures to receive research funding. LNa 1 stated that in spite of the system being computerised, there were still many obstructions. He added that the staff in the office of finance, for instance, asked him to provide them with a great number of receipts. He wondered how academic researchers could do the job of finance. LNa 1 concluded that if financial staff had sympathy with academics' difficulties in conducting research and gave academics clear guidance with the financial procedure, the academics 
would be more motivated to conduct research. If not, this was really a barrier to academics' participation in research activities.

Similarly, LNa 2 expressed that many academics hesitated to be involved in research activities because they thought it was complicated to gain research grants although they had some intention of conducting research. She said that there should be some simplification in administrative procedures related to scientific research activities. Besides, she added:

Our current policy - not encourage lecturers who have PhD degrees to conduct institutional-leveled research projects hugely restricts academics' research activities (LNa 2).

LNa 2 pointed out the shortcoming of her institutional policy that junior academics could not conduct research due to limited research experience while experienced academics who wished to conduct research to support their teaching jobs were not approved by the institution's management staff. She suggested that it needed to determine the scope of their research and examine whether that study fitted with National University level research projects or institutional level ones. LNa 2 continued saying that:

Procedures to get research funding at this institution are complicated, and procedures to get research funding from the National University are even more complicated. (LNa 2)

Related to the procedure to get research for this case study, the finding of item C9 in the survey (Table 6-4) shows that most survey participants agreed that it was a complex and time consuming procedure. Even 13 academic managers (including master and doctorate degree holders) out of 15 academic managers who participated in this research agreed that the procedure to get research grants is very complex and time consuming.

In summary, it seems that the research funding and administrative structure, in many participants' views, had a negative effect on the academics' research engagement. Particularly, procedures to gain institutional research grants and procedures to receive research payment seemed to be very problematic. Moreover, this institution was under 
the management of VNU. Thus, the matter of gaining research grants at higher level management seemed to be harder for Case Three's academics because VNU had a higher priority to fund applied research projects.

\section{Resources}

Lecturers and academic managers had different ideas about the issue of resources for research. From the viewpoint of lecturers, research facilities in this institution were still limited. For instance, LNa 2 said that the limited research resources in this institution partly hindered her research engagement. She noted:

I cannot find out the documents about linguistics in the $17^{\text {th }}, 18^{\text {th }}, 19^{\text {th }}$ centuries in this institution's library, which was considered as the largest one in Vietnam. (LNa 2)

Similarly, the interview LNa 3commented that he rarely went to the Library to search for his disciplinary research; instead, he made use of his own-home library, because he stated that it took a lot of time to search for research documents and he often found nothing. LNa 3 said that he had quite good research documents in his discipline thanks to the introduction of new and interesting research books from the conferences he attended and from recommendations by friends in his research links. In fact, a number of survey participants who agreed that 'the lack of research facilities such as reference books, experiment labs' (item C10 in Table 6-4) nearly tripled the number of participants that disagreed with this item.

However, MNa 1 stated that he often heard many lecturers complaining "we do not have enough time for research and the university does not have sufficient research facilities such as document references and research guidebooks". He asserted that such utterances were not true. From his management angle, he guaranteed that the university nearly had everything needed by academics to conduct their research:

In fact, our institution has nearly everything necessary for lecturers to do research. I believe that the matter of whether academics want to participate in research activities stays in their awareness. (MNa 1)

MNa 1 continued to say that he had a concern that many young academics just wanted to earn money by rushing into finding many classes to teach. They did not have 
an awareness of research as a part of their roles as university lecturers. This interviewee also expressed that his institution was going to do something to change the negative perception of research of many academics so they would understand the significance and value of scientific research. He stated:

At the moment our university has to do something to change their minds and awareness about the significance and value of scientific research. (MNa 1)

It was acknowledged that as a member of VNU, this institution had good research facilities and research networks. It is apparent that academics' research engagement matches individual academics' awareness. However, it is quite hard to find special research materials of particular disciplines from the library. Therefore, it is necessary to create a good communication channel between academics and support staff.

\section{Teaching loads}

It is apparent that the teaching loads partly affected university academics' research engagement because besides the task of research, academics had to fulfil their task of teaching. The findings of the study showed that heavy teaching loads had a considerable impact on academics' involvement in research activities. For instance, MNa 1 admitted that due to heavy teaching loads, the lecturers in his institution had limited time for their research. Thus, it partly caused them not to develop their research capacity. Additionally, MNa 2 said that in her observation, some faculties considered to be less strong in research capacity could be related to a high ratio of students/lecturer such as the Faculty of Oriental Studies, the Faculty of English Linguistics \& Literature, and the Faculty of International Studies. MNa 2 added that besides teaching classes in their faculty, they had to teach in other faculties, and even in other universities and extra classes in evening foreign language centres. MNa 2 raised a question "where is their time for research?" He continued to say that:

The thing concerning me a lot is that most lecturers now become so practical. They want to teach more classes to earn money instead of saving their time for research to gain a better future. (MNa 2)

However, the finding shows that most participants did not consider item B4 (get a reduced teaching loads) as a strong enabler. Perhaps whether academics have enough 
time for research or not relies on their proper time arrangement. It is not a consequence of heavy teaching workloads.

In summary, there appears to be little doubt that heavy teaching loads greatly affect academics' research capacity. In practice, university academics' wages are not as high as in many other countries and the pay for research at Vietnam's tertiary education level is still low. It is acknowledged by the government that now it is hard for Vietnamese academics to live on their own official salaries. Therefore, it can be perceived that the simplest way to gain extra pay is to seek suitable classes to teach. Particularly, in the public's eyes, it seems that university academics receive a high income. For this reason, the task of earning money seems to be an invisible pressure on young academics.

\section{Leadership}

Interestingly, one finding of this study showed an apparent impact of leadership on academics' research capacity, including leadership ability, leadership style, and leadership transition. For instance, LNa 1 considered that the faculty Dean's management roles played an important part in determining the strength or weakness of the faculty's research competence. He stated that when lecturers respected their leader, it would be more comfortable for the leader to run their organisational system. He said that particularly in the academic environment of HEls, the faculty Dean's leadership role was more important than in other organisations. Thus, in order for lecturers to respect leaders, LNa 1 stated that:

The faculty leader or the Dean must have enough professional knowledge and academic title so that they could direct and give good academic advice to the faculty academics. (LNa 1)

LNa 1 added that the faculty leader should also have a good understanding of research activities. He said that the faculty with a less qualified leader would have some difficulties in encouraging academics to engage in research activities. He continued that in addition to having good professional knowledge, the faculty leader should have good management ability, which would mean the faculty leader could understand academics' strong and weak points so that they could give appropriate advice to each academic. 
Moreover, LNa 1 conveyed that the faculty Dean should have a good understanding of management as he said:

The faculty Dean's leadership roles are important. He has good management ability, and vision. He should know how to define its objectives. (LNa 1)

Furthermore, LNa 1 had a concern that the affairs of the institution's recent personnel organisation partly affected academics' research ability. Meanwhile, M6.6 considered that once academics felt pleased with their faculty Dean's leadership style, it would be easier for the faculty Dean or the university Rector to carry out their management role. MNa 6 explained that recently there had been a leadership transition in the institution's management structure; therefore, in most academics' feelings, they seemed to be observing the situation.

In conclusion, the element of leadership was considered to have some impact on academics' research engagement in this institution. This study found that leadership factors that influenced academics' research engagement included leadership ability, leadership style, and leadership transition.

\section{Research environment}

There is no doubt that if an institution has an advantageous research environment, it would enable academics to be active in research engagement, and vice versa. The findings of Case Three showed that the institution had quite a supportive research environment. Firstly, Case Three had a strong profile of scientific research in the field of SS\&H in Vietnam. Secondly, it possessed strong research staff in this field because many leading experts in the field of SS\&H converged in this institution. Its young lecturers were quite energetic and active because this university is located in the hub city of Vietnam. As a member of VNU, Case Three received greater attention from the Government in many aspects. Moreover, it had a range of domestic and international training and research links. Furthermore, it has had a specific goal to become a strong researchoriented university in the region of South East Asia and in the world. Its research activities have been numerous in the previous years. For instance, in 2011 it organised six international conferences, and helped VNU to host two international conferences 
(Case Three, 2014b). There were also many workshops and seminars on sharing and improving research skills held in the faculties.

However, there still existed a big difference in faculties' research capacity. For instance, MNa 1 stated that faculties with heavy teaching loads and that focus more on teaching, had a weaker research capacity. Faculties with no postgraduate training programmes were not strong in engaging research. Having the same idea with MNa 1, MNa 4 considered that in general, her academics were quite strong in research capacity because they were supported and received advice from many leading researchers in her faculty:

One more advantageous point is that many academics in my faculty are teaching postgraduate courses. ( $\mathrm{MNa} 4)$

Similarly, MNa 5 admitted that his faculty was not strong in research capacity because there was no postgraduate training programme in his faculty. He conveyed that his lecturers seemed to have no new ideas in research as he said:

Our lecturers' ideas are just like students' ideas. They hardly have new initiatives because they do not teach in postgraduate classes. (MNa 5)

MNa 5's comments seemed to imply that if academics were in charge of teaching postgraduate programmes, they would have more opportunities to deepen and update their disciplinary knowledge than academics only in charge of teaching undergraduate programmes.

Moreover, LNa 1 expressed that a good research environment could be understood as the faculty that annually organised a wide range of PD and research activities. Then, the lecturers in that faculty could have more opportunities to share and discuss their research experiences together. He stated that:

If a faculty regularly holds many workshops and seminars on PD and research activities, that faculty will become strong in research capacity. Then, of course, its academics can surely become competent in research. (LNa 1)

LNa 1 continued that a positive research environment was where its leader worked as a head researcher and that the leader must know how to create research groups in that faculty and even create research links beyond the faculty. Moreover, the 
leader had to provide professional advice and some encouraging timely words when academics met difficulties in their research activities. LNa 2 said that a positive research environment was the one where all members in the faculty, including the leader and academics, joined in research, and where all members could comfortably raise their research questions to share in the faculty. He said:

Sometimes I feel like I am isolated and unsupported when I share my research problems with my colleagues in my faculty... So, such a faculty is not considered to have a good research environment. (LNa 2)

LNa 3 suggested that the university should create more opportunities for academics to upgrade their knowledge by providing finance for them to attend as many relevant conferences as possible. She said that when attending such conferences, they would enrich their disciplinary and research knowledge as she said in the Vietnamese language 'không bổ bề ngang cũng bổ bề dọc' - literally translated 'their knowledge could be nurtured horizontally or vertically'. She said that in fact, not many academics in her institution were not supported to attend conferences.

\section{Summary of institutional factors}

Case Three had a favourable research environment such as its reputation, its qualified academics in the field of training and research, plenty of domestic and foreign research links, and its clear oriented research strategy. This advantageous research environment has substantially contributed to encouraging its academics to engage in research. Still, there has been a difference in its faculties' research capacity. Therefore, it is necessary for this institution's leaders as well as its faculty leaders to revise their current research capacity and find ways to enhance the research capacity in weaker research faculties.

\subsection{Chapter summary}

In conclusion, with its specific goal to become a research-oriented university by the year 2015 , this institution had issued its own internal relevant policies to enhance the research capacity. Specifically, a wide range of PD and research activities had been held to enhance its academics' research capacity. Additionally, research facilities and the research environment in this institution were relatively good for academics to engage in 
research. However, there were still some concerns about institutional factors impacting on academics' research engagement. Firstly, there was a considerable difference in research capacity among faculties. Secondly, some faculties still had heavy teaching loads and did not have strong leading research academics to direct other academics to engage in research activities. Thirdly, the procedure to address research funding and the procedure for research payment were still complicated. Finally, policies for research support were still not clear to many academics. 


\section{CHAPTER 7. CROSS-CASE ANALYSIS}

\subsection{Chapter overview}

This chapter presents a cross-case analysis of the findings of the three cases: provincial, regional, and national. The study identifies that the research capacities of the three Vietnamese HEls are influenced by factors at three levels: societal, community, and institutional. Factors at societal level comprise socioeconomic, sociocultural, and political factors. Factors at community level consist of resources, research orientation, research networks, and PD practices at the HEls. Factors at institutional level include establishment history, geographical location, and organisation. This study's results support the findings of the previous studies examining factors impacting HE academics' research productivity and their research engagement. Literature shows that the research engagement and research productivity of university academics are affected by various levels: individual, institutional, community, and societal (Bland et al., 2005; Chen el al., 2006; Moore, 2015). However, how individual factors influence the research capacity of the three HEls was not analysed because this study views institutional research capacity as a collective research phenomenon for analysis. Therefore, this study focuses on analysing how social, community and institutional factors affect the research capacity of the three HEls, and how institutional contexts impact on the research perceptions, research motivation, and research engagement of the academics in these institutions. The key findings of this research are discussed in this chapter, followed by a chapter summary.

\subsection{Key findings}

Based on the analytical framework for exploring factors affecting the Vietnamese academics' research engagement in Chapter 3, this study identified the influences of societal, community, and institutional factors on the research capacities of the three HEls and their academics' research perceptions, as presented in Figure 7-1. This figure shows that the research capacity of Vietnamese HEls and the research engagement of the Vietnamese university academics are influenced by societal, community, and institutional factors. The discussions of this study's key findings are based on Figure 7-1 
to analyse how societal, community and institutional factors affect these three Vietnamese HEls' research capacity and their academics' research perceptions.

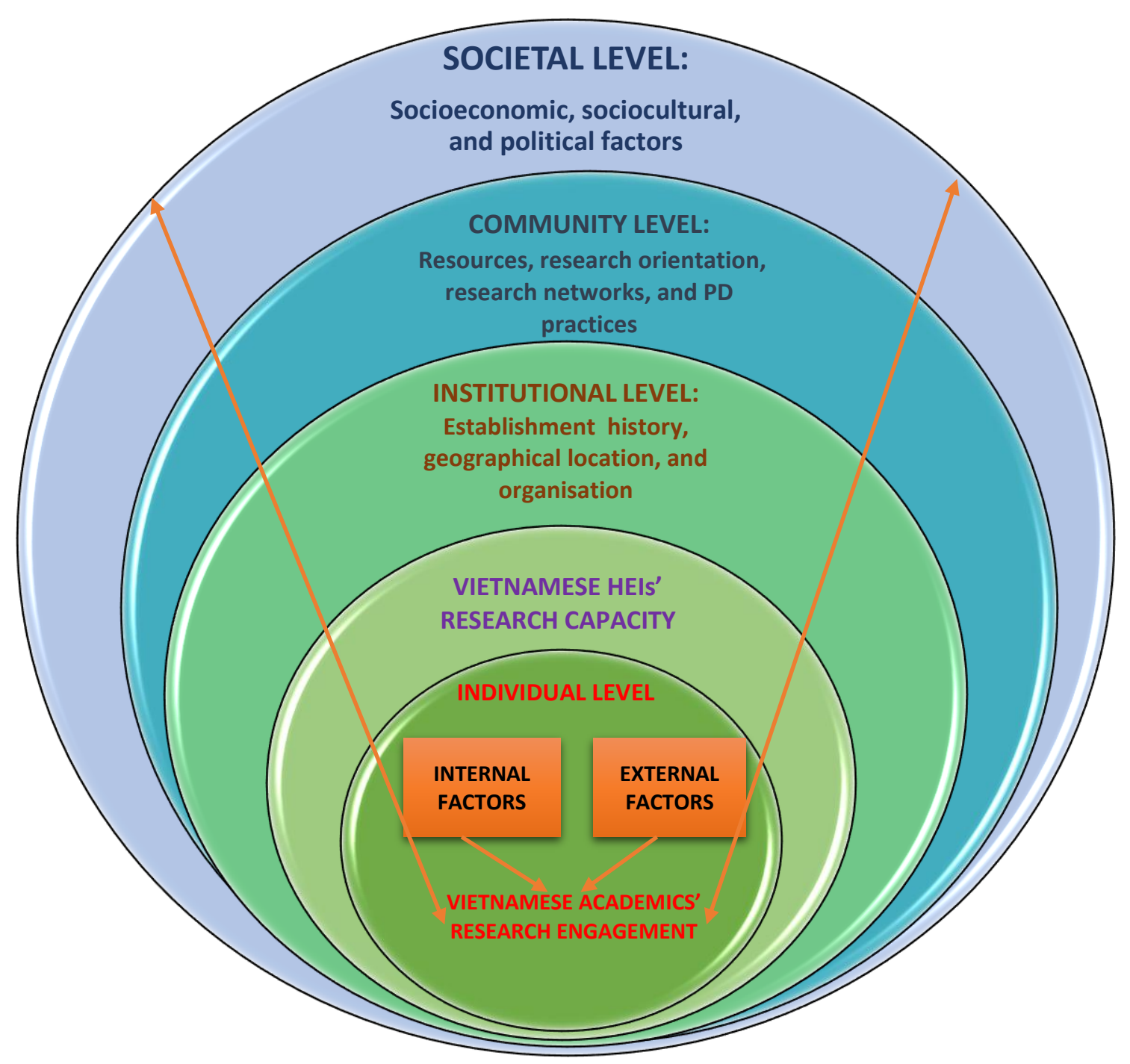

Figure 7-1. The impact of societal, community, and institutional factors on the research capacities of the three HEls studied and their academics' research engagement 


\subsection{Impact of factors at societal level}

Three factors at the societal level affecting the Vietnamese HEls' research capacity as well as their academics' research engagement include socioeconomic, sociocultural and political factors. The impact of the factors at the societal level is analysed in detail in the following sections.

\subsubsection{Socioeconomic factors}

Vietnam's politico-economic reform (Đổi Mới) was launched in 1986, and since then the country adopted the market-oriented economy. Vietnam has transformed its economic, cultural, and social activities from one of the poorest countries in the world, with per capita income around $\$ 100$, to lower middle income status within a quarter of a century with per capita income of over $\$ 2,000$ by the end of 2014 (The World Bank, 2015). Its politico-economic context has impacted the operations of its HE system, especially on HEls' research activities since its Higher Education Reform Agenda (HERA) was activated in 2005. The overall objective of the HERA for the period 2006-2020 is to create the Vietnamese HE system that by 2020 , 'advanced by international standards, highly competitive, and appropriate to the socialist oriented market system.' Its specific objectives are to increase S\&T activities being carried out within universities, to develop key HEls into major scientific centres for the entire country, and to increase income from S\&T activities to account for at least 15\% of total HE income by 2010 and $25 \%$ by $2020^{17}$ (G. Harman \& Ngoc, 2010). Specifically, the research capacity of the three HEls has been affected in three aspects (commercialisation of university research, researchteaching link, and selection criteria for research projects) under the Vietnamese politicoeconomic context (Figure 7-2).

17 Resolution No. 14/2005/NQ-CP, dated 2 November 2005 


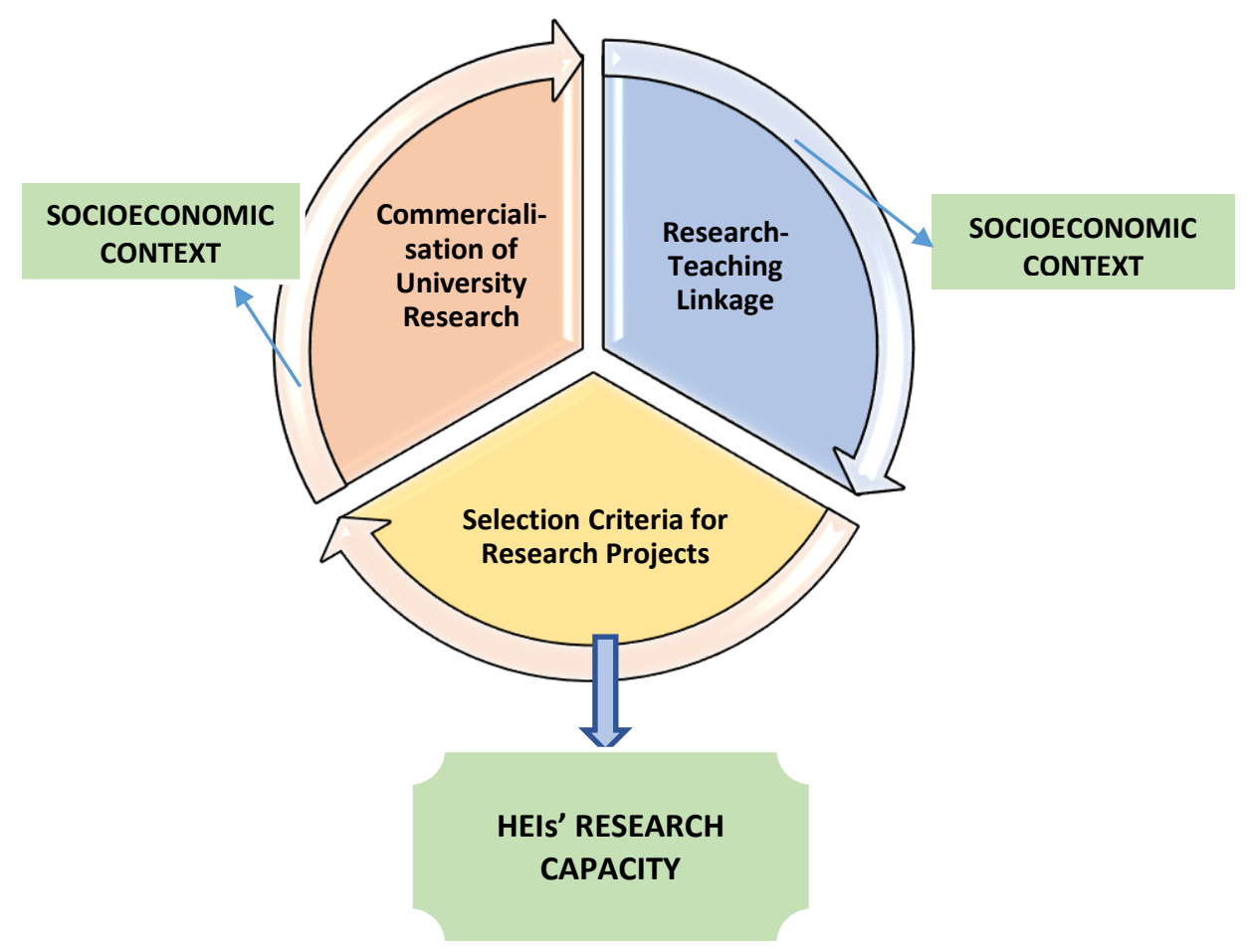

Figure 7-2. Socioeconomic factors affecting the research capacities of the three HEls

\section{Commercialisation of university research}

Commercialisation of university research is seen as the first element affected by political and economic changes. The commercialisation of university research was more visibly reflected in the regional and national institutions. Three academic managers (two from Case Three and one from Case Two) suggested that research activities at Vietnamese HEls were now becoming commercialised. However, the commercialisation of university research was not explicitly identified from Case One because no participants from this institution mentioned it. It was likely because very few important research projects were conducted by its academics for the past ten years. The study found that the commercialisation of university research was reflected by academics' research income and research in specific disciplines.

For academics' research income, the study found that non-material encouragement seemed to be no longer effective for boosting academics' research engagement. Now, academics' thoughts are becoming more materialistic. From different perspectives, two participants (one senior lecturer and one academic manager) from Case Three shared the view that the commercialisation of university research 
originated from effects of market economy. The academic manager perceived that the junior academics in his institution had a tendency to convert everything, including their research tasks, into money. Consequently, the academics have a greater devotion towards research projects that have greater research funding. In fact, since the Government's policy 'Đổi Mới' (Renovation), which transitioned from a centralised planned economy to a market oriented economy, has affected Vietnamese people's activities especially in the aspect of economics, including research activities at HEls. Similarly, an academic manager from Case Two said that the issue of 'cơm-áo-gạo-tiền ${ }^{18 \text { ' }}$ was given a higher priority than professional reputation by the academics when they undertook research. He added that academics' idealisation to contribute into the national development through non-monetary rewards was gradually fading. This finding supports studies of Owen-Smith and Powell (2001), Thursby, Jensen, and Thursby (2001), and Lach and Schankerman (2008), which found a positive link between financial incentives and the motivations of inventors to patents. In summary, financial incentives or monetary rewards seem to be more important than non-pecuniary factors for junior academic researchers, especially the academics in an emerging economy country like Vietnam, to engage in research activities.

This study also found that there was a difference in the influential degree of university research commercialisation on different disciplinary research projects across the three institutions. the commercialisation of basic research projects and research projects in domains of education and SS\&H was much weaker than in other domains. Research commercialisation is obvious in the research environment of the faculties in each institution. The commercialised degree of research projects and the research environment in the applied engineering faculties were stronger and more active than those in other faculties. For example, in Case One, the research environment and research capacity of the faculty of Agriculture \& Natural Resources were more dynamic and stronger than five other faculties (see Table 4-2, Chapter 4). Similarly, in Case Two,

\footnotetext{
18 'cơm-áo-gạo-tiền' is literally translated into English as 'cooked rice - clothes - rice - money'. As it is the fact that Vietnam is an agricultural country - the second largest rice exporter in the world, the culture of rice is exposed in a wide range of Vietnamese everyday language. This phrase has an equivalent meaning that the material benefit is more important than the spiritual benefit.
} 
the research environment and research capacity of the applied engineering faculties and research institutes were very dynamic and strong. In the interview, a senior manager of this institution stated that a majority of the important national and foreign research projects conducted in this institution were undertaken by the academics from the Colleges of Applied Agriculture, Aquaculture \& Fisheries, and the academics from the Institutes of Biotechnology Research \& Development, and Mekong Delta Development. It is also evidenced by the data from Table 5-8 in Chapter 5 that most of Case Two's important research projects conducted in the period 2006-2010 belonged to domains of applied engineering, especially in the fields of agriculture and environment. This result is supported by the interview data from another academic manager from this institution. He stated that the research environment of a university or faculty became dynamic once it gained more external financial support. It was very hard for colleges/schools of SS\&H and Education in this institution to gain external financial support because most of their research projects were for teaching disciplines only, and did not meet the organisation's application requirements.

The research environment and research capacity of Case Three were not as dynamic and strong as those of Case Two because Case Three only provided training courses and conducted research projects related to SS\&H. This institution faced difficulties to gain the research grants from VNU, ministerial and national research agencies because most of the research grants are given to research projects related to applied engineering domains. In reality, businesses generally finance university research that produces intellectual property utilised by the organisation. Commercialisation of university research occurs when university researchers conduct studies that lead to a discovery and have potential to yield commercial value (Smyth \& Smart, 2012). Thus, it is more difficult for the faculties of education and SS\&H in the three institutions to conduct research that yields high commercial value. Consequently, the research environment at HEls, and in their faculties of education and SS\&H is less dynamic. In other words, the research engagement and research capacity of the faculties of education and SS\&H are much weaker than those in applied engineering faculties. 
In conclusion, commercialisation of university research in Vietnam has only begun recently, and especially, since 1993 when the Vietnamese Government began to pay a greater attention to the development of its $\mathrm{HE}$ system and research activities at HEls. The socioeconomic changes in Vietnam at recent times inevitably cause university cutback in research, which affects its HEIs' research capacities, and their academics' research engagement. However, the effects of research university commercialisation are not the same between the HEls and faculties majoring in applied engineering disciplines and those majoring in SS\&H and education. Therefore, it is necessary that the Government and the MOET strongly invest in basic research and give particular support to university research areas to which businesses pay little attention.

\section{A linkage of research and teaching}

The findings across the three institutions indicate that the link between research and teaching at these institutions was not strong and that the research capacity of Case Two was the strongest. For Case Three, despite being considered to be one of the two Vietnamese strongest research HEls in the field of SS\&H, its research and teaching link was not strong. There were two participants from this institution who mentioned the research and teaching link at Vietnamese HEls. One stated that in order to enhance the research capacity of Vietnamese HEls, the link between research and teaching needed to be reinforced. He continued that this link in his institution was not strong due to limited finance and research resources, and especially academics' low motivation for research. The other considered that the link between research and teaching was very important for university academics because they might update their teaching materials, regulate their ways of teaching, and be respected by their students. However, he admitted that this link was not very strong in his institution.

As previously mentioned, although the research environment and research capacity of Case Two was stronger than those of Case One and Case Three, the research and teaching link of Case Two was also identified as not strong as well. For instance, three academic managers ( $M R e 1, M R e ~ 2$, and $M R e ~ 3)$ in this case had the same idea that the link between research and teaching in most Vietnamese HEls in general, and in 
their institution in particular, was not strong. MRe 1 said that the link between research and teaching was likely to be marginally seen in the faculties and research institutes of applied engineering technology but rarely seen in faculties of education and SS\&H in his institution. Similarly, MRe 2 commented that there was actually no link between research and teaching at the Vietnamese HEls, which is completely different to foreign universities that highlight research and teaching link. He added that foreign universities even gave higher priority to research tasks. He implied that the consequence of no research and teaching linkage at Vietnamese universities was that a majority of research reports and postgraduate theses were administratively processed, and left on the library bookshelves without wide publications. He commented that in terms of teaching activities, many Vietnamese HEls were actually 'level four' schools ${ }^{19}$. He implied that the teaching style at university was not different from the teaching style at school, and suggested that the teaching style at Vietnamese universities should be changed. MRe 3 pointed out the reality of teaching and research activities at Vietnamese universities when he stated that many Vietnamese university academics only 'dạy lý thuyết suông' or 'day chay'. These phrases highlight the meaning that they just performed a theoretical teaching, without applying research results. He continued that this style of lecturing was not suitable at HEls and it could neither improve their teaching and research capacity nor students' learning outcomes. He added that when a university had a strong research and teaching link, it is considered as a criterion to differentiate a university and a school, and to distinguish between a university lecturer and a school teacher.

The link between research and teaching was not identified in Case One. It was possible that the number of research conducted at this institution was very limited since it was established. For this reason, the participants from this institution did not feel confident to provide any ideas relating to the link between research and teaching. This finding supports the studies of Knight (1987), Brown (2005), Brew (2006), and Jenkins et al. (2007). For instance, Knight (1987) found it impossible to separate good teachers

\footnotetext{
${ }^{19}$ According to Vietnam education system, school system is general education level (level 1-called primary level: grade 1- grade 5; level 2: lower secondary level: grade 6 - grade 9; upper secondary level: grade 10 - grade 12 ) and tertiary education level.
} 
from good researchers. This view is shared by Brown (2005) who states that research and teaching are said to go together in an essential, symbolic way, leading to a further assumption that a good researcher is a good teacher. Similarly, Brew (2006) adds that creating a strong link between research and teaching will help to develop graduates who are innovative and curious about the world and who will increase the status of the institution. It also helps enhance student's learning experiences by progressing the ways in which coursework teaching is informed by disciplinary-based research at all levels. Jenkins et al. (2007) considered that research and teaching were essential and interwoven characteristics of a university, and enhanced university research. The application and technology of university research can be transferred to organisations that are in need. European Commission (2007) considered the importance of the reciprocal relationship between industry and research institution, which may help the industry to maximise the economic value of research institutions. In turn, researchers in institutions may identify and manage knowledge resources with business potential to ensure the availability of resources and obtain sufficient buy-in by the business.

This study's results support a study by Tuan and Ly (2011), who stated that the research capacity of the Vietnamese HEls is limited in comparison with that of the HEls in Singapore, Malaysia, and Thailand. One of the causes of the low research capacity of the Vietnamese HEls was weak links between research and teaching at the HEls, and between university and industry in Vietnam. Similarly, MRe 3, for example, showed his discontentment by stating that Vietnam had more professors, associate professors and PhD holders than other ASEAN countries like Thailand and Malaysia, but Vietnamese HEIs' research capacity was very limited. This finding is supported by Hien's (2010) study which highlighted that Vietnamese HEls' research capacity was much lower than many HEIs' research capacity in ASEAN nations, except in Laos, Cambodia, and Myanmar. As Professor Nguyen Van Tuan, from the Garvan Medical Institute and the New South Wales University, Australia, said: "It is abnormal for Vietnam when it has more than 9,000 professors and associate professors, hundreds of thousands of doctors and master degree holders, but it has a very small number of US patents". He added that it was more unusual when Vietnam was compared with Thailand. This country had fewer professors and doctors than Vietnam but it had over 310 US patents during the period 
of 2000-2007 whereas Vietnam had merely 19 US patents during the period 2000-2007 (Ut \& Toan, 2012).

Jenkins et al. (2007), European Commission (2007), and Khan (2013) indicated a reciprocal relationship between two links (university and industry, and research and teaching). When the collaboration between university and industry is robust, the link between research and teaching is strong. Khan (2013), for instance, states that the university is a place where knowledge grows and industry is a place where this new knowledge is applied and gives output to the society and the nation. In general, big companies with strong capital resources are able to finance research activities at HEls to serve their commercial needs, which reinforces the collaboration between university and industry. In reality, Vietnam like other low middle income ASEAN nations such as Cambodia, Laos, and Myanmar, has a very limited number of big and wealthy companies. The number of small and medium enterprises (SMEs) accounted for $97 \%$ of the total number of enterprises (Business Insides, 2011). They used $50.1 \%$ of the labor force and contributed over $40 \%$ to the GDP. It is, consequently, unlikely for Vietnamese SMEs to have sufficient capitals to finance research activities at HEls. It is possible that the collaboration between university and industry in Vietnam is limited, affecting negatively the link between research and teaching at its HEls. Thus, when the collaboration between university and industry in Vietnam is reinforced, the research and teaching link at its HEls is strong.

This study's findings also identified, from the interviews conducted in the national and regional institutions, that these Vietnamese universities did not perform particularly well in their teaching or research tasks. The interviewees from these two institutions considered that what most university academics, especially those from newly established institutions and the institutions of education and SS\&H, could do was to perform their professional tasks similar to the teachers at the pre-university level. That meant they spent more time on teaching tasks, rather than on research tasks. However, the academic manager from Case Two supposed that it was not the academics' fault but it was actually because of a complicated, bureaucratic nature of the whole educational system, as well as the market economy mechanism. As previously mentioned, the 
presence of the market economy mechanism in Vietnam since 1986, to some extent, has made academics more materialistic. When their institutions, in general, do not provide a good research environment (in the aspects of financial resources, research resources, and research mechanism), the drives to dedicate their entire professional life to research tasks will be reduced. The academics have had the tendency to scale their research tasks and teaching tasks to see which ones should be done first for their basic needs of life such as 'cơm, áo, gạo, tiền' (cooked rice, clothes, rice, and money). Similarly, many interview participants across the three institutions agreed that in order to enhance institutional research capacity, when their institutions could not provide favourable economic conditions, they had to primarily prepare for themselves as they stated "có thực mới giật được đạo." This is a very common Vietnamese saying, literally translated 'when there is food, Tao (the way) enlightens.' It could have a figurative meaning in the setting of undertaking scientific research: unfavourable economic conditions do not strongly encourage academics to follow their ' $Đ a o^{\prime}-T a o / W a y$, their research tasks, and their research journey.

To summarise, it is apparent that there is a correlation between research and teaching, and it is encouraged to strengthen the link between research and teaching at HEls in many countries, including Vietnam. However, this link was identified to be weak in the three HEls studied.

\section{Selection criteria for research projects}

The Vietnamese Government considered that the developments of S\&T and education and training are the top national priorities. They are key motivations for the country's fast and sustainable development (Vietnam National Assembly, 2000). Particularly, the Government suggests paying special attention to the development of some intersectorial fields between natural sciences, technical and technological sciences and SS\&H for sustainable development. However, recently, the Government has directed the focus on developing specific priorities within the field of technology to meet the basic requirements of a modern industrial country. It aims to lead Vietnam to reach the advanced and modern level of the ASEAN region and that of the world by the year 2020 . 
Prioritised technology directions include information and communication technology (ICT), biotechnology, new material technology, and automation (Vietnam Government, 2012a). It is possible to perceive that applied research projects have a great potential to be approved by the evaluation committee.

The study found that socioeconomic changes also affected ways of selecting research projects by evaluation panels. It appeared that there was a bias in evaluating research projects. The evaluation panel for research projects at all levels seemed to favour those that were applicable and yielded economic values. These research projects were often related to applied engineering or new technology. For instance, MNa 4 perceived that more applied engineering research projects were approved than basic research projects in education and SS\&H. He added that the panel tended to approve research projects in the domain of applied engineering that yield specific results whereas research projects in the domain of education and SS\&H mostly produce abstract results.

Suggesting differences between social sciences and natural sciences, MNa 5 stated that applied sciences such as engineering were like the surface of social issues, and SS\&H were like the core of social issues. Unfortunately, it seemed that the core of social issues did not receive as much attention as the surface of social issues by the management people in scientific research. He agreed that it was appropriate for enterprises to finance more applied research projects at university because of their commercial aims. However, he stated that it was inappropriate for the Government to have greater investments into applied research projects, and paid less attention to education and social sciences research projects.

It is documented in the strategy for S\&T development for the 2011-2020 period that there is a need to synchronously develop SS\&H, and natural sciences in the Vietnamese Government's directions of S\&T development tasks (Vietnam Government, 2012a). However, to meet requirements of a modern industrial country, the Government has directed the development of prioritised technology related to applied sciences. As a result, it is understandable that a range of academic researchers of social 
sciences and education interviewed as part of this study perceived that their research projects did not receive as much attention as applied science projects.

In summary, in addition to different committees' processes of selecting research projects, the amount of money that the Government financed research activities in sciences as well as the ways that national research policies were implemented in various HEls were seen as factors that somehow hindered SS\&H academics from engaging in research. These factors possibly weakened Vietnamese universities' research capacities.

\section{Summary of socioeconomic factors}

To sum up, globalisation and commercialisation have affected research activities at HEls. This study found that Vietnam's socioeconomic changes have affected the research capacity of the Vietnamese HEIs in three aspects: university research commercialisation, research and teaching linkage, and selection criteria for research projects. Commercialisation of university research has only started in some Vietnamese HEls at recent years. The linkage of research and teaching in Vietnamese universities is weak. Criteria for the approval for research projects were not transparent. It is documented in the strategy for S\&T development during the 2011-2020 period that although the Government has an appropriate direction for S\&T development tasks, the academic community in the fields of SS\&H, education, and basic sciences still perceive that the state's research budget for the fields of SS\&H and applied sciences greatly vary. More research projects in the fields of applied engineering and technology sciences were been approved. Additionally, existing research operation management mechanisms in some HEIs, particularly in the three cases, show a difference in research funding between disciplines in SS\&H and in applied engineering sciences or new technology. In summary, the three mentioned aspects of socioeconomic factors somehow have negative impacts on the research capacities of Vietnamese HEls as well as their academics' research engagement. 


\subsubsection{Sociocultural factors}

Sociocultural factors were also found to impact the research capacity of HEls and their academics' research engagement. They included the administration of research, cultures of respect, academic freedom, and the culture of achievement in research activities. The cultures of respect and academic freedom were considered as academics' internal sociocultural factors, and the culture of achievement was seen as an external sociocultural factor.

\section{Administration of research}

The administration of research in this study was seen in two forms: the nomination of academics for the leading position in faculties and offices, and the management of research paperwork. The first form was found to take place in Case One and Case Three whereas the second form was identified in Case Two.

For instance, for the first form of the administration of research, many interview participants from the Case One and Case Three seemed to disagree with some faculty leaders in their institutions being nominated. According to the Charters of the Vietnamese HEls (Vietnam Government, 2010c), academics who are appointed for faculty leaders, heads of important offices, such as the offices of academic affairs, research affairs, and rector board members at Vietnamese HEls must meet two requirements: qualifications (PhD degrees) and management experience. In reality, some faculty and department leaders in the three institutions were nominated although they did not hold suitable degrees. More cases of the nomination of academics who were unqualified for leading positions were found in Case One. Many faculty leaders of this institution were appointed while did not meet required qualifications, which made their academics uncomfortable. For example, an academic in this institutional case showed his discontent about the nominations of such faculty leaders because of their family's political background, although they were neither qualified nor experienced in research management. Some interview participants in Case Three also showed their disappointment of the nomination of some faculty heads in this institution. One senior lecturer in Case Three admitted that some academics were appointed as faculty heads 
because they had good relationships and networks with the top managers rather than they were knowledgeable and experienced in research. This interviewee added that faculties being led by such leaders would not be strong in teaching and research and it would discourage the academics from being involved in research.

The second form of the administration of research was identified in Case Two. For instance, MRe 3 stated that the administrative experiences of academic managers were seen to be more important in many institutions. He mentioned that in fact some academics were appointed as managers or faculty heads because they had qualifications in the political management rather than their 'real' academic degrees for their promotions in research engagement. He commented that such nomination would make scientific research activities in Vietnamese HEls heavily controlled. He meant that scientific research activities were administratively stereotyped, not strategically oriented and regulated. He pointed out the administration of research, including the ineffective management of research paperwork and nominations of unqualified academics for management positions. The former discouraged academics to engage in the research activity, which to some extent created intangible obstacles towards their research engagement. The latter easily led academics to be dishonest in research and have ambition to get a quick promotion in a management position.

This finding supports the study of Ren (2012) who stated that this was a form of academic corruption. His study provided an example of a Chinese professor, wanting to be recognised in the academic community in an unhealthy way. In 2005 this professor was accused of plagiarism - copying others' work 'word-for-word'. Other common forms of academic corruption described by Ren (2012) were bribery, favouritism, and monopoly of academic resources in academic appointments. An example of this is that non-academics were offered academic honours via bribery or power. It is unfortunate that these two forms of academic corruption are found in Vietnamese tertiary education level. Specifically, in April 2014 the MOET handled the case of one Vice Rector in a Hanoi university being accused of plagiarism in his doctoral thesis (Tho, 2014), and in August 2014 the MOET demanded that Thai Nguyen University of Medicine and Pharmacy 
respond to the accusation of an Associate Professor's involvement in the making of a fake doctor of medicine degree (Dtinews/VNN, 2014).

In summary, this study identified two forms of administration of research in Vietnamese HEls. They include the management of research paperwork and nominations of unqualified academics for leading positions. These two factors considerably hindered the academics' engagement in research activities. Therefore, it is true to say that administration of research is an invisible obstacle to academics' research engagement and the enhancement of universities' research capacity.

\section{Internal sociocultural factors}

Internal sociocultural factors such as academics' reputation being recognised by the community and their research freedom were shown to have a substantial impact on academics' research engagement. A majority of the participants in the three institutions revealed that they actively participated in their journey of research because they were recognised by the academic community and society. This finding supports the studies of Babu and Singh (1998), Carayol and Matt (2006), Isfandyari-Moghaddam, Hasanzadeh, and Ghayoori (2012). Babu and Singh (1998) reported that concerns for advancement in the academic community affected the research productivity of scientists. Carayol and Matt (2006) found that French scientists' research productivity was significantly affected by the promotion of social status within the academic sphere. Similarly, IsfandyariMoghaddam et al. (2012) reported that the factors of "getting promoted in scientific rank", and " an attempt to show individual capabilities" enhanced Iranian women in information scientific indexes (ISI) (p. 165).

Regarding the influence of research freedom on academics' research engagement, this study found that the academics in Case Two and Case Three had more academic freedom in research than those in Case One. This was due to the fact that Case One did not have as wide a range of research networks domestically and internationally as the two institutions. Additionally, Case One only had a smaller research budget. It was difficult for its academics to approach major research projects funded by provincial, 
ministerial, and state organisations because they came from a local provincial institution. In theory, all academics are entitled to follow any research interests that suit their professional knowledge. However, in reality, working at a newly established local institution, the academics at the provincial HEls had limited opportunities to approach important national research funding sources in Vietnam.

In summary, the study identified that the factors of academics' recognition and their research freedom affected research engagement across the three institutions. The factor of academics' recognition had the same influence on the three cases. However, for the factor of research freedom, the academics in Case Two and Case Three are more advantageous than those in Case One

\section{External sociocultural factors}

The external sociocultural factor identified in the study as the culture of achievement (văn hóa thành tích), was found to have a considerable impact on academics' research perceptions. One interviewee from Case Three revealed that public refers to the culture of achievement as a disease of achievement, as often seen in reports in Vietnam's society. This kind of disease started to appear in reports of many universities' scientific research activities and gradually diminished the significance of academics' research activities. Actually, it is normal to write and submit reports to management bodies according to their requirements. However, the habitual routine of 'polishing' the reports of many officials at different levels in Vietnamese public organisations was a major concern to the Vietnamese society. The overuse of this routine seemed to become an unhealthy cultural phenomenon in Vietnam. It is called a culture of 'running after achievements in Vietnam's contemporary society', and particularly it is named 'a disease of achievement in education' (bệnh thành tích trong giáo dục). Though this cultural phenomenon was not found the two other institutions, it was mentioned in Case Three by the interviewee LNa 1 . It was possible that with his insight into the realities of research activities in Vietnamese HEIs, LNa 1 provided his research perception by saying "scientific research in Vietnamese universities should avoid the disease of achievement." 
At a glance, the above statement seemed not to be related to research perceptions. However, it actually appeared to be a concern about the national initiative to enhance research capacity in Vietnamese universities. The participant LNa 1 admitted that it was right to have a current policy to strengthen the research capacity of the Vietnamese HEls and enable them to integrate and keep pace with international universities. However, he was concerned that the implementation of this policy would be distorted. He thought that a considerable number of educational managers in localities and HEls had a habit of polishing reports or making up 'fake' reports because they wanted to show off unreliable achievements. Thus, he suggested that it was necessary to have measures to supervise how new policies were being implemented at lower levels, and especially in university research activities.

Related to the phenomenon of 'running after' the achievement culture in education, there was another 'disease' that was repeatedly stated in Vietnamese society, called 'cheating in exams' (bệnh tiêu cực trong thi cử). The Minister of MOET, Nguyen Thien Nhan said that sadly the achievement disease existed in many local educational managers' minds because they attempted to obtain a high achievement in their term of management (Nhan, 2006). For this reason, instead of preventing the disease 'cheating in exams', they even created a favourable condition for this disease to develop in their localities by loosening control and creating conditions for exam takers (students) to cheat in exams. According to the MOET's report in 2006, the Minister said that a small number of university academics had limited awareness, infringed morals and lifestyles. These behaviours contributed to worsening the exam cheating, and in thesis marking and evaluation (Nhan, 2006). Possibly, LNa 1 was concerned that the national policy for enhancing the research capacity of the Vietnamese HEls might be influenced by misconduct of HE managers in charge of research activities. They did not contribute their efforts to strengthening the research capacity of the HEls. In contrast, they created an unhealthy environment of research activities due to their practice of 'the achievement culture'.

To summarise, since 1993, the government acknowledged the importance of university research towards the global integration of the Vietnamese HEls and the 
country's economic development, many HE research policies issued. These policies aimed to strengthen its HEls' research capacity. Thus, it was acknowledged that such a socioeconomic and cultural context in Vietnam has had considerable impacts on the Vietnamese academics' research engagement in general and in the three HEls studied in particular.

\section{Summary of sociocultural factors}

Three key elements of sociocultural factors were found to have negative impacts on the research capacities of the three HEls and their academics' research engagement. They include the administration of research, internal sociocultural factors (the community's recognition of academics, and the academics' research freedom), and external sociocultural factors (the culture of achievement, and the disease of achievement in education and in scientific research). In general, the three elements of sociocultural factors have existed in Vietnam's education system for a long time. Gradually, these cultural phenomena become more common in the contemporary Vietnamese society in general and in the Vietnamese HE context in particular. They are actually becoming invisible barriers to the research capacities of Vietnamese HEls and their academics' research engagement.

\subsubsection{Political factors}

In addition to the impacts of socioeconomic and sociocultural factors mentioned above, this study found that academics' research engagement has been influenced by Vietnamese political factors. The political factors affecting academics' research engagement across the three cases include HE policies and the structure of HEls.

Hirosato and Kitamura (2009) stated that to learn about a nation's education reform, in addition to its domestic education context, its social and political structures need to be considered. They also suggested that its economic setting, its priority tasks, and the global economic impacts on the country need to be taken into consideration. Williams and Cummings (2005) claimed that policy should be placed in a broad process 
so as to understand education reform. Recently, the Vietnamese Government has issued a range of HE reform policies. Consequently, it is likely that Vietnamese university academics' research engagement has been significantly affected by such HE reform policies. Additionally, it is the Vietnamese HE structure that has considerable impact on the academics' research engagement. Figure 7-3 shows the political influence on the research capacity of the three HEls and their academics' research engagement.

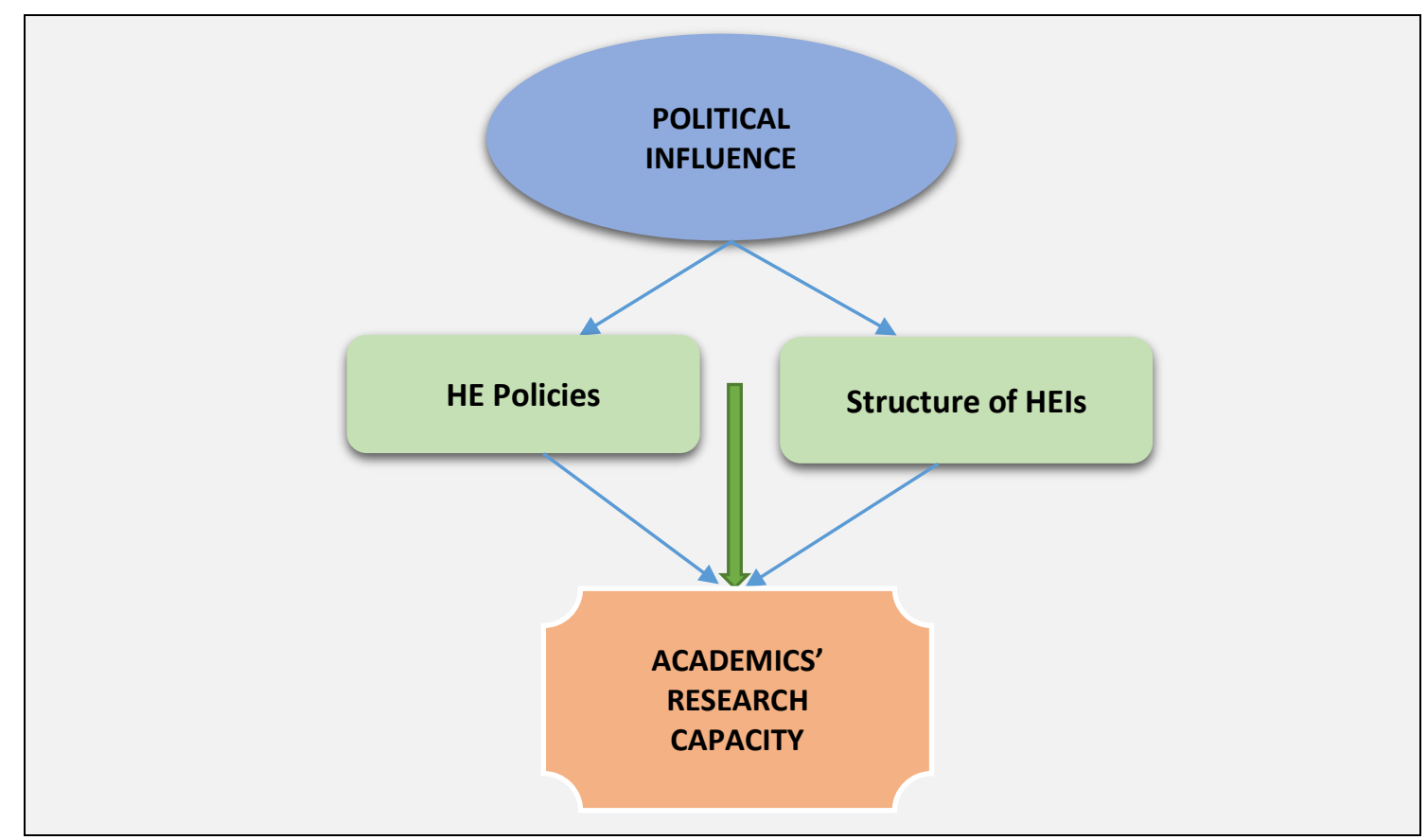

Figure 7-3. Political factors affecting the research capacities of the three HEls

\section{HE policies}

The majority of participants across the three institutions agreed that recent HE reform policies had positively impacted on Vietnamese universities' research capacity in general and academics' research engagement in particular. For instance, one interview respondent from Case Three stated that there had been some positive changes in research activities in Vietnamese universities since Vietnam adopted the Renovation Policy. Especially the Government Resolution 14 on "the substantial and comprehensive renewal of Vietnam's tertiary education in the period 2006-2020 (also known as the HERA) has been in effect since 2005. He added that it was likely that the presence of the HERA was from the recognition of the Party and the Government about the important role of the HE system toward the nation's socioeconomic development. He maintained 
that his institution's research activities had flourished since the implementation of the HERA.

Similarly, MRe 1 from Case Two suggested that recently Vietnamese universities' research capacities developed due to the Renovation Policy. This important policy allowed universities to expand their international relations and their academics to study in foreign universities. He was grateful to the Renovation policy because it improved institutional research policies. Research payment procedures were simpler, which significantly motivated academics to engage in research activities. The participants from Case One approved of recent reforms to the HE system, especially projects relating to sending academics to study postgraduate abroad such as Project 322 , Project 911, and the National Foreign Language (NFL) Project. A lecturer from Case One revealed that in order to be selected by those projects, academics had to actively participate in research activities. Therefore, his institutional research environment was more energetic.

Recent reforms of the Vietnamese HE system, especially emphasising developing its qualified staff and strengthening its research capacity, have been considered to be appropriate Government policies. LaRocque (2007) states that economic and social development increasingly depend on innovation, where HEls operate as incubators of the innovation and creative thinking. He continues that as their role in carrying out research and development as well as in training workers for the knowledge economy, Asian universities have a potentially important role in driving innovation and development. Likewise, recognising that university research plays an important role in developing national innovation capacity, China has dramatically increased its investment in university research in the pursuit of developing a knowledge-based economy (Leydesdorff \& Zeng, 2001). Similarly, the United States Government increased its funding sources for university research through the government's S\&T programmes because they believed in the logic that stronger government support would enhance the effectiveness of the national innovation system (Nelson, 2004; Stephan, 2010).

In recent years, the Party, the State, and the Government of Vietnam have issued a series of policies to boost its HEls' research capacity. These policies include the HERA 
in 2005, the Vietnam National Assembly's Resolution 56 in 2006 on the five year socioeconomic development plan 2006-2010, the NFL Project in 2008, and the Prime Minister's Directive in 2010 "On renovating HE management for the period 2010-2012". In general, all these important policies aimed to be implemented in Vietnamese HEIs as political guidelines to develop its HE system's research capacity.

Indeed, since the implementation of those projects, research activities in Vietnamese universities in general, and in the three HEls in this study in particular have flourished. Thanks to these projects, the number of qualified academics in the three HEls has considerably increased. Specifically, a few academics from the institutions have studied abroad with the Government scholarship. Some academics have studied abroad with foreign governments' scholarship like New Zealand, Australia, and European Nations' Government Scholarships. Moreover, the Government called for foreign investments into developing teaching and research activities in its HE system. Specifically, the Second HE Project (HEP2) funded by the World Bank aimed to increase the quality of teaching and research in universities in ways that improve the employability of graduates and the relevance of research in Vietnam. Additionally, the Government has had greater investments in 18 key national universities to enhance their research capacity. Moreover, the Government has an ambition to build four internationally ranked universities, and two Hi-Tech parks by 2020. These universities and $\mathrm{Hi}$-Tech parks will act as leading national HEls to boost the country's S\&T innovation. Overall, the Government's political policies have recently contributed into creating a more dynamic environment for academics to engage in research activities.

These national policies have had positive impacts on Vietnamese HEls in general and the three HEls studied in particular on their training and research tasks in the global integration of the current HE system. Additionally, it is noted that the requirement of an increase in incomes from S\&T activities urges them to develop their institutional research activities. Moreover, the MOET plans to rank Vietnamese HEls in coming years (Anh, 2014), and the research activity will be considered as an important criterion for ranking. For this reason, all Vietnamese HEls have emphasised strengthening their research activities. 
The influence of these policies on the three HEls' research capacities and their academics' research engagement was different. One major difference was their training capacities. For instance, Case One had no postgraduate training courses whereas the two other institutions have provided MA and PhD training courses for over 15 years. Thus, these two institutions had a considerable number of leading academics in research activities. Additionally, since they were selected as two of the eighteen Vietnamese key national HEls in 2004, they have been given more autonomy in training and research tasks than other institutions. For this reason, the two institutions received financial backing from the government for their developmental strategies. Meanwhile, due to being an institution under the control of its local authority, Case One in this study received less interest from the government and other ministerial agents. It basically received limited financial investment from its province.

To sum up, the national policies for developing research activities in HEls were considered as substantial stimuli for academics to engage in research. However, due to the difference in institutional training capacity across the three institutions, the influence of policies across the three HEls is different. In addition to the effects of HE policies, the structure of HEls had considerable impact on the academics' research perceptions and their research engagement. This is further discussed in the next section.

\section{Structure of HEls}

Figure 7-4 shows the differences in the management structure of Vietnamese public universities. The MOET has strong control over the governance of its HEls. Vietnamese public universities include provincial universities, ministerial universities and two National Universities. Except for the two National Universities (under the Government Office's supervision) all universities must follow MOET's guidelines governing admissions, curriculum design and organisation of instruction. Public universities must follow rules on budgeting, spending and personnel management. Provincial HEls are under the provincial control of personnel and finance (World Bank, 2012). 


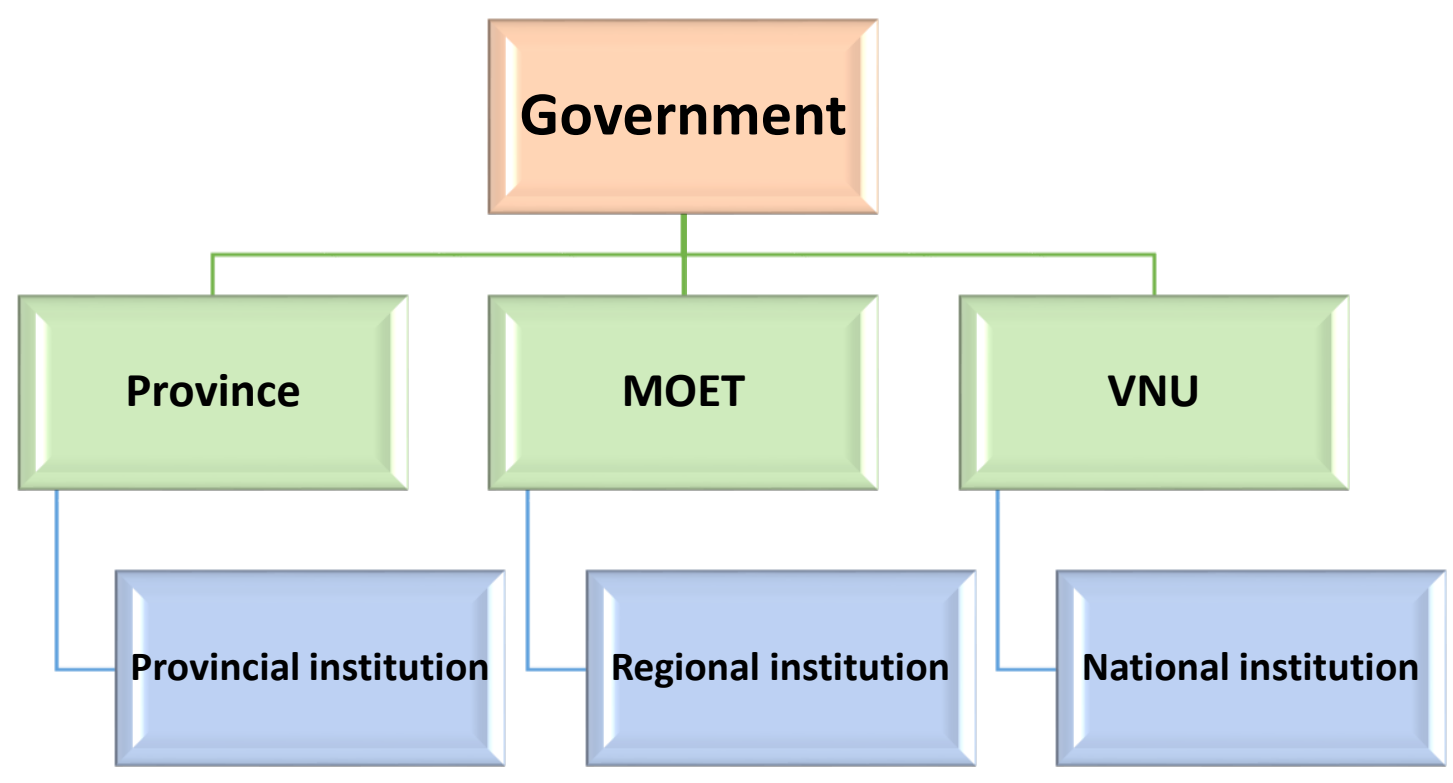

Figure 7-4. The management structure of the Vietnamese public HEls

The difference in the management structure of the three HEIs in this study affected their research strengths. Case One is under the control of its provincial authority in all aspects, except that its training programmes are controlled by the MOET. Case Two is under the control of MOET in terms of budgeting, spending, and personnel management. This case also has priority in receiving the research funding from the national research agencies, other ministries and provinces. Being a key national $\mathrm{HEI}$, this regional institution has had autonomy in international cooperation, training and research activities (Toan, 2013). Case Three is under the supervision of VNU because it is a member. VNU has authority to provide new training for its university members. All institutions in the VNU have more autonomy in training, research activities and international relations. Therefore, it is likely that Case Three has had greater research funding from domestic and foreign agencies.

Case One had less authority in training and research cooperation activities than the regional and national institutions. Therefore, its financial resource for scientific research activities was very limited. Additionally, its opportunity to access research projects from ministerial agencies and other provinces was limited. Likewise, it had to compete with other governmental institutions to win research projects within its own 
province. Furthermore, it was not able to receive the MOET's financial support for training activities.

In conclusion, due to the difference in the management structure of Vietnamese HEls, Case One has limited authority in its training and research activities in comparison with the two other institutions. This institution is mainly dependent upon its local province's major source of finance. It is likely that Case One's research capacity is reliant on the province. In other words, if the province pays enough attention to developing research activities and recognises the research strength of this institution, Case One may have better opportunities to facilitate its research role.

\section{Summary of the impact of factors at societal level}

The study found that the research capacity of the three HEls and their academics' research engagement were affected by societal factors including socioeconomic, sociocultural factors and political factors. The influences of socioeconomic factors were identified in four aspects: research commercialisation, research administration, research and teaching linkage, and research selection criteria. Internal sociocultural aspects (such as academics recognised in the community and their freedom in research) and external sociocultural aspects like the culture of achievement are viewed as the influence of sociocultural factors. HE policies and the structure of HEls in Vietnam were found as two foundational elements of the political factors affecting academics' research engagement in the study. In summary, Vietnam is on the process of industrialisation, modernisation, and international integration. Therefore, the research capacities of the three HEls and their academics' research engagement have been affected by the social, cultural, economic, and political factors of Vietnam's development process.

\subsection{Impact of factors at community level}

According to Moore (2015), factors at community level including universities, research institutes and their virtual research networks affect the research capacity of HEls and their academics' research engagement. Similarly, the study identified that factors at the 
community level such as the resources of HEls, research orientation, research networks, and PD practices affected the research capacity of HEIs, and the research engagement of their academics. The detailed discussions of the impact of factors at community level are presented in the following sections.

\subsubsection{Resources}

HEls with good resources motivate their academics to be active in research engagement. Bland et al. (2005) state that when academics have access to sufficient resources such as funding, facilities, and especially human resources (e.g., local peers for support, research assistants, technical consultants), their research productivity will probably increase. This study found that the research funding of the three institutions was very different. Having a larger scope of training and research, and a better management structure, Case Two and Case Three had a greater research funding to finance their research activities. Table 7-1 shows the expenses for research in the three institutions from 2006-2010.

Table 7-1. Research funding in the three cases in 2006-2010

\begin{tabular}{|c|c|c|c|}
\hline & Case One & Case Two & Case Three \\
\hline 2006-2010 & $\begin{array}{c}2.34 \text { billion VND }\left(^{*}\right) \\
(117,000 \text { USD })\end{array}$ & $\begin{array}{c}75.025 \text { billion VND } \\
(3,751,250 \text { USD) }\end{array}$ & $\begin{array}{c}31.16 \text { billion VND }\left(^{* *}\right) \\
(1,558,000 \text { USD })\end{array}$ \\
\hline Annual expense & $\begin{array}{c}39 \text { million VND } \\
(1,950 \text { USD) }\end{array}$ & $\begin{array}{c}15.050 \text { billion VND } \\
(750,250 \text { USD) }\end{array}$ & $\begin{array}{c}6.232 \text { billion VND } \\
\text { (311,600 USD) }\end{array}$ \\
\hline \multicolumn{4}{|c|}{$\begin{array}{l}\text { Notes: }(*) \text { It is Case One's research funding from } 2006-2011 \\
\left(*^{* *}\right) \text { This sum of money was counted with the value of } 20 \text { million VND }(1,000 \text { USD) for an } \\
\text { institutional research project, and the value of } 500 \text { million VND ( } 25,000 \text { VND) for a } \\
\text { provincial/ministerial/national research project. }\end{array}$} \\
\hline
\end{tabular}

The table illustrates that the annual research funding of Case Two and Case Three was, on average, much larger than that of Case One because they had more prestige and more qualified academics. For this reason, it was not difficult for their academics to gain research funding throughout the country whereas the provincial academics mainly conducted institutional-level research projects. In summary, the reputation and their academics' strengths in research activities enabled Case Two and Case Three to succeed in gaining a range of important research projects. This could contribute to enriching their 
research funding, which to a certain extent encouraged their academics to actively engage in research.

Research facilities of the three institutions were considered modern in comparison with those in most Vietnamese HEls. The three institutions had fairly good library systems. Their library systems were connected with the Internet - called E-Library in Vietnam - so it effectively helped their academics' and students' study. For instance, in addition to its own library system, Case Three had its library system connected with other institution members in the VUN and Taiwan National Library (Case Three, 2015). Its good library system link enables the academics to access a wide range of research resources that considerably facilitates their research.

Case Two was considered to own one of the most modern library systems in the Vietnamese HEls. It is called the Learning Resources Centre, developed from its central library. It is seen as the largest world-class library in southern Vietnam, equipped with more than 500 public desktops with internet connection, video networking system, modern facilities, rich and diverse information resources - both printing and electronic. It also has an interlink with the University of Alberta Libraries, Canada. This library interlink apparently enables its academics to access a wider range of resources for research. It regularly organises technical support workshops to help academics and students to enhance search skills for study. It is likely that it has a good technical support service for research for its academics and students. Its learning resources centre strived to become an ideal information hub that stimulated its institution's PD and research activities (Case Two, 2014d). Additionally, the research facilities in its colleges are relatively complete and modern, which facilitates academic research engagement. However, some survey and interview data indicated that research facilities in this institution, particularly in some specific research domains were still insufficient.

Case One also has a relatively modern E-Library for supporting its academics' and students' research activities. It keeps a special room with 14 new desktops for the academics to search for teaching and research materials, a 25-desktop seminar room, and over 250 desktops serving for students' studies. It has library interlinks with some other Vietnamese HEls. Particularly, this library has sufficient research electronic databases such as Ardi, Proquest, Oare, Springlink, and Agora to meet the research and 
study needs of its academics and students (Case Three, 2015). However, other teaching and research facilities such as experiment laboratories for the Faculty of Agriculture \& Natural Resources and other Faculties were still incomplete. It is likely that the academics in Case One have limited access to resources for research in comparison with the academics in the other two cases.

It is apparent that institutional training and research size plays an important role in providing resources for academic research activities. Dundar and Darrell (1998) reported that departmental size was seen as a critical factor in facilitating research because large institutions may simply become more powerful within a university and receive more resources for research activities. Therefore, it was likely that among the three institutions, Case One had more limited resources in terms of research funding, research facilities, and humans. These limited resources do not serve the academics' needs for research. This partially weakened its institutional research capacity as well as demotivated its academics' research engagement.

\subsubsection{Research orientation}

The three institutions in this study had different missions and visions for their development, which can be seen from Table 7-2. 
Table 7-2. A brief introduction of the three HEls studied

\begin{tabular}{|c|c|c|}
\hline \multirow{4}{*}{ 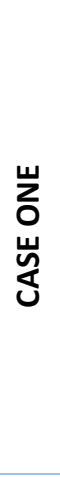 } & $\begin{array}{c}\text { Year of } \\
\text { establishment }\end{array}$ & In the early year of the 21st century \\
\hline & Origin & $\begin{array}{l}\text { - Being a provincial teacher training college for } 25 \text { years until the year } 2000 \\
\text { - } \quad \text { Becoming a provincial multi-disciplinary university by } 2000\end{array}$ \\
\hline & $\begin{array}{l}\text { National } \\
\text { Ranking }\end{array}$ & 17 \\
\hline & $\begin{array}{l}\text { Mission and } \\
\text { vision }\end{array}$ & $\begin{array}{l}\text { Vision }\left({ }^{*}\right) \\
\text { Mission } \\
\text { - To contribute to training HR for its local province and neighbouring } \\
\text { provinces. } \\
\text { - To conduct applied research and transferring technology to serve the } \\
\quad \text { socioeconomic development in the region. }\end{array}$ \\
\hline \multirow{4}{*}{ 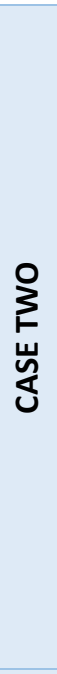 } & $\begin{array}{l}\text { Year of } \\
\text { establishment }\end{array}$ & In the 1970 s \\
\hline & Origin & $\begin{array}{l}\text { - Originally it was a university, including four colleges: Natural Sciences, Law } \\
\text { and Social Sciences, Letters and Pedagogy. } \\
\text { - After 1975, it developed into a comprehensive university for the region. } \\
\text { Now it has } 14 \text { colleges/schools; } 7 \text { centres and } 3 \text { research institutes. }\end{array}$ \\
\hline & $\begin{array}{l}\text { National } \\
\text { Ranking }\end{array}$ & $\mathbf{2}$ \\
\hline & $\begin{array}{l}\text { Mission and } \\
\text { vison }\end{array}$ & $\begin{array}{l}\text { Vision } \\
\text { - To be one of the leading HEls in Vietnam } \\
\text { - To be recognised as one of the top universities in Asia-Pacific in training and } \\
\text { research in } 2022 \text {. } \\
\text { Mission } \\
\text { - To be the leading HEl for education, research and technology transfer; } \\
\text { - To make contributions to the development of high quality HR; } \\
\text { - To foster the talents and the advancement of S\&T to cater for the regional } \\
\text { and national socioeconomic development. }\end{array}$ \\
\hline \multirow{4}{*}{$\begin{array}{l}\text { 岀 } \\
\text { 号 } \\
\text { 岃 } \\
\text { 岁 }\end{array}$} & $\begin{array}{l}\text { Year of } \\
\text { establishment }\end{array}$ & In the 1960 s \\
\hline & Origin & $\begin{array}{l}\text { - In the late of 1960s, it was named the Faculty of Letters in southern } \\
\text { Vietnam } \\
\text { - } 20 \text { years after Vietnam's reunion, it became a part of HCM City University, } \\
\text { covering SS\&H. } \\
\text { - Then, it was officially named as University of SS\&H, a member of VNU. } \\
\text { - Now it has } 28 \text { faculties/departments and } 13 \text { supporting offices. }\end{array}$ \\
\hline & $\begin{array}{l}\text { National } \\
\text { Ranking }\end{array}$ & 28 \\
\hline & $\begin{array}{l}\text { Mission and } \\
\text { vision }\end{array}$ & $\begin{array}{l}\text { Vision } \\
\text { - To gradually become an internationally modern model-research university, } \\
\text { playing an important role in Vietnam's HE system, majoring in SS\&H in } \\
\text { Vietnam and in Asia. } \\
\text { Mission } \\
\text { - To supply high quality HR with a distinguished identity in SS\&H. } \\
\text { - To produce scientific products as grounds for strategically social policies, } \\
\text { partly contributing to establish the status of Vietnamese SS\&H in the region } \\
\text { and in the world. }\end{array}$ \\
\hline
\end{tabular}

Case Two and Case Three had broader missions and visions than Case One. They aim to become top research oriented HEls not only in Vietnam but also in the Pacific Asia region whereas Case One's mission and vision were narrow. Case One aims to contribute to training human resources and transferring the application of S\&T for the 
province' socioeconomic development. The data from the table also indicate that Case Two and Case Three have greater training and research orientation than Case One. Hence, their research capacities appear to be stronger than Case One.

Case Two and Case Three also have stronger research capacities because they have wider domestic and foreign research networks than Case One. As a result, it is understood that they have clearer missions, visions, and goals for research development. This result supports the finding identified in a study of Bland et al. (2005) indicating that academics were more productive in research when there was a high expectation for them to generate as much revenues as possible via research activities to meet the department's goals. It is probable that it is challenging for the leaders of Case One to establish a broader mission and vision because it has a very limited number of qualified academics and limited resources. However, Case One may gradually position its higher mission and vision if it reorganises its available resources and staff, establishes strong research teams, and expand international collaboration to develop some faculties so they become strong training and research faculties. Hence, its academics may work in a more dynamic research environment; then its research capacity will be strong. To summarise, research productivity in an institution considerably depends on what research orientation it targets. Therefore, it is possible that Case One's research capacity was more limited than that of the two other institutions because its scope of research emphasis and orientation was narrower.

\subsubsection{Research networks}

The study identified that research networks were an element of institutional organisation affecting academics' research engagement. Case Two and Case Three had wider national and foreign research networks than Case One because they had a long history of development as a university. They were also strong in research and teaching, and they had a range of qualified, experienced research academics in various disciplines. It could be stated that they had sufficient conditions to establish and expand their domestic and foreign research networks. For example, most of Case Three's research networks were coordinated by the Office of Research and Project Management (for 
domestic projects) and the Office of International Cooperation and Project Development (for foreign projects). Thanks to its prestige and reputation, the institution has a wealth of domestic and international research links. It has partnerships with 150 foreign institutions, including student and teacher exchange programmes, cooperative research projects, and organising conferences (Case Three, 2014a).

Similarly, international cooperation is one of Case Two's strengths. It was documented that from international cooperation programmes, its management, planning, teaching, and research were substantially improved. Also, its research facilities were upgraded from the funding of such programmes. At the time this research was conducted, this institution had cooperative partnerships with more than 80 institutes, universities, and organisations worldwide. Its cooperation with Asian nations such as Cambodia, China, India, Laos, Malaysia, the Philippines, Singapore, Thailand, Taiwan, etc. has been diversified and developed (Case Two, 2014a).

On the other hand, Case One's international cooperation was still limited in comparison with that of the national and regional institutions. Although this institution considered the role of international cooperation important to its development strategy, especially to its research activities and capacity, its number of international cooperation links was limited. There were only 13 memorandums of understanding signed out of the total number of 80 partnerships with foreign institutions and organisations. At the time of conducting this research, this institution had only one cooperation project that enabled it to develop its teaching and research capacity called the TRIG Project funded by the World Bank (Case One, 2014c). After the TRIG Project, the institution gained experience in partnership with foreign institutes and universities in teaching and research fields. This project also enhanced its academics' research capacity.

Research networks played an important part of institutional organisation which might have substantially enhanced academics' research engagement. Melin (2000) stated that research networks and research collaboration may boost academics' research engagement and their research output because they may support each other in their collaboration. However, there still existed a big difference in the experience of 
international collaboration between Case One and the two other institutional cases. Due to the limited number of qualified and experienced research academics and still being new to the structure of Vietnamese HEls, Case One was seen to be weak in expanding its domestic and foreign research networks.

To conclude, Case One had narrower national and international research networks than the two other institutional cases because of its shorter history establishment, its less prestige, and its smaller number of qualified academics. Therefore, it was likely that the research capacity of Case One was weaker than the two other institutional cases.

\subsubsection{PD activities}

PD and research activities were considered to be a substantial factor affecting the research capacity of HEls. The study found that the influence of PD and research activities on the research capacity of the three institutions was different due to the availability of PD and research activities at the three institutions. For instance, the study identified that more PD and research activities were regularly organised in Case Two and Case Three than in Case One. The survey participants from Case Two and Case Three agreed that their institutions and faculties often organised PD and research seminars, so they could gain experience in research and disciplinary knowledge from their senior academics. Indeed, as previously mentioned, Case Two and Case Three had bigger numbers of qualified academics with strong research profiles. Some of these academics were considered to be leading research experts in their disciplines in Vietnam. Additionally, they were often invited to give lectures at foreign institutions. They were also invited to be key speakers and chairpersons at different level research conferences. They undertook various studies at different research project levels. To summarise, a variety of seminars and conferences on research-led activities were regularly held at the two institutional cases.

On the other hand, few conferences on research-led activities have been organised in Case One. Most conferences held in this institution were related to teaching-led activities. It was because Case One's academics had conducted a very 
limited number of high level research projects. For instance, no provincial, ministerial, and national level research projects had been undertaken by this institution's academics since its establishment because they were not qualified and did not have sufficient practical experience. Case One was developed by a local teacher training college. Therefore, it was possible that more conferences related to teaching-led activities rather than research-led activities were organised within it. Perhaps, it was easier for this institution to begin with expanding its training rather than its research capacity in its recent development phase. However, since becoming a member institution of the TRIG Project funded by the World Bank, its research activities increased. Its academics had opportunities to attend some important workshops related to enhancing research skills organised by this Project. Some academics could even conduct their research projects from the research funding of this Project. At recent times, its International Relation Office invited some famous national and foreign research academics from reputable regional and national institutions to present to its academics. Moreover, the return of its academics from studying at foreign institutions probably boosted its research environment to become more active.

In summary, the practices of PD and research activities at the three HEls substantially affected their academics' research perceptions and their research engagement. Yet, the impact of PD and research activities across the three institutions varied. Case Two and Case Three had more research-led practices. Meanwhile, Case One had more teaching-led practices. This different impact results from the difference in the number of qualified academics in the three HEls.

\section{Summary of factors at community level}

The study found that the research capacity of the three HEls was affected by four factors at community level. They include the resources, research orientation, research networks, and PD practices of HEls. Case Two and Case Three have good resources, broader research orientation and research networks, and more research-led PD practices than Case One. Therefore, it is likely that their research capacities are stronger than that of Case One. This finding supports studies of Dundar and Darrell (1998), Bland et al. (2005), 
and Moore (2015) who stated that community factors such as universities, research centres, research institutes, and their virtual research networks considerably affected the research capacity of HEls.

\subsection{Impact of factors at institutional level}

The study identified that factors at institutional level such as the establishment history, geographical location, and organisation of the three HEls had substantial impacts on their research capacities and their academics' research engagement. The study findings support the work of Brasuell (2014) in the Chronicle of Higher Education, reflecting on the relationship between cities and universities. He argues that location is becoming increasingly important as a factor that determines a university's success or failure. Institutions located in cities enjoy a strategic advantage. Additionally, Selingo (2014) reports that the market-leading institutions tend to be in urban areas. This shows that the relationship of the establishment history, geographical location, and organisation of an institution has substantial impacts on its research capacity and the academics' research engagement within it. Figure 7-5 illustrates the influence of factors at the institutional level on the three HEls studied.

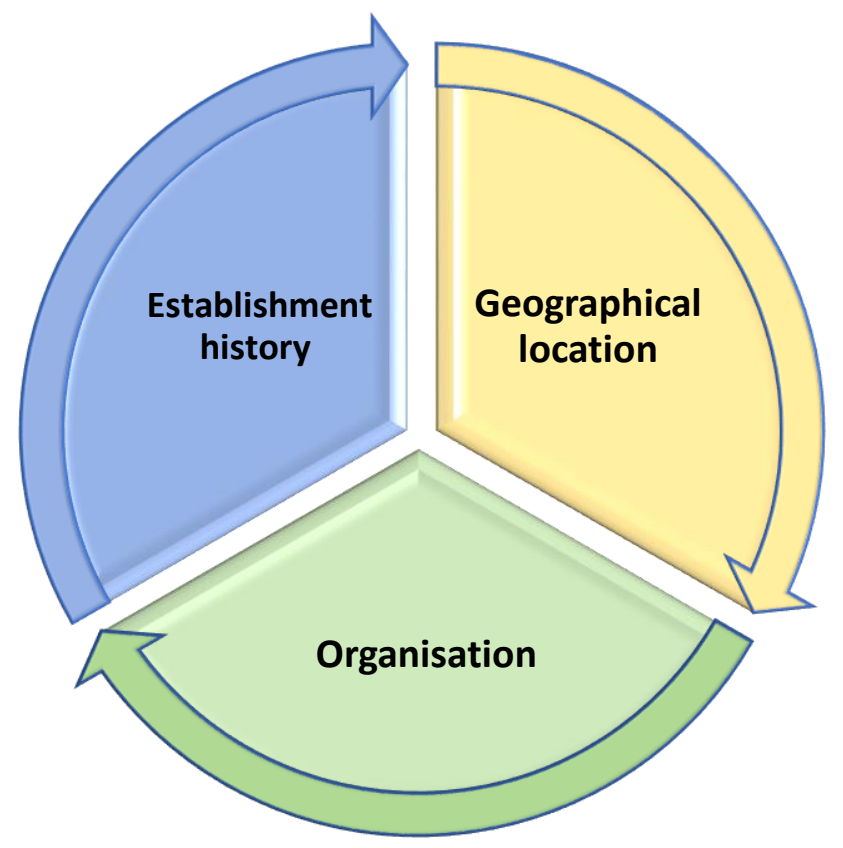

Figure 7-5. Institutional factors affecting the research capacities of the three HEls 


\subsubsection{Establishment history}

The institutional establishment history was considered to be a specific factor having an influence on academics' research engagement across the three institutions. The findings indicated that there was an opposite research perception between academics from Case One and the participants from the two other cases. For instance, a majority of the academics from Case One disagreed with the statement 'research is perceived as a way to fulfil university academics' requirements.' By contrast, a majority of academics in Case Two and Case Three agreed with the statement. The difference in their perceptions was likely to be rooted in their institutions' establishment history that is seen in Table 7-2.

The emergence of Vietnamese local universities under the control of the provincial authority was a result of the State policy of diversifying its public university type to meet the provinces' demand for human resources, and social, cultural and economic development. It suits the world philosophy of HE that shifts from elite to universal system of HE. The first Vietnamese provincial university was established in 1997. Case One in this study was one of the first three local universities in Vietnam. Up to now, there have been 22 provincial universities in the Vietnamese system of HEls (Runchel, 2014).

As a result of being developed from a provincial teacher training college, the profile of research activities of Case One was still very limited in comparison with the regional and national institutions. Meanwhile, the two other institutional cases have been well-established multidisciplinary oriented research universities in southern Vietnam. Case Two is a multidisciplinary oriented research university of basic and applied sciences whereas Case Three is a multidisciplinary oriented research university of social sciences and humanities.

Due to its starting as a newly established institution, the provincial academics rarely performed their PD activities in scientific research activities. Instead, their regular PD activities are mainly associated with teaching. Moreover, for over ten years since its foundation, Case One has put a high priority on expanding the training activities rather 
than on the survival of research. Recently, it began to focus on research as a general development trend of national and foreign HEls. Thus, it was likely the research perception and research engagement seemed to be new to the provincial academics. Moreover, their disagreement of 'research perceived as a way to fulfil academics' requirements' did not align with Vietnam Education Law 2012 that mandates university lecturers to conduct research in their professional careers as one of their roles (Vietnam National Assembly, 2012).

In contrast, Case Two and Case Three have a long history of establishment. These two institutions have developed as recognised universities for nearly five decades. The task of scientific research and technology transfer was documented at their time of establishment. At the time this research was conducted, they were two of the seventeen Vietnam's Key National Universities ${ }^{20}$. One of the criteria of the 'key national universities' is that 75 percent of academics are doctoral degree holders in the future (Nesovietnam, 2013). It was possible that the two institutions' visions - being regionally and globally integrated and becoming research universities - considerably motivated their academics to be actively involved in research engagement. This explains why most of their academics agreed with the statement 'research perceived as a way to fulfil academics' requirements,' as found in survey findings.

In summary, institutional establishment history appeared to have significant influence on academics' research perception and research engagement. The academics from Case Two and Case Three were more research-oriented and their research engagement was more active than Case One's academics.

\footnotetext{
${ }^{20}$ Vietnam's Key National Universities are vital regional or national level institutions that are given autonomy by the Government in printing and granting doctoral degrees, have the right to send their academics to study abroad (except the scholarship from the state budget), have the right to invite foreign visiting academics to work and accept foreign student enrolment, are permitted to open training courses not in the MOET's list. Notably, their Rectors are entitled to make decisions related to basic construction and facility investments without passing through the MOET's authority.
} 


\subsubsection{Geographical location}

The study found that the geographical location of an institution substantially influenced academics' research engagement across the three case studies. Case Two and Case Three were situated in better geographical locations where they were considered to be city hubs in southern Vietnam. For instance, together with its long established history, Case Two has such an advantageous geographical location. It is located in the hub city in the region. It has the best traffic infrastructure system including an international airport, seaport, and modern bridges in the region. It is easy for this institutional case to expand nationwide and abroad. As a result, the advantage of such a good geographical location has partly contributed to its strengths in developing its research capacity. Specifically, the Government has continued to view it as the most important $\mathrm{HEI}$ in the region, and now it is the key national university of Vietnam. Therefore, it still continues to receive greater financial investments and prime policies for the development of its research capacity.

Similarly, in addition to its tradition in research and training, Case Three is located in the largest and most dynamic, populated city in Vietnam. This particular entity has noticeable socioeconomic and cultural development index. Before 1975, the city was named Saigon and seen as the Pearl of the Far East. Case Two and Case Three are often chosen to organise important national and international HE conferences. Such important conferences are held in large neighbouring institutions located in the two cities. Therefore, it is easy for their academics to participate in those conferences pertaining to their disciplines. In summary, in addition to a long, prestigious history of establishment, their favourable geographical locations hugely enabled them to partake in international research cooperation. This is believed to be a considerable factor in enhancing institutional research capacity.

In contrast, Case One was located in a remote bordering province. Its traffic infrastructure system was not as good as that of other provinces in the region. It takes hours to travel to the regional city and nearly six hours by car to the southern capital city from the province. Therefore, it was a real challenge for Case One's academics to 
arrange their time for participating at relevant conferences in the cities. Although the Government is presently making efforts to narrow the socioeconomic development gap among provinces and regions by investing into improving the traffic infrastructure system for disadvantaged provinces, their residents' commute was not as advantageous as that of the central city residents. Moreover, it was less advantageous for Case One to call for domestic and foreign business' investments into research development because of its unfavourable location.

This finding supports the study of Lahr, Hughes, and Kitson (2013), which reported that research quality and geographical distance substantially affected universities' research collaboration. Research quality, interpreted as a strong signal of valuable collaboration opportunities, positively affects geographic distance as expected. They interpreted distance as a cost, and added that the cost of doing business at a distance was greater than doing the same transaction locally.

In comparison with the two other institutional cases, Case One has very limited research quality and was disadvantaged by its geographical location. There was actually great potential for development cooperation between Case One and domestic, foreign organisations, universities and research institutes. However, its isolated location somehow hindered its partnership developments.

In summary, the institution's geographical location significantly affected the expansion of its research capacity and its academics' research engagement. It was apparent that the geographical location was considered to be a competitive advantage for Case Two and Case Three, but not for Case One. Thus, in addition to working in a strong research institution, the provincial academics had more obstacles to participating in conferences related to their PD and research activities.

\subsubsection{Organisation}

Institutional organisation was considered to be a crucial factor that had an explicit impact on institutional research engagement. Its impact across the three institutions was not the same. According to Bland et al. (2005), institutional research capacity was 
affected by three groups of characteristics: individual, institutional, and leadership. This study views institutional organisation through two aspects: institutional characteristics and leadership characteristics. Figure 7-6 indicates institutional organisation affecting academics' research engagement.

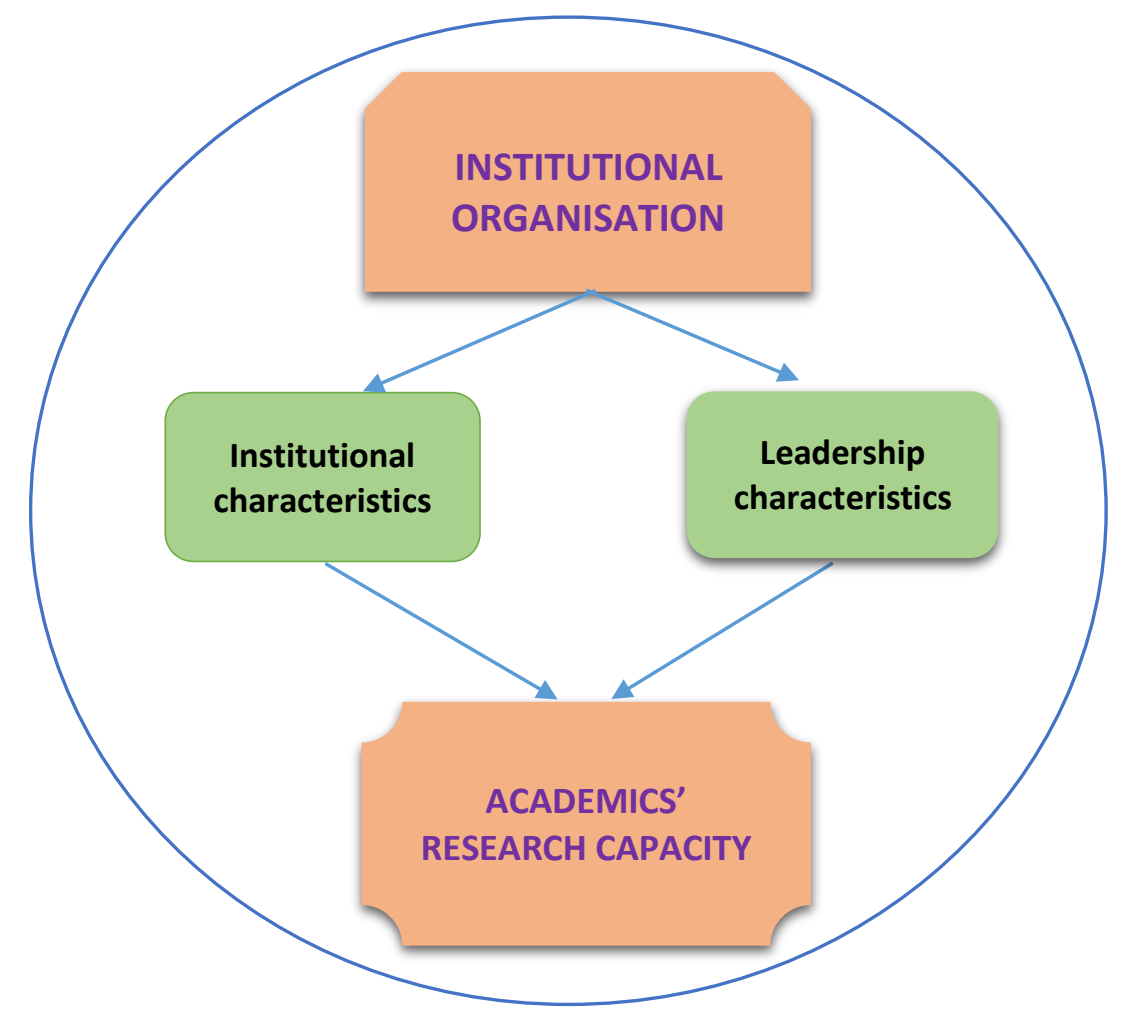

Figure 7-6. Institutional organisation affecting the research capacities of the three HEls

\section{A. Institutional characteristics}

This study identifies the research capacity of the academics across the three institutions affected by institutional characteristics. According to Bland et al. (2005), there are nine sub-elements of institutional characteristics. They include research academics, academics recruitment and selection, research emphasis, time allocated for research and teaching, resources, PD practice, communication, research reward policies, and research networks. However, in this section, this study does not include a comparison of the research emphasis, resources, PD practices, and research networks as institutional factors of the three HEls. These were community level factors analysed in the previous section. 


\section{- Research academics}

The performance of academics at HEls is seen as a decisive factor for their success or failure, especially in their research performance. Among the three institutions, the academics from Case One were viewed as not being qualified as those from the two other cases. Vietnamese university lecturers who were considered to be qualified are the ones who had at least an MA degree and were able to conduct research projects independently or cooperatively (Vietnam Government, 2010a). However, in practice, it was rare for master-degree academics to be selected as the main author for research projects at provincial, ministerial and national levels. They were likely to only conduct institutional level research projects. For research projects at higher levels, in addition to being qualified with academic degrees, the candidate must have a good research profile, and good relationship with research management agents. Additionally, the number of academics who were PhD holders with strong research profiles in Case One was less in comparison with that in the regional and national institutions (see Table 7-3). This finding supports a study by Bland et al. (2005) who said that the most research productive academics in the department had PhDs. Therefore, it was likely that it was too hard for the academics from Case One to win the bids for high level research projects.

Table 7-3. The number of doctoral and MA academics in the three HEls in 2014

\begin{tabular}{|c|c|c|c|c|c|c|c|c|c|c|c|}
\hline \multicolumn{3}{|c|}{$\begin{array}{c}\text { Case One } \\
\text { (841 staff) }\end{array}$} & \multicolumn{4}{c|}{$\begin{array}{c}\text { Case Two } \\
\text { (1,908 staff) }\end{array}$} & \multicolumn{3}{c|}{$\begin{array}{c}\text { Case Three } \\
\text { (890 staff) }\end{array}$} & \\
\hline Prof & A/Prof & PhD & MA & Prof & A/Prof & PhD & MA & Prof & A/Prof & PhD & MA \\
\hline 0 & 1 & 35 & 350 & 7 & 79 & 199 & 687 & 3 & 41 & 150 & 372 \\
\hline
\end{tabular}

As previously mentioned, due to its shorter time of establishment, Case One had less prestige. Its number of qualified academics was smaller than the numbers of qualified academics at the two other institutional cases. Consequently, Case One's research capacity as well as its academics' research engagement was more limited than that of the two other cases.

To summarise, the insufficient number of qualified academics in Case One made it more difficult to develop its research capacity as well as its academics' research engagement than in the two other institutions. It can be stated that in order to enhance 
research capacity, Case One needs to pay attention to developing its academics in terms of quality and quantity.

\section{- Academic recruitment and selection}

Academic recruitment and selection was considered to be the second sub-factor of the institutional characteristics that contributes to strengthening institutional research capacity. Case Two and Case Three were considered as two recognised HEls in Vietnam. Therefore, it was more advantageous for the two institutions to draw qualified academics and junior talent academics to work for. The public generally considered the academics working in these two institutions to have better professional knowledge and research experience than Case One's academics. Therefore, qualified academics from different places want to work for these institutions, which could help strengthen their research capacities. Meanwhile, Case One had difficulty not only in recruiting new qualified and talent academics but also in keeping its own qualified academics. The fact was that the Faculty of Economics \& Business Administration (E\&BA) and the Faculty of Engineering \& Technology could not recruit new academics although they posted their personnel recruitment advertisements for a long time. The leader of E\&BA said that the Faculty was a 'hot' one in his institution. It had a large number of students but lacked academics with relevant qualifications. For a long time, the Faculty advertised for positions but could not recruit any candidates. He continued that the Faculty was not even successful in encouraging excellent students to work for the Faculty after their graduation. Therefore, the institution had to spend a large amount of money to invite visiting academics from other universities. In summary, Case One had more difficulties in recruiting and hiring academics who have the training, goals, commitment, and socialisation that match its recruitment and selection. As a result, its recruitment and selection was actually a factor that affected its research capacity.

\section{- $\quad$ Time allocated for research and teaching}

Bland et al. (2005) mentioned that having fewer hours in teaching reflects the reality of highly productive researchers committing more time to research compared with others. This study's findings indicate that the academics across the three institutions spent a 
great deal of time teaching but had limited time allocated to research, which negatively impacted their institutions' research productivity. The data were reflected by the student-lecturer ratio of each institution. The student-lecturer ratios of the three institutions in 2014 seen in Table 7-4 are 34:1, 50:1, and 38:1, respectively.

Table 7-4. The number of staff and students of three cases in 2014

\begin{tabular}{|c|c|c|c|c|c|c|}
\hline \multirow{11}{*}{ 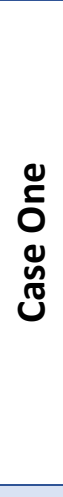 } & \multirow{7}{*}{\begin{tabular}{l}
$\frac{4}{5}$ \\
\multirow{n}{*}{} \\
$\tilde{4}$ \\
0 \\
$\dot{0}$ \\
$z$
\end{tabular}} & \multirow{7}{*}{841} & Support & & & 412 \\
\hline & & & \multirow{5}{*}{$\begin{array}{c}\text { Academic } \\
\text { (429) }\end{array}$} & \multirow[t]{2}{*}{ Titles } & Prof & 0 \\
\hline & & & & & A/Prof & 1 \\
\hline & & & & \multirow{3}{*}{ Qualifications } & $\mathrm{PhD}$ & 35 \\
\hline & & & & & $\mathrm{MA}$ & 350 \\
\hline & & & & & BA & 43 \\
\hline & & & \multicolumn{2}{|c|}{ Percentage of qualified academics } & \multicolumn{2}{|c|}{$89 \%$} \\
\hline & \multirow{4}{*}{ 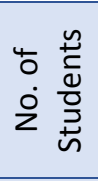 } & \multirow{4}{*}{14,468} & \multirow{3}{*}{\multicolumn{2}{|c|}{ Full-time $(\mathbf{1 1 , 9 0 0 )}$}} & $\mathrm{PhD}$ & 0 \\
\hline & & & & & MA & 378 \\
\hline & & & & & Undergrads & 11,524 \\
\hline & & & \multicolumn{2}{|l|}{ Part-time } & Undergrads & 2,568 \\
\hline & \multicolumn{4}{|c|}{ Student-lecturer ratio } & \multicolumn{2}{|c|}{$34: 1$} \\
\hline \multirow{12}{*}{ 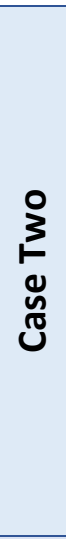 } & \multirow{7}{*}{ 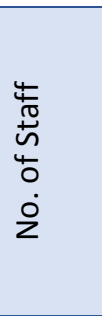 } & \multirow{7}{*}{1,908} & Support & & & 702 \\
\hline & & & \multirow{5}{*}{$\begin{array}{c}\text { Academic } \\
(\mathbf{1}, \mathbf{2 0 6})\end{array}$} & \multirow[t]{2}{*}{ Tiles } & Prof & 7 \\
\hline & & & & & A/Prof & 79 \\
\hline & & & & \multirow{3}{*}{ Qualifications } & PhD & 199 \\
\hline & & & & & MA & 687 \\
\hline & & & & & BA & 234 \\
\hline & & & \multicolumn{2}{|c|}{ Percentage of qualified academics } & & \\
\hline & \multirow{4}{*}{ 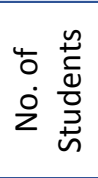 } & \multirow{4}{*}{61,000} & \multirow{3}{*}{\multicolumn{2}{|c|}{ Full-time $(36,656)$}} & $\mathrm{PhD}$ & 287 \\
\hline & & & & & MA & 3,663 \\
\hline & & & & & Undergrads & 32,706 \\
\hline & & & \multicolumn{2}{|l|}{ Part-time } & Undergrads & 24,344 \\
\hline & \multicolumn{4}{|c|}{ Student-lecturer ratio } & \multicolumn{2}{|c|}{$50: 1$} \\
\hline \multirow{12}{*}{ 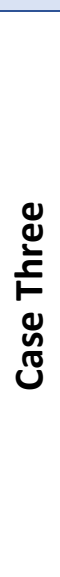 } & & & Support & & 313 & \\
\hline & & & & Titles & Prof & 3 \\
\hline & & & Academic & & A/Prof & 41 \\
\hline & & & (577) & & PhD & 150 \\
\hline & & & & Qualifications & MA & 372 \\
\hline & & & & & BA & 11 \\
\hline & & & Percentag & Ialified academics & & \\
\hline & & & & & $\mathrm{PhD}$ & 68 \\
\hline & 虫蒙 & 22000 & Full-time ( & & MA & 433 \\
\hline & 운 울 & & & & Undergrads & 2,982 \\
\hline & & & Part-time & & Undergrads & 18,517 \\
\hline & Studen & -lecturer & & & & \\
\hline
\end{tabular}

These ratios are higher than the students to lecturer ratio $(28: 1)$ in Vietnamese HEls in 2009, due to the rapid growth in student numbers in recent years (Clark, 2010). 
The students to lecturer ratios of Case Two and Case Three were higher, but their research capacities were stronger than that of Case One because they had more qualified academics with strong research profiles. They also had a few PhD students studying in their institutions who might contribute their research projects to their research productivity. The student-lecturer ratios in faculties of each institution were also different. 'Hot' faculties (which have large numbers of students) such as the faculties of E\&BA, Engineering \& Technology in Case One and Case Two, and the Faculties of Oriental Studies, International Studies, English Language and Literature, Chinese Language and Literature in Case Three had higher student-lecturer ratios than other faculties. Therefore, their research capacities were considered weaker because their academics had heavier teaching loads. The difference in research capacity between faculties in the three institutions also differed by disciplines. For instance, the research capacities of faculties teaching social sciences in Case One and Case Two were weaker than faculties teaching applied engineering and technology. This finding supports a study by Jung (2012) indicating that the academic discipline is one of the most important variables influencing the academic activity and research productivity of academics.

What happened in these three institutions reflects the reality of the present context of the Vietnamese HE. Many Vietnamese HEls are finding their own ways to survive in a new setting required by the Government that Vietnamese HEls need to have financial autonomy after 2015 (Vietnam Ministry of Education and Training, 2005). Meanwhile, they are not strong enough in research performance. It is reasonable for them to choose teaching activities as an easier way in the three main duties of universities (teaching, research, and service) to generate revenues. Thus, they expanded as much part-time training as possible to maintain their operations under the coming pressure of financial autonomy.

In summary, like most Vietnamese HEls, the three institutions in this study set their goals to develop their research capacities. In reality, they have dominant teaching performance rather than research performance due to their demands of maintaining operations to face the pressure of HE reform required by the Government. Therefore, their academics have limited time allocation for research due to their heavy teaching 
loads. This substantially impacts the research capacities of these institutions. It is likely that in order to develop the research capacities of the three HEls, their leaders need to reconsider short-term and long-term objectives in their developmental strategy to balance the teaching and research performance of their operations.

\section{- Communication}

Communication is one of the institutional characteristics that Bland et al. (2005) noted might affect the research engagement of individual academics and institutions. They stated that when institutions had clear and multiple forms of communication, all members felt informed, and their research capacities may increase. In this study, the effect of communication across the three institutions on their academics' engagement was positive because the three institutions had quite effective communication channels. Nearly all information related to national and institutional research policies was uploaded on the website of the Office of Research Management of each institution. However, it happened that the websites of the two offices of Case Two and Case Three provided more information about national and institutional research policies than the website of Case One's Office of Research Management. For instance, the majority of interview participants from the three institutions agreed that there were positive changes in communication in their institutions. They could gain nearly all information related to research activities on their institutions' websites. Therefore, it was not difficult for them to update national and institutional research documents. It was, however, noted that there was a coincidence identified in Case One and Case Three. One senior academic from each institution suggested that it needed a positive change in the relationship between offices supporting research and faculties. This would reinforce the entire research capacities of their institutions.

The disclosure and update of different research reward policies at institutions considered as a form of communication was identified to have a positive influence on HEls' research capacities and their academics' research engagement. However, this effect was different across the HEls studied. For instance, the disclosure and update of research policies in Case Two and Case Three was much better than in Case One. Most 
national, institutional research policies, and research guideline procedures were systematically uploaded on the websites of their Offices of Research Management. Additionally, new announcements for registering research projects from different ministerial, provincial agents were often updated on the websites. Such disclosure of research information considerably facilitated the academics when they were keen to engage in research activities.

Such related research policy information was rarely seen on the website of Case One's Office of Research Management. Likewise, its institutional research document policies were not complete. Actually, its institutional research guideline document policies were completed in early 2014 (six months after the researcher conducted the study). Those simple things might actually have discouraged its academics from engaging in research activities in the past.

In summary, Case One's research communication channel was not as informative as that of the two other cases. In addition, it was in the process of completing its institutional research policies. Therefore, it was identified that it was more difficult for Case One's academics seeking research information, which partly had a negative influence on their research engagement. Moreover, the relationship between offices supporting research and faculties across the three cases to some extent affected their academics' research engagement. Subsequently, this relationship across the three cases needed to be considered for reinforcing the entire research capacities of their institutions.

\section{Summary of institutional characteristics}

It was identified in this study that a range of institutional characteristics affected the research capacity of the academics across the three institutions. The impact of institutional characteristics on each institution was different. It was identified that Case One was more negatively affected by the institutional characteristics than the two other cases. For instance, Case One had fewer academics with strong research profiles and less effective communication for research activities. It was also in the process of working 
towards completing its research policies. Therefore, it is important that Case One improve these institutional factors to enhance its research capacity in the future.

\section{B. Leadership characteristics}

Leadership characteristics were seen as an important part of institutional organisation that impacts academics' research perceptions and engagement. Bland et al. (2005) indicated four leadership characteristics affecting academics' research productivity. This includes scholarship, research orientation, capability in fulfilling critical leadership roles, and participative leadership. In this section, three leadership characteristics (scholarship, capability in fulfilling critical leadership roles, and participative leadership) were included for analysis. This study considered HEls' research orientation as a community factor that affected the research capacity which is discussed in section 7.4. Following is the analysis of the leadership characteristics that affected the research capacity of the three HEls in this study.

\section{- Scholarship}

Bland et al. (2005) stated that when leaders of HEls are regarded as scholars, they serve as sponsors, mentors, and peer models for other group members, and this means that their institutions' research productivity will be positively affected. Unlike western universities, very few Vietnamese HEI leaders act as sponsors in academic research activities and projects because of their limited income. Many leaders of HEls in Vietnam are regarded as scholars, mentors, and peer models. In this study, the degree of scholarliness across the three institutions was different. The institution and faculty leaders in Case Two and case Three were considered more scholarly than those in Case One. Most of them have PhDs, and some are leading researchers in their fields. It was possible that the research experience, the regularity of PD activities, and research achievements of institution/faculty Heads might support junior academics' research interests. For instance, the interviewee MRe 5 from Case Two said that in order to make

a contribution to enhance the faculty's research competence, its leader should be knowledgeable, have leadership skills, a good mind for organisation, a strategy, and vision. He/she should be an approachable and reliable person or 'Brother' for the staff 
to share their difficulties in work. He concluded that the leader, in other words, must have 'tầm và tâm' in Vietnamese, equivalently to 'vision and heart' in English. He continued if the leader was not strong in his professional knowledge and was not a model in his faculty's research activities, it would be difficult for the staff to trust and respect him.

For mentoring and peer modelling, the academic leaders from these two institutions also performed well. For example, a senior lecturer in Case Three revealed that in spite of no longer being the faculty Head, he still demonstrated that he was a good model in the faculty. He encouraged and guided junior academics to conduct research and write scientific articles. He said he could understand his academic staff's professional capacity, so he assigned appropriate tasks to them. He believed that it was important for the leader to understand the capacity of the faculty and academics. The leader could then be an effective mentor for the faculty, and this might make the staff trust and respect their leader.

For Case One, the scholarliness, mentoring and peer modelling of its leading staff were limited. In disciplinary knowledge and research experience, many of its leading staff did not have sufficient qualifications. According to the University Charter and Vietnam Education Law Amendment in 2012, Faculty Deans, Head of the Office of Academics, and Head of the Office of Research Management, and the Rector Board members must be PhD holders (Vietnam National Assembly, 2012). An academic manager from Case One expressed that some faculty leaders in his institution got promotion because of either their 'red' family background (families having contributed to the revolution in the past; grandparents, parents and relatives holding high political positions) or their political activities rather than their academic activities. He considered that some faculty heads in the institution actually had limited research experience, and rarely conducted research projects. Thus, it was hard for them to either ask the staff to implement the given tasks or to win their hearts. He explained that what the academics did was mainly to respond to administrative orders, not to academic and research issues. He continued that what the Office of Research Management \& International Relations was doing at the moment was actually administrative work rather than research work. 
Similarly, another academic manager from this institution stated that currently this Office mainly performed well in its role of international cooperation affairs and administrative work. He went on to say that this Office did not yet have a key person that could help the institution or faculties to make a comprehensive research orientation plan and expand institutional research links. It is likely that it was hard for its academics to benefit from the scholar, mentoring, peer model from their leaders. Therefore, it is possible that this leadership characteristic may have hindered Case One's academics from engaging in research activities.

In conclusion, based on criteria such as qualifications, and research experience and practice, it is likely that the scholarly attribute of the leading staff from Case Two and Case Three is greater than that of Case One. Therefore, the academics from Case Two and Case Three may gain more sponsorship, mentorship, and peer models from their leaders than Case One's academics. Accordingly, it is logical that the research capacities of Case Two and Case Three were higher than that of Case One.

\section{- Capability of fulfilling critical leadership roles}

Capability of fulfilling critical leadership roles is examined by Bland et al. (2015). The critical leadership roles are managers of people and resources, fund raisers, group advocates. They keep the group's mission and shared goals visible to all members. They attend to many individual and institutional features that facilitate research productivity. The study identified that the capability of fulfilling critical leadership roles across three institutions was insufficient. It is likely that institutional leaders are managers of academics and resources rather than faculty/department heads. It is because that the academics and resources are organised and controlled by functional offices such as Offices of Personnel and Facility Management. This complexity is more clearly reflected in Case One as one academic manager revealed that he did not have real power to deal with personnel and resources. He continued that, for the use of resources and dealing with incompetent academics in his faculty, he had to ask permission from these functional offices. Particularly, he felt uncomfortable to work with the academics having a red family background. 
Leaders play a role as fund raisers which was reflected in Case Two and Case Three because many of them were authors of important research projects. They deducted part of the payment of their research projects either to contribute to their faculty's research funding or to pay for the jobs performed by junior academics. This has reciprocal benefits for both the faculty leaders and junior academics in the two institutions. They could complete their research projects quickly and their junior academics might gain some research experience. Therefore, many faculty leaders from the two institutions had group advocates in their institutions.

For the two final aspects (mission and shared goals, and attending to individual and institutional features that facilitate research productivity) in the three institutions, it seemed that these aspects were visible to their academics at the institutional level rather than at the faculty and department level. Especially, for faculties with heavy teaching loads in the three institutions, their missions and shared goals for research were unspecific and vague. The heads of these faculties in the three institutions admitted that they actually had limited time to figure out research strategies for their faculties because of heavy teaching loads. They mostly followed research directives from the institutional level management. As a result, they had limited time to pay attention to many individual and institutional features that facilitate research productivity.

It is apparent that like most Vietnamese HEls, missions and shared goals at faculty and department level are not clear, and this is easily identified in teaching-oriented HEls. For this reason, it is useful for the academics to learn their research orientation and strategy at both institutional and faculty levels besides their teaching responsibility. The academics in this study all acknowledge that they have to fulfil their duties of research and teaching in their institutions. It might, however, make sense that they need to discern what they have to do to conduct research for their faculty. Accordingly, faculty leaders need to make institutional missions and goals visible to all academic members.

It could be concluded that missions and shared goals at faculty and department level in the three institutions were not visible, especially to faculties with heavy teaching loads. Accordingly, it may negatively affect the research engagement of academics in 
faculties. The inactiveness of academics' research involvement at faculties actually entails the stagnation in strengthening the research capacities of their $\mathrm{HEls}$, too.

\section{- Participative leadership}

Participative leadership is the last criterion of leadership characteristics that Bland et al. (2005) asserted to affect academics' research capacity. They listed five things that a participative leader might need: (1) using an assertive, participative style of leadership, (2) attending frequent meetings with clear objectives, (3) creating formal mechanisms and setting expectations for all members to contribute to decision making, (4) making high quality information readily available to the group, and (5) vesting ownership of projects with members and respecting their ideas. It was hard to learn whether the assertive, participative leadership style was used by the leaders in the three institutions. It was because that part of the surveys and the interviews in this study aimed to find out the role of leaders in enhancing their academics to engage in research. Similarly, it was also difficult for this study to identify how often the faculty leaders in the three institutions used items 3,4 , and 5 in their leadership styles. However, this study found that there was a big difference in the utility of the second item of participative leaders by the faculty leaders in the three institutions. Both survey and interview data showed that more conferences and seminars related to PD and research activities were held in Case Two and case Three. Many faculty leaders from the two institutional cases stated that they often organised these conferences and seminars in their faculties for the staff to share professional experiences, and to develop knowledge and research skills. This indicates that the faculty leaders in both Case two and Case Three evidently attended more professional meetings. Therefore, after such conferences and seminars, they could provide specific objectives to strengthen the research capacities for their faculties. It is evidenced from Table 7-4 that the number of qualified academics in these two institutions is much higher than that of Case One. Hence, it is likely that more PD and research activities were held in the two institutions although their student-lecturer ratios are higher. 
To summarise, this study could not give a detailed picture of all aspects of how participative leaders were utilised in the three institutions. However, the study provided one aspect of participative leaders - that is, the frequency of attending meetings with clear objectives by the faculty leaders across the three institutions. The findings showed that the faculty leaders from Case Two and Case Three more frequently attended professional meetings than those in Case One. Consequently, their academics might gain more professional and research experience to enable them to enhance their research engagement and the research capacities of their institutions.

\section{Summary of leadership characteristics}

Like institutional characteristics, the impact of leadership characteristics on the research capacity of the academics across the three institutions was different. It seemed that leadership characteristics have more positive impact on the research capacity of the academics from Case Two and Case Three. It is likely that the faculty leaders in the two institutions might have more experience in their disciplines and leadership skills. Therefore, in addition to benefits from few negative effects of institutional characteristics, it is plausible that their research capacities are stronger than Case One's research capacity.

\section{Summary of the impact of factors at institutional level}

Three major institutional factors found to influence the academics' research engagement across the three institutions include establishment history, geographical location, and organisation (such as institutional characteristics and leadership characteristics). It was likely that the factor of organisation had a more decisive effect on the research capacity of HEls and the research engagement of the academics across the three institutions. In general, Case Two and Case Three received more positive effects from these institutional factors than Case One. Therefore, it was understood that the research capacities of Case Two and Case Three were stronger than that of Case One. 


\subsection{Effects of institutional contexts on academics' motivation and engagement in research}

The study identified that the institutional contexts of the three HEls considerably influenced their academics' motivation and engagement in research. The institutional contexts of the three HEls studied include (i) the availability of leading research academics, (ii) financial resources for research activities, (iii) teaching load, (iv) institutional research environment, $(v)$ and institutional research policies and practices. Details of the effects of institutional contexts are presented in the following sections.

\subsubsection{Availability of leading research academics}

The availability of leading research academics across the three cases greatly differed. As seen in Table 7-3, Case One had much fewer qualified and leading research academics (36 PhD degree holders) than Case Two (283 PhD degree holders) and Case Three (194 PhD degree holders). Case One did not provide PhD training courses as Case Two and Case Three. It was possibly understood that Case One did not have a wide enough research network, and certainly had considerable difficulties to attract much research funding from domestic and foreign sources. It is surely easier for experienced research academics with high academic titles to create and establish research networks and research collaboration. Hu and Gill (2000) found that university lecturers who teach doctoral students had higher research productivity. These lecturers also had opportunities to increase their co-authorship or multi-authorship. It is likely that research academics with high academic ranks who may create opportunities for their HEls to have strong research networks and favourable research collaboration. Accordingly, HEls can attract potential research projects for academics to undertake and create research activities for them to engage in. Therefore, junior academics may have increased opportunities to participate into research projects and research activities. Their research motivation and their research engagement are positively strengthened. This study result is supported by a study of White, James, Burke, and Allen (2012) who considered that academics who hold higher ranks increase opportunities for coauthorship stemming from their longer years of service and potentially larger network of professional contacts. Additionally, they are more likely to be assigned to supervise 
PhD students, which can enhance co-authorship/multi-authorship opportunities for high-ranked academics. In conclusion, HEls with high numbers of leading or starred research academics can strengthen research inspiration, research motivation and research engagement for the academics in their institutional contexts.

\subsubsection{Financial resources for research activities}

Financial resources for research activities were regarded as another factor of the institutional contexts of the three HEls studied that had effects on the research engagement and research motivation of the academics. It was evident that due to a smaller sized institution, Case One's financial resource for research activities was very limited in comparison with that of Case Two and Case Three (see Table 7-1). Perhaps, there were some reasons for the limited expense of Case One's research funding. Firstly, as a provincial institution, it received less financial support from different-levelled domestic research management agencies and foreign research agencies. Secondly, Case One's prestige and its academics were not strong enough to attract the research funding from different sources. Consequently, its research funding was limited. It was thus hard to encourage academics to engage in scientific research. Another thing related to the issue of finance that is also considered to hinder academics from engaging in research is the research payment procedure. In general, this research payment procedure was viewed as a time-spent, complicated and inflexible procedure in the three HEls studied. Perhaps it was more time-consumed and difficult for Case One's academics to receive financial research support due to the very limited research funding of this institutional case. In summary, most Vietnamese HEls, no except for the three HEls in this study, meet difficulties with financial resources for their research activities. This general factor of finance in the institutional context of most HEls impedes their research capacities as well as their academics' motivation and engagement in research.

\subsubsection{Teaching loads}

Heavy teaching load was identified as one of the negative factors of institutional contexts that hamper the academics' research motivation as well as their research engagement across the three HEls studied. Table 7-4 shows that the student-lecturer 
ratios of the three HEls are higher than the average student-lecturer ratio (28:1) of the Vietnamese HEls. The student-lecturer ratios of Case One, Case Two and Case Three are $34: 1,50: 1$, and $38: 1$, respectively. These ratios seemed to indicate that the academics in the three cases allocated their very limited time for research activities. In fact, some interview participants across the cases expressed that many of their colleagues agreed to accept extra hours of teaching to replace their officially compulsory hours of research. It was recognisable that the heavy teaching load in all institutional cases substantially affected their academics' research engagement. It was noticed that the student-lecturer ratios of Case Two and Case Three are higher than Case One, but their research capacities were much stronger than Case One's research capacity. Perhaps superficially, it seemed that heavy teaching load was not a major hindrance for the academics in Case Two to engage in research. In fact, its research projects and research publications were gathered institutes for research, and faculties of agricultural science and applied engineering technology that were considered strong in research activities. The academics from other faculties also had heavy teaching load or unfavourable research environments so their research capacities were limited. In summary, it was possibly affirmed that heavy teaching load was a considerably influential factor that impeded the academics' research motivation and their research engagement.

\subsubsection{Institutional research environment}

My study identified the research environment of the three HEls studied that substantially affected the academics' research motivation and their research engagement. The working environments of Case Two and Case Three provided more favourable conditions for facilitating their academics to engage in scientific research activities. These two institutions both provided a variety of postgraduate training courses. They had a big number of leading research academics, broader research networks and research collaboration. Therefore, the junior academics in these institutions were likely to receive significant research advice, mentorship and peer support from their senior academics. This finding is supported by a study of Raston (1998) who stated that peer support creates a good collaborative research climate within a department or institution. It motivates academics to become actively involved in 
research activities. Kyvik (1995) valued peer support and regarded all forms of support between colleagues as an intellectual energy.

Additionally, the two institutions had obvious missions and visions stated in their institutional development strategies that they would become strong research-oriented $\mathrm{HEIs}$ in Asia-Pacific region. It was likely that working in the institutional environments with a good culture for research, the academics in Case Two and Case Three were more motivated to be involved in research activities. A culture of research is stated by Hannover Research (2014) that it provides a supportive context in which research is uniformly expected, discussed, produced, and valued (Hannover Research, 2014).

Moreover, the study's participants worked in the HEls contexts where English or any other foreign languages are not used, and English is not their official language. Therefore, such institutional contexts really had a negative effect on their research motivation and their research engagement. For instance, two participants from Case Three had the same idea and admitted that their research motivation were much weakened and their research productivity were limited in comparison to the time when they were PhD students abroad. In the same vein, a participant from Case Two considered that although the research environment in his faculty and institution was quite better than that in other Vietnamese HEls, it was not as good as in the university that he studied his PhD there. He continued that there was almost everything (such as the availability of supervisors and English-speaking environment) supporting him in his research. Another participant from Case One said that after returning to work in his institution, he had no academics to share his research interests. He only contacted his former supervisors to ask for advice. It was evident that academics whose English is their official language meet challenges in their research work by nature. For Vietnamese academics, they certainly meet more difficulties in their research work than their colleagues in English-speaking countries because they do not work in English-speaking working environments and English is not their official language.

In conclusion, the institutional research environments of the three HEls studied substantially affected the research motivation and research engagement of their 
academics. Not working in English-speaking environments also had substantial impact on their research motivation and research engagement. However, the effect of institutional research environments on the research motivation and research engagement in the three cases varied a lot. In Case Two and Case Three, this effect seemed to be more positive than it was in Case One because their academics were exposed in better research environments. Consequently, in addition to their intrinsic motivators by nature, they were more likely to be motivated to engage in research activities than their colleagues in Case One.

\subsubsection{Institutional research policies and practices}

Institutional research policies and practices was identified as the final factor of the institutional contexts that affected the research motivation and research engagement of the academics in this study. In reality, research policies and research practices in Case Two and Case Three were established for nearly ten years before the time that this research was conducted in these institutions. Some of their research policies were transparent and appropriately adjusted in response to their institutional settings to encourage their academics to engage in research activities. Additionally, research and PD practices were often organised and performed in their faculties and institutions. Therefore, the academics were aware of their institutional research policies and practices. In contrast, research policies were incomplete and in the process of completion in Case One. The practices of research and PD activities here were not frequent. It was likely that the incomplete research reward policy system and the less frequency of research and PD practices in Case One, to some extent, inhibited its academics from engaging in research activities. In summary, the research policies and research practices of Case Two and Case Three did not have as a negative effect on their academics' research motivation and research engagement as those of Case One.

\section{Summary of the effects of the institutional contexts}

It was acknowledged that institutional contexts evidently affected the research motivation and research engagement of academics at HEls. This study identified that there were several elements of institutional contexts influencing the academics' 
research motivation and their research engagement across three HEIs studied. They included the HEls' availability of leading research academics, the availability of financial support for research, the situation of teaching loads at HEIs, their institutional research environments, and their research policies and practices.

\subsection{Chapter summary}

Vietnam's socioeconomic, sociocultural, and political contexts affect the development of its HE system, especially its HEls' research capacity. Those factors were divided into factors at societal, community, and institutional levels. The factors at societal level include socioeconomic, sociocultural, and political factors. The factors at community level are the resources, research orientation, research networks, and PD practices of HEls. The factors at institutional level consist of establishment history, geographical location, and organisation. The study's findings suggest that various factors influenced academics' research perceptions and their research engagement varied across the three HEls. The factors that seemed to have the most explicit influence on the Vietnamese academics' research perceptions and their research engagement in the three HEls were institutional reputation (as a factor at institutional level), the quality of academics, and research networks (factors at community level), and the commercialisation of university research, linkage of research and teaching, and administration of research. Because of having a longer-standing establishment history (over 50 years), Case Two and Case Three have high prestige in the Vietnamese HE system. Meanwhile, Case One has had only been a university for 15 years. Case Two and Case Three also had a greater number of qualified academics. Several of them were considered as leading experts in their disciplines in Vietnam. Furthermore, these two cases had more ample resources, and broader research networks. Accordingly, it is apparent that their research capacities and their academics' research engagement were stronger and more active than that of Case One. Finally, this study identified that the institutional contexts of these three HEls studied had various effects on their academics' research motivation and research engagement. 



\section{CHAPTER 8. RECOMMENDATIONS AND CONCLUSIONS}

\subsection{Chapter overview}

One of the objectives of Vietnam's HE reform is to enhance its HEls' research capacity and keep up with the challenge of increasingly higher globalisation and internationalisation at the tertiary educational level. However, there have been few studies related to the effects of Vietnamese HE reform on its HEls' research capacity. This study aimed to explore Vietnamese university academics' research perceptions and their research engagement and to suggest possible solutions to enhance Vietnamese HEls' research capacity.

In this chapter, section one, major findings, answers the two research questions of the study. Section two presents the significance of the study. This is followed by recommendations in section three. The limitations of the study are stated in the fourth section. Suggestions for further studies are provided in the fifth section, followed by the thesis conclusion.

\subsection{Major findings}

This study's major findings are presented in two parts. Part one answers the first research question - How do Vietnamese university academics perceive research in tertiary contexts? Part two answers the second research questions - What factors support or hinder Vietnamese university academics from doing research?

\subsubsection{Academics' research perceptions}

Three aspects of the academics' research perceptions identified in this study were (i) knowledge discovery, (ii) understanding the processes of conducting research, and (iii) research significance to individuals and communities. In general, the participants had positive research perceptions in the three aspects because they began research journeys in their postgraduate courses and continued in their professional careers at their working institutions. In addition to these positive research perceptions, the participants and particularly some experienced academics from Case Two and Case Three reflected 
that their research perceptions were to some extent negatively influenced by the contemporary political, social, cultural, and economic contexts in Vietnam. This perception somehow resulted in a negative impact on their research engagement, which is an important consideration for Vietnamese HE policy makers.

\subsubsection{Factors impacting the research capacities of Vietnamese HEls and their academics' research engagement}

The study findings suggested three categories of factors and the institutional contexts influencing the research capacities of the three HEls studied and their academics' research motivation and their research engagement. The factors at different levels affected the three studied HIEs included societal, community and institutional factors. The institutional contexts influencing the research motivation and research engagement of the academics comprised the availability of leading research academics at HEls, their financial resources for research activities, teaching loads, institutional research environments, and institutional research policies and practices.

\section{Factors at the societal level}

There were seven sub-factors in the category of factors at societal level. They included research commercialisation, research-teaching linkage, selection criteria for research projects, administration of research, internal sociocultural factors, external sociocultural factors, HE policies, and HE structure. They were all considerably influenced by socioeconomic, sociocultural, and political contexts in Vietnam.

The research perceptions and the research engagement of the academics had impacts from the three aspects, including internal culture (academics' reputations recognised by the community and their research freedom), HE policies, and the institutional contexts. The effects of these three aspects on the academics' research perceptions, their research motivation, and their research engagement in the three cases were different. It was likely that the academics from Case Two and Case Three received more positive effects than the academics from Case One. The effects of the research commercialisation and HE structure on the academics' research motivation and their research engagement were at an acceptable level. Notably, the study identified that the effects of four other elements (research-teaching linkage, external 
culture, administration of research, and selection criteria for research projects) on the research motivation and research engagement of the academics were negatively considerable.

\section{Factors at the community level}

Factors at community level affecting the research capacities of the Vietnamese HEIs and their academics included the resources, research orientation, research networks, and PD practices at HEls. The impact of the community factors on the research capacities of the three HEls and their academics' research engagement in this study is likely to be summarised as follows.

Case Two and Case Three have more positive community factors than Case One. Specifically, they had good resources and more qualified academics who have experience in research. Due to having big numbers of qualified and leading research academics, they were likely to establish their national and international research emphasis, expand broad research networks, and organise more research-led PD practices. In contrast, Case One had limited resources, a narrow scope of research orientation, limited research networks, and more teaching-led rather than research-led PD practices. To sum up, Case Two and Case Three had more advantaged factors at community level that affected their research capacities than Case One. Therefore, it was likely that their research capacities were stronger, and their academics' research engagement were facilitated more effectively.

\section{Factors at the institutional level}

Institutional factors affecting the research capacities of the three institutions and their academics' research engagement in this study include the establishment history, geographical location, and the organisation of HEls. For instance, the study identified that Case One neither had better impact of establishment history nor an advantaged geographical site as Case Two and Case Three. For this reason, it was hard for Case One to recruit qualified and experienced research academics. For the aspect of the institutional characteristics, the study found that the three elements in Case One (e.g., 
research academics, academic recruitment and selection, and time allocation for research and teaching) were not as effective as those in Case Two and Case Three. The effects of the elements such as communication and research reward policies on Case One's research capacity and its academics' research engagement were regarded as less stronger. Like Case One, the other two cases had the element of time allocation for research and teaching, seen as not good because they were considered to be two famous HEls in Vietnam. These institutions provided a variety of training courses and had big numbers of students, so their academics had limited time for research. However, they had big numbers of qualified academics, and it was easier for them to recruit new talent academics because of their prestige and accessible location. Their research reward policies were also complete. Therefore, it is understood that their research capacities were strong.

The leadership characteristics of Case Two and Case Three were stronger than those of Case One. Specifically, the faculty leaders at Case Two and Case Three were more qualified, and had more experience in research. They also participated in research and provided research mentoring to their junior academics. Meanwhile, Case One had limited leadership characteristics because some of its faculty leaders were not qualified enough, and they did not have much experience to give research mentoring to their academics.

To summarise, Case Two and Case Three had more positive institutional factors affecting their research capacities as well as their academics' research motivation and research engagement than Case One. Understandably, these two institutional cases were two in eighteen key national HEls of Vietnam. Therefore, they could gain greater attention from the government and other national and provincial research management agencies for their developmental strategies.

Institutional contexts affecting the academics' research motivation and research engagement

In addition to the effects of the factors at three different levels on the research capacities of the HEls and their academics' research engagement, the study found that 
the academics' research motivation and their research engagement were impacted by the HEls' institutional contexts. They included the availability of leading research academics at HEls, their financial resources for research activities, teaching loads, institutional research environments, and institutional research policies and practices. Again, the study identify that the effects of the institutional contexts on the academics' research motivation and research engagement were variable. Specifically, the research motivation and their research engagement of Case One's academics were more negatively affected by its institutional contexts than those were in Case Two and Case Three.

\section{Summary of factors affecting the HEls' research capacities and their academics' research engagement}

The three HEls in this study had a multiple of factors at different levels (societal, community, and institutional) influencing their research capacities. Additionally, the study identified that their academics' research motivation and their research engagement were differently affected by each HEl's institutional contexts. These factors and the institutional contexts positively and negatively influenced the research capacities of the three HEls and their academics' research motivation and research engagement. Their effects were very different across the cases. In general, the study identified that among the three cases, Case One did not have as many positive factors at societal, community, and institutional levels as the other two cases. Additionally, Case One's institutional contexts unfavourably affected its academics' research motivation and research engagement. Therefore, it could be concluded that Case One's research capacity and its academics' research motivation and research engagement were more intensely affected by different factors than those of Case Two and Case Three.

\subsection{Significance of the study}

This interpretative qualitative case study about Vietnamese academics' research capacity in tertiary contexts has two major contributions. Its first contributions are supplementing current literature on academics' research productivity and their research engagement in HE contexts, especially in the Vietnamese tertiary educational contexts. 
In addition, this study informs ongoing research and practice in efforts to contribute to building the research capacity of Vietnamese HEls and reinforcing their academics' research engagement.

\subsubsection{Contributions to the literature}

This study has contributed to the literature in a variety of aspects. Firstly, in terms of culture, this research was seen as one of the first interpretive qualitative studies of the Vietnamese academics' research capacity conducted in an emerging economy in Southeast Asia affected by the Confucian philosophy and culture. Previously, similar studies related to HEIs' research capacities and their research productivity have been conducted in developed English-speaking countries and some developed countries in Asia. Therefore, this study provided an outlook of social, cultural and historical contexts affecting the Vietnamese HEls' research capacities in a Southeast Asian country.

Second, in terms of academic contributions, this study can be seen as a systematically comprehensive study investigating the Vietnamese HEls' research capacities. It directly analysed the research perceptions and research engagement of academics and academic managers who differed in management levels in the three HEls in southern Vietnam. Previous studies conducted in Vietnam include a study by Hiep (2006), Hien (2010), Tuan and Ly (2011), and Ly (2013). Hiep's study focused on the enquiry of academics' research capacity in one particular discipline. The two other studies compared the ASEAN nations' research capacities. Ly (2013) conducted a study on the effectiveness of research and innovation management at policy institutional level. This study investigated the factors at different levels affecting the Vietnamese HEls' research capacities. As a result, it can contribute to the literature of academics' research engagement in the HE contexts of ASEAN countries in general and in Vietnam in particular.

Third, in terms of research methodology, this qualitative research employed three data collection instruments (documentation analysis, surveys, and interviews) seen as triangulation to explore academics' research perceptions as well as to achieve greater insights into influential factors impacting their research capacity. The previous studies 
that were conducted in Vietnam seemed not to provide such a good picture of the realities of research practices and activities in Vietnam. For example, Hiep (2006) used document reviews and interviews to collect data whereas (Hien (2010)), and Ly (2013) used governmental document reviews to conduct their comparative studies on nations' research capacities and effectiveness of research management policy. However, this study reviewed national and institutional documents related to research policies. It also investigated the research perceptions and research engagement of the academics and academic managers via the survey. Additionally, this study utilised individual semistructured interviews to explore their practical difficulties in research engagement. This study used three tools to explore factors affecting the Vietnamese HEls' research capacity and their academics' research engagement. It helped to have an insight into the realities of academic research activities, and research development policies at Vietnamese HEls.

Finally, in terms of research results, this study explored factors affecting the research capacities of the Vietnamese HEls. Previous studies such as studies by Bland et al. (2005), and Chen et al. (2006) investigated the factors impacting academics' the research productivity. Bland et al.'s study showed that the faculty's research productivity was affected by individual characteristics, institutional characteristics, and leadership characteristics. Chen et al.'s study indicated that academics' research productivity was affected by intrinsic factors (age, gender, experience, and personalities) and extrinsic factors (promotion, finance, tenure, teaching loads, and research networks). This study identified that the research capacities of Vietnamese HEls and their academics' research engagement were impacted by various factors. They include institutional factors (establishment history, geographical location, and organisation), community factors (resources, research orientation, research networks, and PD practices), and societal factors (socioeconomic, sociocultural, and political). Additionally, the study identified that the research motivation and research engagement of the academics at the three HEls were affected by their institutional contexts.

In summary, this study contributes different aspects of culture, academics, methodology, and research results to the existing literature in the field of academics' 
research productivity and engagement, and HEls' research capacities. It might identify possible directions for other researchers to conduct related studies in the field of HEls' research productivity and their academics' research engagement in the ASEAN community in general and in Vietnam in particular.

\subsubsection{Contributions to future studies}

In addition to the contributions to the literature, this study has also identified potential studies in research capacity building and developing research management policies. It might provide a framework for building and developing strategies and policies to facilitate national and institutional research capacity.

For national research management policies, it is significant that this study's results could be seen as a foundation for HE policy makers and HE researchers in developing nations, particularly in the ASEAN community to study and develop strategies and policies to effectively strengthen the research capacity of their HE system in a time of globalisation. At the institutional level, it is important for the leading staff of HEls to design and build a research oriented development model in their institutions.

In conclusion, the study suggests that broader views of internal and external factors affecting the research capacities of HEls and their academics need to be examined. Having a comprehensive and systematic study on internal and external factors influencing HEls' research capacities may enable the leaders to construct models for the development of their HEIs' research capacities.

\subsection{Recommendations}

The research provides some suggestions for the enhancement of Vietnamese HEls' research capacity as well as university academics' research engagement. Specifically, this research suggests a series of actions to address different research management levels. They include the national and ministerial research management planning, institutional research development plan, and the individual academics' research development plan. 


\section{National and ministerial research management plan}

First, it is important that the five-year and annual research strategic planning of the government, governmental agencies, and ministries are disclosed and clarified to HEls in time. The directors of research management offices of the regional and national institutions revealed that it was hard for southern Vietnamese HEls to address in a timely manner such national or ministerial research strategic announcements. It is the age of information and the internet so it will not be difficult for such governmental agencies to improve their communication channels. Second, the issue of research funding and procedures to obtain research grants also needs to be considered. It is necessary that there be an increase in the state budget for research development at HEls and requirements to simplify the bureaucratic complexity of research funding procedures. Finally, it is important that the Government have policies and initiatives to develop national and international collaborations in research at HEls and to reinforce the links between universities and national research institutes, and between universities and businesses.

\section{Institutional research strategic planning level}

In addition to the Government's support of finance and policy, it is essential that HEls need to focus on the following things. Firstly, they need to be proactive in their own research strategic planning. Secondly, Vietnamese HEls need to increase the number of qualified and leading research academics, especially concentrate on improving academics' research skills, leadership skills in research, and PD and research activities. Hannover Research (2014) states that the academics with strong research skills and leadership skills in research play essential roles towards the enhancement of HEls' research capacity. Therefore, in order to be strong in research, Vietnamese HEls need to have increased numbers of qualified and leading research academics. More conferences related to research, PD activities, and leadership skills for academics need to be held at Vietnamese HEls to strengthen the research skills for junior Vietnamese academics. Thirdly, there should be a need to reconsider the mechanism of research management in Vietnamese HEls. This study identified the mechanism of research management in the three HEls as one factor inhibiting their academics' research 
motivation and their research engagement. Thus, this mechanism need to be simplified so that it is not considered as an invisible barrier to the academics' research engagement. Fourthly, research resources, research networks, research collaborations, and the culture of research in HEls need to be developed and expanded. It is emphasised that collaboration should frequently and intensively occur in order to maintain research motivation among colleagues. Regular collaborations create a supportive culture of research among academics (Bland et al., 2005; Hannover Research, 2014). Particularly, newly established HEls need to develop and expand their domestic and foreign research networks and collaboration channels by calling for financial mobilisation from individuals, organisations, and businesses in the country and abroad to invest in their research activities. In doing so, they need to build a strong link between training, research and industry so that their research projects meet the enterprises' and society's needs. In order to expand their research, HEls are in need of research institutes and universities in foreign nations having similar research interests to cooperate so that their academics can gain research experience from foreign partnerships. Fifthly, it is useful for the leaders of HEls to revise and adjust shortcomings in communication channels between them and superior governmental agencies. Finally, the leaders of HEls also need to reconsider the possible effects of the institutional contexts on their academics' research motivation and research engagement.

\section{Individual academic level}

From the perspective of the individual academic level, recommendations are suggested as follows. Firstly, faculty leaders in Vietnamese HEls should reconsider the utility of leadership styles and skills to strengthen the research capacity of the institutions and their academics. Secondly, academics at the Vietnamese HEls need to proactively develop IT and foreign language competence, especially the English language. It is difficult for them to enter the world of scientific research without strong IT and English competence. Thirdly, it is important that individual academics' negative views (associated with the reasons of complicated procedures to gain research funding, of the lack of time and money) need to be dismissed. Instead, they need to actively engage in research and then report any difficulties in conducting research to responsible agents. 
Fourthly, it is necessary to engage themselves in appropriate research communities to develop their research knowledge and skills. Fifthly, it is important for individual academics to develop their knowledge and motivation with the spirit of undertaking research for the community, for the image of their HEIs and themselves rather than for money. Finally, it is necessary to balance their time allocated for research and teaching suitably so that they will have more time for research.

In conclusion, this study suggests recommendations addressing three different research levels: individual, institutional, and national. It is likely that when such recommendations are addressed to HE policy makers and leaders of HEls in Vietnam, Vietnamese HEls' research capacity and the research engagement of their academics in the near future will improve.

\subsection{Limitations of the study}

All studies have some limitations and this study is no exception. Limitations of this study are as follows:

Firstly, this qualitative research designed with three cases was not presented as typical Vietnamese HEls in the field of research capacity. Thus, the study's results were not general for the research capacity of the entire Vietnamese HE system.

Secondly, the survey and interview participants in this study were not representatives of academics in the three institutions. In other words, their opinions on research perceptions as well as factors affecting their research engagement were fundamentally personal, not collectively representing their institutions' opinions.

Thirdly, from the perspective of research methodology, although the three data collection tools (document analysis, surveys, and individual interviews) were utilised for data triangulation, the data collected were not considered to either indicate all participating academics' daily research practices or the research activities in their institutions. Individuals' perceptions and actions are accurate at a specific time, and in a given community or social context. When there are changes in the community and society, the perceptions and actions of individuals in such a community or society will 
alter accordingly. Moreover, although each part of the survey (research perception, factors enhancing research capacity, and factors demotivating research capacity) has sufficient space for participants to express their ideas on these themes, the survey did not obtain much information from the open-ended question. Similarly, the individual interviews were not fully completed by junior academics. Specifically, in replying on the open-ended questions, the participants appeared hesitant when providing their personal ideas on the limitations of the developmental strategy of their faculty and their institution. Perhaps, in the aspect of the Vietnamese hierarchical culture, they might think they were not permitted to reveal information related to their institutions. They were afraid of being identified when providing such information by their managers. Finally, the study's findings were based on a comparatively small number of surveys and interview participants in each case, so it is not possible to generalise. Despite these limitations, it was important that the shortcomings of using the survey and individual interview were controlled well in this study. In future research, a larger number of survey and interview participants were recruited. Therefore, the trustworthiness of the data would be stronger, and it would be more appropriate for such a study to report about Vietnamese academics' research capacity.

Fourthly, as Kyvik (1995) mentioned the gender had substantial effects on individual academics' research engagement. Yet, this study omitted the finding of the gender of the participant because of ethical considerations mentioned in Chapter 3. As a result, the study did not include the analysis of the effect of the gender on the individual academics' research engagement. This was considered as another shortcoming of this study.

Last but not least, this study concentrated on analysing the factors at higher levels (societal, community, institutional) rather than at individual level (intrinsic and extrinsic factors) that affected the research capacities of HEls. It also analysed some possible institutional contexts influencing the academics' research motivation and research engagement. If the effects of individual factors on academics' research motivation and their research engagement had been analysed as previous studies in the literature, this study would have provided an overview of the effects of all influential factors at 
different levels. Therefore, individual factors (including gender) affecting the research motivation and research engagement of the academics in the ASEAN University Network should be taken in consideration for undertaking.

\subsection{Suggestions for further studies}

Suggestions for further studies could be taken into consideration. They include studies on research management policy, comparative studies on national research polices, studies on the effects of leadership on the research capacity of HEIs and their academics, and studies on the effects of factors on academics' research engagement.

For studies on research management policy, future research could be conducted to examine the effectiveness of Vietnam's research management policies on its $\mathrm{HE}$ system or the effects of the national research management policy on academics' research engagement. Another theme of research management policies that can be concentrated on is to explore the effects of the State management structure of the HE system, and national research development policies on academics' research engagement as well as the research capacity of HEls.

Comparative studies may yield further insights. For instance, further studies can be focused on the comparison of ASEAN nations' research policies and the effects of these policies on academics' research engagement. Other studies could be conducted to compare the research capacities of HEls and their academics in specific disciplines in ASEAN nations.

For the effects of leadership on research capacity, some studies could be conducted to explore the impact of leadership on HEIs' and their academics' research productivity. Inquiry of the nexus between leadership styles and academics' research engagement or inquiry of nexus leadership styles and research attitudes of academics in different disciplines can also be conducted.

Finally, the number of studies on factors affecting the research engagement of the academics in ASEAN countries is still limited. Therefore, it is important to investigate future studies of individual factors (including gender) that affect the research 
engagement and research productivity of the academics of the AUN in the time of the regional economic integration.

\subsection{Thesis conclusion}

Building strong research capacity for a nation's HE system, especially for a developing nation like Vietnam, is an important step in its global integration in the knowledge economy. This is because research at HEls plays an important part in a country's economic, political, social, and cultural development. There is evidence that many countries like the United States, Japan, the UK, Germany, France, Australia, and Korea are prosperous because they are strong in research development and technology innovation. In acknowledging the importance of academic research carried out at HEls and their ambition to gain the status of an industrial nation by the year 2020, the Vietnamese Government has gradually made greater financial investments in HEls' research capacity. The Government also has issued a series of directive documents for its HEls to implement. However, Vietnamese HEls' research capacities remain lower than many other ASEAN nations like Singapore, Malaysia, and Thailand, and the Government still does not know how effective their research directives and policies have been. Therefore, it was significant for this study - Vietnamese academics' research capacity in tertiary contexts - to be conducted because this study's findings to some extent reflect how effectively the Government's research policies have been implemented, and their effects on operations of HEls.

To summarise, the study's findings have contributed to an understanding of the overall contexts of research activities at Vietnamese HEls. Importantly, they provide evidence for Vietnamese HE policy makers to revise current research development strategies as well as research reward policies as part of realigning policies to reinforce enhancing Vietnamese HEls' research capacity. This would possibly boost the global integration of the Vietnamese HE system as well as greatly contribute to helping Vietnam become a strong industrial nation by 2020 . Finally, the findings identified the need for potential further studies. For example, studies investigating national research management policies in the ASEAN community can be undertaken. Comparative studies on the research capacities and research productivity of HEls in Southeast Asia can be 
taken in consideration. There can be some directions for conducting studies of the influences of leadership on the research capacities of HEls and their academics. Finally, further research can focus on gender and other individual factors affecting the research engagement and research productivity of the HEls' academics in each ASEAN member in the time of regional integration. 



\section{REFERENCES}

4International Colleges \& Universities. (2013). Universities in Vietnam by 2013 Univeristy Web Ranking. from http://www.4icu.org/vn/

Abbott, M., \& Doucouliagos, H. (2004). Research output of Australian universities. Education Economics, 12(3), 251-265. doi: 10.1080/0964529042000258608

Åkerlind, G. S. (2008). An academic perspective on research and being a researcher: An integration of the literature. Studies in Higher Education, 33(1), 17-31. doi: 10.1080/03075070701794775

Anh, N. (2014). Đại học Việt Nam sẽ được phân thành 3 tầng, 5 hạng Vietnamnet. Retrieved from http://vietnamnet.vn/vn/giao-duc/200212/dai-hoc-viet-nam-se-duoc-phan-thanh-3tang--5-hang.html

Association of Southeast Asean Nations. (2014). ASEAN overview. Retrieved August, 2015, from http://www.asean.org/asean/about-asean

Association of Southeast Asean Nations University Network. (2015). AUN member universities. Retrieved August, 2015, from http://www.aunsec.org/aunmemberuniversities.php

Association of Southeast Asian Nations. (2008). ASEAN economic community blueprint. Jakarka, Indonesia: Association of Southeast Asian Nations.

Atkinson, P. A., \& Coffey, A. (2004). Analysing documentary realities. In D. E. Silverman (Ed.), Qualitative research: Theory, method and practice (pp. 56-75). London: Sage.

Atkinson, R. C., \& Blanpied, W. A. (2008). Research universities: Core of the US science and technology system. Technology in Society, 30, 30-48.

Babu, A. R., \& Singh, Y. P. (1998). Determinants of research productivity. Scientometrics, 43(3), 309-329. doi: 10.1007/BF02457402

Bai, L., \& Millwater, J. (2011). Chinese TEFL academics' perceptions about research: An institutional case study. Higher Education Research and Development, 30(2), 233-246. doi: 10.1080/07294360.2010.512913

Bai, L., Millwater, J., \& Hudson, P. (2012). Chinese teaching English as a foreign language (TEFL) academics' perceptions about research in a traditional culture. Journal of Higher Education Policy and Management, 34(1), 91-102. doi: 10.1080/1360080X.2012.642336

Ball, S. (2007). Leadership of academics in research. Sage Journal: Educational Management Administration \& Leadership, 35(4), 449-477. doi: 10.1177/1741143207081058

Barnett, R. (1990). The idea of higher education. Buckingham: Open University Press.

Baxter, P., \& Jack, S. (2008). Qualitative case study methodology: Study design and implementation for novice researchers. The Qualitative Report, 13(4), 544-599.

Becher, T., \& Trowler, P. R. (2001). Academic tribes and territories (2nd ed.). Buckingham: The Society for Research into Higher Education and Open University Press.

Ben-David, J. (1984). The scientist's role in society: A comparative study (2nd ed.). Chicago: The University of Chicago Press.

Berg, B. L. (2001). Qualitative research methods for the social sciences. Long Beach: California State University.

Bhattacharya, H. (2008). Interpretive research. In L. M. Given (Ed.), The Sage encyclopedia of qualitative research methods (pp. 465-468). Thousand Oaks, CA: Sage. 
Bitsch, V. (2005). Qualitative research: A ground theory example and evaluation criteria. Journal of Agribusiness, 23(1), 75-91.

Blackburn, R. J., \& Lawrence, J. H. (1995). Faculty at work: Motivation, expectation, satisfaction. Baltimore, MA: The Johns Hopkins University Press.

Blackburn, T., Bieber, J., Lawrence, J., \& Trautvetter, L. (1991). Faculty at work: Focus on research, scholarship and service. Research in Higher Education, 32(4), 385. doi: 10.1007/BF00992183

Bland, C. J., Center, B. A., Finstad, D. A., Risbey, K. R., \& Staples, J. G. (2005). A theoretical, practical, predictive model of faculty and department research productivity. Academic Medicine, 30(3), 225-237. doi: http://dx.doi.org/10.1097/00001888-200503000-00006

Borg, S. (2009). English language teachers' conceptions of research. Applied Linguistics, 30(3), 358-388. doi: 0.1093/applin/amp007

Borg, S., \& Alshumaimeri, Y. (2012). University teacher educators' research engagement: Perspectives from Saudi Arabia. Teaching and Teacher Education, 28(3), 347-356. doi: http://dx.doi.org/10.1016/i.tate.2011.10.011

Bowden, J., Green, R., Barnacle, N., Cherry, N., \& Usher, R. (2005). Academics' ways of understanding success in research activities. In J. A. Bowden \& P. Green (Eds.), Doing developmental phenomenography (pp. 128-144). Melbourne: RMIT University Press.

Boyer, E. L. (1990). Scholarship reconsidered: Priorities of the professionate (1st ed.). New York: The Canergie Foundation for the Advancement of Teaching.

Bozeman, B., \& Elizabeth, C. (2004). Scientists' collaboration strategies: Implications for scientific and technical human capital. Research Policy, 33(4), 599-616. doi: 10.1016/j.respol.2004.01.008

Brasuell, J. (2014). The future of higher education: Location, location, location. Planetizen. from http://www.planetizen.com/node/70542

Braxton, J. M., Luckey, W., \& Helland, P. (2002). Institutionalizing a broader view of scholarship into colleges and universities through Boyer's four domains (1st ed.). San Fransico: Jossey-Basse.

Brew, A. (2001). Conceptions of research: A phenomenographic study. Studies in Higher Education, 26(3), 271-285. doi: 10.1080/03075070120076255

Brew, A. (2003). Understanding research-led teaching. Higher Education Research and Development Society of Australasia, 25(1), 1-5.

Brew, A. (2006). Research and teaching: Beyond the divide. Houndmills, Basingstoke, Hampshire, NY: Palgrave Macmillan.

Brew, A., Boud, D., Namgung, S. U., Lucas, L., \& Crawford, K. (2015). Research productivity and academics' conceptions of research. Higher Education, 1-17. doi: 10.1007/s10734-0159930-6

Brown, R. B. (2005). "Why link personal research and teaching?". Education + Training, 47(6), 393-407. doi: 10.1108/00400910510617024

Bruce, C., Pham, B., \& Stoodley, I. (2004). Constituting the significance and value of research: Views from information technology academics and industry professionals. Studies in Higher Education, 29, 219-238. doi: 10.1080/0307507042000190804 
Burke, C. S., Stagl, K. C., Kline, C., Goodwin, G. F., Salas, E., \& Halpin, S. M. (2006). What type of leadership behaviors are functional in teams? A meta-analysis. Leadership Quarterly, 17(3), 288-307. doi: 10.1016/j.leaqua.2006.02.007

Bushaway, R. W. (2003). Managing research. Maidenhead: Open University Press.

Business Insides. (2011). The development of small and medium enterprises in Vietnam.

Butler, J., \& Cantrell, R. (1989). 'Extrinsic reward valence and productivity of business faculty: A within and between subjects decision modelling experiment'. Psychological Reports, 64, 343-353. doi: 10.2466/pr0.1989.64.2.343

Cadima, R., Ojeda, J., \& Monguet, J. M. (2012). Social networks and performance in distributed learning communities. Educational Technology \& Society, 15(4), 296-304.

Carayol, N., \& Matt, M. (2006). Individual and collective determinants of academic scientists' productivity. Information Economics and Policy, 18, 55-72.

Case One. (2011). Report of scientific research and technology transfer activities in 2011. Paper presented at the The Institutional Scientific Research Conference, Case One.

Case One. (2013). Academic tasks in the year 2013-2014. Vietnam.

Case One. (2014a). The development strategy in period 2011-2020, its vision towards 2030 (A draft version). Vietnam.

Case One. (2014b). Internal expense regulation 2014. Vietnam.

Case One. (2014c). International cooperation. Vietnam.

Case One. (2014d). The overview report on the training activity 2010-2014 and its orientation until 2020. Vietnam.

Case Three. (2012). Strategic development plan in period 2011 - 2015 Ho Chi Minh City, Vietnam.

Case Three. (2013). Introduction. Ho Chi Minh City, Vietnam.

Case Three. (2014a). International cooperation. Ho Chi Minh, Vietnam.

Case Three. (2014b). Report on publications. Ho Chi Minh City, Vietnam.

Case Three. (2015). The central library. Ho Chi Minh, Vietnam.

Case Two. (2009). Decision on "The regulation on recruitment and educational progress towards academics". Vietnam.

Case Two. (2010). Decision on "The regulation of monitoring academics' professional work in Case Two". Vietnam.

Case Two. (2011). A summary report: Evaluation of science and technology activities in the period 2006-2010 \& Building and orienting the plan of science and technology in the period 2011-2015. Vietnam.

Case Two. (2013a). Decision on "The internal expense regulation". Vietnam.

Case Two. (2013b). Decision on "The regulation of monioring academics' professional work". Vietnam.

Case Two. (2014a). International collaboration. Vietnam.

Case Two. (2014b). International collaboration of Case Two's Mekong Delta development research institute. Vietnam. 
Case Two. (2014c). International collabration of Case Two's college of Environment and Natural Resources. Vietnam.

Case Two. (2014d). Introduction to Case Two's learning resources centre. Vietnam.

Case Two. (2014e). Mission and vision. Vietnam.

Case Two. (2014f). Publication of financial income and expenditure towards the MOET's dispatch 9535. Vietnam.

Cavana, R. Y., Delahaye, B. L., \& Sekaran, U. (2001). Applied business research: Qualitative and quantitative methods (Australian ed.). Milton, Queensland, Australia: Wiley.

Chapman, D. W. (2009). Higher education faculty in East Asia. Draft for discussion. Retrieved from http://siteresources.worldbank.org/INTEASTASIAPACIFIC/Resources/EastAsiaHigherEducationFaculty.pdf

Chen, Y., Gupta, A., \& Hoshower, L. (2006). Factors that motivate business faculty to conduct research: An expectacy theory analysis. Journal of Education for Business, 81(4), 179189. doi: 10.3200/JOEB.81.4.179-189

Chen, Y., Marry, R. N., Ashok, G., \& Leon, H. (2010). Research productivity of accounting faculty: An exploratory study. American Journal of Business Education, 3(2), 101-113. doi: http//:dx.doi.org/10.19030/ajbe.v3i2.389

Cho, H., Gay, G., Davidson, B., \& Ingraffea, A. (2007). Social networks, communication styles, and learning performance in a CSCL community. Computers \& Education, 49, 309-329.

Clark, N. (2010). Higher education in Vietnam: Student growth, faculty shortages and international partnerships. World Education News \& Reviews. from http://wenr.wes.org/2010/08/wenr-julyaugust-2010-practical-information/

Cohen, E., \& Lloyd, S. (2014). Disciplinary evolution and the rise of the transdiscipline. Informing Science: the International Journal of an Emerging Transdiscipline, 17, 189-215.

Cole, J. R., \& Zuckerman, H. (1984). The productivity puzzle: persistence and change in patterns of publication of men and women scientists. In P. Maehr \& M. W. Steinkamp (Eds.), Advances in Motivation and Achievement (Vol. 2, pp. 217-258). Greenwich: JAI Press.

Coombs, R., \& Georghiou. (2002). A new "industrial ecology". Science, 296(1). doi: doi: $10.1126 /$ science. 1068350

Corbin, J., \& Strauss, A. (2008). Basics of qualitative research: Techniques and procedures for developing grounded theory ( $3 r d$ ed.). Thousand Oaks, CA: Sage.

Creswell, J. W. (1986). Measuring Faculty Research Performance. San Francisco Jossey Bass.

Creswell, J. W. (1998). Qualitative inquiry and research design: Choosing among five designs. Thousand Oaks, CA: Sage.

Creswell, J. W. (2013). Research design: Qualitative, quantitative, and mixed methods approaches (4th ed.). Thousand Oaks, CA.: Sage.

Danish International Development Agency (DANIDA). (2014). Strengthening research capacity: Strategic framework for Danish support for development research 2014-2018. Copenhagen, Denmark: Ministry of Foreign Affairs of Denmak.

Dawson, S. (2008). A study of the relationship between student social networks and the sense of community. Educational Technology \& Society, 11(3), 224-238.

Denzin, N. K., \& Lincoln, Y. S. (2005). Handbook of qualitative research (3rd ed.). Thousand Oaks, CA: Sage. 
Diaz Adrade, A. (2009). Interpretive research aiming at theory building: Adopting and adapting the case design. The Qualitative Report, 14(1), 42-60.

Dill, D. D., \& Vught, F. A. (2010). National innovation and the academic research enterprise: Public policy in global perspective. Baltimore, MA: Johns Hopkins University Press.

Ding, W. W., Murray, F., \& Stuart, T. E. (2006). Gender Differences in Patenting in the Academic Life Sciences. Science, 313, 665-667. doi: 10.1126/science.1124832

Dtinews/VNN. (2014). Ministry looks into fake PhDs, Vietnamnet bridge. Retrieved from http://english.vietnamnet.vn/fms/education/110260/ministry-looks-into-fakephds.html

Dundar, H., \& Darrell, R. L. (1998). Determinants of research productivity in higher education. Research in Higher Education, 39(6), 607-631. doi: 10.1023/A:1018705823763

Etzkowitz, H., Webster, A., \& Gebhardt, C. T., B. R. C. (2000). The future of the university and the university of the future: Evolution of ivory tower to entrepreneurial paradigm. Research Policy, 29(2), 313-330. doi: 10.1016/S0048-7333(99)00069-4

European Commission. (2007). Improving knowledge transfer between research institutions and industry across Europe: Embracing open innovation. Implementing the Lisbon agenda. (978-92-79-05521-8). Belgium: European Commision.

Fabel, O., Hein, M., \& Hofmeister, R. (2008). Research productivity in business economics: An investigation of Austrian, German and Swiss Universities. German Economic Review, 9(4), 506-531. doi: 10.1111/j.1468-0475.2008.00451.x

Fairweather, J. S. (1993). Faculty reward structures: Toward institutional and professional homogenization. Research in Higher Education, 34(5), 603-623. doi: 10.1007/BF00991922

Flyvbjerg, B. (2011). Case study. In N. K. Denzin \& Y. S. Lincoln (Eds.), The Sage hanbook of qualitative research (pp. 301-316). Thousand Oaks, CA: Sage.

Foreign Affairs and International Trade Canada. (2014). Cultural information - Vietnam. from http://www.intercultures.ca/cil-cai/ci-ic-eng.asp?iso=vn

Fox, M. F. (1983). Publication productivity among scientists. Social Studies of Science, 13, 285305.

Garcia, L., \& Quek, F. (1997). Qualitative research in information systems: Time to be subjective? Information Systems and Qualitative Research (pp. 444-465). Philadelphia, PA: Springer.

Gasson, S. (2004). Rigor in grounded theory research: An interpretive perspective on generating theory from qualitative field studies. In M. E. Whitman \& A. B. Woszczynski (Eds.), The handbook of information systems research (pp. 79-102). Hershey, PA: Idea.

Griffiths, R. (2004). Knowledge production and the research-teaching nexus: the case of the built environment disciplines. Studies in Higher Education, 29(6), 709-726.

Guba, E. G. (1981). Criteria for assessing the trustworthiness of naturalistic inquiries. ERIC/ECTJ Annual Review Paper ECTJ, 29(2), 75-91. doi: 10.1007/BF02766777

Hannan, A., \& Anderson, J. (2007). Questionnaires in education research. from Faculty of Education, University of Plymouth http://www.edu.plymouth.ac.uk/resined/QUESTS/index.htm

Hannover Research. (2014). Building a culture of research: Recommended practices (pp. 33). Washinton, D.C.: Academy Administration Practice. 
Hardre, P. L., Beesley, A. D., Miller, R. L., \& Pace, T. M. (2011). Faculty motivation to do research: Across disciplines in research-extensive universities. The Journal of the Professoriate, 5(1), 35-69.

Harman, G., \& Bich, N. T. N. (2010). Reforming teaching and learning in Vietnam's higher education system. In M. Harman, G. Hayden \& T. N. Pham (Eds.), Reforming Higher Education in Vietnam: Challenges and Priorities (Vol. 29, pp. 65-86). London: Springer.

Harman, G., Hayden, M., \& Nghi, P. T. (2010). Higher education in Vietnam: Reform, challenges and priorities. In G. Harman, M. Hayden \& T. N. Pham (Eds.), Reforming Higher Education in Vietnam: Challenges and Priorities (Vol. 29, pp. 1-14). London: Springer.

Harman, G., \& Ngoc, L. T. B. (2010). The research roles of Vietnam's universities. In G. Harman, M. Hayden \& P. T. Nghi (Eds.), Reforming higher education in Vietnam (Vol. Dynamics, pp. 87-102). London: Springer Netherlands.

Harman, K. (2005). Strengthening the links between teaching, learning and research in higher education. Washington, DC: The World Bank.

Hassan, A., Tymms, P., \& Isamil, H. (2008). Academic productivity as perceived by Malaysian academics. Journal of Higher Education Policy and Management, 30(3), 283-296. doi: doi.org/10.1080/13600800802155184

Hattie, J., \& Marsh, H. W. (1996). The relationship between research and teaching: a metaanalysis. Review of Educational Research, 66(4), 507-542.

Hayden, M., \& Lam, Q. T. (2007). Institutional autonomy for higher education in Vietnam. . Higher Education Research and Development, 26(1), 73-85.

Healey, M. (2005). Linking research and teaching exploring disciplinary spaces and the role of inquiry-based learning. In R. Barnett (Ed.), Reshaping the university: new relationships between research, scholarship and teaching (pp. 30-42). Maidenhead: McGrawHill/Open University Press.

Hedjazi, Y., \& Behravan, J. (2011). Study of factors influencing research productivity of agriculture faculty members in Iran. Higher Education, 62(5), 635-647. doi: $10.1007 / \mathrm{s} 10734-011-9410-6$

Herriott, R. E., \& Firestone, W. A. (1983). Multisite qualitative policy research: Optimizing description and generalzability Educational Researcher, 12, 14-19. doi: doi.org/10.3102/0013189X012002014

Hien, P. D. (2010). A comparative study of research capacity of East Asian countries and implication for Viet Nam. Springer Netherlands, 60(6), 615-625. doi: 10.1007/s10734010-9319-5

Hiep, P. H. (2006). Researching the research culture in English language education in Vietnam. The Electronic Journal for English as a Second Language, 10(2), 1-20.

Hirosato, Y., \& Kitamura, Y. (2009). An integrated framework for analyzing education reforms and capacity development in developing countries: Why, how, and for whom? Netherlands: Springer.

Holbrook, N. J., \& Devonshire, E. (2005). Simulating scientific thinking online: an example of research-led teaching. Higher Education Research and Development, 24(3), 201-213. doi: 10.1080/07294360500153844

Hu, Q., \& Gill, T. G. (2000). IS faculty research productivity: influential factors and implications. Information Resources Management Journal, 13(2), 15-25. 
Huang, J. S. (2014). Building research collaboration networks - An interpersonal perspective for research capacity building. Journal of Research Administration, 45(2), 89-112.

Hughes, C. A. (1998, June). Factors related to faculty publishing productivity. Paper presented at the IATUL Conference, Pretoria, South Africa.

Hunter, D., \& Kuh, G. (1987). The "write wing": Characteristics of prolific contributors to the higher education literature. Journal of Higher Education Economics, 58(4), 443-462. doi: doi.org/10.2307/1981317

Isfandyari-Moghaddam, A., Hasanzadeh, M., \& Ghayoori, Z. (2012). A study of factors affecting research productivity of Iranian women in ISI. Scientometrics, 91, 159-172. doi: 10.1007/s11192-011-0585-5

Jeans, R., \& Murphy, L. (2009). Investigating academic's motivation to pursue research activity. Newport CELT Journal, 2, 17-28.

Jenkins, A., Healey, M., \& Zetter, R. (2007). Linking teaching and research in disciplines and departments. York, United Kingdom: The Higher Education Academy.

Jenson, D. (2008). The Sage encyclopedia of qualitative research methods: Transferability. In L. M. Given (Ed.), Sage knowledge (Vol. 2, pp. 887). Thousand Oaks, CA: Sage.

Johnson, P. (2012). The importance of academic research. from http://www.news.uwa.edu.au/201203194542/vice-chancellor/importance-academicresearch

Jones, A., Burgess, T. A., Farmer, E. A., Fuller, J., Stocks, N. P., Taylor, J. E., \& Waters, R. L. (2003). Building research capacity: An exploratory model of GPs' training needs and barriers to research involvement. Australian Family Physician, 32(11), 955- 958.

Jung, J. (2012). Faculty research productivity in Hong Kong across academic disciplines. Hlgher Education Studies, 2(4), 13. doi: http://dx.doi.org/10.5539/hes.v2n4p1

Kearney, M. L. (2009). Higher education, research and innovation: Charting the course of the changing dynamics of the knowledge society. In V. L. Meek, U. Teichler \& M. Kearney, L. (Eds.), Higher education, research and innovation: Changing dynamics (Vol. Report on the UNESCO Forum on higher education, research and knowledge 2001-2009). Kassel, Germany: International Centre for Higher Education Research.

Kevik, S. (2003). Changing trends in publishing behaviour among university faculty, 1980-2000. Scientometrics, 58(1), 35-48. doi: 10.1023/A:1025475423482

Khan, S. B. (2013). University-industry partnership for development of knowledge. Asian Journal of Social Sciences \& Humanities, 2(2), 268-274.

Khanh, D. V., Ly, P. T., \& Tuan, N. V. (2012a). Đầu tư nghiên cứu khoa học: Tiền chủ yếu 'nuôi'... cán bộ (Investment into scientific research: Money mainly 'feeds'... staff), Vietnamnet. Retrieved from http://vietnamnet.vn/vn/tuanvietnam/99789/tien-chu-yeu-nuoi-can$\underline{\text { bo.html }}$

Khanh, D. V., Ly, P. T., \& Tuan, N. V. (2012b). Scientific research in Vietnam: Contemporary issues and proposed strategic solutions. Paper presented at the Vietnamese higher education in globalization context, Vietnam National University HCMC.

Kiley, M., \& Mullins, G. (2005). Supervisors' conceptions of research: What are they? Scandinavian Journal of Educational Research, 49, 245-262.

Klein, H. K., \& Myers, M. D. (1999). A set of principles for conducting and evaluating interpretive field studies in information systems. Mis Quarterly, 23(1), 67-93. doi: 10.2307/249410 
Knight, P. G. (1987). The relationship between teaching and research. Area, 19, 350-352.

Koswara, J., \& Tadjudin, M. K. (2006). Development and impact of state policies on higher education research in Indonesia. In V. L. Meek \& C. Suwanwela (Eds.), Higher Education, Research, and Knowledge in the Asia Pacific Region. New York: Palgrave Macmillan.

Kvale, S. (1996). Interwiews: An introduction to qualitative research interviewing. Thousand Oaks, CA: Sage.

Kyvik, S. (1990). Age and scientific productivity: Differences between fields of learning. Higher Education, 19(1), 37-55. doi: 10.1007/BF00142022

Kyvik, S. (1995). Are big university departments better than small ones? . Higher Education, 30(3), 295-304.

Lach, S., \& Schankerman, M. (2008). Incentives and invention in universities. RAND Journal of Economics, 39(2), 403-433. doi: 10.1111/j.0741-6261.2008.00020.x

Lahr, H., Hughes, A., \& Kitson, M. (2013). Signalling, absorptive capacity and the geographic patterns of academic knowledge exchange. Paper presented at the 35th DRUID Celebration Conference 2013, Barcelona, Spain. http://druid8.sit.aau.dk/acc papers/mia6jxpt9dj3gfd7qunocn7afv66.pdf

Lam, Q. T. (2005). An overview of higher education in Vietnam: Current situation and issues. Ha Noi. Working Paper retrieved from

Larivière, V., Vignola-Gagné, E., \& Villeneuve, C. (2011). Sex differences in research funding, productivity and impact: An analysis of Québec University professors. Scientometrics, 87(3), 483-498. doi: 10.1007/s11192-011-0369-y

LaRocque, N. (2007). The role of education in supporting the development of science, technology and innovation in developing member countries: An issues paper. Manila: Asian Development Bank.

Lee, S., \& Bozeman, B. (2005). The impact of research collaboration on scientific productivity. Social Studies of Science, 35(5), 673-702. doi: 10.1177/0306312705052359

Leydesdorff, L., \& Zeng, G. (2001). University-industry-government relations in China: An emergent national system innovations. Industry and Higher Education, 15(3), 179-182. doi: org/10.5367/000000001101295632

Lincoln, Y. S. (1995). Emerging criteria for quality in qualitative and interpretive research. Qualitative Inquiry, 1(3), 275-289. doi: org/10.1177/107780049500100301

Lincoln, Y. S., \& Guba, E. G. (1985). Naturalistic inquiry Beverly Hill, CA: Sage.

Lincoln, Y. S., \& Guba, E. G. (1989). Fourth generation evaluation. Newburry Park, CA: Sage.

Lindlof, T. R., \& Taylor, B. C. (2011). Qualitative communication research methods (3rd ed.). Thousand Oaks, CA: Sage.

Ly, P. T. (2013). Case study: The effectiveness of research and innovation management at policy and institutional levels in Vietnam. In A. Olsson \& L. Meek (Eds.), The effectiveness of research and innovation management at policy and institutional levels: Cambodia, Malaysia, Thailand, and Vietnam (pp. 140-162). Paris, France: OECD.

Mai, C. (2013). How are the four international universities in Vietnam?, VietNamNet. Retrieved from http://english.vietnamnet.vn/fms/education/91356/how-are-the-fourinternational-universities-in-vietnam-.html 
Malaysia Ministry of Education. (2004). Establishment of research universities in Malaysia: A concept paper. Kuala Lumpur, Malaysia.

Malaysia Ministry of Higher Education. (2007). The national higher education strategic plan: Laying the foundation beyond 2020. Kuala Lumpur.

Marsh, H. W., \& Hattie, J. (2002). The relation between research productivity and teaching effectiveness: complementary, antagonistic, or independent constructs? The Journal of Higher Education, 73(5), 603-641. doi: 10.1353/jhe.2002.0047

Marvasti, A. B. (2004). Ethics in qualitative research. In A. B. Marvasti (Ed.), Qualitative research in sociology: An introduction (pp. 106). London: Sage.

Meek, L. V., \& Suwanwela, C. (2006). Higher education, research, and knowledge in the Asia Pacific region. New York: Palgrave Macmillan.

Melin, G. (2000). Pragmatism and self-organization: Research collaboration on the individual level. Research Policy, 29(1), 31-40. doi: org/10.1016/S0048-7333(99)00031-1

Merriam, S. B. (1998). Qualitative research and case study applications in education: Revised and expanded from from case study research in education (2 Ed.). San Francisco, USA: JosseyBass.

Merriam, S. B. (2009). Qualitative research: A guide to design and implementation. San Francisco, CA: Jossey-Bass.

Metlich-Medlich, A. I. (2009). Institutional restrictions on scientific productivity: The case study of a Mexican public university. 11(1), 1-17. Retrieved from http://redie.uabc.mx/vol11no1/contents-metlich.html website:

Meyer, J. H. F., Shanahan, M. P., \& Laugksch, R. C. (2005). Students' conceptions of research I: A qualitative and quantitative analysis. Scandinavian Journal of Educational Research, 49, 225-244. doi: 10.1080/00313830500109535

Miles, M., \& Huberman, A. M. (1994). Qualitative data analysis. Thousand Oaks, CA: Sage.

Miles, M. B., \& Huberman, A. M. (1994). Qualitative data analysis: An expanded sourcebook (2nd ed.). Thousand Oaks, CA: Sage.

Mingers, J. (2001). Combining IS research methods: Towards a pluralist methodology. Information Systems Research, 12(3), 240-259. doi: 10.1287/isre.12.3.240.9709

Moore, J. (2015). Socio-Ecological Model: Looking Beyond the Individual. from http://www.balancedweightmanagement.com/TheSocio-EcologicalModel.htm

Mowery, D. C. (2005). Universities in national innovation systems. In D. C. Fagerberg, D. C. Mowery \& R. R. Nelson (Eds.), The Oxford Handbook of Innovation (pp. 22). Oxford: Oxford University Press.

Nelson, R. (2004). The market economy, and the scientific commons. Research Policy, 33(3), 455471. doi: $10.4337 / 9781847201522.00007$

Nesovietnam. (2013). Vietnam's key national universities. from https://www.nesovietnam.org/tin\%20tuc/tin-tuc-2010/cac-truong-dai-hoc-trongdiem-quoc-gia-viet-nam

Nghi, P. T. (2010). The Higher Education Reform Agenda: A Vision for 2020 Reforming Higher Education in Vietnam: Challenges and Priorities (Vol. 29, pp. 51-64). London: Springer.

Nguyen, V. T., \& Pham, T. L. (2011). Scientific output and its relationship to knowledge economy: An analysis of ASEAN countries. Scienctometrics, 89(1). 
Nhan, N. T. (2006). Minister Nguyen Thien Nhan's Report. Retrieved from http://vietbao.vn/Giao-duc/Bao-cao-cua-Bo-truong-Nguyen-ThienNhan/40171110/202/

Olsson, Å., \& Meek, L. (2013). Effectiveness of Research and Innovation Management at Policy and Institutional Levels in Cambodia, Malaysia, Thailand and Vietnam. Paris: OECD.

Owen-Smith, J., \& Powell, W. (2001). To patent or not: faculty decisions and institutional success at technology transfer. Journal of Technology Transfer, 26(1-2), 99-114.

Parker, J. N., Lortie, C., \& Allesina, S. (2010). Characterizing a scientific elite: the social characteristics of the most highly cited scientists in environmental science and ecology. Scientometrics. doi: 10.1007/s11192-010-0234-4

Patton, M. Q. (2002). Qualitative evaluation and Research methods (3rd ed.). Thousand Oaks, CA: Sage.

Pham, D. H. (2006). Hướng trường, viện vào nghiên cứu khoa học tầm quốc tế (Directing universities and academies into doing scientific research with the international level). http://vietbao.vn/Khoa-hoc/Huong-truong-vien-vao-nghien-cuu-khoa-hoc-tam-quocte/20556489/193/

Pravdic, N., \& Oluić-Vuković, V. (1986). Dual approach to multiple authorship in the study of collaborator and scientific output relationship. Scientometrics, 10(5-6), 259-280. doi: 10.1007/BF02016774

Print, M., \& Hattie, J. (1997). Measuring quality in universities: An approach to weighting research productivity. Higher Education, 33, 453-469.

Prosser, M., Martin, E., Trigwell, K., Ramsden, P., \& Lueckenhausen, G. (2005). Academics' experiences of understanding of their subject matter and the relationship of this to their experience of teaching and learning. Instructional Science, 33, 137-157.

Prosser, M., Martin, E., Trigwell, K., Ramsden, P., \& Middleton, H. (2008). University academics' experience of research and its relationship to their experience of teaching. Springer Link, 36, 3-16. doi: 10.1007/s11251-007-9019-4

Raston, C. (1998). Enhancing research productivity by using peer support. In L. Conrad \& O. ZuberSkerritt (Eds.), Developing as researchers (pp. 73-76). Brisbane, QLD: Griffith University.

Ren, K. (2012). Fighting against academic corruption: A critique of recent policy development in China. Higher Education Policy(25), 19-38. doi: 10.1057/hep.2011.20

Runchel, C. (2014). List of large higher education institutions in Vietnam (part of the main article: The Education System in Vietnam) Business in Asia. Retrieved from http://www.business-in-asia.com/vietnam/education system in vietnam.html

Salazar-Clemena, R. M. (2006). Higher education research in the Philippines: Policies, practices, and problems. In V. L. Meek \& C. Suwanwela (Eds.), Higher Education, Research, and Knowledge in the Asia Pacific Region. New York: Palgrave Macmillan.

Santo, A., Engstrom, M. E., Reetz, L., Schweinle, W., \& Reed, K. (2009). Faculty productivity berries and supports at a school of education. Innov High Educ(34), 117-129.

Sarunya, L. (2008). An investigation of factors related to research productivity in a public university in Thailand: A case study. (PhD Thesis), Victoria University, Melbourne, Australia, Melbourne. 
Schwandt, T. A. (1994). Constructivist, interpretivist approaches to human inquiry. In N. K. Denzin \& Y. S. Lincoln (Eds.), Handbook of qualitative research (pp. 118-137). Thousand Oaks, CA: Sage.

Selingo, J. (2014). Location, location, location. Urban hot spots are the place to be. from http://chronicle.com/article/Location-Location-Location-/147931

Senterfitt, J. W., Long, A., Shil, M., \& Teutsch, S. M. (2013). How social and economic factors affect health. Los Angeles: Los Angeles County Department of Public Health.

Sharobeam, M. H., \& Howard, K. (2002). Teaching demand versus research productivity. Journal of College Science Teaching(31), 436-441.

Shenton, A. K. (2004). Strategies for ensuring trustworthiness in qualitative research projects. Education for Information, 22, 63-75.

Simons, H. (2009). Case study research in practice. London: Sage.

Singh, J. K. N., Schapper, J., \& Mayson, S. (2010). The impact of economic policy on reshaping higher education in Malaysia. In M. Devlin, J. Nagy \& A. Lichtenberg (Eds.), Research and development in higher education: Reshaping higher education (Vol. 33, pp. 585-595). Melbourne Mlebourne Higher Education Research and Development Society of Australasia.

Smyth, R., \& Smart, W. (2012). Commercilisation of university research (T. T. E. Sector, Trans.) (Vol. 2012/1, pp. 16). New Zealand: Ministry of Education.

Stack, S. (2004). Gender, children and research productivity. Research in Higher Education, 45(8), 891-920. doi: 10.1007/s11162-004-5953-z

Staffordshire University. (2016). Research Informed Teaching. from http://www.staffs.ac.uk/research/research informed teaching/background/

Stake, R. E. (1995). The art of case study research. Thousand Oaks, CA: Sage.

Stephan, P. (2010). The economics of science: Funding for research. SSRN Electronic Journal, 38. doi: $10.2139 /$ ssrn.1634772

Stubb, J., Pyhalto, K., \& Lonka, K. (2012). Conceptions of research: The doctoral students experience in three domains. Studies in Higher Education, 39(2), 1-14. doi: 10.1080/03075079.2011.651449

Tareef, A. B. (2009). Scientific research in Jordanian higher education institutions: An evaluation of the status and obstacles. Journal of Instituional Psychology, 36(2), 158-168.

Taylor, C. (1995). Philosophy and human sciences Philosophical Papers 2. Cambridge: Cambridge University Press.

Teodorescu, D. (2000). Correlates of faculty publication productivity: A cross-national analysis. Higher Education, 39(2), 201-222. doi: http://www.jstor.org/stable/3447970

The National Science Board. (2004). U.S. and International Research and Development: Funds and Technology Linkages. In N. S. Board (Ed.), Science and Engineering Indicators 2004 (Vol. 1, pp. 70). Arlington, VA: National Science Foundation.

The World Bank. (2015). Overview of Vietnam. from http://www.worldbank.org/en/country/vietnam/overview\#3

Tho, V. (2014). Vietnam professor found plagiarizing doctoral thesis Thanhnien News. Retrieved from http://www.thanhniennews.com/society/vietnam-professor-found-plagiarizingdoctoral-thesis-25320.html 
Thursby, J. G., Jensen, R., \& Thursby, M. C. (2001). Objectves, characteristics and outcomes of university licensing: A survey of major U.S. universities. Journal of Technology Transfer, 26(1-2), 59-72.

Tien, F. F. (2007). To what degree does the promotion system reward faculty research productivity? British Journal of Sociology of Education, 28(1), 105-123. doi: 10.1080/01425690600996741

Tien, F. F. (2008). What kind of faculty are motivated to perform research by the desire for promotion? Higher Education, 55, 17-32. doi: 10.1007/s10734-006-9033-5

Timperley, H. S., \& Parr, J. M. (2007). Closing the achievement gap through evidence-based inquiry at multiple levels. Journal of Advanced Academics, 19(1), 90-115.

Toan, H. T. (2013). Case Two: Enhancing quality to promote collaboration. Paper presented at the Connecting Asia: preparing higher education to meet the demands of the 21th Century, Ho Chi Minh City, Vietnam.

Trowler, P., \& Wareham, T. (2008). Tribes, territories, research and teaching: Enhancing the teaching-research nexus. Higher Education Academy.

Tuan, N. V., \& Ly, P. T. (2011). Scientific output and its relationship to knowledge economy: An analysis of ASEAN countries. Scientometrics, 89(1), 107-117. doi: 10.1007/s11192-0110446-2

Ut, L. V., \& Toan, T. V. (2012). Over 9,000 professors, why does Vietnam not have patents?, Vietnamnet. Retrieved from http://english.vietnamnet.vn/fms/specialreports/24696/over-9-000-professors--why-does-vietnam-not-have-patents-.html

Varghese, N. V. (2008). Contribution of higher education and research to education for all (EFA) (pp. 58). Paris, France: International Institute for Educational Planning.

Vietnam Government. (2000). Project "Training scientific and technical staff overseas with the state budget" (Quyết định số 322/2000/QĐ-TTg). Ha Noi.

Vietnam Government. (2001). Vietnam's educational development strategy in 2001-2010. (201/2001/Decision-Prime Minister). Hanoi: Retrieved from http://moj.gov.vn/vbpq/en/Lists/Vn\%20bn\%20php\%20lut/View Detail.aspx?ltemID=1 $\underline{0345}$.

Vietnam Government. (2005). Nghị quyết về đổi mới cơ bản và toàn diên giáo dục đại học Việt Nam giai đoạn 2006-2020 (Resolution on Basic and Comprehensive Innovation for Higher Education in Vietnam in the period of 2006-2020). Ha Noi: Office of Prime Minister Government Retrieved from http://dangcongsan.vn/cpv/Modules/News/NewsDetail.aspx?co id=28340670\&cn id $=518857 \#$.

Vietnam Government. (2006). Decree: Regulating autonomy, responsibilities for performing the duties, and organising operations, personnel, and finance towards public agencies. Ha Noi, Vietnam: Retrieved from www.haugiang.gov.vn/Portal/DocView.aspx?pageid=2782\&ltemID=24801... $\cdot$ PDF file.

Vietnam Government. (2008). Teaching and learning foreign languages in the national education system in the period 2008-2020. (No. 1400/Decision-Prime Minister, dated on September 30, 2008). Ha Noi: Retrieved from http://ipf.org.vn/iwtcore/uploads/2012/08/1-3Decision 1400 QD-TTg-Eng.pdf.

Vietnam Government. (2010a). The charter of university. Office of Government. 
Vietnam Government. (2010b). Project 911 - "Training college and university lecturers to achieve PhD degrees in 2010-2020. Prime Minister, Government of Vietnam.

Vietnam Government. (2010c). Vietnamese university charter. (58/2010/Decision - Prime Minister). Ha Noi.

Vietnam Government. (2012a). The strategy for science and technology development for the 2011-2020 period. Vietnam: Retrieved from http://www.most.gov.vn/Desktop.aspx/Details-Article/STstratergy/The translation is for reference/.

Vietnam Government. (2012b). Vietnam's educational development strategy in 2011 - 2020. Ha Noi.

Vietnam Ministry of Education and Training. (2005). Vietnam higher education renovation agenda period 2006-2020, Resolution No.14/2005/NQ-CP on the fundamental and comprehensive reform of higher education in Vietnam 2006-2020.

Vietnam Ministry of Education and Training. (2006). Higher education in Vietnam. Retrieved 15/01, 2014, from http://en.moet.gov.vn/?page=6.7\&view=4404

Vietnam Ministry of Education and Training. (2008a). Framework on academics' working time. Ha Noi: Retrieved from http://thuvienphapluat.vn/archive/Quyet-dinh-64-2008-QDBGDDT-Quy-dinh-che-do-lam-viec-doi-voi-giang-vien-vb82446.aspx.

Vietnam Ministry of Education and Training. (2008b). The regulation on teaching workload for university lecturers. Ha Noi, Viet Nam.

Vietnam Ministry of Science and Technology. (2004). Vietnam's report on science and technology in 2004. Hanoi, Vietnam.

Vietnam Ministry of Science and Technology. (2012). The strategy for science and technology development for the 2011-2020 period. (No.418/QD-TTg). Ha Noi: Retrieved from http://www.most.gov.vn/Desktop.aspx/Details-Article/STstratergy/The translation is for reference/.

Vietnam National Assembly. (2000). Vietnam Law on science and technology. Hanoi, Vietnam: Retrieved from http://www.most.gov.vn/Desktop.aspx/S T Legistations/STLegistation/The translation is for reference/.

Vietnam National Assembly. (2005). Vietnam Education Law. (38/2005/QH11). Ha Noi: Vietnam National Assembly.

Vietnam National Assembly. (2012). Vietnam Education Law. Ha Noi, Vietnam: Vietnam National Assembly.

Vroom, V. C. (1964). Work and motivation. New York: Wiley.

Wanner, R. A., Lewis, L. S., \& Gregorio, D. I. (1981). Research productivity in academia: A comparative study of the sciences, social sciences and humanities. Sociology of Education, 54(4), 238-253.

White, C. S., James, K., Burke, L. A., \& Allen, R. S. (2012). What makes a "research star"? Factors influencing the research productivity of business faculty. International Journal of Productivity and Performance Management, 61(6), 584-602. doi: 10.1108/1741041211249175

Wilkson, B., \& Chirot, L. (2010). Beyond the apex: Toward a system approach to higher education reform in Vietnam. 
Williams, J. H., \& Cummings, W. K. (2005). Policy-making for education reform in developing countries: Contexts and processes (Vol. 1). Lanham, MD: Scarecrow Education.

Wong, M. P., \& Tierney, W. G. (2001). Reforming faculty work: Culture, structure \& dilemma of organizational change. Teacher Collegue Record, 103(6), 1081-1101. doi: 10.1111/01614681.00143

Wood, F. (1990). Factors influencing research performance of university academic staff. Higher Education, 19, 81-100. doi: 10.1007/BF00142025

World Bank. (2012). Putting higher education to work: Skills and research for growth in East Asia (pp. 248). Washington, DC.

Yin, R. K. (2003). Case study research: Design and methods. Thousand Oaks, CA: Sage.

Yin, R. K. (2009). Case study research: Design and methods (4th ed.). Thousand Oaks, CA: Sage.

Zainab, A. N. (1999). Personal, academic, and departmental correlates of research productivity: a review of literature. Malysian Journal of Library \& Information Science, 4(2), 73-110.

Zanetta, C. (2012). Implementation completion and result report (IDA-43280 TF-56736) to the socialist republic of Vietnam for a second higher education project. Washington, DC: Human Development Sector Unit. 


\section{APPENDIX 1. QUESTIONNAIRES}

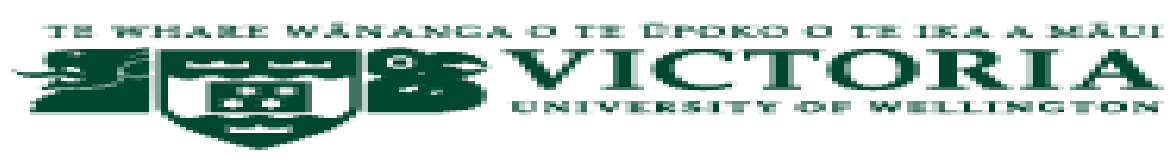

\section{FACULTY OF EDUCATION}

The questionnaire consists of two parts: Part $A$ is about the background information of the respondents. Part $B$, the main part of this survey, consists of 4 subparts: subpart 1 understanding the academics' perception of research; subpart 2 - exploring factors to encourage academics' research engagement; subpart 3-exploring factors that hinder academics' research engagement; and subpart 4-identifying their regular research activities.

\section{A. BACKGROUND INFROMATION}

Name of the institution:

Discipline/Faculty:

Position:

Degree:

MA

$\square \mathrm{PhD}$

Academic rank:

Lecturer

Senior Lecturer

Professor Rank:

Ass. Prof

$\square$ Prof

If you would like to kindly participate in the interview section, you may offer your contact information below.

Contact person:

Email address: 


\section{B. MAIN SURVEY}

\section{B1. Academics' research perceptions}

Tick on the statements that are true to you and evaluate their degree of importance to you in the scale 1 to 5 opinions (attitudes) on an agreement-disagreement continuum, in which 1 is being strongly disagree, and 5 is being strongly agree

\begin{tabular}{|l|l|l|l|l|l|l|}
\hline \multicolumn{1}{|c|}{ Academics' research perceptions } & \multicolumn{3}{|c|}{ Strongly disagree } \\
\hline For me research is/means ... & $\begin{array}{l}\text { Box } \\
\text { tick }\end{array}$ & 1 & 2 & 3 & 4 & 5 \\
\hline $\begin{array}{l}\text { a process of discovering, uncovering or creating } \\
\text { understanding meanings }\end{array}$ & & $\square$ & $\square$ & $\square$ & $\square$ & $\square$ \\
\hline $\begin{array}{l}\text { a kind of social market place where the exchange of } \\
\text { products takes place }\end{array}$ & & $\square$ & $\square$ & $\square$ & $\square$ & $\square$ \\
\hline $\begin{array}{l}\text { a personal journey of discovery, possibly leading to } \\
\text { transformation }\end{array}$ & $\bigcirc$ & $\square$ & $\square$ & $\square$ & $\square$ & $\square$ \\
\hline $\begin{array}{l}\text { the gathering of information or collection of data } \\
\text { the discovery of the truth }\end{array}$ & $\bigcirc$ & $\square$ & $\square$ & $\square$ & $\square$ & $\square$ \\
\hline finding solutions to problems or answering questions & $\bigcirc$ & $\square$ & $\square$ & $\square$ & $\square$ & $\square$ \\
\hline $\begin{array}{l}\text { the creation of new knowledge and innovative } \\
\text { approaches to the discovery of that knowledge }\end{array}$ & $\bigcirc$ & $\square$ & $\square$ & $\square$ & $\square$ & $\square$ \\
\hline $\begin{array}{l}\text { presenting new ways of seeing the world, oneself or a } \\
\text { problem }\end{array}$ & $\bigcirc$ & $\square$ & $\square$ & $\square$ & $\square$ & $\square$ \\
\hline fulfilling academic requirements & $\square$ & $\square$ & $\square$ & $\square$ & $\square$ & $\square$ \\
\hline $\begin{array}{l}\text { establishing oneself in the field, and developing oneself } \\
\text { personally }\end{array}$ & $\bigcirc$ & $\square$ & $\square$ & $\square$ & $\square$ & $\square$ \\
\hline Other ideas: & $\square$ & $\square$ & $\square$ \\
\hline
\end{tabular}




\section{B2. Factors encouraging academics' research engagement}

As a faculty member, please evaluate the importance of the following to you using a scale of 1 to 5 , with $\underline{1}$ being not important at all, and $\underline{\mathbf{5}}$ being very important.

\begin{tabular}{|l|l|l|l|l|l|}
\hline \multicolumn{1}{|c|}{$\begin{array}{l}\text { Factors encouraging academics' research } \\
\text { engagement }\end{array}$} & \multicolumn{3}{|l}{ Not at all Important } \\
\hline Importance of the following to me: & 1 & 2 & 3 & 4 & 5 \\
\hline $\begin{array}{l}\text { Becoming a (associate) professor or receiving } \\
\text { promotion }\end{array}$ & $\square$ & $\square$ & $\square$ & $\square$ & $\square$ \\
\hline Getting better salary raises & $\square$ & $\square$ & $\square$ & $\square$ & $\square$ \\
\hline Getting an administrative assignment & $\square$ & $\square$ & $\square$ & $\square$ & $\square$ \\
\hline Getting a reduced teaching load & $\square$ & $\square$ & $\square$ & $\square$ & $\square$ \\
\hline Increasing my professional status & $\square$ & $\square$ & $\square$ & $\square$ & $\square$ \\
\hline Allowing me to reflect on and improving my teaching & $\square$ & $\square$ & $\square$ & $\square$ & $\square$ \\
\hline Helping me to find better ways of teaching & $\square$ & $\square$ & $\square$ & $\square$ & $\square$ \\
\hline Getting respect from students & $\square$ & $\square$ & $\square$ & $\square$ & $\square$ \\
\hline Satisfying my need to contribute to the field & $\square$ & $\square$ & $\square$ & $\square$ & $\square$ \\
\hline Satisfying my need for creativity or curiosity & $\square$ & $\square$ & $\square$ & $\square$ & $\square$ \\
\hline Having satisfying collaboration with others & $\square$ & $\square$ & $\square$ & $\square$ & $\square$ \\
\hline Satisfying my need to stay current in the field & $\square$ & $\square$ & $\square$ & $\square$ & $\square$ \\
\hline Othepartment/institution & $\square$ & $\square$ & $\square$ & $\square$ & $\square$ \\
\hline
\end{tabular}




\section{B3. Factors hindering academics' research engagement}

As a faculty member, please evaluate the importance of the following to you using a scale of 1 to 5 opinions (attitudes) on an agreement-disagreement continuum, with $\underline{\mathbf{1}}$ being strongly disagree, and $\underline{\mathbf{5}}$ being strongly agree.

\begin{tabular}{|l|l|l|l|l|l|}
\hline \multicolumn{1}{|c|}{$\begin{array}{l}\text { Factors hindering academics' research } \\
\text { engagement }\end{array}$} & \multicolumn{3}{l}{ strongly disagree } \\
& 1 & 2 & 3 & 4 & 5 \\
\hline research provides low salaries & $\square$ & $\square$ & $\square$ & $\square$ & $\square$ \\
\hline research is a waste of time & $\square$ & $\square$ & $\square$ & $\square$ & $\square$ \\
\hline research is an extra burden on university academics & $\square$ & $\square$ & $\square$ & $\square$ & $\square$ \\
\hline there is a lack of opportunities to conduct research & $\square$ & $\square$ & $\square$ & $\square$ & $\square$ \\
\hline there is a lack of research grants & $\square$ & $\square$ & $\square$ & $\square$ & $\square$ \\
\hline $\begin{array}{l}\text { there is inadequate time available for research (much } \\
\text { teaching workloads and services time) }\end{array}$ & $\square$ & $\square$ & $\square$ & $\square$ & $\square$ \\
\hline there is a (high) pressure to publish & $\square$ & $\square$ & $\square$ & $\square$ & $\square$ \\
\hline $\begin{array}{l}\text { there is an increase of difficulty/time spent in obtaining } \\
\text { research grants }\end{array}$ & $\square$ & $\square$ & $\square$ & $\square$ & $\square$ \\
\hline there is a lack of research facilities & $\square$ & $\square$ & $\square$ & $\square$ & $\square$ \\
\hline there is a lack of institutional/departmental supports & $\square$ & $\square$ & $\square$ & $\square$ & $\square$ \\
\hline I do not understand procedures to conduct research & $\square$ & $\square$ & $\square$ & $\square$ & $\square$ \\
\hline I am not confident about research methods & $\square$ & $\square$ & $\square$ & $\square$ & $\square$ \\
\hline my job is to teach not to do research & $\square$ & $\square$ & $\square$ & $\square$ & $\square$ \\
\hline most of my colleagues do not do research & $\square$ & $\square$ & $\square$ & $\square$ & $\square$ \\
\hline
\end{tabular}




\section{B4. Academics' frequent research activities for professional development}

1. Activities organised by institution/work unit

How would you rate the availability of traning in research skills or methods in your institution and work unit? Using the scale in which $\mathbf{1}$ is very poor, and $\mathbf{5}$ is very good.

a. institution

\begin{tabular}{|c|c|c|c|c|c|}
\hline 1 & 2 & 3 & 4 & 5 & Not sure \\
$\square$ & $\square$ & $\square$ & $\square$ & $\square$ & $\square$ \\
\hline
\end{tabular}

b. faculty/centre

\begin{tabular}{|l|l|l|l|l|r|}
\hline 1 & 2 & 3 & 4 & 5 & Not sure \\
$\square$ & $\square$ & $\square$ & $\square$ & $\square$ & $\square$ \\
\hline
\end{tabular}

2. Please write down at least five activities/workshops organised in your institution or work unit to improve academic research capacity or professional development in twelve previous months?

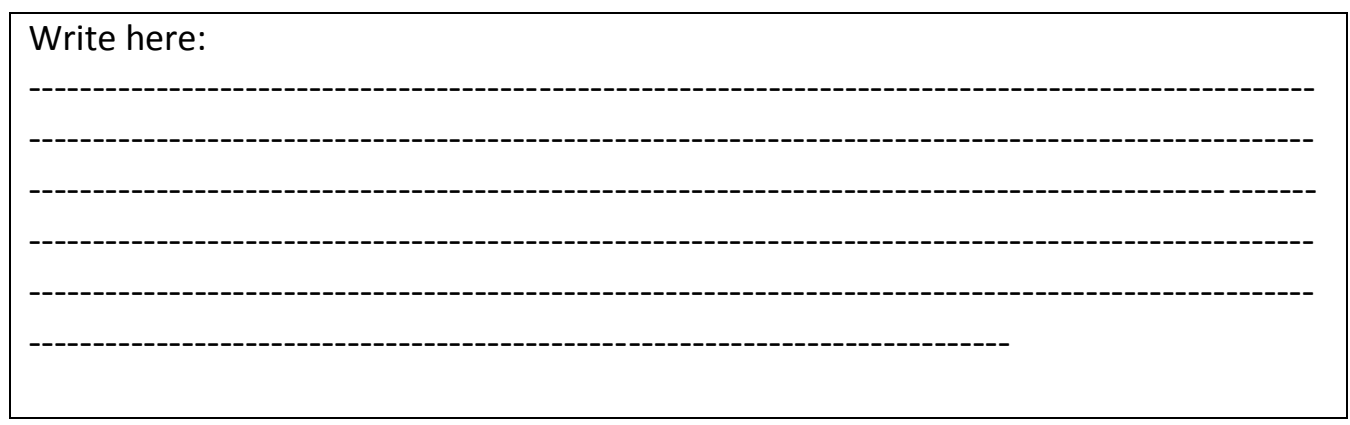

3. Please write down at least five activities that you frequently do to improve your academic research capacity and professional development in twelve previous months?

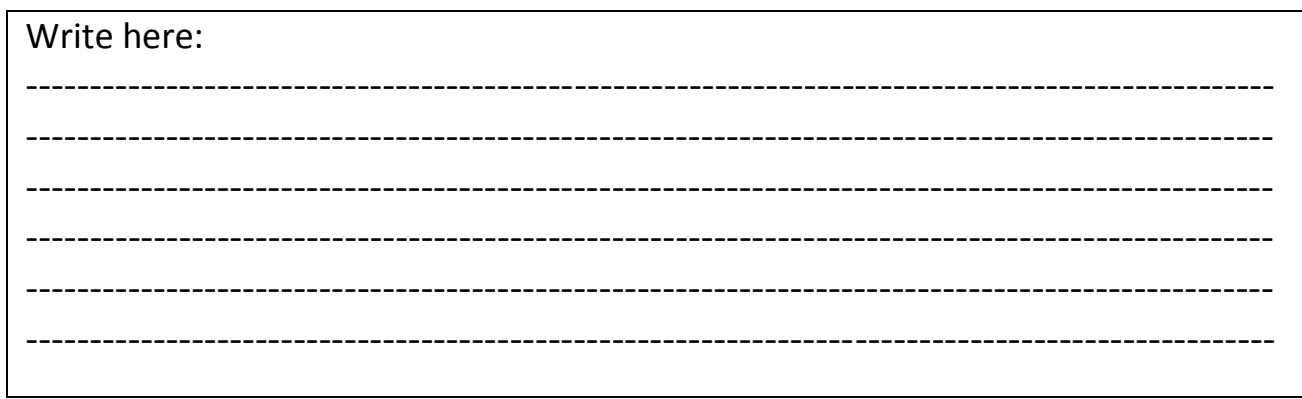

THANK YOU FOR YOUR COOPERATION 


\section{APPENDIX 2. INTERVIEW QUESTIONS}

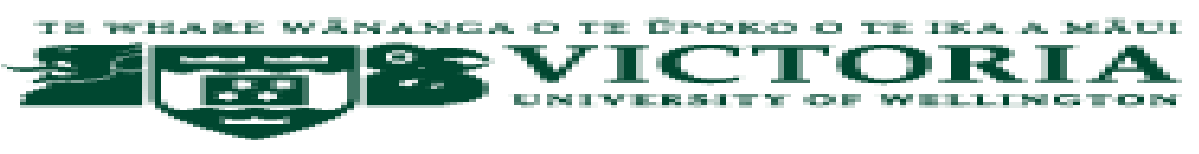

\section{FACULTY OF EDUCATION \\ Sample of Interview Questions}

\begin{tabular}{|c|c|}
\hline & \\
\hline $\begin{array}{l}\text { Research } \\
\text { manager }\end{array}$ & $\begin{array}{l}\text { 1. What are your perceptions of research? (A/B) } \\
\text { 2. What are your roles towards research activities in your institution/unit? (A) } \\
\text { 3. How is research work important to you / your institution/unit? (A/B) } \\
\text { 4. How is research environment in your university? (A/B) } \\
\text { 5. What are the factors that motivate YOU / your academics to engage in } \\
\text { research? (A/B) } \\
\text { 6. What are the factors that de-motivate YOU/ your academics to engage in } \\
\text { research? (A/B) } \\
\text { 7. How does workload impact your academics' research performance? (A/B) } \\
\text { 8. How do you support lecturers to improve research skills, in your role? (A) } \\
\text { 9. What do you think about your institution/unit's research funding? (A/B) } \\
\text { 10. How do HE reform policies affect your institution/unit's research strategic } \\
\text { plans? } \\
\text { 11. What should your institution do to enhance your academics' research } \\
\text { 12. What activities are frequently organised to enhance academics' research } \\
\text { capacity? } \\
\text { 13. Can you share some typical research cultures / management / relationship } \\
\text { in your institution / unit? (A/B) }\end{array}$ \\
\hline $\begin{array}{l}\text { Research } \\
\text { academics }\end{array}$ & $\begin{array}{l}\text { 14. How does your institution/unit support lecturers to improve research skills? } \\
\text { (B) } \\
\text { 15. What activities do you usually do to improve your research activities? (B) } \\
\text { 16. Can you share your routine research activities? (B) }\end{array}$ \\
\hline
\end{tabular}




\section{APPENDIX 3. LETTER OF ETHICAL APPROVAL}

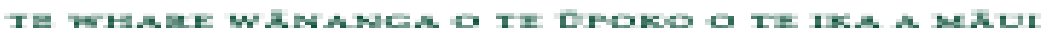

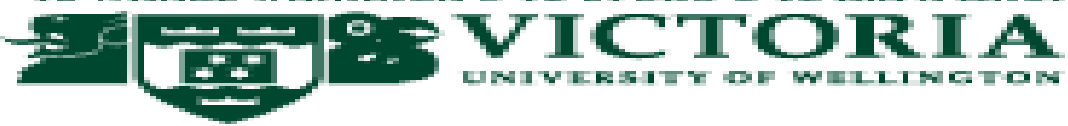

\section{9}

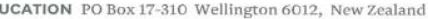

Website www.victoria.ac.nz

26 October 2012

Tien Huynh

PhD student

Victoria University of Wellington Faculty of Education

$\mathrm{C} /$ - School of Educational Policy and Implementation

Donald Street

Wellington

Dear Tien

RE: Ethics application SEPI/2012/61 RM 19529

I am pleased to advise you that your ethics application 'Vietnamese Academics' Research Capacity in Tertiary Contexts', with the required changes, has been approved by the Victoria University of Wellington Faculty of Education Ethics Committee. Please note that the approval for your research to commence is from the date of this letter.

Best wishes for your research.

Yours Sincerely

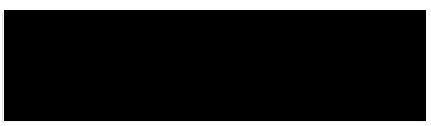

Dr Judith Loveridge

Co-Convener

Victoria University of Wellington Faculty of Education Ethics Committee 


\section{APPENDIX 4. LETTER TO THE RECTOR}

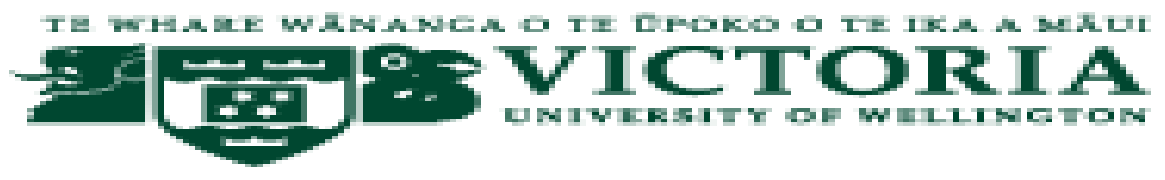

FACULTY OF EDUCATION

\section{Subject: Asking for permission to conduct research}

\section{Dear the Rector,}

I am a doctoral student at School of Educational Policy and Implementation, Faculty of Education, Victoria University of Wellington in New Zealand. As part of this degree, I am required to conduct a research project leading to a thesis. My thesis title is "Vietnamese academics' research capacity at tertiary contexts." I am writing to ask for your permission in order to implement my research in your university from February 2013 to June 2013.

My research aims to explore academics' research perceptions and factors influencing their research engagement. The implementation process of this research will be as follows:

- Visiting your institution: I will initially visit your institution to have a meeting with you, your management staff and academics to provide the background information of the research;

- Selecting participants: I will invite your staff to participate in the research. Prior to selection, all participants will be fully provided with necessary information about the research for their consideration to participation. Their participation is voluntary and they may withdraw from the research at any time without any sort of disadvantage;

- Collecting data: I will deliver questionnaires to all participants selected by hand and email and conduct individual audio-interviews with 6 interviewees (3 research managers and 3 research academics). Questionnaire respondents can complete the form in 45 minutes, and each interview session will last around 45 minutes.

- Document analysis: I also would like to borrow some of your documents related to research practices to possibly double-check the data collected from the two previous tools for the stage of data analysis later.

This research has been approved by the Human Ethics Committee, Faculty of Education, Victoria University of Wellington in New Zealand. I ascertain that all the identities related to the participants and your institution will be protected, and all research data will be kept confidential. No information obtained in the study will be discussed with anyone else except for me and my supervisors and the participants without their written permission.

For more information about the procedures of my data collection, please find the copy of the Research Information Sheet attached.

I am very grateful if you would grant permission for this research. Thank you so much for your regard of this request.

Please contact me at the Student Affairs Office, An Giang University, and my office phone: +84 076 6296559, my cell phone: , and my email: httien@agu.edu.vn 
You can also contact my supervisors, Prof. Dr. Rob Strathdee at Rob.Strathdee@vuw.ac.nz or Ass. Prof. Dr. Joanna Higgins at Joanna.Higgins@vuw.ac.nz for further information about the project.

Yours sincerely,

\section{Huynh Thanh Tien}




\section{APPENDIX 5. CONSENT FORM FOR RECTOR}

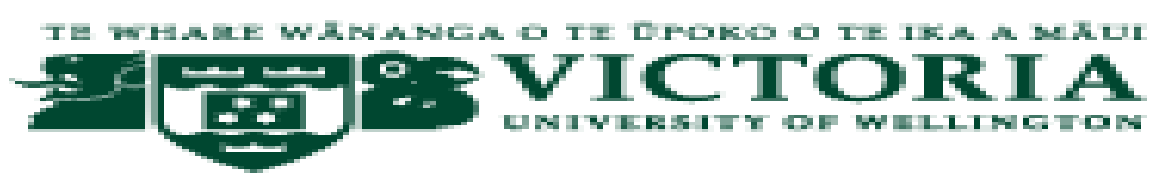

FACULTY OF EDUCATION

\section{Title of project:}

\section{VIETNAMESE ACADEMICS' RESEARCH CAPACITY IN TERTIARY CONTEXTS}

Please tick each box to indicate that you understand each point and you are willing to allow Mr. Huynh Thanh Tien to conduct his doctoral research at your university.

I have been given information about this research and discussed the research project with Mr. Huynh Thanh Tien. I have had an opportunity to ask questions and have them answered to my satisfaction.

I understand what is required of the participants from this university who take part in the research project.

I understand that participation in the research is voluntary and the participants may withdraw from it during the data gathering (before data analysis begins) without having to give reasons without penalty.

I understand that the researcher will give my institution a pseudonym.

I understand that all research data will be stored in password protected files and will be destroyed within five years after the end of the research.

I consent to the researcher who can conduct his research project in this university.

I understand that the data collected from my university will be used for a doctoral thesis, for conference papers and/or publications in scholarly journals, and I consent for it to be used in that manner.

I consent to the researcher having access to relevant documents including the university's research development, plans and any other items related to research activities and policies at my university. The researcher may translate these documents into English for data analysis and discussion in his thesis, and I consent for it.

If you would like a copy of the summary of the summary findings of my research in English, I would forward it to you at the conclusion of the research? YES

Signed: Name:
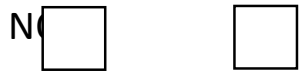

Date:

(The Rector will be given a copy of this to keep after signing this form) 


\section{APPENDIX 6. LETTER TO THE DIRECTOR/HEAD}

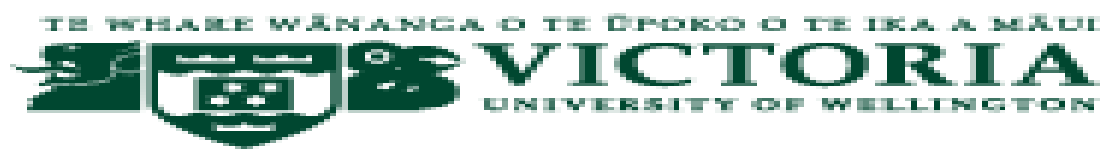

\section{Subject: Asking for permission to conduct research}

\section{Dear the Director/Head of}

I am a doctoral student at School of Educational Policy and Implementation, Faculty of Education, Victoria University of Wellington in New Zealand. As part of this degree, I am required to conduct a research project leading to a thesis. My thesis title is "Vietnamese academics' research capacity at tertiary contexts." I am writing to ask for your permission in order to implement my research in your university from February 2013 to June 2013. I have already contacted the Rector

My research aims to explore academics' research perceptions and factors influencing their research engagement. The implementation process of this research will be as follows:

- Visiting your work office: I will initially visit your work office to have a meeting with you to provide the background information of the research;

- Selecting participants: I will invite you and your staff to participate in the research. Prior to selection, all participants will be fully provided with necessary information about the research for their consideration to participation. Their participation is voluntary and they may withdraw from the research at any time without any sort of disadvantage;

- $\quad$ Collecting data: I will deliver questionnaires to all participants selected by hand and email and conduct individual audio-interviews with 6 interviewees (3 research managers and 3 research academics). Questionnaire respondents can complete the form in 30 minutes, and each interview session will last around 45 minutes.

- Document analysis: I also would like to borrow some of your documents related to research practices to possibly double-check the data collected from previous tools for the stage of data analysis later.

This research has been approved by the Human Ethics Committee, Faculty of Education, Victoria University of Wellington, New Zealand. I ascertain that all the identities related to the participants and your institution will be protected, and all research data will be kept confidential. No information obtained in the study will be discussed with anyone else except for me and my supervisors and the participants without their written permission.

For more information about the procedures of my data collection, please find the copy of the Research Information Sheet attached. The Recommendation Letter from the Rector of

Please contact me at the Student Affairs Office, An Giang University, and my office phone: +84 076 6296559, my cell phone: , and my email: httien@agu.edu.vn

You can also contact my supervisors, Prof. Dr. Rob Strathdee at Rob.Strathdee@vuw.ac.nz or Ass. Prof. Dr. Joanna Higgins at Joanna.Higgins@vuw.ac.nz for further information about the project. 
Grateful if you would grant me permission to conduct the research. I hope that you will be willing to offer me favourable conditions in order that the research will be successfully conducted.

Thank you for your consideration of this request.

Yours sincerely

Huynh Thanh Tien 


\section{APPENDIX 7. CASE ONE'S ORGANISATIONAL STRUCTURE}

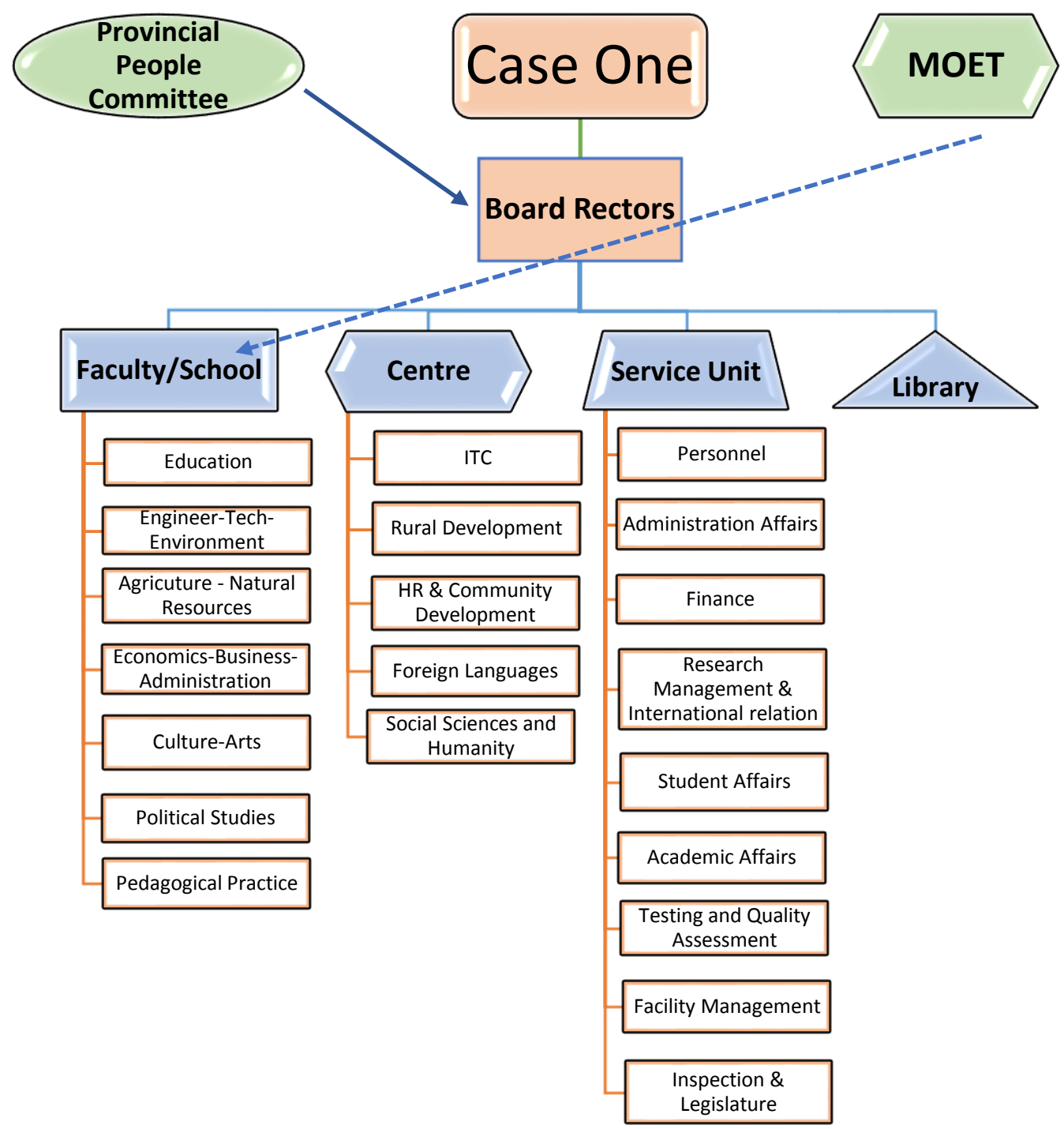




\section{APPENDIX 8. RESEARCH INFORMATION SHEET}

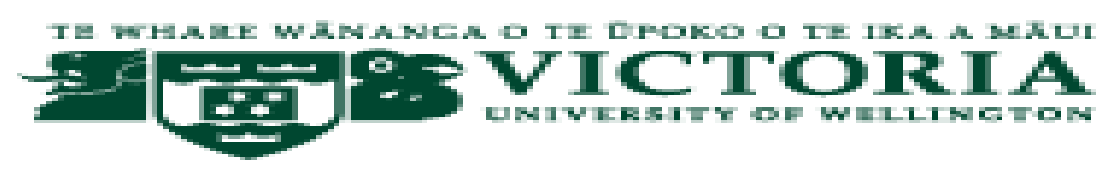

\section{FACULTY OF EDUCATION \\ (To be given to the participants)}

\section{Thesis title: Vietnamese academics' research capacity in tertiary contexts Dear Sir/Madame}

Researcher: Huynh Thanh Tien; Faculty of Education; School of Educational Policy and Implementation, Victoria University of Wellington

I am a doctoral student at Victoria University of Wellington in New Zealand. As part of this degree I am required to conduct a research leading to a thesis. My thesis aims to explore Vietnamese academics' research perceptions and factors influencing their research engagement.

I would like to invite you to participate in this study and I highly appreciate your participation and believe that your cooperation will be very valuable for this study.

If you agree to participate in this study, you will be asked to complete a questionnaire (about 45 minutes) asking you specific questions on your perceptions of research, your research motivation, and routine research activities for professional development in your institution. You may join in an individual audio-recorded interview lasting around 45 minutes. The interview is about your habitual research activity, your insights of research procedures, and your institutional/departmental research policies/plans/cultures. The interviews will be recorded to enable me to transcribe and analyse the data at a later stage in the research. I will contact interviewees personally to set up a convenient time for the interview session.

Participants' identity and confidentiality will be protected at all stages of the study. All research findings reported will remain confidential. Any information related to participants' identity in this study will remain confidential to the researcher (and his supervisors). You will not be identified by name in any reports of the completed study. You will be sent a copy of your interview transcripts for verification, review and clarification.

The responses to the questionnaire may be returned anonymously. The audio interview data collected will be deleted at the conclusion of the study but its raw data will be stored for five years, and after this time it will be destroyed. During your participation, if you feel hesitant or uneasy you may decline to answer any specific questions or withdraw from this research at any time with no harm at all.

I confirm that the study will strictly adhere to the Human Ethics Policy promulgated by the Victoria University of Wellington. This research has been approved by the Human Ethics Committee, Faculty of Education, Victoria University of Wellington. 
If you agree to participate in this project, please go through this information sheet carefully before signing the attached consent form. Should you have any queries, please do not hesitate to contact me at

or email me at: httien@agu.edu.vn

You can also contact my supervisors, Prof. Dr. Rob Strathdee at Rob.Strathdee@vuw.ac.nz or Ass. Prof. Dr. Joanna Higgins at Joanna.Higgins@vuw.ac.nz for further information about the project.

Yours sincerely

\section{Huynh Thanh Tien}




\section{APPENDIX 9. CONSENT TO PARTICIPATE IN RESEARCH: QUESTIONNAIRE}

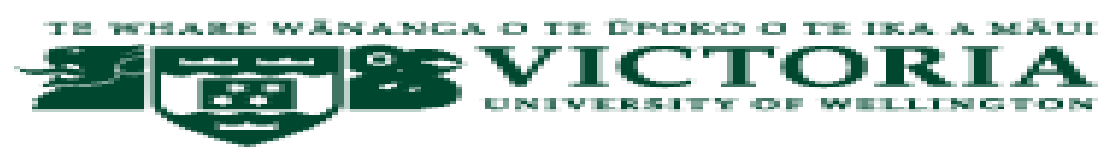

\section{FACULTY OF EDUCATION}

Title of project: Vietnamese academics' research capacity in tertiary contexts

Surname and given name:

Position:

School/Faculty/research centre/office:

University:

Telephone (optional):

Address (optional):

- I have been given information about this research and I have understood the explanation of this research project. I have had an opportunity to ask questions and have them answered to my satisfaction.

- I understand that I may withdraw myself (or any information I have provided) from this research (before data collection and analysis is complete) with no need to give reasons or without penalty of any kind.

- I understand that any information I provide will be kept confidential to the researcher, the supervisors, the published results will not use my name, and that no opinions will be attributed to me in any way that will identify me.

- I would like to receive feedback on the findings of this research.

- I have given my consent to be involved in this project.

Participant's signature:

Date:

Researcher's signature:

Date:

OR

(v) I have emailed my consent to httien@agu.edu.vn

(The participant will be given a copy of this to keep after signing this form) 


\section{APPENDIX 10. CONSENT TO PARTICIPATE IN RESEARCH: AUDIO- RECORDED INTERVIEW}

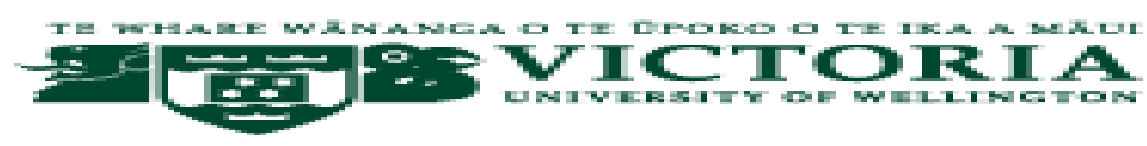

\section{FACULTY OF EDUCATION}

\section{Title of project: Vietnamese academics' research capacity in tertiary contexts}

Surname and given name:

Position:

School/Faculty/research centre/office:

University:

Telephone (optional): Address (optional):

- I have been given information about this research project and I have understood an explanation of this research project. I have had an opportunity to ask questions and have them answered to my satisfaction.

- I understand that I may withdraw myself (or any information I have provided) from this project (before data collection and analysis is complete) without having to give reasons or without penalty of any sort.

- I understand that any information I provide will be kept confidential to the researcher, the supervisor, the published results will not use my name, and that no opinions will be attributed to me in any way that will identify me.

- I would like to receive feedback on the findings of this research.

- I have given my consent to be involved in this project.

Signed:

Name of participant:

(Please print clearly)

Date:

OR

(v) I have emailed my consent to Tien.Huynh@vuw.ac.nz 


\section{APPENDIX 11. CASE TWO'S ORGANISATIONAL STRUCTURE CHART}

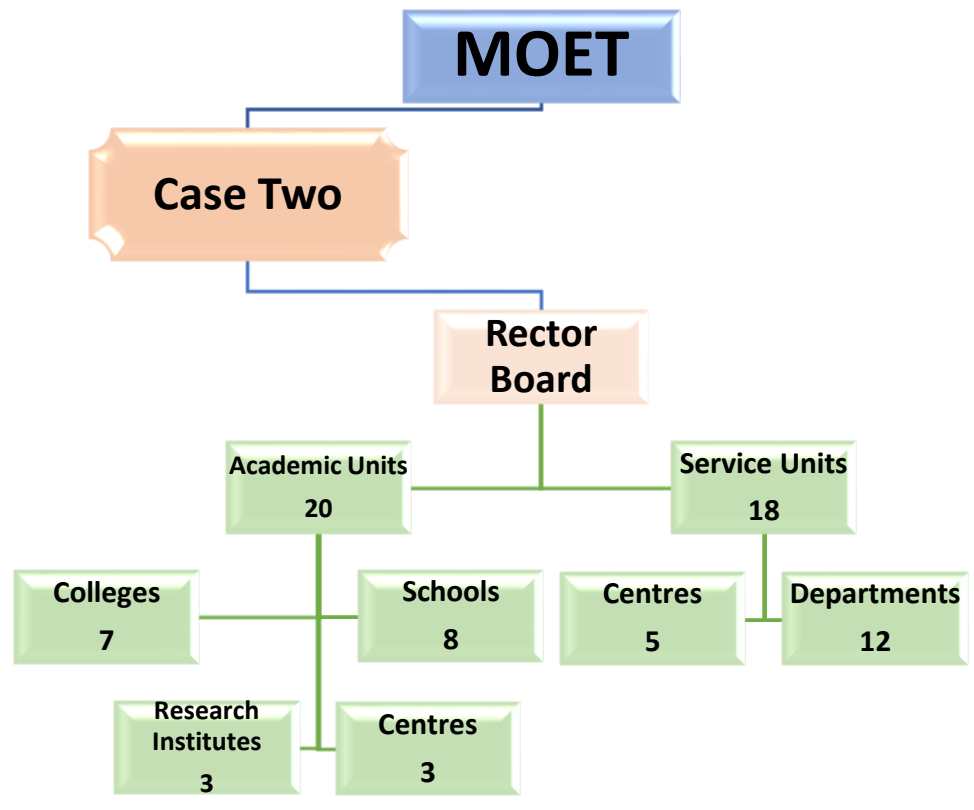

\section{Academic Units}

- Colleges: (1) Agriculture \& Applied Biology, (2) Aquaculture and Fisheries, (3) Engineering Technology, (4) Environment \& Natural Resources, (5) Rural Development, (6) Natural Sciences, (7) Information Technology \& Communications

- $\quad$ Research Institutes: (1) Biotechnology Research \& Development, (2) Mekong Delta Development, (3) Climate Change

- Schools: (1) Education, (2) Post Graduate, (3) Law, (4) Political Sciences, (5) Pre-university, (6) Social sciences and Humanities, (7) Physical Education

- Centres: (1) Foreign Languages, (2) Cooperative Training, (3) National Defence Education

\section{Service Units}

- Departments: (1) Academic Affairs, (2) Administration and Planning, (3) Construction Management Board, (4) International Relations, (5) Facility Management, (6) Financial Affairs, (7) Legality, (8) Personnel, (9) Political Affairs, (10) Publishing House, (11) Scientific Affairs, (12) Student Assistance

- Centres: (1) Information and Network Management, (2) Learning Resources, (3) Quality Assurance, (4) Services and Technology Transfer, (5) Software 


\section{APPENDIX 12. CASE THREE'S ORGANISATIONAL STRUCTURE}

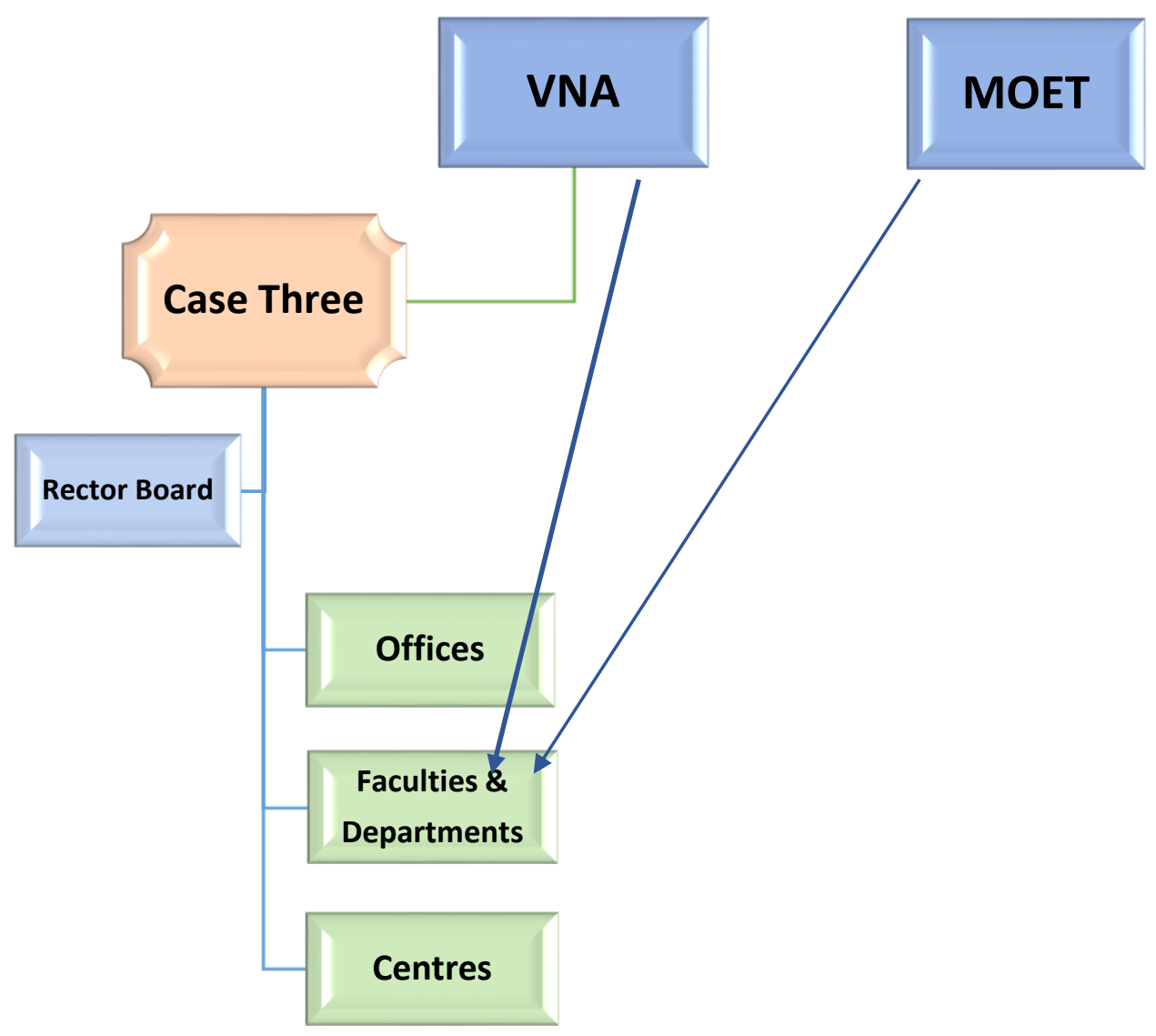

- Offices: (1) Administrative Affairs, (2) Human Resources and Organisation, (3) Student Affairs, (4) Academic Affairs, (5) International Cooperation and International Project Development, (6) Planning and Finance, (7)Testing and Quality Assurance, (8) Facility and Equipment Management, (9) Postgraduate Training, (10) Scientific Research and Project Management, (11) Legal Consultancy, (12) Secondary Campus's Office.

- Faculties/Departments: (1) Anthropology, (2) Cultural Studies, (3) Education, (4) Geography, (5) History, (6) International Relations, (7) Journalism and Communication, (8) Library and Information Sciences, (9) Literature and Linguistics, (10) English Literature and Linguistics, (11) French Literature and Linguistics, (12) Chinese Literature and Linguistics, (13) German Literature and Linguistics, Literature and Linguistics, (14) Russian Literature and Linguistics, (15) Spanish Literature and Linguistics, (16) Italian Literature and Linguistics, (17) Oriental Studies, (18) Philosophy, (19) Psychology, (20) Social Works, (21) Sociology, (22) Urban Studies, (23) Vietnamese Studies, (24) Korean Studies, (25) Japanese Studies, (26) Tourism, (27) Archives and Office Management, (28) Physical Education.

- Centres: (1) Applied Sociology, (2) Career Orientation and Human Resources Development, (3) Foreign Languages, (4) Informatics, (5) Religion Studies, (6) International Education, (7) Korean Studies, (8) Sea and Island Studies, (9) Services for International Students, (10) Strategic and National Policy Studies, (11) Human Resources Training and Development, (12) Theoretical and Applied Culturology, (13) Vietnamese and Southeast Asian Studies, (14) Museum of History and Culture. 